DANIELA GOMES HORTA

EFEITO DA CRISTALINIDADE E DA CINÉTICA DE DISSOLUÇÃO NO DESEMPENHO DA FLOTAÇÃO DE APATITAS E CALCITAS 
DANIELA GOMES HORTA

\section{EFEITO DA CRISTALINIDADE E DA CINÉTICA DE DISSOLUÇÃO NO DESEMPENHO DA FLOTAÇÃO DE APATITAS E CALCITAS}

Tese apresentada à Escola Politécnica da Universidade de São Paulo para a obtenção do Título de Doutor em Engenharia.

Área de concentração:

Engenharia Mineral

Orientador:

Prof. Dr. Laurindo de Salles Leal Filho

São Paulo 
FICHA CATALOGRÁFICA

Horta, Daniela Gomes

Efeito da cristalinidade e da cinética de dissolução no desempenho da flotação de apatitas e calcitas / D.G. Horta. -São Paulo, 2013.

p.

Tese (Doutorado) - Escola Politécnica da Universidade de São Paulo. Departamento de Engenharia de Minas e de Petróleo.

1. Flotação de minérios I. Universidade de São Paulo. Escola Politécnica. Departamento de Engenharia de Minas e de Petróleo II. t. 
Dedico aos meus pais Manoela e

Otoganizo que, com amor, acompanharam e apoiaram minha formação acadêmica. 


\section{AGRADECIMENTOS}

A autora agradece a todos que direta, ou indiretamente contribuíram para que esta tese fosse elaborada:

Ao Professor Laurindo de Salles Leal Filho pela supervisão acadêmica e confiança;

À empresa Vale pelo patrocínio da pesquisa e à Engenheira Keila Gonçalves por sua contribuição para o planejamento e desenvolvimento da pesquisa;

Ao Projeto AMIRA P260F que fomenta a pesquisa na qual esta tese está inserida. Aos pesquisadores da Universidade do Sul da Austrália (UNISA), Bill Skinner e Max Zanin, pelo convite para participarmos do projeto e pelas discussões enriquecedoras;

À CAPES pela bolsa concedida;

À Dra. Selma Gutierrez Antonio e ao Professor Carlos O. Paiva Santos pelo valioso auxílio com os refinamentos do método de Rietveld;

À PANanalytical por permitir que as medidas difração de raios- $X$ tenham sido realizadas em seu laboratório, em especial ao Dr. Luciano Gobbo pela ajuda com as análises;

À Profesora Patríca Matai pelo apoio com a elaboração do texto e ao Professor Eduardo Sansoni pelo auxílio com o tratamento estatístico dos resultados;

Aos funcionários da biblioteca Cristina, Ana e Adalberto e à secretária da pós graduação Maristela; 
Aos colegas do Instituto de Química da UNESP, Araraquara, em que concluí a graduação e o mestrado, em especial aos Professores Oswaldo Garcia Junior (In Memoriam), Denise Bevilaqua, Heloisa Acciari e Assis Benedetti que guiaram meus primeiros passos no mundo da pesquisa acadêmica;

Ao grupo de pesquisa do LFQI pela ajuda com os afazeres laboratoriais e por compartilhar com harmonia os dias de trabalho. Obrigada Ivani, Odair, Thiago, Marisa, Paulo, Kelly, Adriana, Rosendo, Simone, André, Gabriela, Marco, Reinaldo e Helder;

Aos alunos de graduação que participaram deste projeto Aimée (Iniciação Científica), Nicolas, Alexandre e Camila (Estágio);

A todos os colegas do Departamento de Engenhara de Minas e Petóleo da USP;

Aos meus amigos, Julia, Juliana, Chicão, Luciane, Paulo, Ceila, Eunir, Santos, Breno, Janaina, Amanda, Marcos, Fernanda, Marina, Marcela, Laura, Mariana, Fátima e Cícero, que de perto ou de longe vibraram para o sucesso deste trabalho;

Ao meu noivo Evandro, pelo amor e paciência;

A minha família, pai Otoganizo, mãe Manoela, irmão César, cunhada Paula, sobrinhas Giovanna e Julia, pelo carinho com que apoiaram a realização deste sonho;

A Deus e aos meus anjos protetores.

Muito Obrigada! 
"Nada na vida deve ser temido, apenas compreendido."

(Marie Curie) 


\section{RESUMO}

Diferentes estratégias de flotação (reagentes, pH e rota) têm sido utilizadas na separação entre apatita e carbonatos em todo o mundo. Há evidências na literatura de que a cristalinidade afeta a flotação de apatitas e calcitas com oleato de sódio. Além disso, a dissolução dos sais semi-solúveis pode influenciar a interação entre a superfície dos minerais e os reagentes de flotação, uma vez que o mecanismo de adsorção mais importante é a precipitação de oleato de cálcio na interface sólido/líquido. Portanto, o objetivo deste trabalho é investigar a relação entre cristalinidade, cinética de dissolução e resposta à flotação de apatitas e calcitas de diferentes gêneses (ígnea, metamórfica e sedimentar) e origens. Quatro tipos de minerais foram utilizados: purificados a partir de minérios, previamente purificados, naturalmente puros e amostras de coleção. As amostras foram caracterizadas por fluorescência de raios- $X$ e microanálise (WDS/EDS). Características físicas como densidade (d), área superficial $(S)$ e porosidade $(P)$ também foram determinadas. $O$ método de Rietveld aplicado à difração de raios- $X$ foi usado tanto para comprovar a pureza das amostras como para estudar a cristalinidade dos minerais por meio da determinação dos parâmetros de rede (distâncias a e $c$, e volume da cela unitária$\mathrm{V}_{\mathrm{CU}}$ ), além do grau de cristalinidade (GC), tamanho de cristalito (TC) e microdeformação (MD). Ensaios de dissolução, conduzidos na ausência de $\mathrm{CO}_{2}$, forneceram a quantidade (mol) de íons $\mathrm{Ca}^{2+}\left(\mathrm{nCa}^{2+}\right)$ dissolvidos em função do tempo (t) e normalizada em relação à área superficial. Os resultados se ajustam a um modelo de primeira ordem: $\mathrm{nCa}^{2+}=$ $\mathrm{Ca}^{2+}{ }_{\operatorname{MAX}}\left(1-\mathrm{e}^{-k t}\right)$. Este procedimento permitiu calcular os valores da quantidade máxima de íons $\mathrm{Ca}^{2+}$ dissolvidos $\left(\mathrm{Ca}^{2+}{ }_{\mathrm{MAX}}\right.$ ), bem como da constante cinética ( $\mathrm{k}$ ). Além disso, a velocidade de dissolução foi determinada para a etapa rápida $\left(V_{R}\right)$, que caracteriza o início da reação, e para a etapa lenta $\left(V_{L}\right)$, que ocorre nas proximidades do estado estacionário. $A$ resposta à flotação com oleato de sódio foi determinada por meio de experimentos de microflotação. Várias relações de causa e efeito são encontradas: flotabilidade (F) versus $V_{R}$, e $V_{R}$ versus características intrínsecas (parâmetros de rede, de cristalinidade e físicos). $V_{R}$ foi selecionado para participar de tais modelos, pois, caracteriza o intervalo de tempo em que o condicionamento (1 minuto) e a microflotação (1 minuto) ocorrem. Observa-se que a flotabilidade dos minerais aumenta com o aumento de $V_{R}$, sugerindo que apatitas e calcitas que disponibilizam mais íons $\mathrm{Ca}^{2+}$ em solução para interagir com o oleato, exibem mais elevada flotabilidade. Equações lineares de $F$ em função de $V_{R}$ em pH $8 \quad(R=0,97$ para apatitas e $\mathrm{R}=0,66$ para calcitas) e $\mathrm{pH} 10$ ( $R=0,95$ para apatitas e $\mathrm{R}=0,63$ para calcitas) foram encontradas. Correlações lineares múltiplas foram utilizadas para relacionar $V_{R}(e m$ pH 8 e 10) com as características intrínsecas que exercem maior influência sobre este parâmetro. Para as apatitas, $\mathrm{V}_{\mathrm{R}}$ foi equacionado em função de $\mathrm{GC}, \mathrm{TC}$ e $c$, enquanto para as calcitas, os parâmetros GC, TC, d e P foram selecionados para compor o modelo. Os valores de $V_{R}$ calculados se ajustam aos observados dentro de um intervalo de confiança de $95 \%$. As equações lineares propostas para as apatitas foram usadas para se estimar $F$ das amostras de Anitápolis-SC e Tapira-MG, que não foram submetidas aos ensaios de dissolução. Os valores de $\mathrm{F}$ calculados estão em concordância com aqueles experimentalmente determinados.

Palavras-chave: Flotação, apatita, calcita, cristalinidade, dissolução. 
Different flotation strategies (reagents, $\mathrm{pH}$ and route) have been adopted to separate apatite from carbonates around the world. Literature provides evidences that crystallinity affects flotation response of apatite and calcite with sodium oleate. Furthermore, dissolution of salt-type minerals influences the interaction between mineral surface and flotation reagents, because the most important adsorption mechanism is the surface precipitation of calcium oleate onto mineral/water interface. Therefore, the objective of this research is to investigate the relationship between crystallinity, dissolution kinetics and flotation response of apatites and calcites from different genesis (igneous, metamorphic and sedimentary) and origins. Four sorts of minerals were utilized: minerals purified from ores, minerals previously purified, naturally pure minerals and collection samples. They were characterized by X-ray fluorescence and X-ray microanalysis (WDS/EDS). Physical characteristics, as specific gravity (d), surface area (S) and porosity $(P)$, were also determined. The Rietveld method applied to X-ray diffraction data was used either to probe the purity of samples or to study the crystallinity of the minerals by means of determining their lattice parameters ( $a$ and $c$ dimensions plus lattice volume- $\mathrm{V}_{\mathrm{CU}}$ ), in addition to crystallinity degree (GC), crystallite size (TC) and microstrain (MD). Dissolution experiments, conducted in the absence of $\mathrm{CO}_{2}$, yielded curves which relate the amount (mol) of dissolved $\mathrm{Ca}^{2+}$ ions $\left(\mathrm{nCa}^{2+}\right)$ versus time $(\mathrm{t})$, normalized by the surface area. They fit a first order model: $\mathrm{nCa}^{2+}=\mathrm{Ca}^{2+}{ }_{\operatorname{MAX}}\left(1-\mathrm{e}^{-\mathrm{kt}}\right)$. Curve fitting via exponential adjustment was accomplished to calculate values of the maximum amount of dissolved $\mathrm{Ca}^{2+}$ ions $\left(\mathrm{Ca}^{2+}{ }_{\mathrm{MAX}}\right)$ and the kinetic constant $(\mathrm{k})$. In addition, the dissolution rate was determined for the fast step $\left(V_{R}\right)$, which characterizes the beginning of the reaction, and for the slow step $\left(\mathrm{V}_{\mathrm{L}}\right)$, as it tends to the steady state. Flotation response with sodium oleate was determined by microflotation experiments. Several cause-effect relationships are found: floatability $(F)$ versus $V_{R}$, and $V_{R}$ versus intrinsic characteristics of minerals (lattice, crystallinity and physical parameters). $V_{R}$ was selected to participate in the model because it characterizes the length of time along which reagent conditioning (1 minute) plus microflotation ( 1 minute) take place. It is observed that $F$ increases as $V_{R}$ becomes greater, suggesting that samples of apatites and calcites which place more $\mathrm{Ca}^{2+}$ ions in solution to interact with oleate exhibit higher flotation performance. Linear equations of $F$ versus $\mathrm{V}_{\mathrm{R}}$ at $\mathrm{pH} 8(\mathrm{R}=0,97$ for apatites and $\mathrm{R}=0,66$ for calcites) and $\mathrm{pH} 10(\mathrm{R}=0,95$ for apatites and $R=0,63$ for calcites) were found. Likewise, multiple linear correlations were used to relate $\mathrm{V}_{\mathrm{R}}$ (at $\mathrm{pH} 8$ and 10) with the intrinsic characteristics of apatites and calcites that affect $V_{R}$ to a greater extent. For apatites, $V_{R}$ was modeled as a function of GC, TC and $c$, while for calcites, the parameters GC, TC $d$ and $P$ were selected to compose the model. The calculated $V_{R}$ values fit the experimental ones within $95 \%$ of confidence. The linear equations developed for apatites were used to estimate floatability of the samples from Anitápolis-SC and Tapira-MG, which were not submitted to dissolution experiments. The values of calculated floatability are in agreement with the experimental ones.

Keywords: Flotation, apatite, calcite, crystallinity, dissolution. 


\section{Capítulo 2}

Figura 2.1 - Evolução da produção mundial de concentrado de fosfato de 1880 a 2008 (ABOUZEID, 2008).

Figura 2.2 - Produção mundial de rocha fosfática distribuída entre os 12 principais produtores (FONSECA; SILVA, 2012).

Figura 2.3 - Interação entre as variáveis que afetam o processo de flotação (FUERSTENAU, 1995)

Figura 2.4 - Fórmula molecular do ácido oleico com destaque para a cadeia carbônica simplificada por $\mathrm{R}$ (elaboração própria).

Figura 2.5 - Isotermas de adsorção de oleato na superfície dos minerais apatita (LU; DRELICH; MILLER, 1998), fluorita (KELLAR, 1992 apud LU; DRELICH; MILLER, 1998) e calcita (YOUNG, 1994 apud LU; DRELICH; MILLER, 1998) em pH 9,5.

Figura 2.6 - Diagrama de distribuição das espécies do ácido oleico em diferentes valores de $\mathrm{pH}$ para a concentração de oleato de $3,0 \times 10^{-5} \mathrm{~mol} \mathrm{~L}^{-1}$ (GUAN, 2009).

Figura 2.7 - Representação esquemática das cadeias de (A) amilose e (B) amilopectina (FRANCISCO-JUNIOR, 2008 - modificada).

Figura 2.8 - Fluxograma geral das operações unitárias envolvidas na concentração de apatita proveniente de rocha ígnea nas usinas brasileiras (LEAL FILHO; MARTINS; HORTA, 2010).

Figura 2.9 - Organização estrutural dos materiais cristalinos: de átomos a grãos (JENKINS; SNYDER, 1996 - modificada).

Figura 2.10 - Parâmetros $a$ e b utilizados no cálculo do índice de cristalinidade por Rodrigues e Brandão (1993) a partir dos picos de difração (211) e (112) da apatita.

Figura 2.11 - Modelo da estrutura da fluorapatita, em corte perpendicular ao eixo $c$, segundo o programa ATOMS for Windows (TOLEDO; PEREIRA, 2001)

Figura 2.12 - (A) Cela unitária da fluorapatita (SLANSKY, 1980); (B) Localização dos íons $\mathrm{F}^{-}, \mathrm{OH}^{-}$e $\mathrm{Cl}^{-}$na estrutura cristalina da apatita (KANAZAWA, 1989) 
Figura 2.13 - Sistemas utilizados para descrever a estrutura cristalina da calcita: (A) Romboédrico e (B) Hexagonal (REEDER, 1983)

Figura 2.14 - Comparação entre a solubilidade da apatita e da calcita em água pura e no sobrenadante uma da outra (AMANKONAH; SOMASUNDARAN; ANANTHAPADMANABHAN, 1985).

Figura 2.15 - Modelo de especiação da superfície da fluorapatita de acordo com o pH da solução proposto por Wu, Forsling e Schindler (1991)

Figura 2.16 - Curvas de dissolução de amostras de calcita de diferentes origens (ARVIDSON et al., 2002).

Figura 2.17 - Representação esquemática do efeito sinérgico de pH e temperatura no controle da cinética de dissolução da calcita (RICKARD; SJÖBERG, 1983)

\section{Capítulo 3}

Figura 3.1- Imagens das amostras de coleção

Figura 3.2 - Localização dos depósitos brasileiros que originaram as amostras contempladas neste trabalho.

Figura 3.3 - Etapas do processo de purificação de minerais a partir de minérios.

Figura 3.4 - Esquema geral das etapas de purificação por separação densitária.

Figura 3.5 - Variação do Campo magnético (em T) com a corrente aplicada (em A) para o separador magnético Frantz de Barreira (BRUMATTI, 2008 - modificado)

Figura 3.6 - Gráfico de Rietveld: compração entre perfis de difração observado e calculado após o refinamento

Figura 3.7 - Representação esquemática do reator Atlas Potassium utilizado nos ensaios de dissolução de apatitas e calcitas (elaboração própria)

Figura 3.8 - Diagrama representativo das etapas dos ensaios de dissolução... 106

Figura 3.9 - Representação das velocidades de dissolução calculadas a partir do gráfico de dissolução

Figura 3.10 - Representação esquemática do aparato experimental utilizado nos ensaios de microflotação (elaboração própria) 


\section{Capítulo 4}

Figura 4.1 - Imagem dos minerais utilizados, na forma de pó (entre 103 e $43 \mu \mathrm{m})$.

Figura 4.2 - Imagens de MEV com exemplos de partículas de apatitas analisadas por WDS/EDS.

Figura 4.3 - Espectros de FTIR (número de onda entre 4.000 e $400 \mathrm{~cm}^{-1}$ ) das apatitas.

Figura 4.4 - Espectro de FTIR da apatita ASO (número de onda entre $=2.000$ e $400 \mathrm{~cm}^{-1}$ ) com a identificação das vibrações do $\mathrm{CO}_{3}$.

Figura 4.5 - Imagens de MEV com exemplos de partículas de calcitas analisadas por WDS/EDS.

Figura 4.6 - Gráfico de Rietveld do padrão $\mathrm{LaB}_{6}$. Comparação entre perfis de difração: - observado e - calculado (- resíduo).

Figura 4.7 - Exemplo de gráfico de Rietveld da apatita AAR. Comparação entre perfis de difração: - observado e - calculado (- resíduo). $O$ quadro interno exibe a região $25^{\circ}<2 \theta<38^{\circ}$.

Figura 4.8 - Variação dos parâmetros de cristalinidade das apatitas com a origem das amostras.

Figura 4.9 - Variação dos parâmetros de cristalinidade das calcitas com a origem das amostras.

Figura 4.10 - Exemplo de gráfico de Rietveld da calcita CCI. Comparação entre perfis de difração: - observado e - calculado ( - resíduo). O quadro interno exibe a região $25^{\circ}<2 \Theta<35^{\circ}$.

Figura 4.11 - Exemplo de curvas de dissolução em pH 8 e 10: apatita AAR e calcita CRO.

Figura 4.12 - Variação dos parâmetros de dissolução das apatitas com a origem da amostra e com o pH da reação.

Figura 4.13 - Variação dos parâmetros de dissolução das calcitas com a origem da amostra e o com o pH da reação.

Figura 4.14 - Flotabilidade das apatitas em função de sua origem e do pH de flotação.

Figura 4.15 - Flotabilidade das calcitas em função de sua origem e do pH de flotação.

Figura 4.16 - Flotabilidade de calcitas com oleato de sódio $\left(7,11 \times 10^{-6} \mathrm{~mol} \mathrm{~L}^{-1}\right)$ em pH 8 na presença de gases contendo diferentes concentrações de gás carbônico (HORTA; LEAL FILHO, 2012).. 
Figura 4.17 - Variação da flotabilidade das apatitas com os parâmetros de dissolução $\mathrm{V}_{\mathrm{R}}$ e $\mathrm{Ca}^{2+}{ }_{\mathrm{MAX}}$ em pH 8 e 10

Figura 4.18 - Diagrama de autovalores da matriz de correlação dos parâmetros de rede, de cristalinidade e físicos das apatitas.

Figura 4.19 - Valores observados versus calculados pelo modelo de regressão linear múltipla de $\mathrm{V}_{\mathrm{R}}$ em função de $\mathrm{GC}, \mathrm{TC}_{\mathrm{M}}$ e $c$ para as apatitas.

Figura 4.20 - Variação da flotabilidade das calcitas com os parâmetros de dissolução $\mathrm{V}_{\mathrm{R}}$ e $\mathrm{Ca}^{2+}{ }_{\mathrm{MAX}} \mathrm{em} \mathrm{pH} 8$ e 10 .

Figura 4.21 - Diagrama de autovalores da matriz de correlação dos parâmetros de rede, de cristalinidade e físicos das calcitas

Figura 4.22 - Valores observados versus calculados pelo modelo de regressão linear múltipla de $V_{R}$ em função de $G C, T C$, d e $P$ para as calcitas. 


\section{LISTA DE TABELAS}

\section{Capítulo 1}

Tabela 1.1 - Estratégias de flotação mais adequadas para a separação apatita/carbonatos por flotação em diferentes lugares do mundo.

\section{Capítulo 2}

Tabela 2.1 - Informação sobre mineralogia e esquema de reagentes das principais operações industriais de concentração de fosfato no Brasil (LEAL FILHO; MARTINS; HORTA, 2010)....................... 48

Tabela 2.2 - Tipos e ocorrência das apatitas (TOLEDO; PEREIRA, 2001)....... 56

Tabela 2.3 - Particularidades do controle da velocidade de dissolução da calcita em função dos parâmetros $\mathrm{pH}$ e $\mathrm{pCO}_{2}$ (BERNER; MORSE, 1974; PLUMMER; WIGLEY, PARKHURST, 1978)........

\section{Capítulo 3}

Tabela 3.1 - Descrição dos tipos de amostras minerais utilizadas no trabalho.

Tabela 3.2 - Informação sobre os minérios de fosfato que foram utilizados para a concentração dos minerais apatita e calcita.

Tabela 3.3 - Características das apatitas previamente purificadas no LFQI.... 87

Tabela 3.4 - Características dos minerais naturalmente puros........................ 87

Tabela 3.5 - Identificação das amostras ao longo do texto............................. 90

Tabela 3.6 - Densidade dos minerais e líquidos utilizados na separação densitária .............................................................. 93

Tabela 3.7 - Elementos analisados por WDS e EDS ................................ 97

Tabela 3.8 - Características dos padrões utilizados nas análises por WDS..... 98

Tabela 3.9 - Concentrações e fluxos de adição das soluções ácida e básica utilizadas no ajuste de $\mathrm{pH}$ (Etapa 2 da Figura 3.8).................... 106

Tabela 3.10 - Parâmetros de dissolução..................................................... 110 


\section{Capítulo 4}

Tabela 4.1 - Análise química das apatitas por FRX ..................................... 116

Tabela 4.2 - Análise química das apatitas por WDS/EDS................................ 118

Tabela 4.3 - Teores de flúor determinados nesta tese e reportados por trabalhos da literatura para apatitas de mesma origem............... 121

Tabela 4.4 - Pureza dos concentrados de apatita determinada por análise semi-quantitativa do método de Rietveld.................................... 122

Tabela 4.5 - Números de onda das vibrações das espécies de apatita determinadas por FTIR.

Tabela 4.6 - Número de onda das vibrações encontradas nos espectros de FTIR das apatitas.

Tabela 4.7 - Propriedades físicas das apatitas..

Tabela 4.8 - Análise química das calcitas por FRX.

Tabela 4.9 - Análise química das calcitas por WDS/EDS.

Tabela 4.10 - Pureza dos concentrados de calcita determinada por análise semi-quantitativa do método de Rietveld.....

Tabela 4.11 - Propriedades físicas das calcitas.

Tabela 4.12 - Parâmetros de rede e de cristalinidade das apatitas.

Tabela 4.13 - Comparação entre os parâmetros de rede das apatitas determinados nesta tese e encontrados em trabalhos da literatura.

Tabela 4.14 - Coeficientes de correlação linear $(R)$ entre os parâmetros de rede $\left(a, c\right.$ e $\mathrm{V}_{\mathrm{CU}}$ ), de cristalinidade (GC, TC e MD) e físicos (d, $\mathrm{S}$ e $\mathrm{P})$ para as apatitas.

Tabela 4.15 - Parâmetros de rede e de cristalinidade das calcitas.

Tabela 4.16 - Coeficientes de correlação linear $(R)$ entre os parâmetros de rede $\left(a, c\right.$ e $V_{c u}$ ), de cristalinidade (GC, TC e MD) e físicos (d, $\mathrm{S}$ e $\mathrm{P})$ para as calcitas.

Tabela 4.17 - Parâmetros de dissolução das apatitas.

Tabela 4.18 - Parâmetros de dissolução das calcitas.

Tabela 4.19 - Flotabilidade das apatitas com oleato de sódio $\left(1,42 \times 10^{-5} \mathrm{~mol} \mathrm{~L}^{-1}\right)$.

Tabela 4.20 - Variáveis de controle da precipitação de oleato de cálcio em suspensões aquosas que contêm 1 grama da apatita ACJ........

Tabela 4.21 - Flotabilidade das calcitas com oleato de sódio $\left(7,11 \times 10^{-6} \mathrm{~mol} \mathrm{~L}^{-1}\right)$. 
Tabela 4.22 - Variáveis de controle da precipitação de oleato de cálcio em suspensões aquosas que contêm 1 grama da calcita CCJ........

Tabela 4.23 - Coeficientes de correlação linear $(R)$ entre flotabilidade e parâmetros de dissolução $\left(\mathrm{V}_{\mathrm{R}}, \mathrm{V}_{\mathrm{L}}, \mathrm{Ca}^{2+}{ }_{\mathrm{MAX}} \mathrm{e} \mathrm{k}\right)$ das apatitas em pH 8 e 10 .

Tabela 4.24 - Coeficientes de correlação linear $(R)$ entre $V_{R}$ e os parâmetros de rede, de cristalinidade, e físicos das apatitas

Tabela 4.25 - Comparação entre valores previstos (Equações 4.1 a 4.4) e experimentalmente obtidos da flotabilidade de concentrados de apatita.

Tabela 4.26 - Coeficiente de correlação linear $(R)$ entre flotabilidade e parâmetros de dissolução $\left(\mathrm{V}_{\mathrm{R}}, \mathrm{V}_{\mathrm{L}}, \mathrm{Ca}^{2+}{ }_{\mathrm{MAX}} \mathrm{e} \mathrm{k}\right)$ das calcitas em $\mathrm{pH} 8$ e 10 ......

Tabela 4.27 - Coeficientes de correlação linear $(R)$ entre $V_{R}$ e os parâmetros de rede, de cristalinidade e físicos das calcitas. 


$\begin{array}{ll}\text { AAN } & \text { Apatita de Anitápolis-SC } \\ \text { AAR } & \text { Apatita de Araxá-MG } \\ \text { ACJ } & \text { Apatita de Cajati-SP } \\ \text { AFM } & \text { Microscopia de força atômica (Atomic Force Microscopy) } \\ \text { AIP } & \text { Apatita de Ipirá-BA } \\ \text { ASQ } & \text { Apatita de Santa Quitéria-CE } \\ \text { ASO } & \text { Apatita de Sra Ouertane } \\ \text { ATP } & \text { Apatita de Tapira-MG } \\ \text { CAM } & \text { Calcita de Amorinópolis-GO } \\ \text { CCI } & \text { Calcita de Cachoeiro do Itapemirim-ES } \\ \text { CCJ } & \text { Calcita de Cajati-SP } \\ \text { CRO } & \text { Romboedro opaco de calcita } \\ \text { CRT } & \text { Romboedro transparente de calcita } \\ \text { CSQ } & \text { Calcita de Santa Quitéria-CE } \\ \text { EDS } & \text { espectroscopia de dispersão de energia (Energy Dispersive X- } \\ \text { FRX } & \text { ray Spectrocopy) } \\ \text { FTIR } & \text { Fluorescência de raios-X } \\ \text { GOF } & \text { Espectroscopia no infravermelho com transformada de Fourier( } \\ & \text { Fourier Transform Infrared Spectroscopy) } \\ \text { ICP-OES } & \text { goodness of fit } \\ & \text { Espectrometria de emissão óptica por plasma acoplado } \\ \text { individualmente (Inductively Coupled Plasma - Atomic Emission } \\ \text { LabCACC } & \text { Spectrometry) } \\ \text { LCT } & \text { Infravermelho } \\ \text { LFQI } & \text { Crisoratório Computacional de Análises Cristalográficas e } \\ \text { LTM } & \text { Laboratório de Caracterização Tecnológica } \\ \text { MEV } & \text { Laboratório de Físico-Química de Interfaces } \\ \text { NIST } & \text { Laboratório de Tratamento de Minérios } \\ \text { PF } & \text { Microscopia Eletrônica de Varredura } \\ \text { SRM } & \text { Instituto nacional de padrões e tecnologia (National Institute of } \\ \text { WDS } & \text { Standards and Technology) } \\ & \text { Perda ao Fogo } \\ \text { Material referência (Standard Reference Material) } \\ \text { espectroscopia de dispersão de comprimento de onda } \\ \text { (Wavelength Dispersive X-ray Spectroscopy) }\end{array}$




\section{LISTA DE SÍMBOLOS}

\begin{tabular}{|c|c|}
\hline KPS & Produto de solubilidade \\
\hline$\zeta$ & Potencial zeta \\
\hline$w_{n}$ & Quantidade acumulada de mol de $\mathrm{H}^{+}$consumido \\
\hline $\mathrm{t}$ & Tempo \\
\hline $\mathrm{W}_{\infty}$ & Quantidade de $\mathrm{H}^{+}$consumido no equilíbrio \\
\hline$y, z$ & $\begin{array}{l}\text { Constante relacionada com a distribuição de probabilidade de íons } \\
\text { superficiais deixarem a superfície }\end{array}$ \\
\hline$V_{D}$ & Velocidade de dissolução \\
\hline $\mathrm{v}^{+}$ & Velocidade de dissolução direta por unidade de área superficial \\
\hline Aq & Afinidade química da reação \\
\hline $\mathrm{R}_{\mathrm{g}}$ & Constante dos gases \\
\hline $\mathrm{T}$ & Temperatura \\
\hline$\sigma$ & Número estequiométrico de Tempkin \\
\hline$\Omega$ & Grau de saturação da solução \\
\hline $\mathrm{P}_{\mathrm{Al}}$ & Produto de atividade iônica \\
\hline $\mathrm{m}_{\text {calcita }}$ & Massa da calcita \\
\hline A & Área superficial do sólido \\
\hline $\mathrm{V}_{\mathrm{s}}$ & Volume da solução \\
\hline k & Constante cinética \\
\hline $\mathrm{n}$ & Ordem da reação \\
\hline KPS' & Produto de solubilidade aparente (relativo ao estado estacionário) \\
\hline a & Atividade \\
\hline $\mathrm{k}_{1}, \mathrm{k}_{2}, \mathrm{k}_{3}$ & Constantes de velocidade da reação direta de dissolução \\
\hline$k_{4}$ & Constante da velocidade de precipitação \\
\hline $\mathrm{R}^{\prime}$ & $\begin{array}{l}\text { Produto entre a constante da lei de Henry para o } \mathrm{CO}_{2} \text {, a primeira e a } \\
\text { segunda constantes de dissociação do ácido carbônico }\end{array}$ \\
\hline $\mathrm{pCO}_{2}$ & Pressão parcial de $\mathrm{CO}_{2}$ \\
\hline $\mathrm{xCO}_{2}$ & Fração de $\mathrm{CO}_{2}$ na mistura gasosa \\
\hline$p_{\text {total }}$ & Pressão barométrica \\
\hline $\mathrm{pH}_{2} \mathrm{O}$ & Pressão de vapor da água \\
\hline
\end{tabular}




\begin{tabular}{|c|c|}
\hline$P_{1}$ & Pressão inicial \\
\hline $\mathrm{P}_{2}$ & Pressão final \\
\hline $\mathrm{V}_{\mathrm{a}}$ & Volume da câmara que contém a amostra \\
\hline $\mathrm{V}_{\mathrm{s}}$ & Volume da câmara de expansão \\
\hline $\mathrm{V}_{\mathrm{e}}$ & Volume do sólido \\
\hline$\theta$ & Ângulo de contato \\
\hline$\gamma$ & Tensão superficial \\
\hline $\mathrm{y}_{\mathrm{ci}}$ & Intensidade calculada $\left(\mathrm{y}_{\mathrm{ci}}\right)$ em cada ponto $(\mathrm{i})$ \\
\hline$b$ & Pico de Bragg \\
\hline$\varnothing$ & Fase \\
\hline$\varnothing_{\text {rsi }}$ & Rugosidade superficial \\
\hline$S^{\prime}$ & Fator de escala \\
\hline J & Fator de multiplicidade \\
\hline$L_{p}$ & Fator de polarização de Lorentz \\
\hline$F^{\prime}$ & Fator de estrutura \\
\hline G & Função de perfil de reflexão \\
\hline $\mathrm{F}_{\mathrm{a}}$ & Função assimétrica \\
\hline$P^{\prime}$ & Função orientação preferencial \\
\hline$y^{\prime}{ }_{l i}$ & Refinamento da linha base \\
\hline $\mathrm{R}_{\mathrm{pp}}$ & Resíduo padrão ponderado \\
\hline $\mathrm{R}_{\mathrm{exp}}$ & Valor estatisticamente esperado de $R_{p p}$ \\
\hline TC & Tamanho médio de cristalito \\
\hline MD & Microdeformação \\
\hline GC & Grau de cristalinidade \\
\hline $\mathrm{TC}_{(\mathrm{h} 00)}$ & Tamanho de cristalito ao longo da orientação cristalográfica (h00) \\
\hline $\mathrm{TC}_{(0 \mathrm{k} 0)}$ & Tamanho de cristalito ao longo da orientação cristalográfica (0k0) \\
\hline $\mathrm{TC}_{(00)}$ & Tamanho de cristalito ao longo da orientação cristalográfica (00) \\
\hline $\mathrm{TC}_{\mathrm{M}}$ & Média geométrica entre $\mathrm{TC}_{(\mathrm{ho0})}, \mathrm{TC}_{(0 \mathrm{k} 0)}, \mathrm{TC}_{(00 \mathrm{~A})}$ \\
\hline a, $c$ & Parâmetros de rede \\
\hline $\mathrm{V}_{\mathrm{cu}}$ & Volume da célula unitária \\
\hline $\mathrm{nCa}^{2+}$ & Quantidade em mol de íons $\mathrm{Ca}^{2+}$ dissolvidos \\
\hline $\mathrm{V}_{\mathrm{ac}}$ & Volume acumulado de solução ácida adicionada \\
\hline $\mathrm{C}_{\mathrm{ac}}$ & Concentração da solução ácida utilizada \\
\hline
\end{tabular}




$\begin{array}{ll}\mathrm{m} & \text { Massa } \\ \mathrm{Ca}^{2+}{ }_{\mathrm{MAX}} & \text { Quantidade máxima de íons } \mathrm{Ca}^{2+} \text { dissolvidos } \\ \mathrm{V}_{\mathrm{R}} & \text { Velocidade de dissolução na etapa rápida } \\ \mathrm{V}_{\mathrm{L}} & \text { Velocidade de dissolução na etapa lenta } \\ \mathrm{F} & \text { Flotabilidade } \\ \mathrm{m}_{\mathrm{FL}} & \text { Massa de material flutuado } \\ \mathrm{m}_{\mathrm{AF}} & \text { Massa de material afundado } \\ \mathrm{d} & \text { Densidade } \\ \mathrm{S} & \text { Área superficial } \\ \mathrm{P} & \text { Porosidade } \\ \mathrm{R} & \text { Coeficiente de correlação } \\ \varepsilon \% & \text { Erro relativo percentual }\end{array}$


Capítulo 2 Revisão Bibliográfica.

2.1 Produção de concentrado de apatita............................................... 28

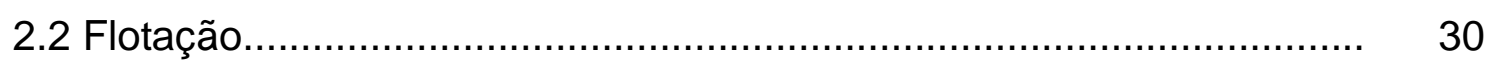

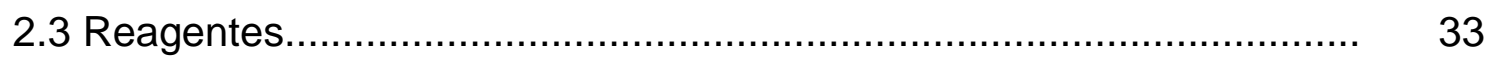

2.3.1 Oleato de sódio................................................................ 34

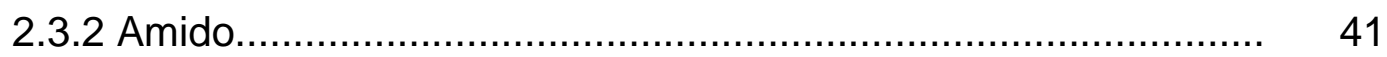

2.4 Estratégias de flotação................................................................ 44

2.5 Cristalinidade ....................................................................... 51

2.5.1 Estrutura cristalina da apatita.............................................. $\quad 55$

2.5.2 Estrutura cristalina da calcita............................................... 59

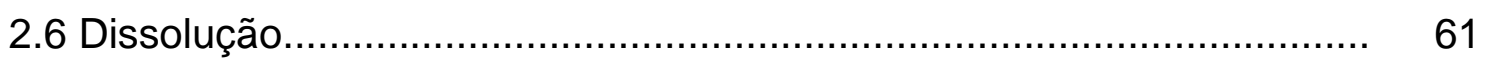

2.6.1 Dissolução da apatita........................................................ 66

2.6.2 Dissolução da calcita............................................................. 71

Capítulo 3 Materiais e Métodos................................................................. 84

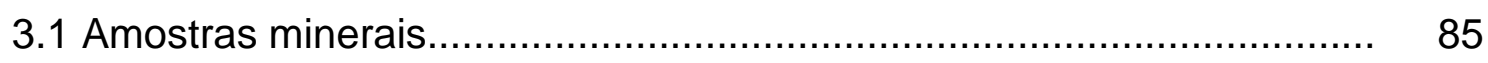

3.1.1 Identificação................................................................. 85

3.1.2 Preparação...................................................................... 91

3.1.3 Purificação............................................................................ 92

3.1.4 Caracterização............................................................. 96

3.2 Determinação da cristalinidade ...................................................... 100

3.3 Ensaios de dissolução................................................................. 103

3.4 Ensaios de microflotação............................................................. 110

3.5 Tratamento dos resultados........................................................... 112 
4.1 Caracterização das amostras de apatita e calcita............................ 114

4.1.1 Caracterização das apatitas.............................................. 115

4.1.2 Caracterização das calcitas............................................ 129

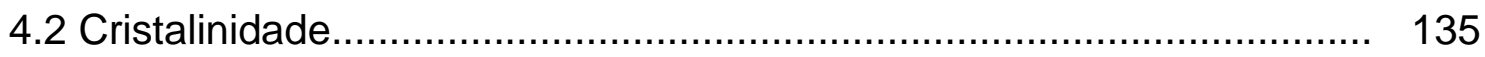

4.2.1 Cristalinidade das apatitas................................................... 136

4.2.2 Cristalinidade das calcitas............................................... 145

4.3 Dissolução.......................................................................... 150

4.3.1 Dissolução das apatitas.............................................. 151

4.3.2 Dissolução das calcitas................................................. 154

4.4 Flotação com oleato de sódio................................................... 158

4.4.1 Flotabilidade das apatitas................................................ 158

4.4.2 Flotabilidade das calcitas................................................. 162

4.5 Relações de causa e efeito entre características intrínsecas, dissolução e flotabilidade.

4.5 .1 Apatitas.............................................................. 167

4.5.2 Calcitas................................................................. 176

Capítulo 5 - Conclusões................................................................................... 183

5.1 Conclusões relativas ao estudo com as apatitas............................ 184

5.2 Conclusões relativas ao estudo com as calcitas............................. 186

Referências..................................................................................... 189

Apêndices................................................................................................... 204

Apêndice A - Análises WDS/EDS..................................................... 204

Apêndice B - Gráficos de Rietveld..................................................... 218 


\section{Capítulo 1}

\section{Introdução, Relevância e Objetivos}

Este capítulo contém a introdução do assunto abordado pela tese à luz de sua aplicação bem como os objetivos do trabalho. 
Por ser um dos maiores produtores de commodities agrícolas do mundo, o Brasil é um grande consumidor de fertilizantes, o que realça a importância da produção local de concentrados de apatita (fosfato) com qualidade adequada a especificações de mercado e custo compatível com padrões de produtividade internacional. Deste modo, o sucesso da produção doméstica de fertilizantes reforça - agrobusiness brasileiro, que opera num contexto globalizado e altamente competitivo (ABOUZEID, 2008; SIS; CHANDER, 2003a).

Diferentemente do Marrocos, Estados Unidos da América (EUA) e China, cujos concentrados de apatita são oriundos de jazidas de gênese sedimentar e produzidos com tecnologia desenvolvida e consolidada na primeira metade do século XX, o fosfato brasileiro é predominantemente de origem ígnea. Sua tecnologia de concentração foi desenvolvida localmente e ainda se encontra em fase de consolidação, demandando da Academia aporte de conhecimentos aplicados a sua realidade (ABOUZEID, 2008; SIS; CHANDER, 2003a).

Na Escola Politécnica da Universidade de São Paulo, o Grupo de Pesquisa em Tratamento de Minérios exibe um rico histórico de pesquisas voltadas à flotação de fosfatos, que teve início com o exitoso trabalho do eminente professor Paulo Abib Andery nos anos 60-70 do século XX e prossegue até o presente, gerando conhecimento aplicado à realidade local. Esta tese vem dar continuidade a este tradicional esforço.

A prática industrial e estudos de laboratório têm revelado que uma estratégia desenvolvida para a concentração de fosfato de um determinado depósito pode falhar completamente quando aplicada na flotação de outro. Este fato se torna explícito ao se observar as informações apresentadas na Tabela 1.1 onde se observa que, para alguns minérios, é mais compensador realizar a flotação direta da apatita. Para outros, todavia, é mais viável executar a flotação reversa dos carbonatos (ABDEL-KHALEK, 2000; ASSIS et al., 1985; LEAL FILHO; MARTINS; HORTA, 2010; PUGH; STENIUS, 1985; ZHENG et al., 2006).

Critérios baseados somente na composição mineralógica e teor de pentóxido de fósforo $\left(\mathrm{P}_{2} \mathrm{O}_{5}\right)$ não são suficientes para justificar as diferenças observadas na Tabela 1.1. Várias pesquisas realizadas entre 1985-1990 alertam para a influência de características intrínsecas (heterogeneidade química e textura superficial) dos minerais em sua interação com reagentes de flotação (ASSIS; VIANA; SILVA, 1987; LEAL FILHO, 1991; SILVA et al., 1985). 
Tabela 1.1 - Estratégias de flotação mais adequadas para a separação apatita/carbonatos por flotação em diferentes lugares do mundo.

\begin{tabular}{|c|c|c|c|c|c|}
\hline Gênese & Origem & Rota de flotação & Agente Coletor & $\begin{array}{c}\text { Reagentes } \\
\text { Modificadores }\end{array}$ & $\mathrm{pH}$ \\
\hline Sedimentar & $\begin{array}{c}\text { China } \\
\text { Brasil }\left(^{*}\right)\end{array}$ & Aniônica reversa & Ácidos graxos & $\mathrm{H}_{2} \mathrm{SO}_{4}$ e $\mathrm{H}_{3} \mathrm{PO}_{4}$ & $<5$ \\
\hline \multirow[b]{2}{*}{ Ígneo } & $\begin{array}{c}\text { Moçambique e } \\
\text { Brasil }\end{array}$ & Aniônica direta & $\begin{array}{l}\text { Sarcosinatos de alquila }\left({ }^{* \star}\right) \\
\text { Sulfosuccinamato de alquila }(+)\end{array}$ & $\begin{array}{l}\text { Amido } \\
\mathrm{NaOH}\end{array}$ & $>10.5$ \\
\hline & África do Sul & Aniônica direta & Ácidos graxos & $\begin{array}{l}\text { Silicato de sódio } \\
\text { Goma arábica } \\
\text { Nonilfenol }\end{array}$ & $\begin{array}{l}\text { Natural } \\
(8-8,5)\end{array}$ \\
\hline \multirow{2}{*}{ Metamórfico } & Brasil & Aniônica reversa & Ácidos graxos (\#) & $\mathrm{H}_{3} \mathrm{PO}_{4}$ & Meio ácido \\
\hline & Índia & Aniônica direta & Alquil Sarcosinatos & Amido & Meio básico \\
\hline
\end{tabular}

$\left({ }^{*}\right)$ Irecê-BA $\left.\quad{ }^{* *}\right)$ Cajati-SP e Evate-Moçambique $\quad(+)$ Minério granulado de Tapira-MG $\quad$ (\#) Santa Quitéria-CE 
Diferentes características intrínsecas (cristalinidade e composição) exibidas por calcitas $\left(\mathrm{CaCO}_{3}\right)$ e apatitas $\left(\mathrm{Ca}_{10}\left(\mathrm{PO}_{4}\right)_{6}(\mathrm{~F}, \mathrm{OH}, \mathrm{Cl})_{2}\right)$ que sofreram condicionamento geológico diverso poderiam explicar as variadas estratégias de flotação adotadas para separação que são apesentadas na Tabela I.1.

A cristalinidade de apatitas tem sido apontada como fator determinante da sua interação com reagentes de flotação, dado a influência que exerce nas propriedades superficiais. O que se observa geralmente é que quanto maior a cristalinidade, melhor é o desempenho do processo de flotação com ácidos graxos (ASSIS et al., 1985; ASSIS; VIANA; SILVA, 1987; LENHARO, 1994; RODRIGUES; BRANDÃO, 1993; SILVA et al., 1985). Por outro lado, nenhuma correlação foi encontrada na literatura no que diz respeito ao comportamento das calcitas.

Com base nas informações e premissas anteriormente apresentadas nesta seção, esta tese objetiva estudar a influência de características físicas intrínsecas aos minerais apatita e calcita de diferentes gêneses e origens, correlacionando os resultados com sua cinética de dissolução e resposta à flotação com oleato de sódio. Neste contexto os objetivos específicos da tese são:

1. Obter amostras de calcita e apatita a partir de minérios de diferentes gêneses e origens, com o maior elevado grau de pureza que for possível por técnicas que não afetem os demais experimentos;

2. Caracterizar as amostras quanto aos seus parâmetros de rede, de cristalinidade (grau de cristalinidade, tamanho de cristalito, microdeformação) e físicos (densidade, área superficial, porosidade), assim como o seu grau de pureza;

3. Estudar a cinética da dissolução dos minerais em meio aquoso;

4. Avaliar a flotabilidade dos minerais com oleato de sódio em meio básico;

5. Verificar se existe relação de causa-efeito entre características intrínsecas das apatitas e calcitas, sua cinética de dissolução e resposta à flotação (flotabilidade), discutindo os resultados à luz do atual estado da arte.

Para concluir este capítulo, é importante salientar que esta tese se insere em um projeto denominado AMIRA P260F - Mineral Flotation, através de uma colaboração entre a University of South Australia - Ian Wark Research Institute e o Grupo de Pesquisa de Tratamento de Minérios da USP, sob o patrocínio da empresa Vale Fertilizantes. 


\section{Capítulo 2}

\section{Revisão Bibliográfica}

Este capítulo abrange uma revisão dos trabalhos da literatura a respeito do tema estudado. Inicialmente faz-se uma análise da produção de concentrados de apatita no mundo (Seção 2.1). Em seguida, dedica-se algumas páginas à teoria envolvida no processo de flotação (Seção 2.2). Também são apresentadas informações pertinentes a respeito dos reagentes de flotação empregados, bem como dos mecanismos de interação entre estes e os sais semi-solúveis (Seção 2.3). Na Seção seguinte, 2.4, abordam-se as principais estratégias de flotação adotadas para a concentração de apatita. Posteriormente, são discutidos os principais aspectos envolvidos na cristalinidade e na dissolução (Seções 2.5 e 2.6, respectivamente) de apatitas e calcitas. 


\subsection{Produção de concentrado de apatita}

A produção comercial de rocha fosfática teve início em meados do século XIX, tendo sido produzidas 500 toneladas em 1847 na cidade de Suffok no Reino Unido. A partir daí, a produção mundial aumentou para 10 milhões de toneladas em 1928 e 100 milhões em 1974 (CISSE; MRABET, 2004). Uma curva do crescimento da produção anual de fosfato no mundo de 1880 a 2008 está ilustrada na Figura 2.1 (ABOUZEID, 2008). Nos últimos anos este valor se mantém por volta de 150 milhões de toneladas/ano (ABOUZEID, 2008; SIS; CHANDER, 2003a, 2003b).

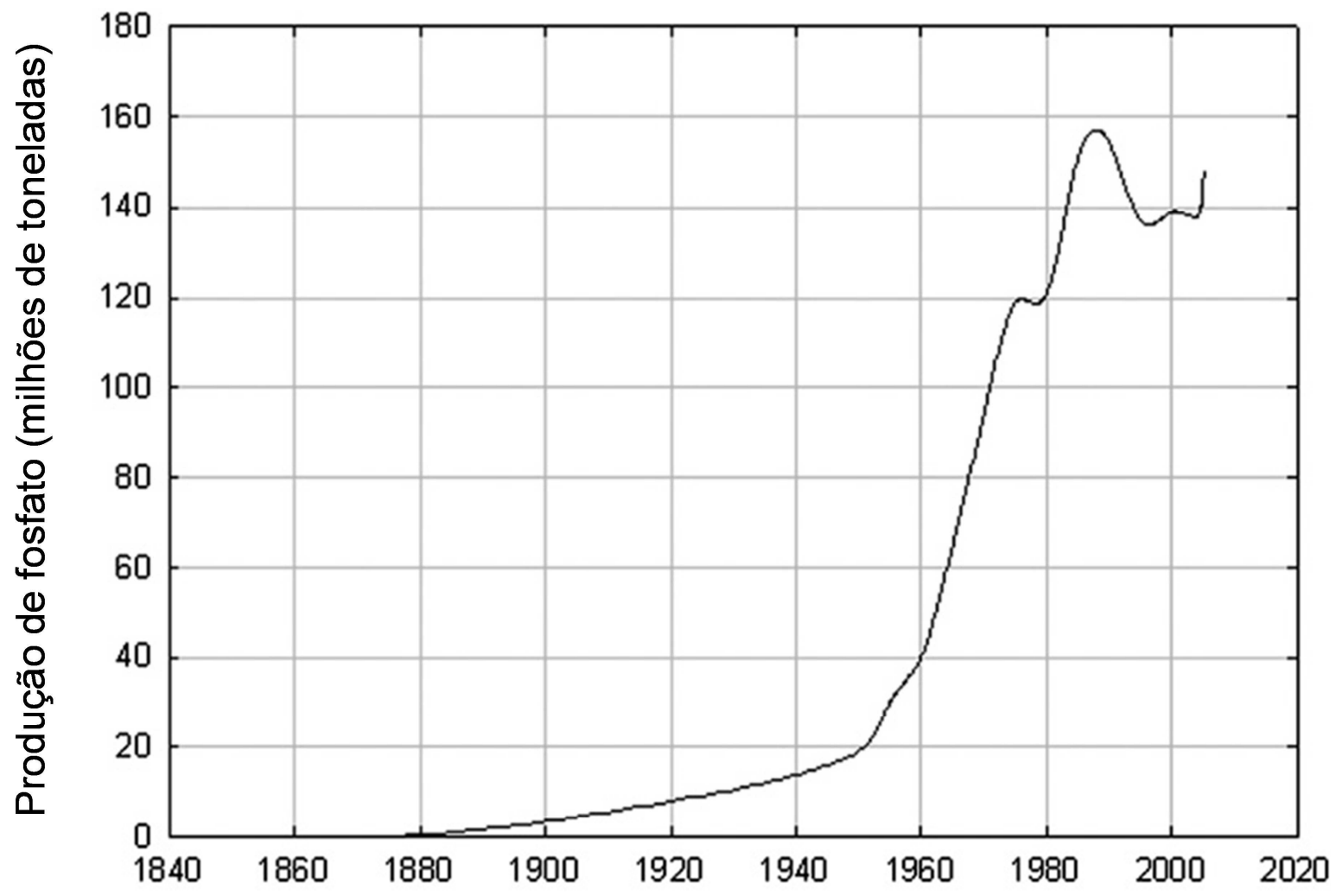

Ano

Figura 2.1 - Evolução da produção mundial de concentrado de fosfato de 1880 a 2008 (ABOUZEID, 2008). 
Atualmente, 40 países são responsáveis pelo fornecimento de concentrado de fosfato, entre os quais, 12 contribuem com $92 \%$ da produção mundial. A produção de concentrado de fosfato destes países em 2011 está ilustrada na Figura 2.2 (FONSECA; SILVA, 2012).

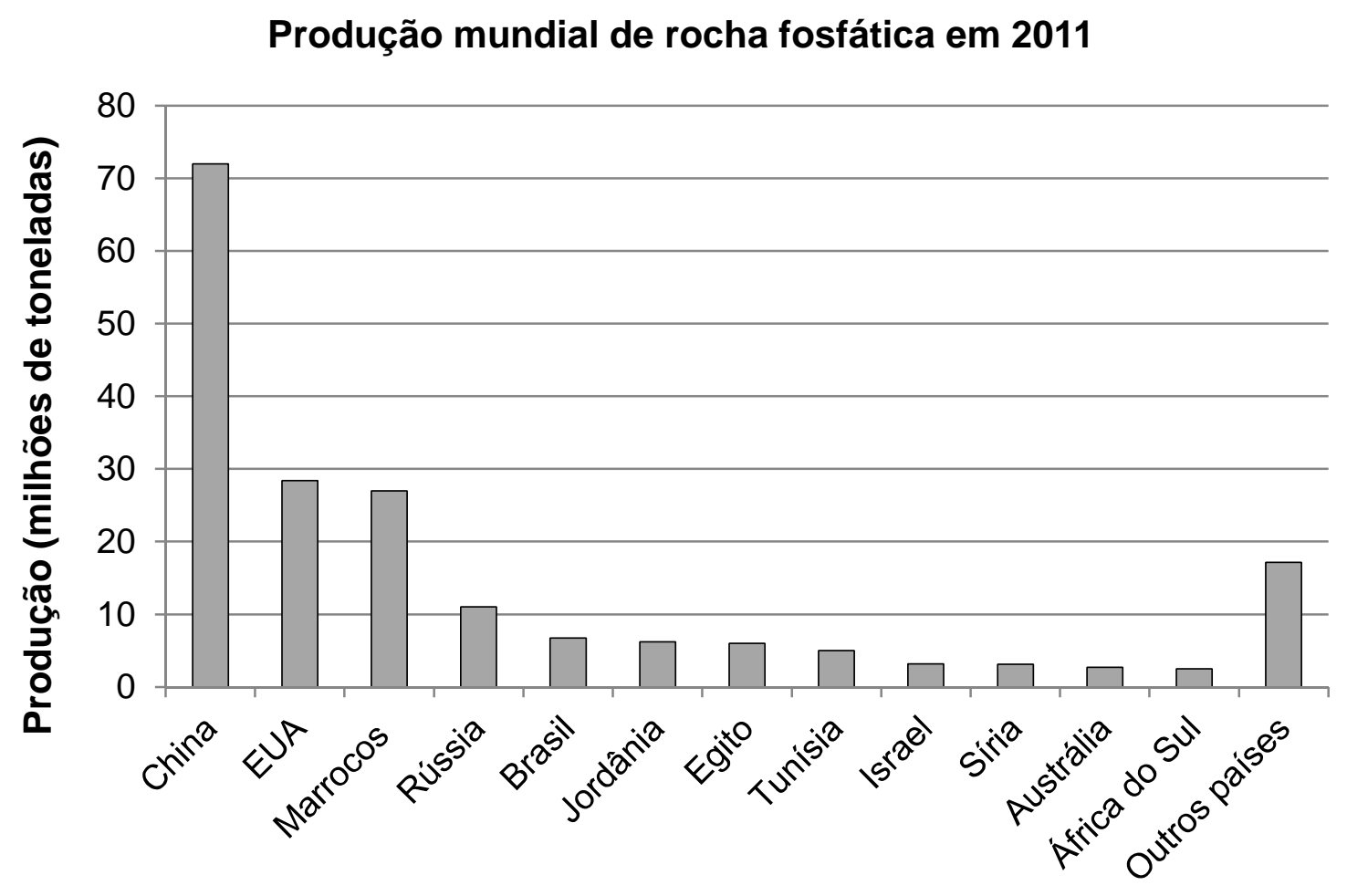

País

Figura 2.2 - Produção mundial de rocha fosfática distribuída entre os 12 principais produtores (FONSECA; SILVA, 2012).

$\mathrm{O}$ concentrado de fosfato de valor comercial deve conter teor de $\mathrm{P}_{2} \mathrm{O}_{5}$ igual ou superior a $30 \%$, razão $\mathrm{CaO} / \mathrm{P}_{2} \mathrm{O}_{5}<1,6$; razão $\mathrm{MgO} / \mathrm{P}_{2} \mathrm{O}_{5}<0,022$ e porcentagem de $\mathrm{MgO}$ < 1\% (ABOUZEID, 2008; LAWENDY; McCLELLAN, 1993; SIS; CHANDER, 2003a, 2003b). No entanto, observa-se uma redução contínua na qualidade do concentrado de fosfato produzido pelos circuitos industriais de flotação, devido ao esgotamento de reservas compostas por minérios com elevado teor de $\mathrm{P}_{2} \mathrm{O}_{5}$ e que apresentam associações mineralógicas, cujo sistema de reagentes em vigor produz a seletividade almejada. Deste modo, o desenvolvimento de estratégias para 0 beneficiamento de rocha fosfática com teores inferiores e com associações 
mineralógicas problemáticas (apatita/dolomita, apatita/micas/carbonatos) é um desafio tecnológico nos dias atuais (LEAL FILHO; MARTINS; HORTA, 2010).

As reservas de fosfato podem ser distribuídas de acordo com seu tipo, sendo que, aproximadamente $75 \%$ são depósitos marinhos sedimentares, $15-20 \%$ são de gênese ígnea/metamórfica e 2-3\% são de origem biogênica. Contudo, rochas de gênese ígnea e sedimentar são as de maior relevância econômica para o beneficiamento de minério de fosfato (ABOUZEID; EL-JALLAD; ORPHY, 1980; ABOUZEID; NEGM; ELGILLANI, 2009). No Brasil, em especial, $80 \%$ das reservas de fosfato são de gênese ígnea, com associações mineralógicas problemáticas que impõem desafios à concentração, como é o caso do minério micáceo-carbonático de Catalão-GO e Araxá-MG (GUIMARÃES; ARAUJO; PERES, 2005).

\subsection{Flotação}

Todas as técnicas de separação mineral têm como base uma propriedade física ou química que diferencia as espécies envolvidas. A seletividade do processo de flotação é fundamentada pelo fato de que diferentes minerais podem apresentar distintos graus de hidrofobicidade, isto é, serem molhados pela água em diferente extensão e/ou intensidade. A técnica consiste, basicamente, em introduzir bolhas de ar em vasos (células mecânicas ou colunas) que contêm água misturada aos sólidos, permitindo que as partículas de minerais hidrofóbicos (que apresentam afinidade pelo ar) colidam, sofram adesão às bolhas e flutuem. Paralelamente, as partículas dos minerais hidrofílicos (que têm afinidade pela água), por sua vez, permanecem suspensas no meio aquoso e afundam (CHAVES, 2006; CHAVES; LEAL FILHO; BRAGA, 2010).

Poucos minerais apresentam superfície naturalmente hidrofóbica como a molibdenita, o talco, o carvão, o enxofre e a grafita, enquanto a grande maioria dos minerais (sulfetos, carbonatos, óxidos e silicatos) exibe caráter hidrofílico. No entanto, a seletividade da flotação é alcançada pela introdução de reagentes químicos que promovem a hidrofobicidade no mineral que se deseja flotar. Tais 
reagentes são chamados agentes coletores (CHAVES, 2006; CHAVES; LEAL FILHO; BRAGA, 2010).

Os agentes coletores são moléculas anfifílicas, ou seja, apresentam uma porção polar (carboxila, xantato, sulfato, sulfonato, amina) acoplada a uma cadeia hidrocarbônica com diferentes comprimentos e graus de saturação. A porção polar é responsável pela seletividade da adsorção na interface mineral/solução e a porção apolar é aquela que promove a hidrofobicidade das partículas minerais que sofreram adsorção do coletor (CHAVES, 2006; CHAVES; LEAL FILHO; BRAGA, 2010).

Além dos agentes coletores, modificadores e espumantes constituem o domínio dos reagentes de flotação. Os modificadores podem ser depressores, ativadores ou reguladores, dependendo de sua função no sistema. Eles [receberão atenção especial nos parágrafos vindouros. Os agentes espumantes, por sua vez, são moléculas capazes de reduzir a tensão superficial da interface líquido-gás e aumentar a elasticidade das bolhas de ar, tornando-as mais estáveis e dispersas. Em muitos casos, os agentes coletores de cadeia longa podem agir também como espumantes (CHAVES, 2006; CHAVES; LEAL FILHO; BRAGA, 2010).

Depressores são modificadores utilizados para impedir a ação do agente coletor sobre um determinado mineral (ou grupo de minerais) que não se deseja flotar, reforçando o seu caráter hidrofílico. Para isto, sua ação é mais efetiva quando são adicionados ao sistema antes do coletor. Na flotação aniônica direta da apatita de Cajati, por exemplo, o amido é utilizado para deprimir carbonatos, enquanto que na flotação aniônica direta dos fosfatos de Araxá-MG, Tapira-MG e Catalão-GO, o mesmo reagente é utilizado para deprimir óxidos portadores de ferro e de titânio (CHAVES, 2006; CHAVES; LEAL FILHO; BRAGA, 2010; LEAL FILHO; MARTINS; HORTA, 2010).

Ativadores são modificadores que promovem a interação entre o agente coletor e o mineral que se deseja flotar. Embora este tipo de reagente não seja utilizado na flotação de fosfatos, ele encontra grande aplicação na flotação de sulfetos e também na separação quartzo $\left(\mathrm{SiO}_{2}\right) /$ feldspato. Por outro lado, a seletividade da flotação aniônica direta da apatita em meio básico pode ser afetada pela ativação de silicatos devida, por exemplo, à adsorção de hidroxocomplexos (de $\mathrm{Mg}^{2+}, \mathrm{Ca}^{2+}$ e $\mathrm{Fe}^{2+}$ ) na interface silicato/solução (LEAL FILHO, 1999b; LEAL FILHO; MARTINS; HORTA, 2010;). 
Os reguladores são agentes modificadores que atuam no seio da solução e têm a função de gerar condições ótimas ( $\mathrm{pH}$, Eh, dispersão) para a atuação dos demais reagentes, sejam eles coletores, depressores ou ativadores (CHAVES, 2006; CHAVES; LEAL FILHO; BRAGA, 2010).

A flotação é um processo complexo por envolver uma série de variáveis que podem ser classificadas como: mineralógicas, químicas e de processo. A forma como estas variáveis interagem entre si, proposta por Fuerstenau (1995), está ilustrada na Figura 2.3. As variáveis mineralógicas constituem, além da composição das fases minerais, características como porosidade, forma e grau de liberação. $O$ fato de estas características não serem passíveis de modificação justifica a flecha unidirecional da figura partindo das variáveis mineralógicas (FUERSTENAU, 1995; GUAN, 2009).

\section{Variáveis \\ mineralógicas}

Variáveis químicas

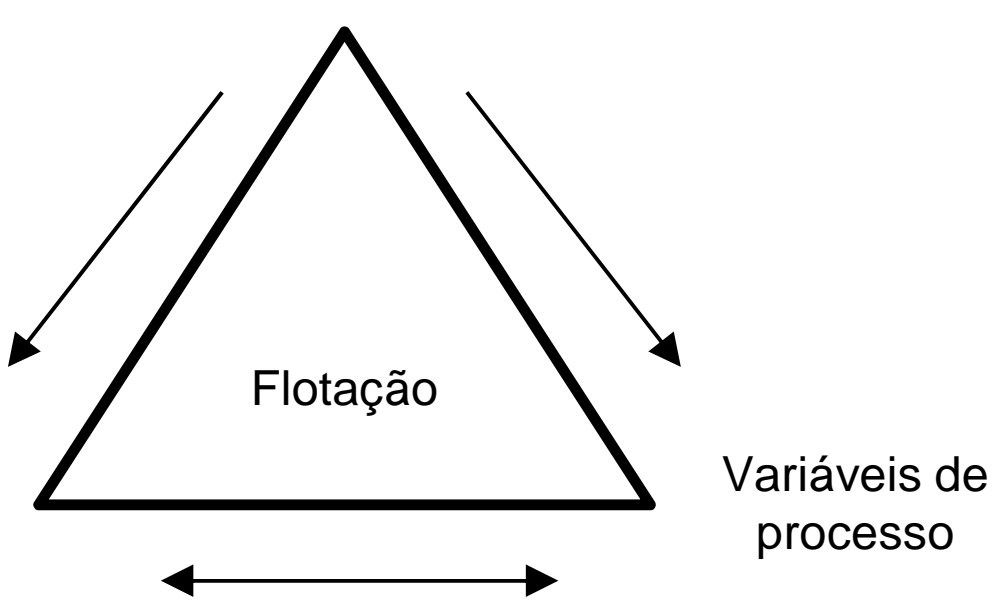

Figura 2.3 - Interação entre as variáveis que afetam o processo de flotação (FUERSTENAU, 1995).

As variáveis de processo constituem em desenho dos equipamentos e parâmetros operacionais. As variáveis químicas constituem o esquema de reagentes que pode ser continuamente alterado em função de mudanças nas variáveis mineralógicas e de processo, como representado na Figura 2.3 (FUERSTENAU, 1995; GUAN, 2009). 


\subsection{Reagentes}

Diferentes tipos de coletores e modificadores têm sido utilizados na concentração de apatita por flotação. A escolha do esquema de reagentes depende da natureza do minério, bem como da rota (direta ou reversa) e do pH de flotação.

$\mathrm{Na}$ concentração de fosfatos de origem sedimentar, os ácidos graxos de cadeia longa (principalmente ácido oleico) e seus sabões têm sido utilizados como coletores de apatita. Por outro lado, na concentração de fosfatos de origem ígnea, uma gama mais ampla de coletores aniônicos é comumente utilizada: sarcosinatos, sulfossuccinatos e sulfossuccinamatos de alquila, além dos tradicionais ácidos graxos que podem ser utilizados sozinhos ou em misturas com os demais (HANNA; SOMASUNDARAN, 1976; LEAL FILHO; MARTINS; HORTA, 2010; SNOW; ZHANG, 2006; YEHIA; MILLER; ATEYA, 1993).

Como apatita e calcita são minerais semi-solúveis portadores de cálcio, e os coletores aniônicos usualmente empregados interagem intensamente com íons $\mathrm{Ca}^{2+}$, faz-se necessário o uso de agentes depressores para garantir a seletividade da flotação (KHOSLA; BISWAS, 1984; LEAL FILHO et al., 2000). Como observado na Tabela 1.1, existem estratégias de concentração que adotam a rota de flotação direta em que apatita flutua e os carbonatos são deprimidos. Algumas usinas de beneficiamento brasileiras utilizam amido de milho como agente depressor de carbonatos na rota direta de flotação. Existem minérios, no entanto, que respondem melhor à rota de flotação reversa, em que a apatita é deprimida e os carbonatos flutuam. Nesta rota, a utilização de ácido fosfórico e seus derivados, como agente depressor de apatita, tem sido reportada por trabalhos da literatura (ELGILLANI; ABOUZEID, 1993; PRASAD; MAJUNDER; RAO, 2000; SOMASUNDARAN; ZHANG, 1999).

A seguir, faz-se uma revisão sobre oleato de sódio (coletor de apatita ou carbonatos) e amido de milho (depressor de carbonatos), abordando-se os mecanismos de adsorção entre estes reagentes e os minerais apatita e calcita. 


\subsubsection{Oleato de sódio}

Ácidos graxos de cadeia longa, como oleico, linoleico e esteárico, além de seus sabões, são largamente utilizados como agentes coletores de minerais portadores de cálcio na concentração de fosfatos por flotação (FINKELSTEIN, 1989; HANNA; SOMASUNDARAN, 1976; LEAL FILHO, 1991; MALTESH; SOMASUNDARAN; GRUBER, 1996; PUGH; STENIUS, 1985). Fatores como o grau de insaturação e o tamanho da cadeia carbônica influenciam a ação coletora dos ácidos graxos durante a flotação. Segundo Snow e Zhang (2006), os ácidos graxos insaturados apresentaram melhor desempenho em detrimento dos saturados na flotação direta de apatita. No que concerne ao número de carbonos da cadeia, melhor capacidade coletora é obtida pelos ácidos oleico (uma insaturação) e linoleico (duas insaturações), ambos com 18 carbonos (SNOW; ZHANG, 2006). De fato, a maioria dos trabalhos da literatura é dedicada à investigação da adsorção de ácido oleico e seus derivados na superfície dos minerais portadores de cálcio.

O ácido oleico é geralmente utilizado na forma de oleato de sódio que é o produto da saponificação com hidróxido de sódio de acordo com a Reação 2.1.

$$
\mathrm{RCOOH}_{(\mathrm{l})}+\mathrm{OH}_{(\mathrm{aq})} \rightleftarrows \mathrm{RCOO}_{(\mathrm{aq})}^{-}+\mathrm{H}_{2} \mathrm{O}_{(\mathrm{l})}
$$

$\mathrm{Na}$ qual $\mathrm{R}$ é uma cadeia com 17 carbonos, contendo uma insaturação entre os carbonos 9 e 10, como observado na Figura 2.4 que contém a fórmula estrutural do ácido oleico.

A extensão da adsorção de ácido graxo na superfície dos minerais influencia a seletividade do processo de flotação. Ela é afetada por condições tais como pH, temperatura, concentração inicial dos reagentes e porcentagem de sólidos na polpa (LU; DRELICH; MILLER, 1998; MALTESH; SOMASUNDARAN; GRUBER, 1996; RAO; CASES; FORSSBERG, 1991; RAO; FORSSBERG, 1991; YEHIA; MILLER; ATEYA, 1993). 


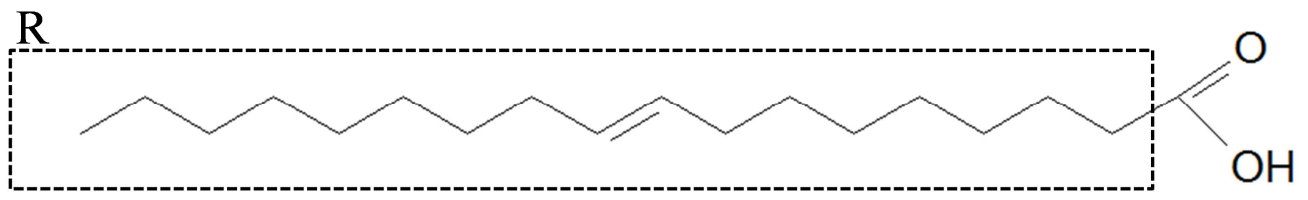

Figura 2.4 - Fórmula molecular do ácido oleico com destaque para a cadeia carbônica simplificada por R (elaboração própria).

Yehia, Miller e Ateya (1993) investigaram a adsorção do oleato em diferentes apatitas sintéticas após as mesmas terem sido flotadas em tubo de Hallimond. Os autores observaram que quanto mais negativo é o valor da energia livre de adsorção $\left(\Delta G^{0}{ }_{a d s}\right)$ maior é a densidade de adsorção do coletor na interface mineral/solução. Estas condições foram corroboradas por um valor mais alto de ângulo de contato e maior recuperação nos ensaios de microflotação. Entre as apatitas estudadas, a ordem decrescente dos valores de $\Delta G^{0}{ }_{a d s}$ encontrada foi: fluorapatita > carbonatoapatita > hidroxiapatita > cloroapatita (YEHIA; MILLER; ATEYA, 1993).

A literatura corrente aponta três mecanismos para explicar a adsorção de oleato na superfície dos minerais semi-solúveis: (1) Quimissorção, (2) Precipitação na superfície e (3) Precipitação no bulk seguida de heterocoagulação. O termo em inglês bulk é utilizado neste texto para descrever a região da solução distante da interface sólido/líquido. Excelentes revisões a respeito dos mecanismos de adsorção são encontradas nos trabalhos de Hanna e Somasundaran (1976), e Finkelstein (1989).

A quimissorção resulta de uma interação direta entre o ânion coletor (oleato) e os sítios ativos superficiais $\left(\mathrm{Ca}^{2+}\right)$. Por outro lado, segundo o mecanismo de precipitação na superfície, cátions metálicos $\left(\mathrm{Ca}^{2+}\right)$ interagem com o ânion coletor imediatamente após deixarem a rede cristalina do mineral, ocasionando a precipitação de oleato de cálcio na interface mineral/solução. A formação de oleato de cálcio é descrita pela Reação 2.2. O mecanismo de precipitação no bulk, por sua vez, assume que a interação entre oleato e íons $\mathrm{Ca}^{2+}$ ocorre no seio da solução. Após a sua precipitação, coloides de oleato de cálcio podem recobrir partículas minerais presentes na polpa (heterocoagulação) de acordo com as condições termodinâmicas previstas pela teoria DLVO (FINKELSTEIN, 1989; HANNA; SOMASUNDARAN, 1976). 


$$
\mathrm{Ca}^{2+}{ }_{(\mathrm{aq})}+2 \mathrm{RCOO}_{(\mathrm{aq})}^{-} \rightleftarrows \mathrm{Ca}(\mathrm{RCOO})_{2(\mathrm{~s})} \quad \mathrm{pK}_{\mathrm{pS}}=-16,0
$$

Levando em consideração os três mecanismos, a adsorção do ânion oleato na interface apatita/solução se inicia por meio de uma quimissorção (em baixas concentrações de oleato), seguida pela precipitação do oleato de cálcio na interface apatita/solução, que ocorre em mais altas concentrações de coletor (FA et al., 2003). Quando a flotação é conduzida em meio aquoso rico em cálcio ou magnésio, também pode ocorrer a precipitação de oleato de cálcio (ou de magnésio) no seio da solução antes de o coletor chegar à superfície da apatita. Tal fenômeno contribui para aumento no consumo de coletor e perda de seletividade. Esta última ocorre quando também há interação entre coloides de oleato de cálcio/magnésio e partículas de ganga (LEAL FILHO, 1999b).

Segundo Somasundaran e Zhang (1999), em concentrações inferiores a $1 \times 10^{-4} \mathrm{~mol} \mathrm{~L}^{-1}$, a adsorção do ânion oleato na superfície da dolomita e da francolita ocorre por meio de quimissorção. Em concentrações superiores a $1 \times 10^{-4} \mathrm{~mol} \mathrm{~L}^{-1}$ os produtos de solubilidade do oleato de cálcio e de magnésio são atingidos na região interfacial, mas não na solução, o que sugere a precipitação de oleato de cálcio e magnésio na superfície dos dois minerais (SOMASUNDARAN; ZHANG, 1999).

Os mecanismos de adsorção têm sido propostos com base em resultados obtidos por meio da construção de isotermas de adsorção, medidas de potencial zeta e espectroscopia no Infravermelho (IV). Esta ultima técnica é uma ferramenta que permite a determinação dos grupos funcionais das espécies adsorvidas. Uma grande evolução, neste sentido, foi atingida com o advento da Espectroscopia no Infravermelho com Transformada de Fourier (FTIR-Fourier Transform Infrared) na década de 90, quando o espectrômetro passou a ser manejado por programas de computador. Com isto, tornou-se possível investigar aspectos mais complexos da adsorção, como a formação de mono ou múltiplas camadas e suas estruturas. Tais informações podem ser obtidas por meio do estudo da variação da intensidade e posição das bandas de absorção na região do IV (FA; NGUYEN; MILLER, 2006; FREE; MILLER, 1996; MALTESH; SOMASUNDARAN; GRUBER, 1996; MATHUR; 
MOUDGIL, 1994; MIELCZARSKI et al., 1993; MIELCZARSKI et al., 2000; RAO; CASES; FORSSBERG, 1991; YOUNG; MILLER, 2000).

Os resultados dos estudos espectroscópicos na região do IV mais recentes sugerem a existência de três diferentes formas de oleato adsorvidas na interface sólido/líquido dos minerais portadores de cálcio: (1) Oleato quimissorvido, cuja relação oleato/cálcio superficial é de 1:1, sendo o recobrimento superficial limitado a uma monocamada. Esta interação é caracterizada por uma banda de absorbância em aproximadamente $1.500 \mathrm{~cm}^{-1}$; (2) Adsorção não específica de oleato de cálcio caracterizada por duas bandas em 1.575 e $1.535 \mathrm{~cm}^{-1}$ (precipitação na superfície); (3) Adsorção não específica de ácido oleico, no caso de soluções ácidas, representada por uma banda de absorção em aproximadamente $1.712 \mathrm{~cm}^{-1}$ (MATHUR; MOUDGIL, 1994; MIELCZARSKI et al., 1993; YOUNG; MILLER, 2000).

Mielczarski et al. (1993) observaram que, no caso da hidroxiapatita, a quimissorção forma uma estrutura bem organizada com fortes interações laterais, mesmo em níveis de recobrimento inferiores à monocamada. Em contrapartida, o mecanismo de precipitação na superfície conduz à adsorção de moléculas de oleato de cálcio pouco organizadas estruturalmente. A presença de impurezas (isômeros e homólogos) no sistema reduz ainda mais a organização estrutural das camadas do sal orgânico adsorvido.

Devido às similaridades físico-químicas entre os minerais portadores de cálcio, pode-se admitir que o mecanismo por meio do qual o oleato é adsorvido em suas superfícies seja o mesmo. No entanto, existem diferenças no que concerne à quantidade adsorvida em função da concentração do reagente em solução, que contribuem para a seletividade no processo de flotação (LU; DRELICH; MILLER, 1998; RAO; CASES; FORSSBERG, 1991; RAO; FORSSBERG, 1991).

Lu, Drelich e Miller (1998) organizaram a Figura 2.5 que contém isotermas de adsorção de oleato na superfície dos minerais apatita, fluorita e calcita em pH 9,5. Os dados a respeito da apatita foram obtidos pelos próprios autores, enquanto os da fluorita e da calcita foram retirados das teses de Kellar (1992 apud LU; DRELICH; MILLER, 1998) e Young (1994 apud LU; DRELICH; MILLER, 1998), respectivamente. 


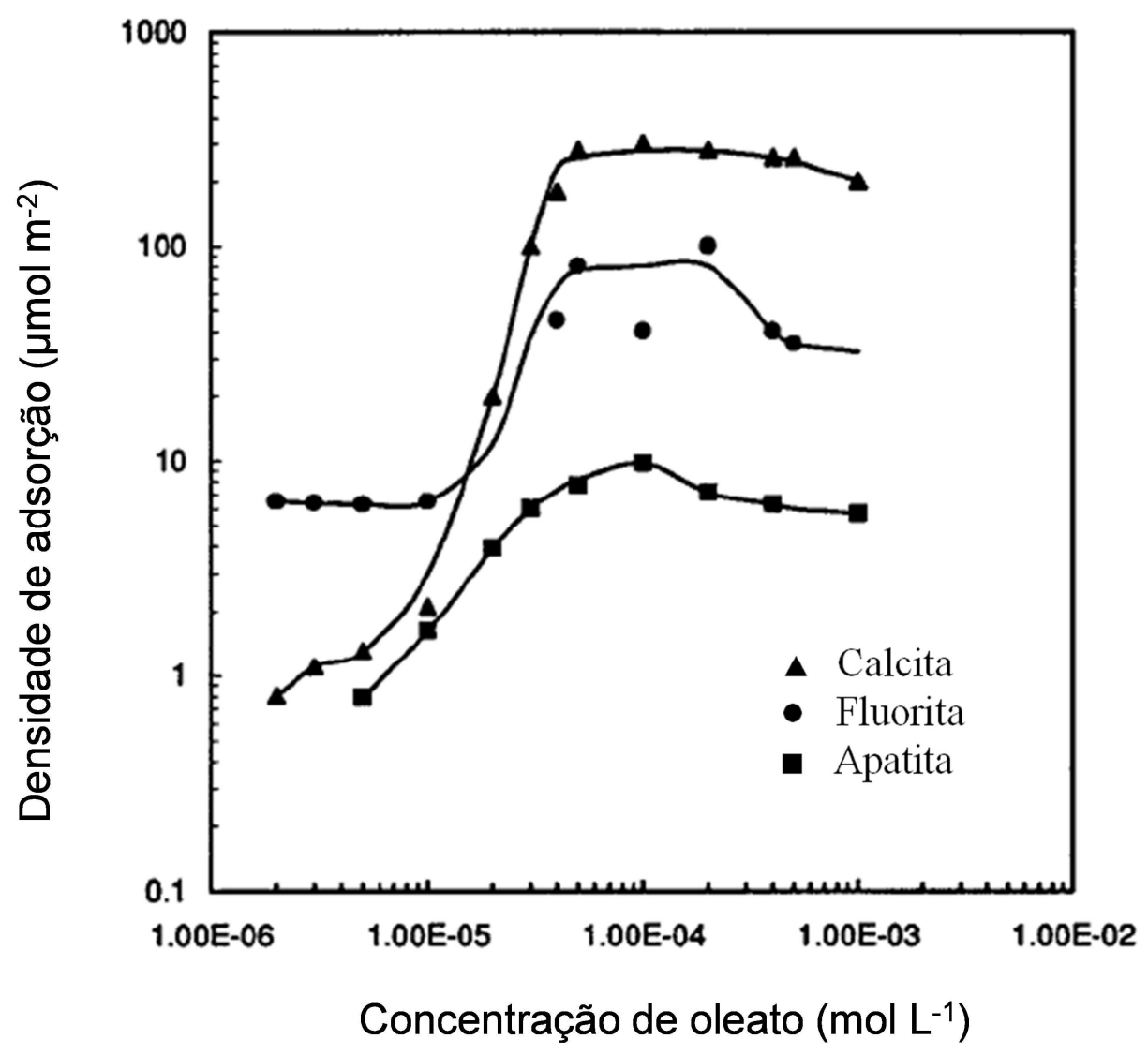

Figura 2.5 - Isotermas de adsorção de oleato na superfície dos minerais apatita (LU; DRELICH; MILLER, 1998), fluorita (KELLAR, 1992 apud LU; DRELICH; MILLER, 1998) e calcita (YOUNG, 1994 apud LU; DRELICH; MILLER, 1998) em pH 9,5.

Observa-se na Figura 2.5 que na região de concentração de oleato compreendida entre $2 \times 10^{-6}$ e $2 \times 10^{-5} \mathrm{~mol} \mathrm{~L}^{-1}$ a ordem preferencial de adsorção obtida é: fluorita $\left(11,1-12,9 \mu \mathrm{mol} \mathrm{m}{ }^{-2}\right)>$ calcita $\left(8,2 \mu \mathrm{mol} \mathrm{m}{ }^{-2}\right)>$ apatita $\left(5,1-6,6 \mu \mathrm{mol} \mathrm{m}{ }^{-2}\right)$. Tal ordem é proporcional à densidade de sítios ativos superficiais. Já em concentrações de coletor superiores a $2 \times 10^{-5} \mathrm{~mol} \mathrm{~L}^{-1}$, há uma mudança na ordem de adsorção: calcita > fluorita > apatita. Tal ordem é coerente com o produto de solubilidade $\left(K_{P S}\right)$ dos minerais envolvidos: calcita $\left(K_{P S}=4,6 \times 10^{-9}\right)>$ fluorita $\left(K_{P S}=5,0 \times 10^{-11}\right)>>>$ fluorapatita $\left(K_{P S}=6,3 \times 10^{-126}\right)$. Este resultado indica que a precipitação na superfície ocorre preferencialmente e em maior extensão nos minerais mais solúveis (LU; DRELICH; MILLER, 1998). Como os valores de $K_{P S}$ são relativos a uma condição de equilíbrio, e este raramente é atingido dentro do intervalo de tempo em que ocorre o processo de flotação, há necessidade de se introduzir condições de contorno (cinética de dissolução e composição química da 
solução) para descrever ou prever o comportamento dos minerais semi-solúveis em sistemas reais. Esta é uma contribuição desta tese.

Paiva et al. (2011) investigaram a precipitação de oleato de cálcio na superfície de apatita por meio de Microscopia de Força Atômica (MFA). Os autores observaram que quando a apatita foi imersa em solução contendo oleato e elevada concentração de íons $\mathrm{Ca}^{2+}$, a superfície do mineral foi recoberta por aglomerados de oleato de cálcio. A presença de tais aglomerados tornou a superfície da apatita mais rugosa e heterogênea (PAIVA et al., 2011). Trata-se, pois, de mais um indicativo do mecanismo predominante na adsorção de oleato em apatita.

Fa et al. (2003) mediram, por meio de MFA, a força de interação entre esferas coloidais de oleato de cálcio e a superfície dos minerais calcita e fluorita na faixa de $\mathrm{pH}$ entre 5,2 e 10,0. Observou-se a existência de força repulsiva entre coloides de oleato de cálcio e a superfície da calcita, e a ocorrência de força atrativa entre tais coloides hidrofóbicos e a superfície da fluorita. Resultados de microflotação dos minerais com oleato de cálcio na forma coloidal estão de acordo com as forças atrativa e repulsiva observados por MFA, uma vez que a flotabilidade da fluorita foi muito superior à da calcita (FA et al., 2003).

Fa et al. (2003) também explicaram a diferença de flotabilidade entre calcita e fluorita na mesma faixa de $\mathrm{pH}(5,2-10,0)$ com base em medidas de potencial zeta $(\zeta)$ das partículas de ambas espécies versus esferas de oleato de cálcio. Os resultados revelaram que o plano de clivagem da calcita é negativamente carregado. Tal plano repele as esferas de oleato de cálcio que também são negativamente carregadas $(-60<\zeta<-58 \mathrm{mV})$. A carga negativa desse plano pode ser uma consequência da dissolução preferencial de íons $\mathrm{Ca}^{2+}$, deixando a superfície rica em grupos $\mathrm{CO}_{3}{ }^{2-}$. No caso da fluorita, embora a carga superficial determinada para o plano de clivagem tenha sido negativa, os autores verificaram a ocorrência de força atrativa entre tal mineral e os coloides de oleato de cálcio. Os autores sugerem que, depois de alcançado o equilíbrio, a carga superficial da fluorita deve ser positiva devido à dissolução preferencial de íons $\mathrm{F}^{-}$. A diferença entre cargas das superfícies da fluorita e oleato de cálcio explicaria a força atrativa observada por MFA (FA et al., 2003). Por outro lado, se os autores tivessem aplicado a Teoria DLVO a este sistema, outra explicação poderia ser proposta. 
No trabalho de Fa, Nguyen e Miller (2006), os autores consideram que as forças atrativa e repulsiva entre oleato de cálcio versus fluorita ou calcita podem ser explicadas com base em diferenças na organização das moléculas da água existente na interface mineral/solução. Por meio de modelagem molecular, tais autores observaram que o acúmulo de moléculas de água é menor na interface fluorita/solução (três camadas de água) do que na interface calcita/solução (cinco ou seis camadas de água). A mais intensa hidratação da superfície da calcita pode ser responsável pela repulsão observada entre calcita e oleato de cálcio, enquanto o oposto ocorreria para a fluorita (FA; NGUYEN; MILLER, 2006).

Vários trabalhos da literatura consideram, ainda, que a ação coletora do oleato é influenciada pelo dímero $(\mathrm{RCOO})_{2}{ }^{2-}$ e pelo complexo ionomolecular $(\mathrm{RCOO})_{2} \mathrm{H}^{-}$formados por meio das Reações 2.3 e 2.4, respectivamente (FA; NGUYEN; MILLER, 2006; FREE; MILLER, 1996; PUGH; STENIUS, 1985). De acordo com Pugh e Stenius (1985), o sucesso da flotação de minerais portadores de cálcio deve-se ao efeito sinérgico de todas as espécies anfifílicas provenientes do oleato, tanto na interface sólido/líquido como na interface líquido/gás.

$$
\begin{aligned}
& 2 \mathrm{RCOO}^{-}(\mathrm{aq}) \rightleftarrows(\mathrm{RCOO})^{2-}{ }_{2(\mathrm{aq})} \\
& \mathrm{RCOOH}_{(\mathrm{l})}+\mathrm{RCOO}_{(\mathrm{aq})} \rightleftarrows\left(\mathrm{RCOO}_{2} \mathrm{H}_{(\mathrm{aq})}\right.
\end{aligned}
$$

Na Figura 2.6 está ilustrado o diagrama de especiação do ácido oleico. Observa-se neste diagrama que as concentrações de oleato e do dímero aumentam com o pH até o valor de 7,8, a partir do qual ficam constantes. A concentração do complexo ionomolecular também aumenta até $\mathrm{pH}$ 7,8 e diminui em valores de $\mathrm{pH}$ mais básicos. Além disso, observa-se na Figura 2.6 que a precipitação de ácido oleico ocorre em soluções com pH inferior a 7,8 (GUAN, 2009).

De acordo com Ananthapadmanabhan e Somasundaran (1988), a atividade do complexo ionomolecular na interface líquido/gás é cinco vezes maior do que a da molécula neutra de ácido oleico e seis vezes maior do que a do íon oleato. Por outro 
lado, a adsorção do dímero na interface sólido/líquido também ocorre em larga extensão (ANANTHAPADMANABHAN; SOMASUNDARAN, 1988).

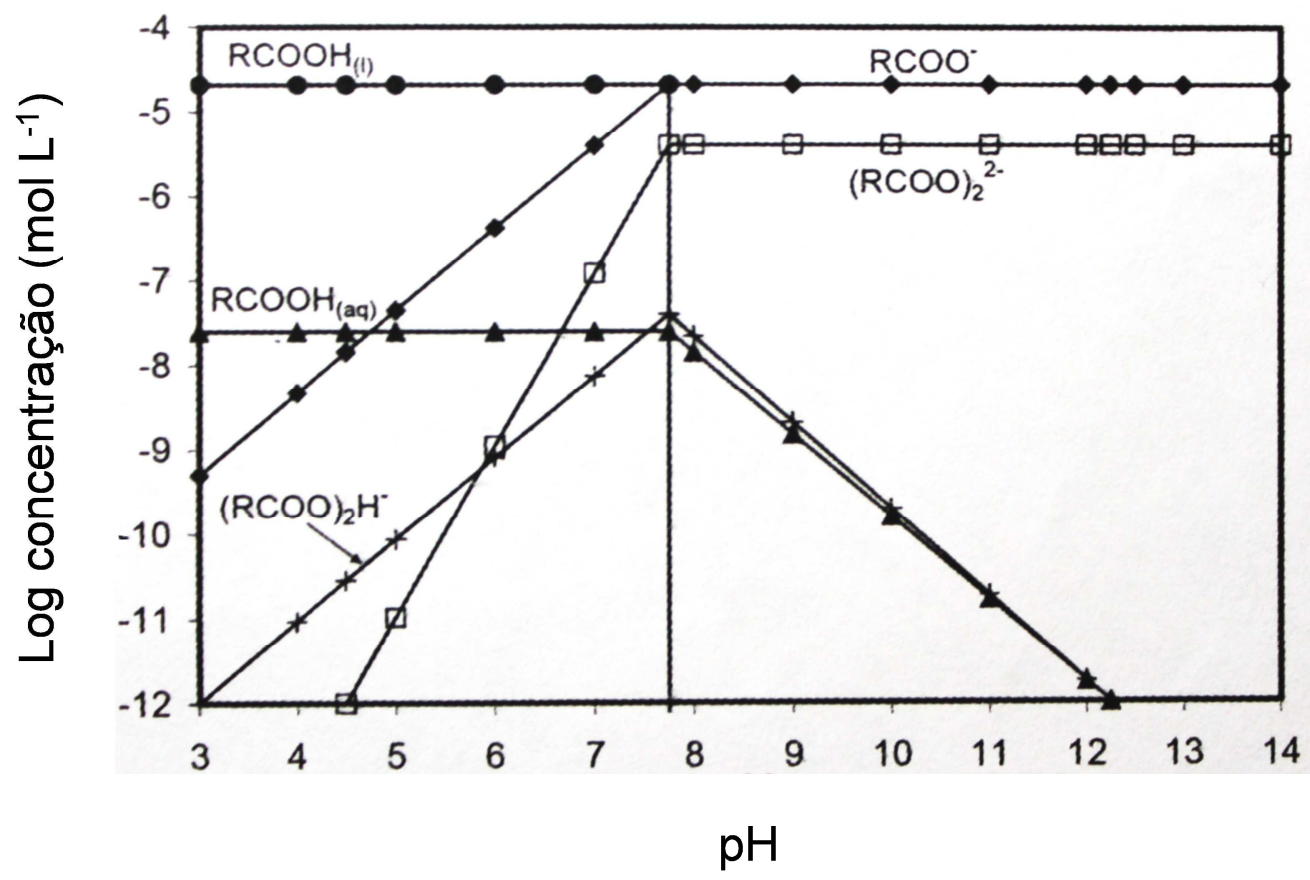

Figura 2.6 -Diagrama de distribuição das espécies do ácido oleico em diferentes valores de $\mathrm{pH}$ para a concentração de oleato de $3,0 \times 10^{-5} \mathrm{~mol} \mathrm{~L}^{-1}$ (GUAN, 2009).

\subsubsection{Amido}

O amido é o agente depressor de carbonatos mais mencionado em trabalhos científicos. Além disso, este reagente tem sido satisfatoriamente aplicado na flotação de minério fosfático com ganga carbonatada de gênese ígnea pela indústria de mineração brasileira (ARAUJO et al., 2006; BARROS; FERREIRA; PERES, 2008; LEAL FILHO, 1999a; LEAL FILHO et al., 2000; LEAL FILHO; MARTINS; HORTA, 2010).

Amido é um polissacarídeo, ou um polímero natural, formado pela condensação $a-d(+)$ de moléculas de glicose. Em geral, o amido é composto por 20 a $25 \%$ de amilose que é uma molécula não ramificada de estrutura helicoidal, e 75 a 
$80 \%$ de amilopectina que é uma macromolécula ramificada (ARAUJO et al., 2006; KHOSLA; BISWAS, 1984). A Figura 2.7 contém um esquema representativo das cadeias de amilose (A) e amilopectina (B).

A
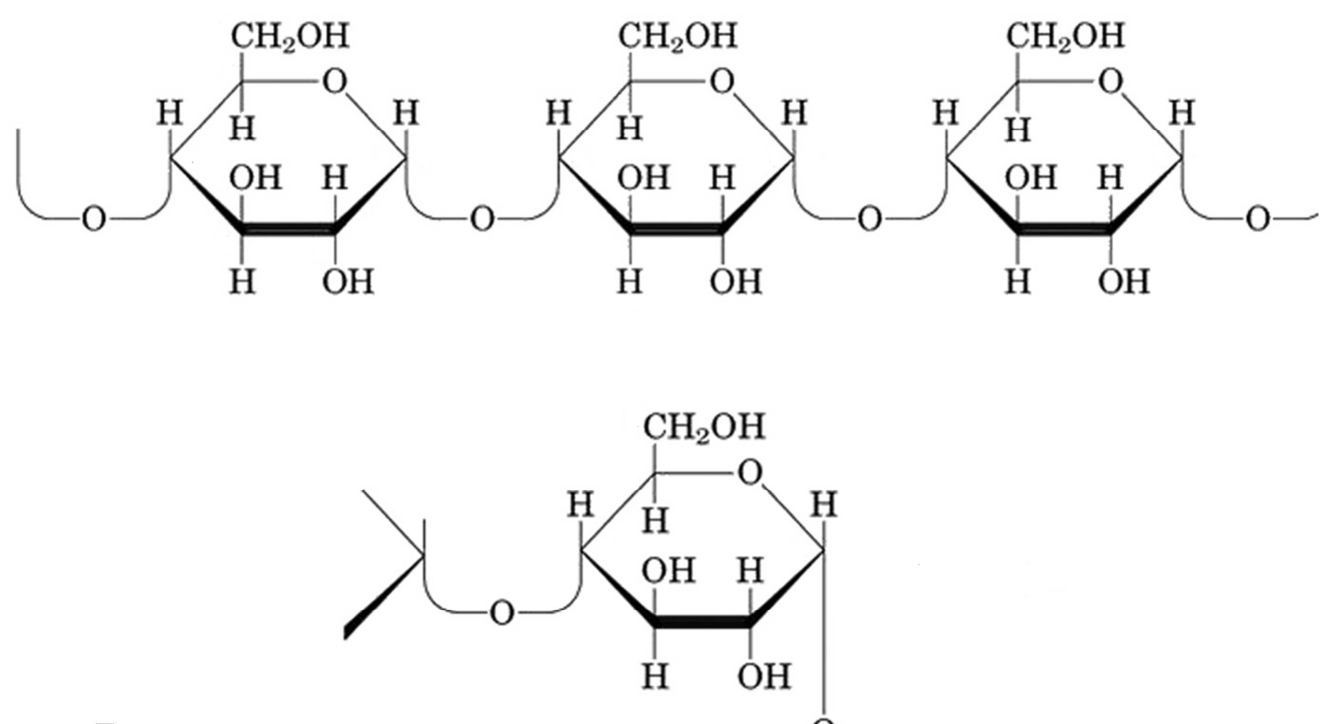

B

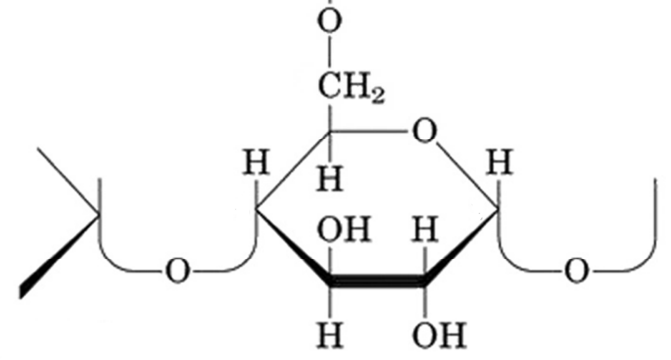

Figura 2.7 - Representação esquemática das cadeias de (A) amilose e (B) amilopectina (FRANCISCO-JUNIOR, 2008 - modificada).

A adsorção de amido na interface mineral/solução ocorre predominantemente por meio de interações entre grupos hidroxila $(\mathrm{OH})$, existentes em sua estrutura molecular, e cátions metálicos hidroxilados $(\mathrm{MOH})$ existentes na estrutura cristalina dos minerais. Tal interação pode ser classificada como específica, e ocorre em maior intensidade, na faixa de $\mathrm{pH}$ em que o cátion metálico $\mathrm{M}$ (exposto na superfície dos minerais) está hidroxilado (RAJU; HOLMGREN; FORSLING, 1997, 1998).

Segundo o mecanismo proposto por Raju, Holmgren e Forsling $(1997,1998)$, o amido deveria deprimir apatita, calcita e dolomita, uma vez que todos estes minerais são portadores de cálcio (e também magnésio no caso da dolomita). No entanto, na prática industrial da usina de Cajati-SP, observa-se que há seletividade 
na adsorção do amido sobre calcita em detrimento da interação amido/apatita (LEAL FILHO, 1991; LEAL FILHO; MARTINS; HORTA, 2010). Comparando a resposta à microflotação com oleato de sódio, na presença de amido, Leal Filho et al. (2000) reportaram, por exemplo, que o amido deprime seletivamente a calcita em concentrações abaixo de $15 \mathrm{mg} \mathrm{L}^{-1}$ sem deprimir a apatita. Além disso, minerais de diferentes origens podem reagir de maneira desigual frente à atividade depressora do amido. Um exemplo é o fato de que amido deprime a calcita existente no fosfato de Cajati-SP (LEAL FILHO, 1991), mas não deprime a calcita do fosfato de ItataiaCE (ASSIS; VIANA; SILVA, 1987).

A seletividade da adsorção amido/calcita em detrimento da adsorção amido/apatita pode ser explicada pela estereoquímica da interação entre moléculas de amido e a superfície desses minerais (LEAL FILHO, 1999a; LEAL FILHO et al., 2000). De acordo com Leal Filho et al. (2000), a depressão da calcita pelo amido está relacionada à compatibilidade estérica entre as posições dos íons $\mathrm{Ca}^{2+}$ da superfície da calcita, e os grupos $\mathrm{OH}$ da molécula do amido. O mesmo não ocorre com a apatita. O autor propôs um parâmetro denominado fitting number, que é determinado pela comparação entre a distância dos sítios ativos na molécula de amido (distâncias $\mathrm{OH}-\mathrm{OH}$ ) e a distância entre os cátions (Ca-Ca) na estrutura cristalina dos minerais (LEAL FILHO et al., 2000). Tais resultados indicam que se uma determinada amostra de calcita não é bem cristalizada, a ação depressora do amido pode ser desfavorecida, caso as distâncias entre os átomos de cálcio existentes na interface mineral/solução sejam muito alteradas.

Barros, Ferreira e Peres (2008) observaram por meio de ensaios de microflotação que baixas concentrações de amido (aproximadamente $5 \mathrm{mg} \mathrm{L}^{-1}$ ) são suficientes para deprimir calcita, enquanto que concentrações superiores a $50 \mathrm{mg} \mathrm{L}^{-1}$ são necessárias para fazer com que a recuperação de dolomita seja inferior a 40\%. Tal comportamento sugere a existência de uma baixa compatibilidade estérica entre a molécula de amido e o mineral dolomita que foi utilizado nos experimentos, de acordo com o conceito proposto por Leal Filho et al. (2000).

Diferenças na adsorção de amido na superfície dos carbonatos também podem ser associadas à origem do polissacarídeo (batata, milho ou mandioca). Esta relação de causa-efeito pode ser devida a fatores como conteúdo de amilose versus 
amilopectina, assim como a quantidade de impurezas oferecidas por cada vegetal (KHOSLA; BISWAS, 1984; RAJU; HOLMGREN; FORSLING, 1997, 1998).

Somasundaran (1969) observou que a presença de amido aumenta a adsorção de oleato na superfície da calcita devido a um tipo de interação cooperativa entre os mesmos reagentes, o que pode conduzir à adsorção de ambos. Tal fenômeno foi explicado pelo autor em termos da formação de um "clatrato" (tradução do termo inglês clathrate) formado pelo aprisionamento de oleato dentro das hélices das moléculas de amido. Este fenômeno explica o porquê da superfície da calcita não se tornar hidrofóbica embora contenha moléculas de oleato adsorvidas (SOMASUNDARAN, 1969).

\subsection{Estratégias de flotação}

A concentração por flotação de apatita a partir de minério de gênese ígnea contendo ganga carbonatada é praticada em países como Brasil, Finlândia e África do Sul (LEAL FILHO; MARTINS; HORTA, 2010; PRASAD; MAJUMDER; RAO, 2000). No entanto, diferentes respostas frente aos processos de flotação são obtidas com minérios de composição mineralógica similar, mas de diferentes origens ou até mesmo de diferentes frentes de lavra dentro de uma mesma reserva (Tabela 1.1). Silva e Coelho (1984), por exemplo, reportaram que o processo aplicado com sucesso na concentração de apatita do fosfato de Cajati-SP (com teor de $\mathrm{P}_{2} \mathrm{O}_{5}$ igual a $5 \%$ e $80 \%$ de carbonatos) era inadequado para concentrar o fosfato de Itataia-CE (que continha maior teor de $\mathrm{P}_{2} \mathrm{O}_{5}$ e menor conteúdo de carbonatos). Tais autores concluíram que a composição mineralógica do minério não é o único parâmetro que controla o desempenho da flotação, mas também a heterogeneidade física (textura) e química (presença de impurezas) na superfície dos minerais (SILVA; COELHO, 1984).

Além disso, uma estratégia de flotação aplicada com sucesso em um fosfato de gênese ígnea pode não ser satisfatória para um minério sedimentar (ABDEL- 
KHALEK, 2000; ASSIS et al., 1985; BAUDET; SAVE, 1999; LAWENDY; MCCLELLAN, 1993; PRASAD; MAJUMDER; RAO, 2000; PUGH; STENIUS, 1985; SIS; CHANDER, 2003b; ZHENG et al., 2006). Os problemas de desempenho na flotação de fosfato de gênese sedimentar estão associados a características como: (1) área superficial elevada devido à presença de poros; (2) presença de carbonatos recobrindo parcialmente as partículas de apatita ou com elas formando agregados (como os pellets que caracterizam o fosfato de Bayovar-Peru); (3) elevado grau de substituição nas apatitas; (4) tendência em gerar muita lama devido à natureza friável dos minerais. Tais características justificam os baixos teores de $\mathrm{P}_{2} \mathrm{O}_{5}$ nos concentrados de apatita, elevado consumo de reagentes e redução de seletividade da adsorção de agentes coletores e depressores, principalmente quando a separação envolve o sistema apatita/carbonatos (ABOUZEID; NEGM; ELGILLANI, 2009; LAWENDY; McCLELLAN, 1993; PRASAD; MAJUMDER; RAO, 2000).

No Brasil, o beneficiamento de fosfato ígneo obedece ao fluxograma de processo ilustrado na Figura 2.8, em que se destacam as operações unitárias descritas nos próximos parágrafos (LEAL FILHO; MARTINS; HORTA, 2010).

Após homogeneização em pilhas alongadas que permitem que a usina seja alimentada com material de mesma qualidade durante vários dias, o minério alimenta um circuito de moagem (barras e/ou bolas). Em seguida, o material é submetido a uma operação unitária de separação magnética de baixo campo que é realizada para remoção de magnetita e também para aumentar a capacidade do sistema de moagem. O produto do último estágio de moagem alimenta ciclones que controlam a distribuição de tamanho do produto final. $\mathrm{O}$ underflow (material mais grosso) retorna à moagem, enquanto que o overflow (produto da moagem) é enviado à deslamagem que também é realizada em hidrociclones (LEAL FILHO; MARTINS; HORTA, 2010). 


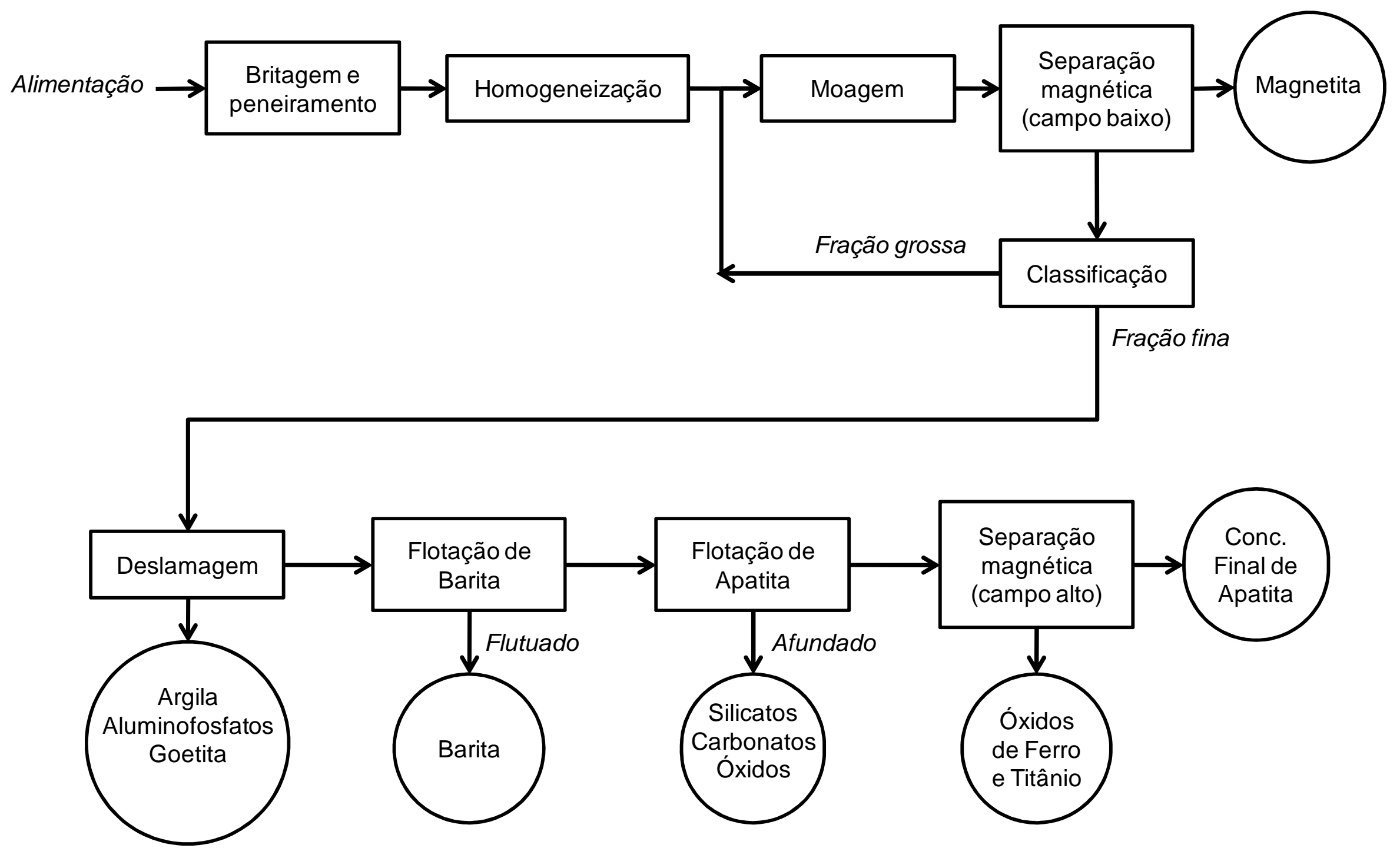

Figura 2.8 - Fluxograma geral das operações unitárias envolvidas na concentração de apatita proveniente de rocha ígnea nas usinas brasileiras (LEAL FILHO; MARTINS; HORTA, 2010) 
Depois da deslamagem, nas usinas de Catalão-GO e Araxá-MG, o material é submetido à flotação aniônica reversa de barita com sulfato de alquila em meio básico, seguido da flotação aniônica direta da apatita. Nas usinas de Cajati-SP e Tapira-MG, devido à ausência de barita, realiza-se somente a flotação aniônica direta da apatita (LEAL FILHO; MARTINS; HORTA, 2010).

A flotação aniônica direta da apatita é conduzida de acordo com o esquema de reagentes apresentado na Tabela 2.1, em que se verifica que cada usina faz uso de reagentes adequados às características mineralógicas e tecnológicas de seus respectivos minérios (LEAL FILHO; MARTINS; HORTA, 2010).

Quando os concentrados de fosfato são muito ricos em ferro, e tal elemento é oriundo de inclusões de hematita $\left(\mathrm{Fe}_{2} \mathrm{O}_{3}\right) /$ goethita $(\mathrm{FeO}(\mathrm{OH}))$ existentes nas partículas de apatita, faz-se necessário o uso de separação magnética de alto campo para diminuição do teor de Fe no concentrado final, atendendo às especificações de mercado (LEAL FILHO; MARTINS; HORTA, 2010).

Os depósitos de fosfato de origem ígnea são compostos de um manto de intemperismo que se sobrepõe à rocha primária. Tal manto pode exibir espessura de até 200 metros, dependendo de cada situação em particular. A existência desses dois tipos de rocha (intemperizada versus primária) acarreta diferenças de textura e mineralogia no minério de fosfato que alimenta a flotação. Tais diferenças são encontradas na Tabela 2.1 (LEAL FILHO; MARTINS; HORTA, 2010).

O minério intemperizado que ainda é lavrado em Araxá-MG e Catalão-GO exibe maior quantidade de apatita (20-40\%) e menor quantidade de carbonatos $(<5 \%)$, além de conter barita (2-10\%), óxidos portadores de ferro e titânio $(50 \%)$, quartzo (<10\%) e micas que exibem diferentes graus de intemperismo (Tabela 2.1). A concentração deste tipo de minério envolve a flotação reversa de barita, seguida por flotação de apatita. Amido de milho é utilizado para deprimir óxidos portadores de ferro e titânio, e ácidos graxos são utilizados como coletores de apatita (LEAL FILHO; MARTINS; HORTA, 2010). 
Tabela 2.1 - Informação sobre mineralogia e esquema de reagentes das principais operações industriais de concentração de fosfato no Brasil (LEAL FILHO; MARTINS; HORTA, 2010).

\begin{tabular}{|c|c|c|c|c|c|c|}
\hline \multirow{2}{*}{$\begin{array}{l}\text { Empresa/ } \\
\text { Local }\end{array}$} & \multicolumn{2}{|l|}{ Características do minério } & \multicolumn{3}{|c|}{$\begin{array}{l}\text { Características da solução de } \\
\text { flotação }\end{array}$} & \multirow{2}{*}{$\begin{array}{l}\text { Reagentes de } \\
\text { flotação }\end{array}$} \\
\hline & Mineralogia & Textura & $\mathrm{pH}$ & $\mathrm{pCa}$ & pMg & \\
\hline $\begin{array}{l}\text { Vale } \\
\text { Fertilizantes/ } \\
\text { Cajati-SP }\end{array}$ & $\begin{array}{c}\text { Apatita } 12 \% \text {, Calcita } 70 \% \text {, } \\
\text { Dolomita } 13 \% \text {, Silicatos } 4 \% \text {, } \\
\text { Magnetita } 1 \%\end{array}$ & Rocha fresca & 10,5 & 3,3 & 3,8 & $\begin{array}{l}\text { Amido de milho, } \\
\text { Sarcosinato de alquila } \\
\text { e } \mathrm{NaOH} .\end{array}$ \\
\hline $\begin{array}{l}\text { Vale } \\
\text { Fertilizantes/ } \\
\text { Tapira-MG }\end{array}$ & $\begin{array}{l}\text { Apatita } 16 \% \text {, Carbonatos } 21 \% \text {, } \\
\text { Silicatos } 32 \% \text {, Óxidos } 31 \%\end{array}$ & $\begin{array}{l}\text { Rocha fresca } \\
+ \text { manto de } \\
\text { intemperismo }\end{array}$ & 9,5 & 3,5 & 3,9 & $\begin{array}{l}\text { Amido de milho, } \\
\text { Sulfossuccinato de } \\
\text { alquila, ácido graxo e } \\
\mathrm{NaOH}\end{array}$ \\
\hline $\begin{array}{l}\text { Copebrás S.A./ } \\
\text { Catalão-GO }\end{array}$ & $\begin{array}{c}\text { Apatita } 24-38 \% \text {, Carbonatos }<5 \% \text {, } \\
\text { Barita } 2 \% \text {, Silicatos }<10 \% \text {, Óxidos } 52 \%\end{array}$ & $\begin{array}{l}\text { Manto de } \\
\text { intemperismo }\end{array}$ & 10,5 & 3,3 & 3,7 & $\begin{array}{c}\text { Amido de milho, ácido } \\
\text { graxo, nonilfenol, } \\
\text { sulfato de alquila e } \\
\mathrm{NaOH}\end{array}$ \\
\hline $\begin{array}{l}\text { Vale } \\
\text { Fertilizantes/ } \\
\text { Araxá-MG }\end{array}$ & $\begin{array}{c}\text { Apatita } 24-33 \% \text {, Carbonatos }<5 \% \text {, } \\
\text { Barita } 7-10 \% \text {, Silicatos } 10-37 \% \text {, } \\
\text { Óxidos } 30-51 \%\end{array}$ & $\begin{array}{l}\text { Manto de } \\
\text { intemperismo }\end{array}$ & 11,5 & 4,2 & 4,1 & $\begin{array}{l}\text { Amido de milho, ácido } \\
\text { graxo, sulfato de } \\
\text { alquila, Flotanol C14 e } \\
\qquad \mathrm{NaOH}\end{array}$ \\
\hline
\end{tabular}


Minério composto de rocha fresca (carbonatito) é lavrado em Cajati-SP, conforme ilustra a Tabela 2.1. Tal minério é mais pobre em apatita (12\%) e mais rico em carbonatos (>80\%), demandando o uso de amido de milho como depressor de carbonatos e um coletor sintético (sarcosinato de alquila) para prover adequada seletividade ao sistema (LEAL FILHO; MARTINS; HORTA, 2010).

Uma situação peculiar ocorre no depósito de Tapira-MG, onde o manto intemperizado (minério friável) contém porções de minério primário parcialmente intemperizado (chamado de granulado). Na Tabela 2.1 observa-se que tal peculiaridade demanda o uso de amido/ácidos graxos para concentrar o tipo friável e o sistema amido/sulfossuccinato de alquila + ácidos graxos para flotar o minério granulado (BARROS; LEAL FILHO; PERES, 2001).

Apesar de a Tabela 2.1 conter informação a respeito dos esquemas estabelecidos de reagentes que são adequados para a flotação de cada fosfato em particular, cada um dos depósitos exibe minérios "problema" que são refratários à concentração por flotação por meio dos esquemas tradicionais. Papini, Guimarães e Peres (2002) chamam atenção para os minérios problemáticos da mina de AraxáMG, argumentando que uma característica das reservas ígneas é a existência de diversos tipos de minérios com diferentes respostas ao processo de flotação. A mina de Araxá-MG contém três tipos de minério denominados oxidado, micáceo e sílicocarbonatado. Contudo, apenas o minério oxidado vem sendo processado por flotação desde os anos 70 do século XX. A dificuldade de concentrar os demais minérios indica que há necessidade de pesquisa fundamental para elucidar mecanismos e ajudar a propor novos processos de flotação além de aprimorar os existentes. Esta tese se propõe a contribuir para o entendimento das causas para este tipo de problema.

Nos Estados Unidos, a produção de fosfato da Flórida corresponde a aproximadamente $75 \%$ da produção do país e $30 \%$ da produção mundial. A maioria do minério de alto teor da Flórida é proveniente da mina de gênese sedimentar de Bone Valley. O minério proveniente deste depósito tem sido beneficiado há 80 anos pelo processo de flotação em duas etapas denominado "Crago". Neste processo, após moagem e deslamagem, o minério é condicionado com ácidos graxos e óleo combustível em pH entre 9,0 e 9,5. Devido ao fato da água do processo ser muito dura, a seletividade na separação quartzo/apatita por flotação é prejudicada, 
produzindo-se concentrados com alto teor de sílica $\left(\mathrm{SiO}_{2}\right)$. Para resolver este problema, faz-se necessário lavar o concentrado de apatita com ácido sulfúrico, espessar a polpa e realizar flotação catiônica reversa dos silicatos em pH neutro, a fim de se produzir concentrado de fosfato contendo teor de $\mathrm{P}_{2} \mathrm{O}_{5}$ superior a $30 \%$ (CRAGO, 1942; SIS; CHANDER, 2003a; SNOW; ZHANG, 2006).

O processo Crago era aplicado com desempenho satisfatório ao minério de Bone Valley de elevado teor de fósforo, contendo silicatos liberados como principal mineral de ganga. Contudo, como consequência do esgotamento do minério de alto teor, a indústria fosfateira da Flórida tem sido forçada a beneficiar minério contendo elevado teor de dolomita. Por esta razão, O Instituto de Pesquisa de Fosfato da Flórida (Florida Institute of Phosphate Research) tem, por vários anos, tentado desenvolver um processo em escala industrial adequado ao beneficiamento do minério de fosfato rico em dolomita (EL-SHALL; ZHANG; SNOW, 1996; GRUBER; ZHENG; HWANG, 2001; PENG; GU, 2005; ZHENG; SMITH, 1997; ZHENGXING; ZHIZHONG; SHIBO, 1999).

Peng e Gu (2005) testaram a flotação reversa em duas etapas no minério de fosfato carbonatado da Flórida. Na primeira etapa, o minério abaixo de $140 \mu \mathrm{m}$ é flotado pela utilização de uma mistura de ácido fosfórico e ácido sulfúrico na proporção 2:1 para controlar o pH $(5-5,5)$ e deprimir apatita. Ainda na primeira etapa, ácido graxo é utilizado como agente coletor de carbonatos. Na segunda etapa, o afundado é moído para granulometria abaixo de $38 \mu \mathrm{m}$ e submetido à flotação catiônica dos silicatos com aminas. Os autores obtiveram, em ensaios de bancada, um concentrado de fosfato com 31,6\% de $\mathrm{P}_{2} \mathrm{O}_{5}$ e 0,8\% de $\mathrm{MgO}$ com recuperação de $92 \%$ de $\mathrm{P}_{2} \mathrm{O}_{5}$ a partir de minério contendo $26,7 \%$ de $\mathrm{P}_{2} \mathrm{O}_{5}$ e 2,2\% de MgO (PENG; GU, 2005).

$\mathrm{Na}$ China, $90 \%$ das reservas de fosfato são dolomíticas com teor de $\mathrm{MgO}$ entre 2 e 10\%. Para a utilização econômica e racional do minério doméstico, pesquisadores do Instituto de pesquisa de Lianyungang (CLDRI - Lianyungang Design and Research Institute) desenvolveram uma metodologia para flotação de partículas finas. Neste processo o minério é moído, geralmente até abaixo de 105 $\mu \mathrm{m}$, para a liberação de carbonatos e outras impurezas da apatita. Não há etapa de deslamagem e a fração moída é submetida à flotação de carbonatos com ácido graxo como agente coletor, em meio ácido, cujo ajuste de $\mathrm{pH}$ é realizado com ácido 
fosfórico e sulfúrico. $O$ afundado do processo anterior pode ser purificado pela flotação direta ou reversa de apatita-sílica (GAO; ZHENG; GU, 2002; GRUBER; ZHENG; HWANG, 2001; ZHENGXING; ZHIZHONG; SHIBO, 1999).

O mesmo processo foi aplicado, por Zhengxing, Zhizhong e Shibo (1999), a uma amostra de minério de fosfato carbonatado da Flórida em experimentos em escala laboratorial. Segundos os autores, foi possível produzir um concentrado com $31 \%$ de $\mathrm{P}_{2} \mathrm{O}_{5}$ e menos de $1 \%$ de $\mathrm{MgO}$ a partir de minério com $26 \%$ de $\mathrm{P}_{2} \mathrm{O}_{5}$ e $2 \%$ de $\mathrm{MgO}$, sendo a recuperação maior que 85\% (ZHENGXING; ZHIZHONG; SHIBO, 1999). Gao, Zheng e Gu (2002) testaram o mesmo processo para purificação do fosfato da Flórida utilizando experimentos em escala laboratorial e piloto. Os autores obtiveram teor de $\mathrm{P}_{2} \mathrm{O}_{5}$ igual a $30 \%$ com menos de $1 \%$ de $\mathrm{MgO}$ e recuperação por volta de $80 \%$. No entanto, ambos os trabalhos mencionam problemas de alto custo relacionado ao elevado consumo de reagentes, aliado à grande quantidade de energia gasta no processo de moagem (GAO; ZHENG; GU, 2002; ZHENGXING; ZHIZHONG; SHIBO, 1999).

\subsection{Cristalinidade}

O termo cristalinidade é abordado de diferentes maneiras pelos diversos ramos da ciência. De acordo com literatura especializada em física, a cristalinidade é definida pelos parâmetros microestruturais: tamanho de cristalito e deformação de rede (microdeformação) (COELHO, 2007; JENKINS; SNYDER, 1996). O grau de cristalinidade é a razão entre a massa de material cristalino e a massa de material amorfo mais cristalino (JENKINS; SNYDER, 1996).

Cristalitos compõem a primeira organização espacial de células unitárias como observado na Figura 2.9. Cada cristalito constitui-se de um ou mais domínios coerentes de difração. Os cristais, por vezes chamados grãos, são formados por um ou mais cristalitos (BALZAR, 1999; COELHO, 2007; JENKINS; SNYDER, 1996). Materiais policristalinos apresentam cristalitos ordenados, enquanto cristalitos desordenados caracterizam materiais amorfos, como observado na Figura 2.9 
(JENKINS; SNYDER, 1996). A microdeformação, por sua vez, representa uma série de deslocamentos de átomos de seus sítios na estrutura cristalina causados por imperfeições, como: vacâncias, substituições ou defeitos similares (COELHO, 2007). Desta forma, quanto maior o tamanho de cristalito e menor a deformação de rede, mais cristalino é o material (JENKINS; SNYDER, 1996).

Trabalhos publicados na década de 80 (século $X X$ ) por pesquisadores da Universidade Federal de Minas Gerais (UFMG) abordam, direta ou indiretamente, a influência da cristalinidade das apatitas brasileiras na resposta à flotação (ASSIS et al., 1985; ASSIS; VIANA; SILVA, 1987; SILVA et al., 1985). Silva et al. (1985), por exemplo, determinaram o grau de cristalinidade, por análise de espectros na região do infravermelho, de amostras amorfas e cristalinas com vários graus intermediários. As apatitas com elevado grau de cristalinidade apresentaram melhor desempenho na flotação. Além disso, observou-se que as apatitas menos cristalinas exibiram maior teor de ferro e maior rugosidade superficial (SILVA et al., 1985).

\section{Átomos Cela unitária}

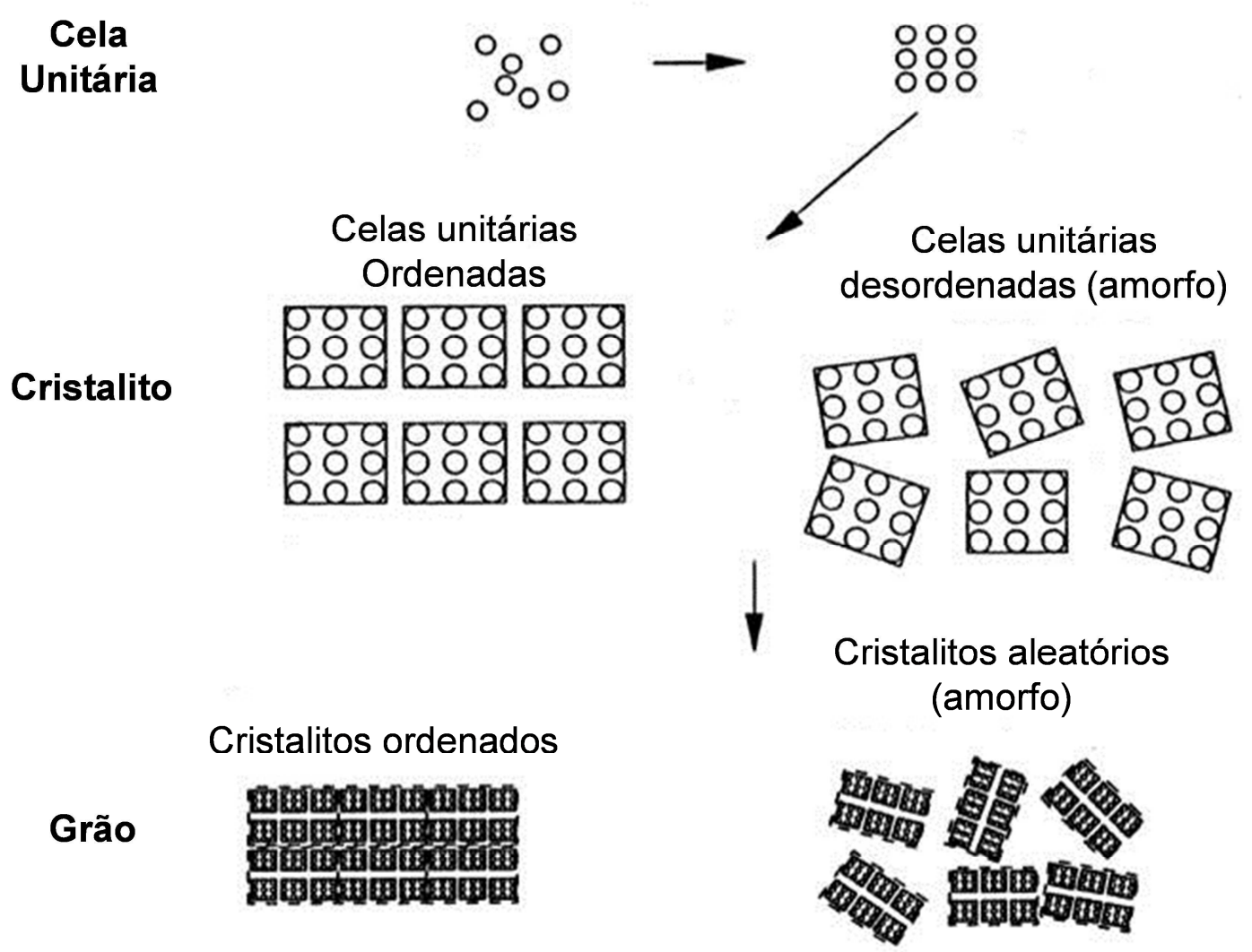

Figura 2.9 - Organização estrutural dos materiais cristalinos: de átomos a grãos (JENKINS; SNYDER, 1996 - modificada). 
Um estudo semelhante foi realizado com as calcitas de Cajati-SP e Itataia-CE por Assis et al. (1985). Nesse trabalho, a cristalinidade foi abordada de maneira indireta pela observação da rugosidade superficial e da regularidade das linhas de contorno dos planos de clivagem em imagens de Microscopia Eletrônica de Varredura (MEV). Observou-se que quanto mais bem formado é o cristal, menor será a rugosidade superficial que contribuirá para um melhor desempenho da flotação com oleato de sódio (ASSIS et al., 1985).

Assis, Viana e Silva (1987) investigaram o efeito da granulação e da rugosidade superficial de amostras de apatita, calcita e dolomita provenientes de diferentes minas brasileiras na resposta à flotação. A rugosidade superficial foi quantificada pelo cálculo do número de interseções pontuais por unidade de comprimento de uma linha de ensaio. Para todas as amostras estudadas, observouse que quanto maior é o tamanho do grão e menor é a rugosidade superficial, melhor é o desempenho dos ensaios de microflotação com oleato de sódio em meio básico (ASSIS; VIANA; SILVA, 1987).

Rodrigues e Brandão (1993) também trabalharam no sentido de estabelecer uma correlação entre a cristalinidade de uma série de apatitas de vários depósitos brasileiros com sua resposta à microflotação com oleato de sódio. Para tanto, os autores utilizaram 0 índice de cristalinidade, determinado por um método inicialmente proposto por Murata e Norman (1976 apud RODRIGUES; BRANDÃO, 1993), que consiste no cálculo da razão entre as distâncias a e $b$, ilustradas na Figura 2.10. O método é baseado no fato de que a diminuição da cristalinidade das apatitas conduz à redução da intensidade e ao aumento do alargamento dos picos de difração. Observou-se que a resposta das apatitas à flotação com $2,5 \times 10^{-5} \mathrm{~mol} \mathrm{~L}^{-1}$ de oleato de sódio em pH 10,0 aumenta com o aumento do índice de cristalinidade, especialmente para valores deste índice superiores a 8 . De acordo com a gênese de cada reserva estudada, a ordem decrescente de cristalinidade e consequentemente, de desempenho na flotação foi: ígneo > metamórfico > sedimentar (RODRIGUES; BRANDÃO, 1993).

Todos esses trabalhos são de indiscutível valor científico. No entanto, nenhum deles explica o porquê dos minerais com maior cristalinidade apresentarem maior flotabilidade com oleato de sódio. Além disto, os autores se referem à cristalinidade de uma maneira mais geral, sem distinção entre conteúdo de material 
cristalino e a cristalinidade caracterizada pelos parâmetros microestruturais. Para preencher esta lacuna, esta tese buscou determinar a cristalinidade por meio do método de Rietveld, que é uma ferramenta de análise estrutural que permite distinguir entre os diversos parâmetros que caracterizam a cristalinidade dos minerais: porcentagem de matéria cristalina, tamanho de cristalito e deformação de rede (microdeformação).

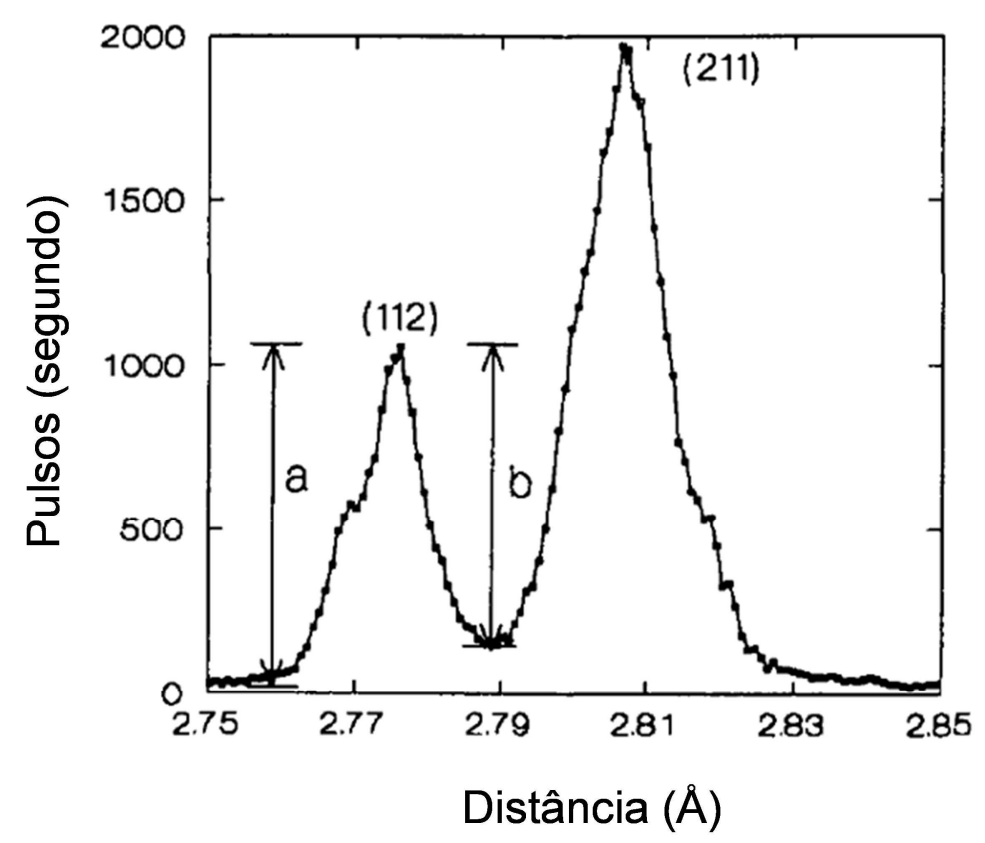

Figura 2.10 - Parâmetros a e $b$ utilizados no cálculo do índice de cristalinidade por Rodrigues e Brandão (1993) a partir dos picos de difração (211) e (112) da apatita.

Recentemente, vários trabalhos nas áreas de metalurgia, saúde e cerâmica têm utilizado o método de Rietveld, aplicado a análises de difração de raios- $X$, na determinação da cristalinidade de materiais (PAIVA-SANTOS, 2009; PAPANGKORN et al., 2008; YOUNG, 1993). Uma vantagem do método de Rietveld é a utilização de todo o perfil de difração durante a análise ou refinamento. Como este método foi eleito para a determinação da cristalinidade das amostras envolvidas no presente trabalho, detalhes a respeito da metodologia de análise são encontrados na descrição de materiais e métodos (Capítulo 3).

O método do Rietveld foi desenvolvido inicialmente para a análise estrutural e, em seguida, aplicado para a análise semi-quantitativa de fases (ANTONIO, 2010; RIETVELD, 1966, 1969; YOUNG, 1993). Esta última aplicação é encontrada em 
vários estudos no escopo da engenharia mineral. Kirwan et al. (2009), por exemplo, utilizaram o método de Rietveld na determinação quantitativa das fases minerais de diferentes minérios de bauxita Jamaicana. Oerter et al. (2007) também tiveram sucesso na determinação da quantidade de sulfetos em rejeitos de beneficiamento de minério por meio do método de Rietveld.

Exemplos interessantes sobre a aplicação do método de Rietveld em análise estrutural são encontrados em trabalhos com apatitas utilizadas como modelo para o estudo das propriedades físico-químicas de ossos e dentes animais. Papangkorn et al. (2008) investigaram a influência da cristalinidade, determinada pelo método de Rietveld, na solubilidade de carbonato-apatitas. Os autores observaram que a solubilidade aumenta com o aumento da microdeformação (PAPANGKORN et al., 2008). Meneghini et al. (2003) determinaram o tamanho de cristalito e a microdeformação de bioapatitas provenientes de ossos de mamíferos. Os autores analisaram as modificações microestruturais em função da idade das amostras e do processo de mineralização.

\subsubsection{Estrutura cristalina da apatita}

A apatita é o mineral-minério de depósitos fosfáticos de origem ígnea (como nos complexos alcalino-carbonatíticos da Russia, Uganda, Brasil e África do Sul); sedimentar (fosforitos marinhos como aqueles do Norte da África e Flórida) e fosfatos de acumulação orgânica (como os depósitos de guano do Peru e Chile). Depósitos com diferentes gêneses são caracterizados pela presença de diversos tipos de apatita, como se observa na Tabela 2.2 (ABOUZED; EL-JALLAD; ORPHY, 1980; TOLEDO; PEREIRA, 2001).

A fórmula química geral da apatita é $\mathrm{Ca}_{10}\left(\mathrm{PO}_{4}\right)_{6}(\mathrm{~F}, \mathrm{OH}, \mathrm{Cl})_{2}$, em que a ocupação do sítio aniônico monovalente caracteriza suas principais denominações: fluorapatita, hidroxiapatita e cloroapatita. Os sítios ocupados por $\mathrm{PO}_{4}{ }^{3-}$ ou do $\mathrm{F}^{-}$ podem ser substituídos por $\mathrm{CO}_{3}{ }^{2-}$ originando carbonato-apatitas (Tabela 2.2). 
Tabela 2.2 - Tipos e ocorrência das apatitas (TOLEDO; PEREIRA, 2001).

\begin{tabular}{ccc}
\hline Tipo de apatita & Fórmula & Ocorrência \\
\hline Fluorapatita & $\mathrm{Ca}_{10}\left(\mathrm{PO}_{4}\right)_{6} \mathrm{~F}_{2}$ & Rochas ígneas \\
\hline Hidroxiapatita & $\mathrm{Ca}_{10}\left(\mathrm{PO}_{4}\right)_{6}(\mathrm{OH})_{2}$ & $\begin{array}{c}\text { Biogênica (excremento } \\
\text { de aves, ossos e } \\
\text { dentes) }\end{array}$ \\
\hline Clorapatita & $\mathrm{Ca}_{10}\left(\mathrm{PO}_{4}\right)_{6} \mathrm{Cl}_{2}$ & $\begin{array}{c}\text { Rochas ígneas } \\
\text { básicas, rochas } \\
\text { afetadas por }\end{array}$ \\
& $\begin{array}{c}\text { metassomatismo com } \\
\text { cloro e em alguns } \\
\text { ambientes }\end{array}$ \\
& sedimentares
\end{tabular}

Carbonato-fluorapatita $\quad(\mathrm{Ca}, \mathrm{Na}, \mathrm{Mg})_{10}\left(\mathrm{PO}_{4}, \mathrm{CO}_{3}\right)_{6}(\mathrm{~F}, \mathrm{OH})_{2} \quad$ Rochas sedimentares

Carbonato-

hidroxiapatita

$$
\mathrm{Ca}_{10}\left(\mathrm{PO}_{4}, \mathrm{CO}_{3}\right)_{6}(\mathrm{OH})_{2} \quad \text { Ossos e dentes }
$$

A fluorapatita é o mineral de fósforo mais comum, e geralmente encontrado em rochas ígneas associadas aos carbonatitos (Tabela 2.2). A fluorapatita cristaliza no sistema hexagonal, grupo espacial $\mathrm{P} 6_{3} / \mathrm{m}$. De acordo com Slansky (1980), a fluorapatita apresenta dois planos de simetria paralelos ao plano (001) e tetraedros $\mathrm{PO}_{4}$ associados a colunas $\mathrm{Ca}-\mathrm{O}$, formando uma estrutura em colmeia. Perpendicularmente ao plano (001), há dois tipos de canais, sendo que o primeiro, com diâmetro de cerca de $2 \AA$, corresponde aos eixos ternários da estrutura e é rodeado por íons $\mathrm{Ca}^{2+}$ na posição $\mathrm{Ca}-1$, coordenados por nove átomos de oxigênio. O segundo tipo de canal tem diâmetro de 3-3,5 $\AA$ e é formado por eixos helicoidais rodeados por íons $\mathrm{Ca}^{2+}$ na posição $\mathrm{Ca}-2$, coordenados por sete átomos de oxigênio. Esta estrutura resulta em uma malha elementar correspondente a um prisma reto de base losangular, com quatro átomos de $\mathrm{Ca}$ no sítio $\mathrm{Ca}-1$ e seis no sítio $\mathrm{Ca}-2$, seis átomos de $\mathrm{P}$, dois de $\mathrm{F}$ e vinte e quatro átomos de $\mathrm{O}$ (SLANSKY, 1980). Na Figura 2.11 está ilustrado o modelo da estrutura da fluorapatita, em corte perpendicular ao 
eixo $c$, destacando os átomos de $\mathrm{F}$ e de $\mathrm{Ca}$, em suas duas posições $\mathrm{Ca}-1$ e $\mathrm{Ca}-2$ além dos triângulos de $\mathrm{PO}_{4}{ }^{3-}$.

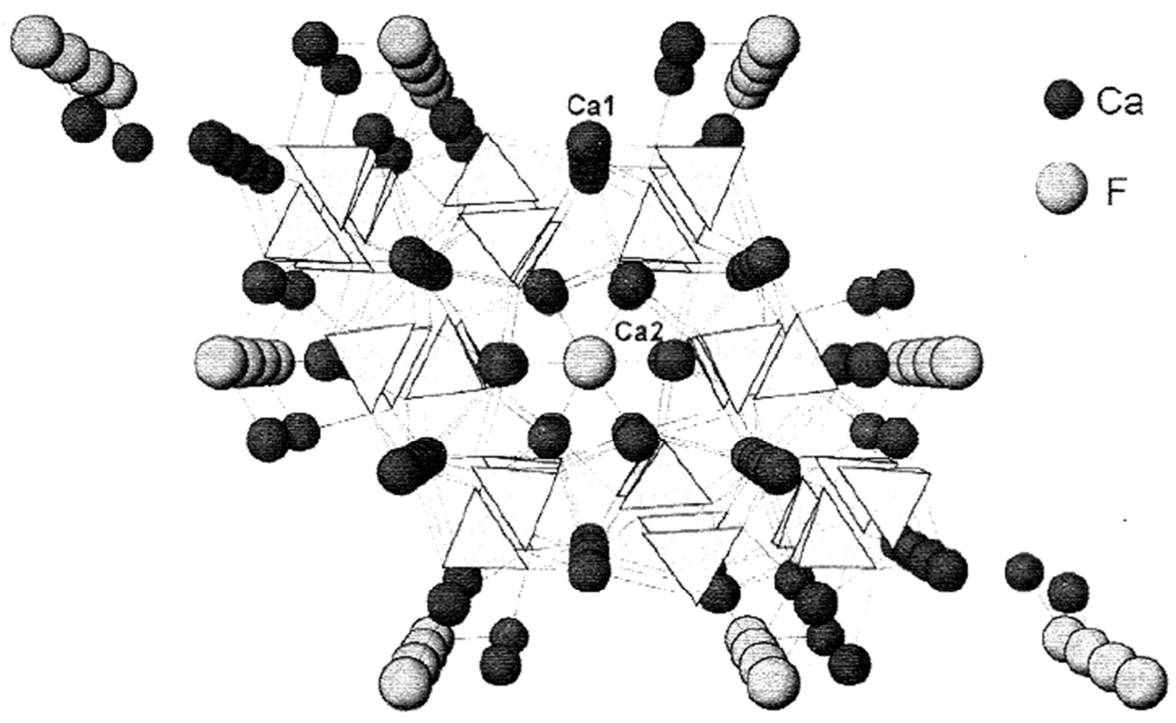

Figura 2.11 - Modelo da estrutura da fluorapatita, em corte perpendicular ao eixo $c$, segundo o programa ATOMS for Windows (TOLEDO; PEREIRA, 2001).

A cela unitária da fluorapatita constitui um prisma regular de base romboide com os parâmetros de rede $a=9,37 \AA$ e $c=6,88 \AA$, como observado na Figura 2.12A (SLANSKY, 1980). As principais diferenças estruturais entre as três espécies ocorrem devido às diferentes localizações dos íons $\mathrm{F}^{-}, \mathrm{Cl}^{-}$e $\mathrm{OH}^{-}$como visto na Figura 2.12-B (KANAZAWA, 1989).

É comum a ocorrência de uma série de substituições isomórficas na estrutura cristalina de apatitas de todos os ambientes geológicos, e mesmo em materiais apatíticos orgânicos e sintéticos (BORN; LENHARO; KAHN, 1996; KANAZAWA, 1989; McCLELLAN, 1980; SLANSKY, 1980; TOLEDO et al., 2004; TOLEDO; PEREIRA, 2001). Como consequência, nenhuma das composições simplificadas da Tabela 2.2 é atingida por apatitas naturais (TOLEDO; PEREIRA, 2001).

O ânion $\mathrm{PO}_{4}{ }^{3-}$ pode ser substituído por $\mathrm{CO}_{3}{ }^{2-}, \mathrm{SiO}_{4}{ }^{4-}, \mathrm{SO}_{4}{ }^{4-}, \mathrm{VO}_{4}{ }^{3-}, \mathrm{AsO}_{4}{ }^{3-}$, $\mathrm{CrO}_{4}{ }^{2-}$, enquanto o sítio aniônico do $\mathrm{F}^{-}$pode ser ocupado por $\mathrm{OH}^{-}, \mathrm{Cl}^{-}$ou $\mathrm{CO}_{3}{ }^{2-}$. Os cátions $\mathrm{Ca}^{2+}$, por sua vez podem ser substituídos por $\mathrm{Na}^{+}, \mathrm{Mg}^{2+}, \mathrm{Sr}^{2+}, \mathrm{Ba}^{2+}, \mathrm{Fe}^{2+}$, $\mathrm{Fe}^{3+}, \mathrm{Mn}^{2+}, \mathrm{U}^{4+}, \mathrm{U}^{6+}, \mathrm{K}^{+}, \mathrm{Cd}^{2+}, \mathrm{Al}^{3+}, \mathrm{Zn}^{2+}, \mathrm{Pb}^{2+}, \mathrm{Be}^{2+}$ e elementos terras raras com carga 2+ ou 3+ (TOLEDO; PEREIRA, 2001). 
$\mathbf{A}$

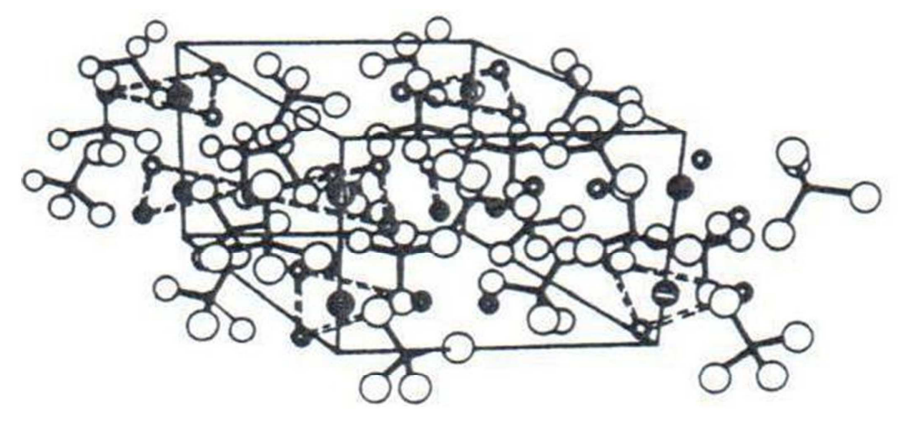

- Flúor

Oxigênio

- Cálcio I

- Cálcio II

B
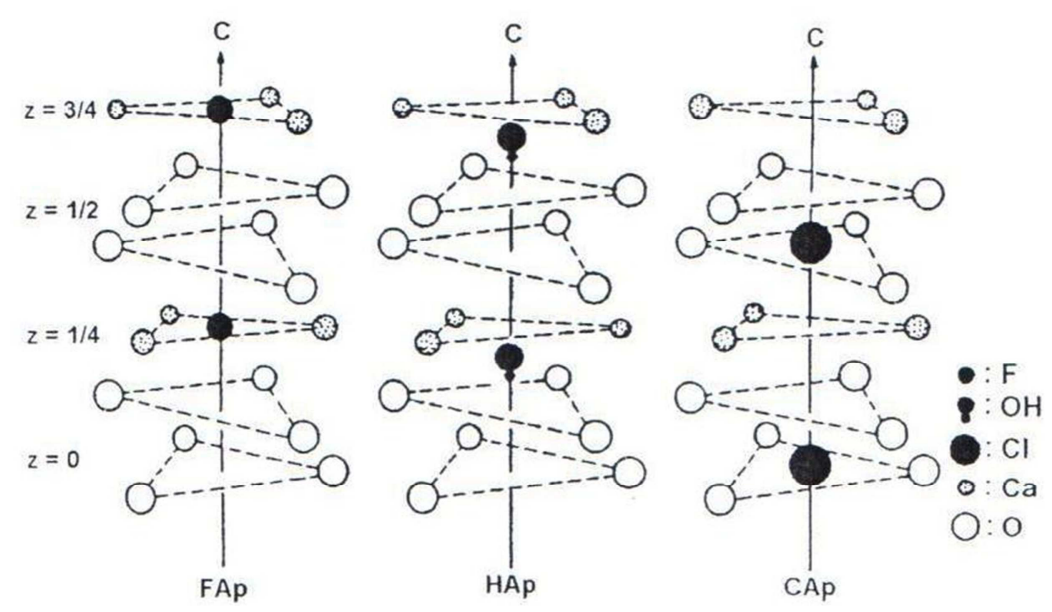

Figura 2.12 - (A) Cela unitária da fluorapatita (SLANSKY, 1980); (B) Localização dos íons $\mathrm{F}^{-}, \mathrm{OH}^{-}$e $\mathrm{Cl}^{-}$na estrutura cristalina da apatita (KANAZAWA, 1989).

As substituições podem provocar profundas perturbações nos arranjos internos dos átomos e íons, e causar variações significativas nos parâmetros de rede, comprometendo o grau de cristalinidade do mineral (LENHARO, 1994; TOLEDO et al., 2004). De maneira geral, substituições no sítio dos íons $\mathrm{Ca}^{2+}$ ocasionam mudanças mais significativas nos parâmetros de rede, enquanto substituições no sítio dos íons $\mathrm{PO}_{4}{ }^{3-}$ influenciam as dimensões dos parâmetros a e $c$ de maneira diferente o que resulta em anisotropia. Variações de rede menos significativas são ocasionadas por substituições no sítio do $\mathrm{F}^{-}$(BORN; LENHARO; KAHN, 1996; LENHARO, 1994).

De acordo com Toledo e Pereira (2001), a variabilidade de composição, admitindo as diferentes substituições, resulta em alterações de densidade, índice de refração, birrefringência, susceptibilidade magnética e solubilidade. Tais alterações também afetam a morfologia superficial das apatitas o que compromete seu 
desempenho frente ao processo de concentração por flotação (TOLEDO; PEREIRA, 2001).

Existe consenso entre os autores de que o aumento da quantidade de $\mathrm{CO}_{3}{ }^{2-}$ conduz à diminuição da cristalinidade das apatitas (BAIG et al., 1996; BORN; LENHARO; KAHN, 1996; YAO; LEGEROS; LEGEROS, 2009). Baig et al. (1996) observaram que em carbonato-apatitas, na medida em que a quantidade de $\mathrm{CO}_{3}{ }^{2-}$ aumenta, o tamanho de cristalito diminui e a microdeformação aumenta. Yao, Legeros e Legeros (2009) observaram que o aumento de $\mathrm{CO}_{3}{ }^{2-}$ e $\mathrm{Na}^{+}$na estrutura cristalina de hidroxiapatitas sintéticas conduz à redução do tamanho de cristalito e aumento da solubilidade. Por outro lado, o aumento de íons $\mathrm{F}^{-}$, mantendo-se $\mathrm{CO}_{3}{ }^{2-}$ constante, teve como consequência o aumento do tamanho de cristalito e redução na dissolução de íons $\mathrm{Ca}^{2+}$ (YAO; LEGEROS; LEGEROS, 2009). De acordo com Born, Lenharo e Kahn (1996), o aumento da quantidade de $\mathrm{CO}_{3}{ }^{2-}$ também acarreta e a redução do parâmetro de rede $a$.

\subsubsection{Estrutura cristalina da calcita}

Calcita e dolomita correspondem a mais de $90 \%$ dos carbonatos de ocorrência natural. Os carbonatos de cátions com número atômico menor ou igual ao do cálcio cristalizam no sistema romboédrico. Estes minerais apresentam altos índices de refração e alta birrefringência devido à forma plana do íon carbonato (BETEJTIN, 1977; REEDER, 1983).

A descrição da estrutura cristalina de carbonatos que cristalizam no sistema romboédrico pode ser feita com base no sistema axial romboédrico ou hexagonal (Figura 2.13). Quando a estrutura é descrita como um romboedro agudo primitivo, os parâmetros que o identificam são os comprimentos $a_{1}, a_{2}$ e $a_{3}$ das arestas, e o ângulo formado por quaisquer duas arestas que compõem o ápex do romboedro (Figura 2.13-A). Se a estrutura é descrita como um prisma hexagonal, a linha que conecta os vértices do romboedro constitui um eixo ternário. Assim, todos os pontos 
do retículo cristalino podem ser descritos em função de um sistema axial hexagonal como observado na Figura 2.13-B (REEDER, 1983).

O sistema hexagonal é o mais utilizado pela literatura mais recente. De acordo com este sistema (Figura 2.13-B), os três eixos a de mesmo comprimento se interceptam mutuamente formando ângulos de $120^{\circ}$ entre si. Os três eixos se situam em um plano perpendicular ao eixo $c$. Este arranjo torna visualmente mais simples os aspectos planares que ocorrem em diferentes níveis ou cotas ao longo do eixo $c$ (LEAL FILHO, 1991; REEDER, 1983).

A

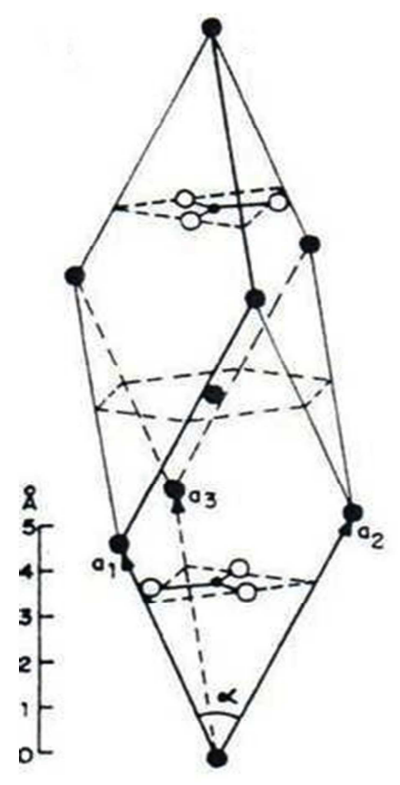

B

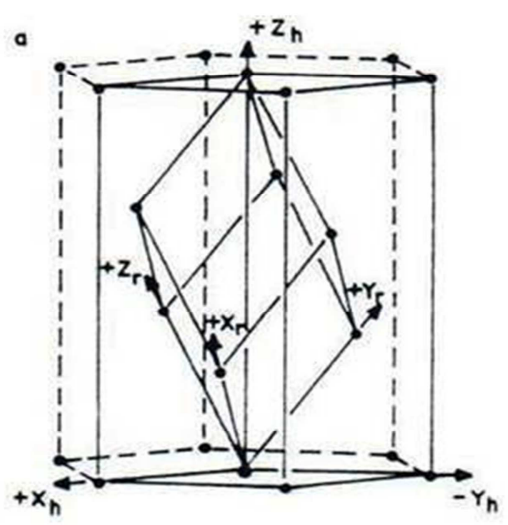

Oxigênio

- Cálcio

- Carbono

$a_{1}, a_{2}, a_{3}:$ comprimento das arestas do romboedro $\alpha$ : ângulo formado por quaisquer duas arestas que compõem o ápex do romboedro $\left(46,07^{\circ}\right)$

- Cálcio

$Z_{h}$ : eixo $Z$ do sistema hexagonal $Z_{r}$ : eixo $Z$ do sistema romboédrico $Y_{h}$ : eixo $Y$ do sistema hexagonal $Y_{r}$ : eixo $Y$ do sistema romboédrico $X_{h}$ : eixo $X$ do sistema hexagonal $X_{r}$ : eixo $X$ do sistema romboédrico

Figura 2.13 - Sistemas utilizados para descrever a estrutura cristalina da calcita: (A) Romboédrico e (B) Hexagonal (REEDER, 1983). 


\subsection{Dissolução}

Os sais semi-solúveis são caracterizados por apresentarem solubilidades inferiores às dos sais simples, como silvita $(\mathrm{KCl})$ e halita $(\mathrm{NaCl})$, mas muito superiores as dos óxidos e silicatos. Essa diferença é relevante para a química do processo de flotação devido às inúmeras possibilidades de interação entre a superfície dos minerais e as espécies presentes na solução (FINKELSTEIN, 1989). A relevância da solubilidade dos sais semi-solúveis também reside no fato de que se acredita que o principal mecanismo de adsorção dos coletores aniônicos seja a precipitação na superfície (FINKELSTEIN, 1989; LU; DRELICH; MILLER, 1998).

O comportamento dos minerais semi-solúveis em solução aquosa pode ser avaliado considerando-se aspectos termodinâmicos ou cinéticos. A solubilidade é um parâmetro termodinâmico do equilíbrio químico, condição em que as reações direta (dissolução) e inversa (precipitação) ocorrem com a mesma velocidade (MORSE, 1986; MORSE; ARVIDSON, 2002). Diferentes tempos de alcance do equilíbrio químico são reportados para calcita e apatita. Plummer, Wigley e Parkhurst (1978), por exemplo, observaram que o equilíbrio entre calcita e solução é atingido após 7 horas de reação, enquanto para Marinakis e Shergold (1985) este tempo é de 6 dias. No que concerne à apatita, Chaïrat et al. (2007a) reportaram tempos de 3 a 5 dias, enquanto Valsami-Jones et al. (1998) observaram a obtenção do equilíbrio em tempos superiores a 60 dias.

O fato de diferentes tempos para o alcance do equilíbrio serem reportados pela literatura pode ser explicado porque, muitas vezes, um estado estacionário em que não há modificações significativas nas reações direta e inversa, pode ser confundido com o equilíbrio propriamente dito (MORSE, 1983). O tempo decorrido para o alcance do equilíbrio químico também pode variar com a heterogeneidade química da solução e do sólido (MORSE, 1986). No caso das apatitas, as inúmeras substituições possíveis (Seção 2.5.1) podem ocasionar mudanças significativas em sua solubilidade (FINKELSTEIN, 1989).

A velocidade de dissolução, por outro lado, é um parâmetro físico-químico cinético, que caracteriza quão rapidamente os íons deixam a superfície dos minerais 
(BERNER; MORSE, 1974). A velocidade de dissolução da calcita, por exemplo, é geralmente medida em termos da quantidade de íons $\mathrm{Ca}^{2+}$ ( $\mathrm{g}$ ou mol) por unidade de tempo (s ou min), por unidade de área superficial $\left(\mathrm{cm}^{2}\right.$ ou $\left.\mathrm{m}^{2}\right)$ (BERNER; MORSE, 1974; MORSE, 1986; PLUMMER; PARKHURST; WIGLEY, 1979). A normalização em relação à área superficial das amostras minerais permite a comparação entre as velocidades de dissolução de amostras com diferentes distribuições granulométricas.

Uma premissa básica em cinética química é a de que reações em meio aquoso consistem em uma série de processos químicos e físicos que podem ser separados em etapas. Para o processo de dissolução estas etapas geralmente incluem: (1) Difusão dos reagentes da solução até a interface sólido/líquido; (2) Adsorção dos reagentes na superfície e possível migração os reagentes adsorvidos para os sítios ativos (deslocamento); (3) Reações químicas superficiais; (4) Dessorção dos produtos que pode ser precedida pela migração a partir dos sítios ativos; (5) Transporte dos produtos da interface sólido/líquido para a solução (CHRISTOFFERSEN; CHRISTOFFERSEN; KJAERGAARD, 1978; PLUMMER, 1976; MORSE, 1983, 1986; MORSE; ARVIDSON, et al., 2002; SJÖBERG, 1978).

Os passos 1 e 5 envolvem o transporte de reagentes e produtos entre solução e superfície. Quando estes processos limitam a velocidade de dissolução, a reação é controlada por transporte (CHRISTOFFERSEN; CHRISTOFFERSEN; KJAERGAARD, 1978; MORSE, 1986; MORSE; ARVIDSON, 2002; SJÖBERG, 1978). Nesta situação, os íons deixam o sólido rapidamente formando uma fase saturada adjacente à superfície. A velocidade é então controlada por difusão de espécies dissolvidas para a vizinhança insaturada (BERNER, 1978). O controle por transporte é geralmente evidenciado pela dependência da velocidade de dissolução em relação às condições hidrodinâmicas do sistema (CHRISTOFFERSEN; CHRISTOFFERSEN; KJAERGAARD, 1978; MORSE, 1986; MORSE; ARVIDSON, 2002; SJÖBERG, 1978).

Já as etapas 2 a 4 ocorrem na superfície, e quando limitam a velocidade, a reação é controlada por reações superficiais (CHRISTOFFERSEN; CHRISTOFFERSEN; KJAERGAARD, 1978; MORSE, 1986; MORSE; ARVIDSON, 2002; SJÖBERG, 1978). Nesta situação, o desligamento dos íons da superfície é suficientemente lento para que a concentração na região da solução adjacente à 
interface sólido/líquido seja igual à concentração no bulk. Nesse caso, condições hidrodinâmicas não exercem nenhum efeito na velocidade de dissolução (MORSE, 1986; MORSE; ARVIDSON, 2002; SJÖBERG, 1978). Velocidades controladas por reações superficiais são normalmente menores em relação àquelas controladas por transporte (BERNER, 1978; MORSE, 1983).

Minerais muito solúveis tendem a sofrer reações controladas por transporte, enquanto minerais pouco solúveis se dissolvem com velocidade controlada por reações superficiais até que elevados graus de desequilíbrio são atingidos. A calcita possue solubilidade intermediária e, portanto, sua dissolução é governada por ambos os tipos de controle cinético (BERNER, 1978). As apatitas, todavia, são muito pouco solúveis e sua dissolução é governada preferencialmente por reações superficiais (CHRISTOFFERSEN, CHRISTOFFERSEN; KJAERGAARD, 1978). Christoffersen, Christoffersen e Kjaergaard (1978) encontraram, para a fluorapatita, um coeficiente de difusão igual a $10^{-9} \mathrm{~cm}^{2} \mathrm{~s}^{-1}$, em $\mathrm{pH} 7$, valor muito inferior àquele correspondente ao controle por transporte $\left(10^{-5} \mathrm{~cm}^{2} \mathrm{~s}^{-1}\right)$.

Poucos trabalhos na área de flotação de sais semi-solúveis são dedicados à tentativa de se estabelecer uma relação entre solubilidade ou dissolução e resposta ao processo de flotação (AMANKONAH; SOMASUNDARAN; ANANTHAPADMANABHAN, 1985; MARINAKIS; SHERGOLD, 1985). Marinakis e Shergold (1985), por exemplo, estudaram o efeito do agente coletor oleato de sódio na dissolução de alguns minerais levemente solúveis. Os autores observaram que a dissolução de apatita, fluorita e calcita é inibida pela adição de oleato de sódio, provavelmente devido ao recobrimento da superfície destes minerais pelo oleato de cálcio (MARINAKIS; SHERGOLD, 1985).

É importante ressaltar que a solubilidade de um mineral pode afetar a do outro e vice-versa. Por exemplo, Amankonah, Somasundaran e Ananthapadmanabhan (1985) reportaram que a solubilidade da calcita é influenciada pelo sobrenadante da apatita e o inverso também ocorre. Como observado na Figura 2.14, embora as solubilidades da calcita e da apatita sejam diferentes em água pura, um valor intermediário é atingido quando a reação é conduzida nos sobrenadantes uma da outra (AMANKONAH; SOMASUNDARAN; ANANTHAPADMANABHAN, 1985). Uma consequência deste fenômeno é a depressão dos minerais apatita e calcita durante a flotação como observado por 
Ananthapadmanabhan e Somasundaran (1984, apud AMANKONAH; SOMASUNDARAN; ANANTHAPADMANABHAN, 1985).

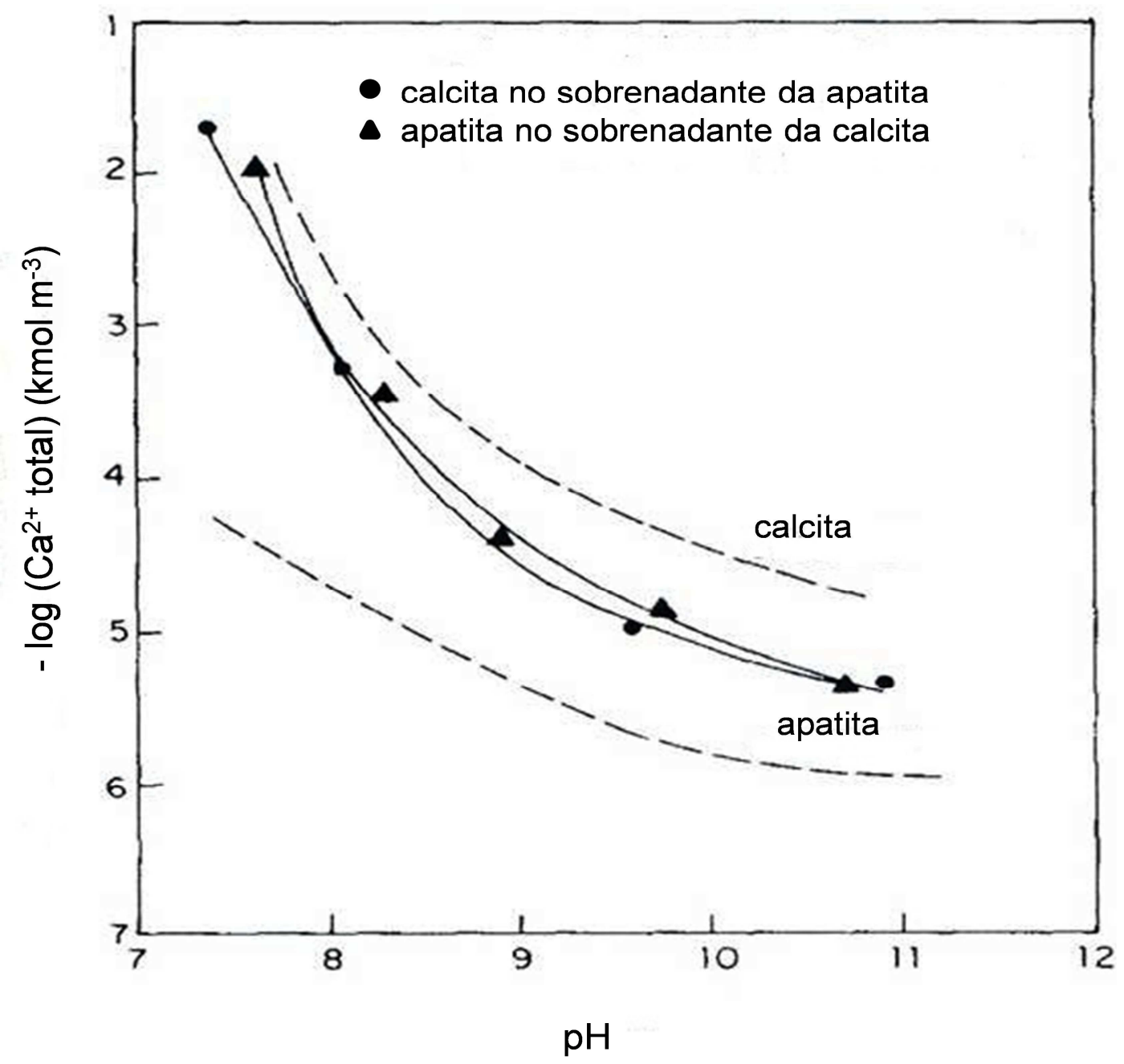

Figura 2.14 - Comparação entre a solubilidade da apatita e da calcita em água pura e no sobrenadante uma da outra (AMANKONAH; SOMASUNDARAN; ANANTHAPADMANABHAN, 1985).

Este comportamento foi explicado pelos autores como sendo consequência da formação de uma terceira fase com características tanto de calcita como de apatita que os autores chamaram graciosamente "capatita" (AMANKONAH; SOMASUNDARAN; ANANTHAPADMANABHAN, 1985). Finkelstein (1989) sugere a formação de monetita (hidrogenofosfato de cálcio, $\mathrm{CaHPO}_{4}$ ), cuja solubilidade é 
intermediária a da calcita e da apatita. Cabe aqui ponderar sobre o tempo necessário para a formação de "capatita" ou monetita na superfície da calcita ou apatita e, mais ainda, se este tempo é compatível com a realidade industrial ou dos ensaios de flotação em bancada.

A despeito dos poucos trabalhos sobre dissolução dos sais semi-solúveis no âmbito da literatura especializada em tecnologia mineral, a área de Geociências e Oceanografia oferece muitas contribuições sobre a dissolução de calcita, seja em água doce ou do mar. A calcita é um dos minerais mais abundantes e amplamente distribuídos na crosta terrestre, além de ser um dos mais reativos. Sendo assim, reações de precipitação e dissolução são relevantes no controle de sua composição e distribuição em sedimentos marinhos (COMPTON; DALY, 1987; MORSE; BERNER, 1979; PLUMMER; WIGLEY; PARKHURST, 1978; SJÖBERG, 1978; SJÖBERG; RICKARD, 1983).

No que concerne à apatita, grande parte dos estudos sobre sua cinética de dissolução tem como escopo aplicações na área de saúde porque a hidroxiapatita e a carbonatoapatita são constituintes fundamentais dos ossos e dentes. A dissolução ácida da apatita é um processo abordado em estudos que envolvem, por exemplo, cáries e desmineralização de ossos causada por algumas doenças (PAPANGKORN et al., 2008; ROOTARE; DEITZ; CARPENTER, 1962). Outros trabalhos abordam a dissolução de apatitas naturais sob condições geológicas relevantes (DOROZHKIN, 1997a, 1997b; GUIDRY; MACKENZIE, 2003; VALSAMI-JONES et al., 1998). Finalmente, pequena parte dos estudos é motivada pela presença de apatita em processos industriais, com destaque para a produção de fertilizantes (CHAIIRAT et al., 2007a, 2007b; HAROUIYA et al., 2007).

Os trechos desta seção que serão apresentados a seguir são dedicados às particularidades da dissolução de apatitas e calcitas. 


\subsubsection{Dissolução da apatita}

Um fator a ser considerado no estudo de dissolução da apatita é a ocorrência de diversas fases. Na literatura são encontrados estudos sobre fluorapatita, hidroxiapatita e carbonato-hidroxiapatita. As reações de dissolução de fluorapatita e hidroxiapatita são exibidas nas Reações 2.5 e 2.6, respectivamente (LINDSAY, 1979).

$$
\begin{gathered}
\mathrm{Ca}_{5}\left(\mathrm{PO}_{4}\right)_{3} \mathrm{~F}_{(\mathrm{s})}+6 \mathrm{H}^{+}{ }_{(\mathrm{aq})} \rightleftarrows 5 \mathrm{Ca}^{2+}{ }_{(\mathrm{aq})}+3 \mathrm{H}_{2} \mathrm{PO}_{4}^{-}{ }_{(\mathrm{aq})}+\mathrm{F}_{(\mathrm{aq})}^{-} \\
\mathrm{Ca}_{5}\left(\mathrm{PO}_{4}\right)_{3} \mathrm{OH}_{(\mathrm{s})}+7 \mathrm{H}^{+}{ }_{(\mathrm{aq})} \rightleftarrows 5 \mathrm{Ca}^{2+}{ }_{(\mathrm{aq})}+3 \mathrm{H}_{2} \mathrm{PO}_{4}^{-}{ }_{(\mathrm{aq})}+\mathrm{H}_{2} \mathrm{O}_{(\mathrm{l})}
\end{gathered}
$$

Em grande parte dos trabalhos de dissolução de apatita, a reação é conduzida a temperatura constante em reatores agitados de onde alíquotas da solução são retiradas ao longo do tempo para análise química $(\mathrm{Ca}, \mathrm{P}, \mathrm{F})$ da solução (CHAÏRAT et al., 2007a, 2007b; GUIDRY; MACKENZIE, 2003; HAROUIYA et al., 2007).

Com relação à influência do $\mathrm{pH}$, vários trabalhos reportam uma diminuição linear da velocidade de dissolução com o aumento do $\mathrm{pH}$ até uma região de transição a partir da qual a cinética passa a ser independente deste parâmetro (CHAÏRAT et al., 2007a, 2007b; GUIDRY; MACKENZIE, 2003; VALSAMI-JONES et al., 1998). Guidry e Mackenzie (2003) observaram que a região de transição ocorre entre os valores de $\mathrm{pH} 5$ e 6 para fluorapatitas e 4 e 7 para carbonatoapatitas.

Chaïrat et al. (2007b) estudaram a variação da velocidade de dissolução de uma fluorapatita natural (Paraíba, Brasil) com o pH na região entre 2 e 12. Os autores observaram que a diminuição de velocidade ocorre nas regiões entre $\mathrm{pH} 2 \mathrm{e}$ 7 e entre 10 e 12. A inclinação do gráfico de $\log \left(V_{D}\right)=f(p H)$, encontrada foi de $-0,9$ e $-0,5$ para os dois intervalos de $\mathrm{pH}$, respectivamente (em que $\mathrm{V}_{\mathrm{D}}$ é velocidade de 
dissolução). Já na região compreendida entre pH 7 e 10, a dissolução foi independente do pH. Harouiya et al. (2007) encontraram a inclinação de -0,6 para $\mathrm{pH}$ variando de 1 a 6 e reportaram que essa inclinação é independente da temperatura de dissolução.

Variações no comportamento da dissolução com o pH em reações controladas por reações superficiais estão relacionadas às características da superfície (BERNER, 1978). Por meio de ensaios de titulação potenciométrica, Wu, Forsling e Schindler (1991) propuseram um modelo de especiação na superfície da fluorapatita, que é ilustrado na Figura 2.15, em que se identifica o ponto de carga zero (PZC). Tal modelo tem como base a protonação e desprotonação da superfície por íons $\mathrm{H}^{+}$de acordo com as Reações superficiais 2.7 e 2.8 .

$$
\begin{gathered}
\equiv \mathrm{P}-\mathrm{O}^{-}+\mathrm{H}^{+}{ }_{(\mathrm{aq})} \rightleftarrows \equiv \mathrm{P}-\mathrm{OH} \\
\equiv \mathrm{Ca}-\mathrm{OH}_{2}^{+}-\mathrm{H}^{+}{ }_{(\mathrm{aq})} \rightleftarrows \equiv \mathrm{Ca}-\mathrm{OH}
\end{gathered}
$$

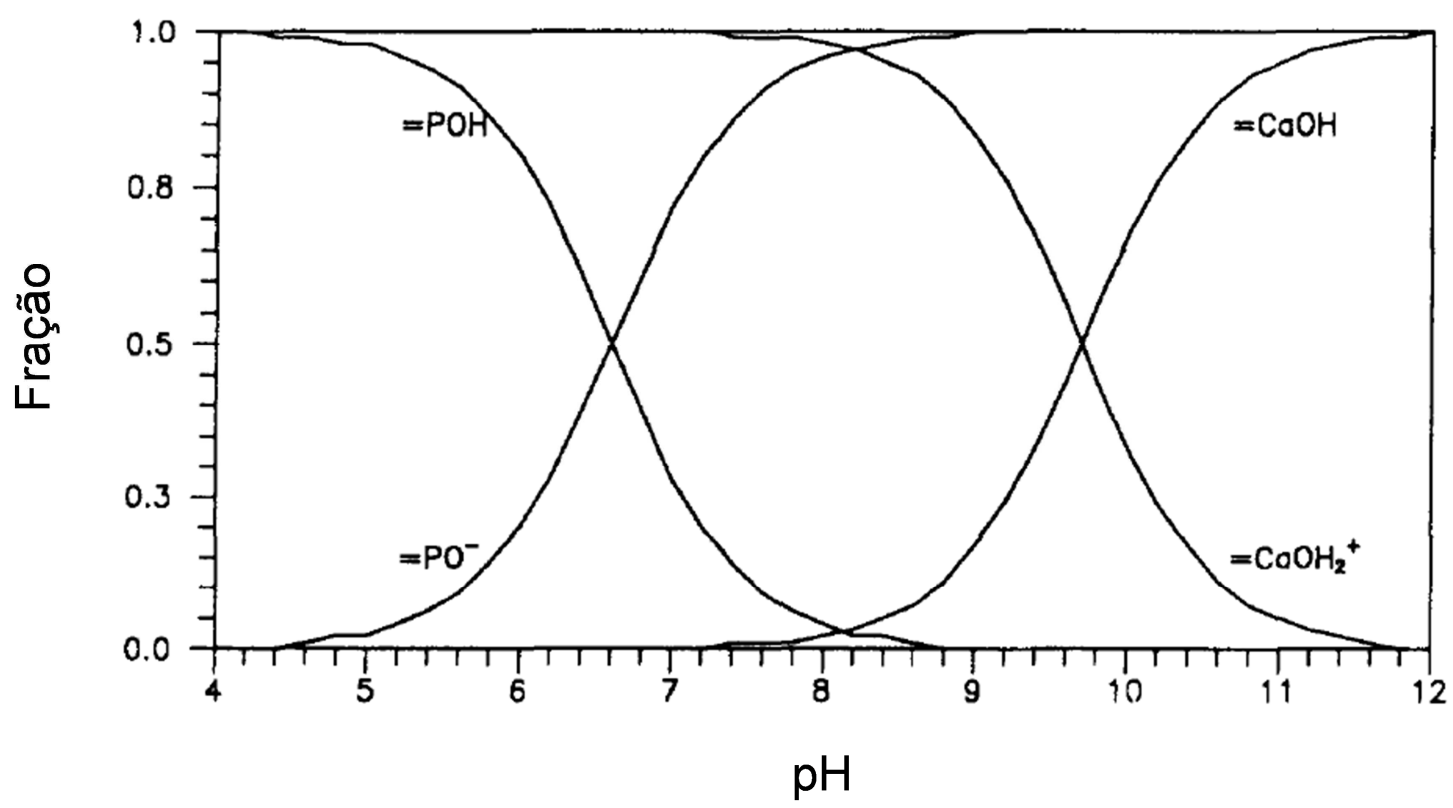

Figura 2.15 - Modelo de especiação da superfície da fluorapatita de acordo com o pH da solução, proposto por Wu, Forsling e Schindler (1991). 
A maioria dos trabalhos reporta que a dissolução da apatita se dá de maneira não estequiométrica nos primeiros momentos de reação e tende à congruência na medida em que a reação evolui (GUIDRY; MACKENZIE, 2003; ROOTARE; DEITZ; CARPENTER, 1962; SMITH; POSNER; QUIRK, 1974). Durante a dissolução não estequiométrica da fluorapatita, cálcio é preferencialmente liberado em detrimento do fósforo de acordo com a maioria dos autores (CHAÏRAT et al., 2007a, 2007b; GUIDRY; MACKENZIE, 2003; SMITH; POSNER; QUIRK, 1974).

Chaïrat et al. (2007a, 2007b) observaram a formação de fases superficiais enriquecidas com $\mathrm{P}$ e pobres em $\mathrm{Ca}$ e $\mathrm{F}$ nos primeiros momentos da dissolução de fluorapatita. De acordo com os autores, a estequiometria de dissolução sugere que reações de troca iônica entre $\mathrm{H}^{+}$e $\mathrm{Ca}^{2+}$ na região ácida, e entre $\mathrm{OH}^{-}$e $\mathrm{F}^{-}$, na região básica, ocorreriam na superfície da fluorapatita de acordo com as Reações 2.9 e 2.10, respectivamente (CHAÏRAT et al., 2007a, 2007b). A segunda reação de troca iônica (Reação 2.10) é consistente com o fato dos íons $\mathrm{F}^{-}$e $\mathrm{OH}^{-}$ocuparem o mesmo sítio na estrutura cristalina da apatita, formando fluorapatita e hidroxiapatita, respectivamente (CHAÏRAT et al., 2007b).

$$
\begin{gathered}
\mathrm{Ca}_{10}\left(\mathrm{PO}_{4}\right)_{6} \mathrm{~F}_{1,4}(\mathrm{OH})_{0,6}+2 \mathrm{xH}^{+} \rightleftarrows \mathrm{Ca}_{10-\mathrm{x}} \mathrm{H}_{2 \mathrm{x}}\left(\mathrm{PO}_{4}\right)_{6} \mathrm{~F}_{1,4}(\mathrm{OH})_{0,6}+\mathrm{xCa}^{2+} \\
\mathrm{Ca}_{10}\left(\mathrm{PO}_{4}\right)_{6} \mathrm{~F}_{1,4}(\mathrm{OH})_{0,6}+\mathrm{yOH}^{-} \rightleftarrows \mathrm{Ca}_{10}\left(\mathrm{PO}_{4}\right)_{6} \mathrm{~F}_{1,4-\mathrm{y}}(\mathrm{OH})_{0,6+\mathrm{y}}+\mathrm{yF}^{-}
\end{gathered}
$$

A Reação 2.9 indica que o consumo de $\mathrm{H}^{+}$durante a dissolução da fluorapatita não se dá apenas pela sua adsorção na superfície como proposto por Wu, Forsling e Schindler (1991). Além da reação de troca iônica, alguns autores sugerem a penetração de prótons na estrutura cristalina da apatita como um terceiro mecanismo de consumo de $\mathrm{H}^{+}$em meio ácido (CHAÏRAT et al., 2007a; DOROZHKIN, 1997b).

Chaïrat et al. (2007a) ainda contribuíram com um esclarecimento sobre a estequiometria de dissolução da fluorapatita, com base em ligações interatômicas. Considerando-se a força eletrostática relativa das ligações interatômicas que compõem a apatita, os autores sugerem que a ordem com que tais ligações são 
rompidas é: $\mathrm{Ca}-\mathrm{F}>\mathrm{Ca}-1-\mathrm{O}>\mathrm{Ca}-2-\mathrm{O}>\mathrm{P}-\mathrm{O}$. Ca-1 e Ca-2 são átomos de cálcio que ocupam as posições 1 e 2 descritas na Seção 2.5.1. De acordo com esta ordem de força de ligação interatômica, a estrutura da apatita é destruída quando todas as ligações $\mathrm{Ca}-\mathrm{F}$ e $\mathrm{Ca}-\mathrm{O}$ são desfeitas, não havendo essencialmente, a necessidade de rompimento da ligação $\mathrm{P}-\mathrm{O}$. Além disto, átomos de cálcio presentes no sítio 1 são mais facilmente removíveis do que aqueles presentes no sítio 2, devido à suas coordenações e distâncias interatômicas (CHAÏRAT et al., 2007a).

A dissolução incongruente pode conduzir à formação de fases intermediárias na superfície da apatita durante a dissolução. Tais fases podem estar associadas à composição química do mineral e do meio aquoso em que a dissolução ocorre (CHAÏRAT et al., 2007a; ROOTARE; DEITZ; CARPENTER, 1962). Contudo, vários trabalhos demonstram (por meio de MEV e espectroscopia no IV) que fases secundárias não são formadas. Sendo assim, as fases intermediárias seriam modificações dos grupos fosfato, cuja identidade será discutida no próximo parágrafo (CHAÏRAT et al., 2007a; CHHETTRY et al., 1999; HAROUIYA et al., 2007; ROOTARE; DEITZ; CARPENTER, 1962).

Rootare, Deitz e Carpenter (1962) propuseram a formação da espécie $\mathrm{Ca}_{2}\left(\mathrm{HPO}_{4}\right)(\mathrm{OH})_{2}$ na superfície durante a dissolução de hidroxiapatita. Dorozhkin (1997b) reporta a formação de fosfato de cálcio $\left(\mathrm{Ca}_{3}\left(\mathrm{PO}_{4}\right)_{2}\right)$ durante a dissolução de fluorapatita natural em meio ácido $\left(\mathrm{H}_{3} \mathrm{PO}_{4}\right)$. Ainda para a fluorapatita, Chaïrat et al. (2007a) sugeriram a formação de uma fase lixiviada de hidrogenofosfato de cálcio $\left(\mathrm{CaHPO}_{4}\right)$. No caso da dissolução da carbonatoapatita, é reportada a formação de hidroxiapatita como fase intermediária (CHHETTRY et al., 1999).

Um número reduzido de trabalhos aborda a influência da temperatura na dissolução da apatita. Guidry e Mackenzie (2003) observaram que a fluorapatita apresenta solubilidade reversa, ou seja, a solubilidade diminui em contraste com o aumento da velocidade de dissolução na medida em que a temperatura aumenta. Tais autores utilizaram velocidades de dissolução em diferentes temperaturas (35 a $55^{\circ} \mathrm{C}$ ) para determinar a energia de ativação aparente de 8,3 $\pm 0,2 \mathrm{kcal} \mathrm{mol}^{-1} \mathrm{em} \mathrm{pH}$ 3 (GUIDRY; MACKENZIE, 2003). Harouiya et al. (2007) encontraram o valor de energia de ativação aparente igual a $11 \mathrm{kcal} \mathrm{mol}^{-1}$ para fluorapatita natural brasileira, em pH 3-5,6. 
Rootare, Deitz e Carpenter (1962) observaram que a solubilidade de hidroxiapatitas diminui com o aumento da porcentagem sólido/líquido. Tal redução é mais proeminente em amostras contendo maior quantidade de impurezas. Desta forma, quanto maior a quantidade de sólidos maior o desprendimento de impurezas que poderiam ter um efeito inibidor da dissolução (ROOTARE; DEITZ; CARPENTER, 1962). Esta informação pode ser extrapolada para minérios de fosfato presentes em uma polpa de flotação.

No que diz respeito a análises em escala microscópica, Chaïrat et al. (2007b) observaram por MEV que a apatita dissolvida em meio ácido exibiu formação de pites, enquanto modificações superficiais insignificantes foram observadas após dissolução na região básica. Dorozhkin (1997a) investigou a dissolução de fluorapatita natural em mili e micro escalas por meio de Microscopia Óptica e MEV, respectivamente. Em escala milimétrica, o autor observou que a velocidade de dissolução de todas as faces cristalográficas aumenta linearmente com o tempo até 10 minutos de reação. Em microescala a dissolução ocorre por meio da formação aleatória e crescimentos de pites (DOROZHKIN, 1997a).

Poucos trabalhos se dedicam à elaboração de equações cinéticas para a dissolução de apatita. Considerando-se o formato exponencial das curvas de concentração de espécie dissolvida por tempo de reação, Smith, Posner e Quirk (1977) propuseram o seguinte modelo para ensaios de dissolução com composição constante (ensaios que se assemelham ao pH-stat da calcita).

$$
-\left(\frac{d w_{n}}{d t}\right)=y\left(w_{\infty}-w_{n}\right) e^{-z w_{n}}
$$

Em que, $\mathrm{w}_{\mathrm{n}}$ é a quantidade acumulada de mol de $\mathrm{H}^{+}$consumida no tempo de dissolução $t$, $w_{\infty}$ é a quantidade de $\mathrm{H}^{+}$consumida no equilíbrio e y e z são constantes relacionadas com a distribuição de probabilidade de íons superficiais deixarem a superfície (SMITH; POSNER; QUIRK, 1977).

Chaïrat et al. (2007b) e Harouiya et al. (2007) utilizaram a teoria do estado de transição (TET), geralmente aplicada no estudo de dissolução e cristalização de 
minerais para modelar sua velocidade de dissolução. De acordo com essa teoria, a velocidade total de dissolução $\left(V_{D}\right)$ de um mineral pode ser descrita como (CHAÏRAT et al., 2007b):

$$
V_{D}=v^{+}\left(1-\exp \left(-A q / \sigma R_{g} T\right) t\right)
$$

Em que $\mathrm{v}^{+}$é a velocidade de dissolução direta por unidade de área superficial, Aq é a afinidade química da reação, $R_{g}$ é a constante dos gases, $T$ é a temperatura e $\sigma$ é o número estequiométrico de Tempkin, que é igual à razão entre a velocidade de destruição do complexo ativo e a velocidade de dissolução total (CHAïRAT et al., 2007b; HAROUIYA et al., 2007). Aq é função do grau de saturação $(\Omega)$ da solução e da temperatura, conforme se ilustra na Equação 2.13.

$$
A q=2,3 R_{g} T \ln \Omega
$$

\subsubsection{Dissolução da calcita}

A dissolução de calcita no sistema aberto $\mathrm{CaCO}_{3}-\mathrm{H}_{2} \mathrm{O}-\mathrm{CO}_{2}$ envolve: (1) hidrólise da água, (2) dissolução do carbonato e (3) reações do sistema ácido carbônico/gás carbônico, cujas principais reações são apresentadas abaixo (LINDSAY, 1979; PLUMMER; PARKHURST; WIGLEY, 1979).

1 - Hidrólise da água

$$
\mathrm{H}_{2} \mathrm{O}_{(\mathrm{l})} \rightleftarrows \mathrm{H}^{+}{ }_{(\mathrm{aq})}+\mathrm{OH}_{(\mathrm{aq})} \quad \quad \mathrm{pK}_{\mathrm{pS}}=-14,0
$$


2 - Dissolução da calcita

$$
\begin{array}{crr}
\mathrm{CaCO}_{3(\mathrm{~s})} \rightleftarrows \mathrm{Ca}^{2+}{ }_{(\mathrm{aq})}+\mathrm{CO}_{3}{ }^{2-}{ }_{(\mathrm{aq})} & \mathrm{pK}_{\mathrm{pS}}=-8,4 \\
\mathrm{CaCO}_{3(\mathrm{~s})}+\mathrm{H}^{+}{ }_{(\mathrm{aq})} & \rightleftarrows \mathrm{Ca}^{2+}{ }_{(\mathrm{aq})}+\mathrm{HCO}_{3(\mathrm{aq})}{ }^{-} & \mathrm{pK}_{\mathrm{PS}}=1,9
\end{array}
$$

3 - Sistema ácido carbônico/gás carbônico

$$
\begin{aligned}
& \mathrm{CO}_{2(\mathrm{~g})} \longrightarrow \mathrm{CO}_{2 \text { (aq) }} \\
& \mathrm{CO}_{2(\mathrm{aq})}+\mathrm{H}_{2} \mathrm{O}_{(\mathrm{l})} \rightleftarrows \mathrm{H}_{2} \mathrm{CO}_{3(\mathrm{aq})} \quad \quad \mathrm{pK}_{\mathrm{pS}}=-1,5 \\
& \mathrm{H}_{2} \mathrm{CO}_{3(\mathrm{aq})} \rightleftarrows \mathrm{HCO}_{3}^{-}{ }_{(\mathrm{aq})}+\mathrm{H}^{+}{ }_{(\mathrm{aq})} \quad \mathrm{pK}_{\mathrm{pS}}=-6,4 \\
& \mathrm{HCO}_{3 \text { (aq) }}^{-{ }^{-}} \rightleftarrows \mathrm{CO}_{3}{ }^{2-}{ }_{(\mathrm{aq})}+\mathrm{H}^{+}{ }_{(\mathrm{aq})} \quad \mathrm{pK}_{\mathrm{pS}}=-10,3
\end{aligned}
$$

A Reação 2.14 representa a hidrólise da água; as Reações 2.15 e 2.16, a dissolução de calcita; a Reação 2.17, o processo físico de dissolução de gás carbônico em água; as Reações 2.18 e 2.19, a hidrólise do gás carbônico; e a Reação 2.20 caracteriza o equilíbrio carbonato/bicarbonato (LINDSAY, 1979; PLUMMER; PARKHURST; WIGLEY, 1979).

Para o estudo científico da dissolução de carbonatos, pesquisadores podem optar por três diferentes sistemas experimentais:

- Reatores agitados que promovem a suspensão das partículas de calcita (MORSE, 1974; PLUMMER; WIGLEY; PARKHURST, 1978);

- Reatores com disco rotatório em que os ensaios são realizados por meio da rotação de cristais de minerais polidos embutidos em resina com formato cilíndrico (COMPTON; DALY, 1987; SJÖBERG; RICKARD, 1983);

- Reações in situ em células fluidizadas conectadas a um microscópio de força atômica (HILLNER et al., 1992; LIANG, et al., 1996). 
Além disto, duas metodologias de determinação da velocidade de dissolução são geralmente aplicadas em reatores agitados e discos rotatórios: ensaios em $\mathrm{pH}$ constante (em inglês $\mathrm{pH}$-stat) e em pH variável (em inglês free-drift). Ambos os métodos consistem no cálculo da quantidade de íons $\mathrm{H}^{+}$consumidos com o tempo de dissolução.

Em ensaios realizados com o método do pH variável, o sólido é adicionado à solução, e o aumento de pH com o tempo decorrente da dissolução é monitorado. A variação de $\mathrm{pH}$ é, então, utilizada para o cálculo da quantidade de íons $\mathrm{H}^{+}$ consumida com o tempo de reação. Segundo Morse (1983), a desvantagem deste método é a probabilidade de determinação de velocidades irreais em condições muito abaixo ou acima da saturação. O método do $\mathrm{pH}$ variável é, assim, mais adequado para a medida da velocidade de dissolução nas proximidades do equilíbrio (MORSE, 1983; PLUMMER; PARKHURST; WIGLEY, 1979).

O método do pH constante, por sua vez, consiste na conservação da composição química da solução por meio da estabilização do pH e da pressão parcial de gás carbônico $\left(\mathrm{CO}_{2}\right)$. O pH é mantido invariável pela constante adição de solução ácida que contrapõe o aumento de $\mathrm{pH}$ ocasionado pela dissolução da calcita. A velocidade de dissolução é, deste modo, determinada pela velocidade de adição de solução ácida durante a dissolução (MORSE; BERNER, 1979; SJÖBERG, 1978). A pressão parcial de $\mathrm{CO}_{2}$ pode ser mantida invariável por meio da adição de uma mistura deste gás e ar ou nitrogênio a um fluxo constante (BERNER, 1978; MORSE, 1974). $\mathrm{O} \mathrm{CO}_{2}$ também pode ser totalmente removido por meio da adição de nitrogênio $\left(\mathrm{N}_{2}\right)$ durante a dissolução (SJÖBERG, 1976; SJÖBERG; RICKARD, 1983, 1984). Assim, a dissolução de carbonatos durante o ensaio em pH constante pode ser descrita pela Reação 2.21.

$$
\mathrm{CaCO}_{3(\mathrm{~s})}+2 \mathrm{H}^{+}{ }_{(\mathrm{aq})} \rightleftarrows \mathrm{Ca}^{2+}{ }_{(\mathrm{aq})}+\mathrm{H}_{2} \mathrm{O}_{(\mathrm{l})}+\mathrm{CO}_{2(\mathrm{aq})}
$$

Além de ser mais apropriado para a determinação da cinética de dissolução na região de elevada insaturação, este método é mais adequado para a investigação do efeito de espécies interferentes (MORSE, 1983; PLUMMER; PARKHURST; 
WIGLEY, 1979). Segundo Morse (1974), com ensaios em pH constante em reator agitado é possível medir velocidades de, no mínimo, $6 \times 10^{-13} \mathrm{~mol} \mathrm{~s}^{-1} \mathrm{~cm}^{-2}$. Em disco rotatório de $0,7 \mathrm{~cm}^{2}$ de diâmetro e atmosfera livre de $\mathrm{CO}_{2}$, Sjöberg e Rickard (1983) mediram velocidades da ordem de $2 \times 10^{-10} \mathrm{~mol} \mathrm{~s}^{-1} \mathrm{~cm}^{-2}$.

Vários modelos cinéticos são propostos para descrever o processo de dissolução da calcita em meio aquoso. Estes modelos são descritos em função do grau de saturação da solução ou das concentrações (ou atividades) de espécies presentes em solução ou na superfície, que participam das reações determinantes da velocidade. $O$ grau de saturação $(\Omega)$ representa a razão entre o produto de atividade iônica $\left(\mathrm{P}_{\mathrm{Al}}\right)$ e o produto de solubilidade $\left(\mathrm{K}_{\mathrm{PS}}\right)$ como observado na Equação 2.22. (MORSE, 1983; MORSE; ARVIDSON, 2002).

$$
\Omega=\frac{P_{A I}}{K_{P S}}
$$

Serão apresentadas, em ordem cronológica, as equações de velocidade mais mencionadas nos estudos de dissolução da calcita. A equação mais comumente utilizada é a proposta por Morse e Berner (1972), em que a velocidade de dissolução e o grau de saturação são relacionados como segue:

$$
V_{D}=-\frac{d m_{\text {calcita }}}{d t}=\left(\frac{A}{V_{S}} k\right)(1-\Omega)^{n}
$$

Em que $V_{D}$ é a velocidade de dissolução, $m_{\text {calcita }}$ é a quantidade (em mol) da calcita presente no reator em determinado intervalo de tempo t. A área superficial do sólido é representada pela letra $A$ e $V_{s}$ é o volume da solução, $k$ é a constante cinética e $n$ é a ordem da reação. Uma vantagem desta equação é que o gráfico de $\log \left(V_{D}\right)=f(1-\Omega)$ fornece a constante cinética (interseção com o eixo das ordenadas) e a ordem da reação é a inclinação da reta (MORSE; BERNER, 1972). 
Sjöberg (1976) propôs uma equação cinética em função da concentração de

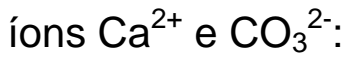

$$
V_{D}=k A\left(K_{P S}^{\prime}-\left[\mathrm{Ca}^{2+}\right]^{1 / 2}\left[\mathrm{CO}_{3}^{2-}\right]^{1 / 2}\right)
$$

Em que K'PS é o produto de solubilidade aparente (relativo ao estado estacionário) e $\left[\mathrm{Ca}^{2+}\right]$ e $\left[\mathrm{CO}_{3}^{2-}\right]$ são as concentrações molares dos íons $\mathrm{Ca}^{2+}$ e $\mathrm{CO}_{3}{ }^{2-}$, respectivamente. Esta equação pode ser escrita em termos do grau de saturação:

$$
V_{D}=k A\left(1-\Omega^{1 / 2}\right)
$$

Plummer, Wigley e Parkhurst (1978) desenvolveram um modelo mais complexo (Equação 2.26) que descreve a dissolução da calcita em termos de Reações superficiais heterogêneas 2.27 a 2.29.

$$
\begin{gathered}
V_{D}=k_{1} a H^{+}+k_{2} a H_{2} \mathrm{CO}_{3}+k_{3} a \mathrm{H}_{2} \mathrm{O}+k_{4} a \mathrm{Ca}^{2+} a \mathrm{HCO}_{3}^{-} \\
\mathrm{CaCO}_{3(\mathrm{~s})}+\mathrm{H}_{(\mathrm{aq})}^{+} \rightleftarrows \mathrm{Ca}_{(\mathrm{aq})}^{2+}+\mathrm{HCO}_{3}^{-}{ }_{(\mathrm{aq})} \\
\mathrm{CaCO}_{3(\mathrm{~s})}+\mathrm{H}_{2} \mathrm{CO}_{3(\mathrm{aq})} \rightleftarrows \mathrm{Ca}_{(\mathrm{aq})}^{2+}+2 \mathrm{HCO}_{3(\mathrm{aq})} \\
\mathrm{CaCO}_{3(\mathrm{~s})}+\mathrm{H}_{2} \mathrm{O} \rightleftarrows \mathrm{Ca}_{(\mathrm{aq})}^{2+}+\mathrm{HCO}_{3}^{-}{ }_{(\mathrm{aq})}+\mathrm{OH}_{(\mathrm{aq})}
\end{gathered}
$$

Em que a é a atividade das espécies $\mathrm{H}^{+}, \mathrm{H}_{2} \mathrm{CO}_{3}, \mathrm{H}_{2} \mathrm{O}, \mathrm{Ca}^{2+}$ e $\mathrm{HCO}_{3}{ }^{-} ; \mathrm{k}_{1}, \mathrm{k}_{2} \mathrm{e}$ $k_{3}$ são as constantes de velocidade da reação direta de dissolução; $k_{4}$ está relacionada com a velocidade de precipitação, que é função da temperatura e pressão parcial de $\mathrm{CO}_{2}$ (PLUMMER; WIGLEY; PARKHURST, 1978). 
Em função do grau de saturação a equação de Plummer, Wigley e Parkhurst (1978) pode ser escrita como:

$$
V_{D}=k_{3} a H_{2} O\left(1-\frac{a H_{\text {solução }}^{+}}{a H_{\text {superfície }}^{+}} \Omega\right)
$$

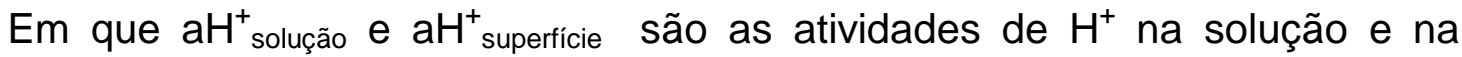
superfície, respectivamente.

Compton e Daly (1987) aplicaram uma série de equações cinéticas de dissolução da calcita a ensaios em disco rotatório conduzidos até o equilíbrio. Os modelos de Sjöberg (1976) e Plummer, Wigley e Parkhurst (1978) melhor se ajustaram aos dados experimentais coletados pelos autores (COMPTON; DALY, 1987). De maneira similar, Svensson e Dreybrodt (1992) aplicaram o modelo de Plummer, Wigley e Parkhurst (1976) a uma série de calcitas sintéticas e naturais. Os autores observaram que o modelo é apropriado para a descrição do comportamento das calcitas sintéticas, mas falha no caso da dissolução de amostras de origem natural.

Os principais parâmetros que influenciam a cinética de dissolução da calcita são $\mathrm{pH}$, temperatura, pressão parcial de gás carbônico $\left(\mathrm{pCO}_{2}\right)$, grau de saturação da solução pelos solutos $\mathrm{Ca}^{2+}$ e $\mathrm{CO}_{3}{ }^{2-}$, morfologia superficial e concentração de espécies estranhas em solução, entre as quais, o íon $\mathrm{Mg}^{2+}$, que é o mais mencionado pela literatura. A variação da velocidade de dissolução com os diversos parâmetros é, geralmente, discutida em termos do controle cinético preferencial (controle por transporte ou por reações superficiais) (MORSE, 1983; MORSE; BERNER, 1979; PLUMMER; PARKHURST; WIGLEY, 1979).

No que concerne ao efeito do $\mathrm{pH}$, a velocidade de dissolução das calcitas é maior em meio ácido devido à participação dos íons $\mathrm{H}^{+}$como reagentes na Reação 2.7. Este comportamento fica evidente na Figura 2.16, em que estão ilustrados os perfis da velocidade de dissolução de calcitas de várias origens em função do $\mathrm{pH}$ da solução. Os resultados da Figura 2.16 foram compilados por Arvidson et al. (2002) a 
partir de dados coletados por diversos autores por meio de diferentes metodologias experimentais.

Observa-se na Figura 2.16 que a velocidade de dissolução da calcita diminui linearmente com o aumento do $\mathrm{pH}$ até um $\mathrm{pH}$ de transição $(4<\mathrm{pH}<6)$, a partir do qual passa a ser constante. $\mathrm{O}$ pH de transição depende de fatores como origem da amostra, força iônica do meio e características hidrodinâmicas do aparato experimental (MORSE; ARVIDSON, 2002; PLUMMER; WIGLEY; PARKHURST, 1978; SJÖBERG; RICKARD, 1983, 1984).

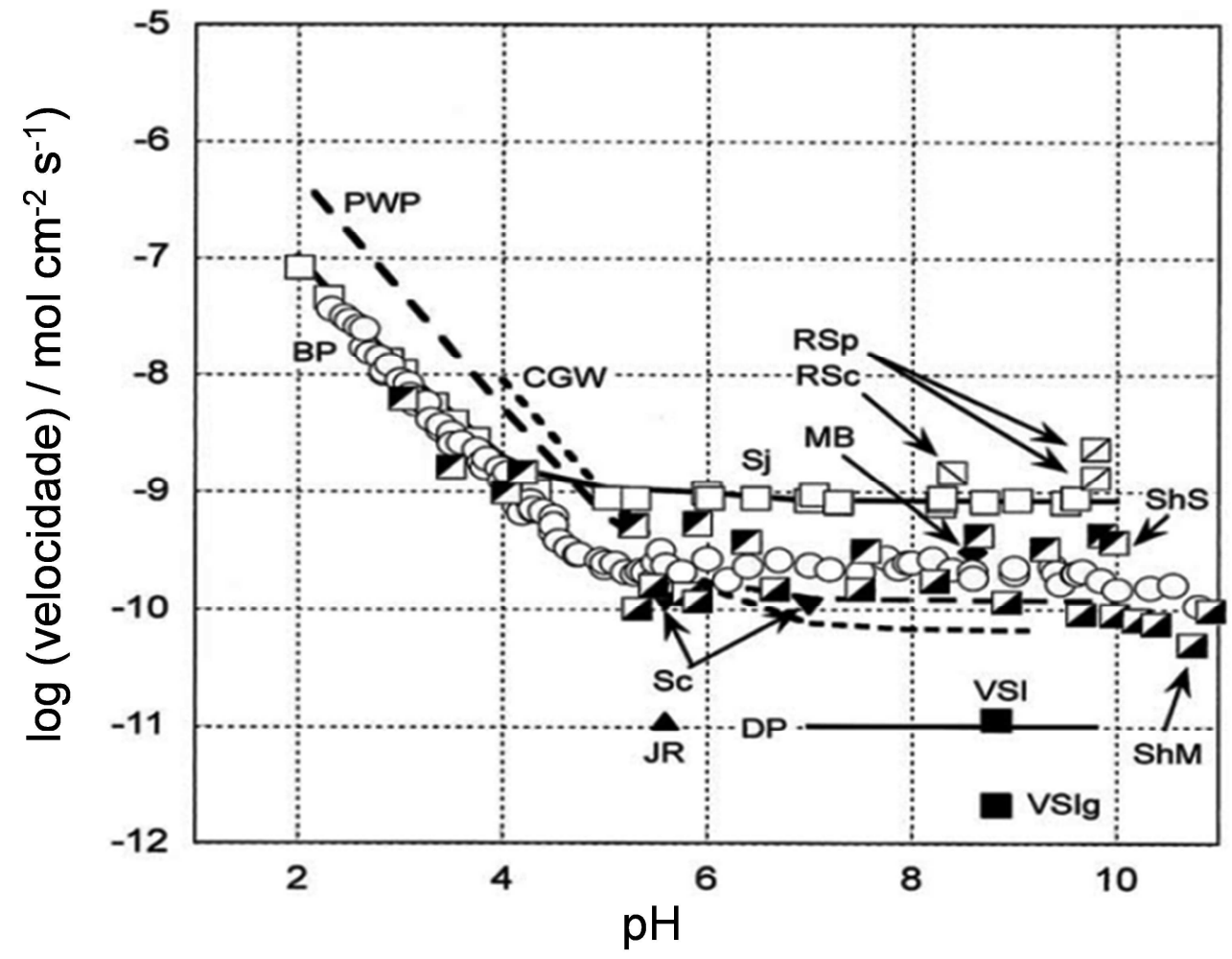

Figura 2.16 - Curvas de dissolução de amostras de calcita de diferentes origens (ARVIDSON et al., 2002).

Diferentes autores concordam que a velocidade de dissolução da calcita é controlada principalmente por transporte de íons $\mathrm{H}^{+}$na região ácida da escala de $\mathrm{pH}$ (BERNER; MORSE, 1974; MORSE; BERNER, 1972; PLUMMER; WIGLEY; PARKHURST, 1978; SJÖBERG, 1978; SJÖBERG; RICKARD, 1983). Esta afirmação é suportada pela baixa energia de ativação aparente $\left(10,5 \mathrm{~kJ} \mathrm{~mol}^{-1}\right)$, além da dependência da cinética de dissolução em relação à velocidade de agitação. Já na 
região básica da escala de $\mathrm{pH}$, a velocidade de dissolução é controlada principalmente por reações superficiais, o que é evidenciado por valores altos de energia de ativação $\left(25,7 \mathrm{~kJ} \mathrm{~mol}^{-1}\right.$ para cristais e $35,0 \mathrm{~kJ}^{-1}$ para material particulado) aliados à independência da velocidade de dissolução em relação à velocidade de agitação (BERNER; MORSE, 1974; PLUMMER; WIGLEY; PARKHURST, 1978; SJÖBERG, 1978).

Em meio básico, a prevalência do controle da cinética de dissolução por reações superficiais pode justificar as dissimilaridades observadas para as diversas calcitas, cujo comportamento é apresentado na Figura 2.16. Se o controle da dissolução se dá por reações químicas que ocorrem na interface calcita/solução, existe uma dependência da cinética em relação à densidade de sítios ativos às reações de dissolução na superfície do mineral. Tais características variam de uma amostra para outra e também com a metodologia de preparação da amostra como sua cominuição e método de purificação, por exemplo (MORSE; BERNER, 1972; RICKARD; SJÖBERG; 1983).

Pokrovsky e Schott (2002) desenvolveram um modelo de especiação para a análise da cinética de dissolução de calcita. Este modelo assume a existência de dois sítios primários de hidratação, $\equiv \mathrm{CaOH}^{0} \mathrm{e} \equiv \mathrm{CO}_{3} \mathrm{H}^{0}$, cuja protonação e hidratação controlam a reatividade dos carbonatos em solução aquosa. Com base neste modelo, a dissolução promovida por íons $\mathrm{H}^{+}$em $\mathrm{pH}<5$ pode ser explicada pela protonação de grupos carbonato superficiais $\left(\equiv \mathrm{CO}_{3} \mathrm{H}^{0}\right)$, enquanto os sítios metálicos hidratados $\left(\equiv \mathrm{CaOH}_{2}{ }^{+}\right)$governam a dissolução promovida pela água em $\mathrm{pH}>6$ (POKROVSKY; SCHOTT, 2002; POKROVSKY; SCHOTT; THOMAS, 1999).

Com relação ao efeito da temperatura, Rickard e Sjöberg (1983) criaram um esquema representativo (Figura 2.17) para descrever o efeito sinérgico entre $\mathrm{pH}$ e temperatura da solução no controle da cinética de dissolução da calcita, configurando três diferentes regiões: 1) Região mais ácida, em que a cinética é controlada pelo transporte do $\mathrm{H}^{+}$(difusão) da solução para a interface calcita/solução e consequente difusão das espécies dissolvidas para o seio da solução; 2) Região neutra a básica $(\mathrm{pH}>6)$ em que a cinética é controlada por reações superficiais que envolvem sítios metálicos hidratados; 3) Região de transição $(4<\mathrm{pH}<6)$, caracterizada por uma cinética complexa que envolve tanto transporte como reações de superfície. 
$\mathrm{Na}$ Figura 2.17 verifica-se, ainda, que as curvas que dividem as três diferentes regiões se inclinam para a esquerda (na direção da faixa ácida) na medida em que a temperatura aumenta. Tal comportamento pode ser explicado pelo fato de que uma temperatura mais elevada favorece o mecanismo de difusão (transporte). Por outro lado, na medida em que a temperatura decresce, as curvas que dividem as três regiões se deslocam para a direita (na direção da faixa básica). Este comportamento pode ser explicado pelo aumento da influência das reações superficiais em detrimento da difusão no controle da dissolução (RICKARD; SJÖBERG, 1983).

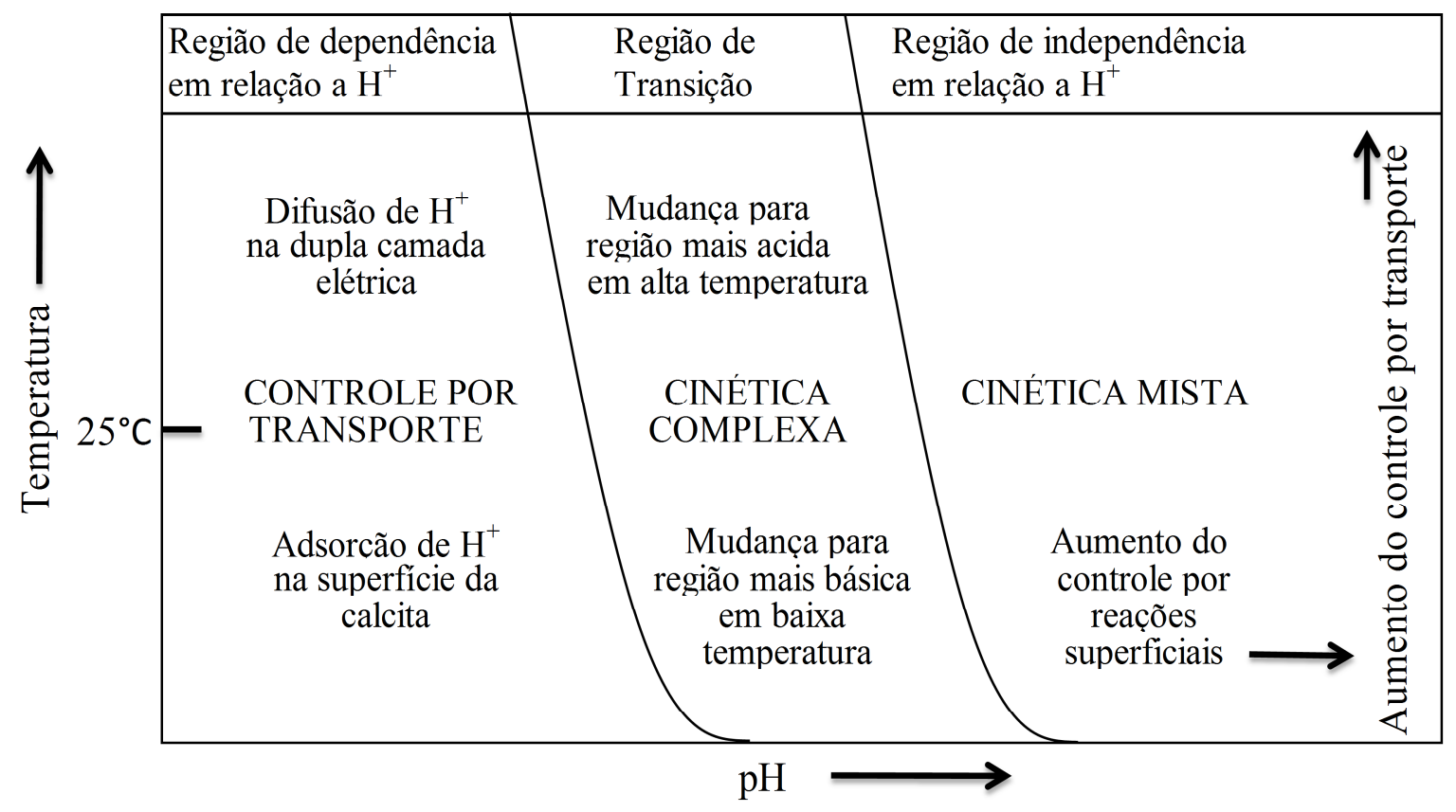

Figura 2.17 - Representação esquemática do efeito sinérgico de pH e temperatura no controle da cinética de dissolução da calcita (RICKARD; SJÖBERG, 1983).

No que concerne à influência da concentração de $\mathrm{CO}_{2}$ na dissolução dos carbonatos, esta é explicada pela sua participação no sistema de reações que envolvem o ácido carbônico (Reações 2.18 a 2.20). A relação entre atividade de $\mathrm{CO}_{3}{ }^{2-}\left(\mathrm{aCO}_{3}{ }^{2-}\right)$, pressão parcial de $\mathrm{CO}_{2}\left(\mathrm{pCO}_{2}\right)$ e $\mathrm{pH}$ pode ser descrita pela Equação 2.31, em que se observa que $\mathrm{pCO}_{2}$ e $\mathrm{pH}$ podem variar num intervalo de valores, sem que haja variação da atividade de $\mathrm{CO}_{3}{ }^{2-}$ na solução (MORSE; ARVIDSON, 2002). 


$$
a \mathrm{CO}_{3}^{2-}=\log \mathrm{R}^{\prime}+\log p \mathrm{CO}_{2}+2 p H
$$

Em que R' é o produto entre a constante da lei de Henry para $\circ \mathrm{CO}_{2}$, a primeira e a segunda constantes de dissociação do ácido carbônico (MORSE; ARVIDSON, 2002).

De acordo com Plummer, Wigley e Parkhurst (1978), nos ensaios de solubilidade em pH constante, a pressão parcial de $\mathrm{CO}_{2}\left(\mathrm{pCO}_{2}\right)$ nas bolhas de gás que são borbulhadas na suspensão durante os experimentos de dissolução pode ser calculada por meio da Equação 2.32:

$$
p \mathrm{CO}_{2}=x \mathrm{CO}_{2}\left(p_{\text {total }}-\mathrm{pH}_{2} \mathrm{O}\right)
$$

Em que $\mathrm{xCO}_{2}$ é a fração de $\mathrm{CO}_{2}$ na mistura gasosa, p ptotal é a pressão barométrica e $\mathrm{pH}_{2} \mathrm{O}$ é a pressão de vapor da água (PLUMMER; WIGLEY; PARKHURST, 1978).

Alguns autores dividem três regiões de $\mathrm{pH}$ para explicar o efeito sinérgico dos parâmetros $\mathrm{pH}$ e $\mathrm{pCO}_{2}$ na dissolução da calcita, cujas principais particularidades estão ilustradas na Tabela 2.3. (BERNER; MORSE, 1974; MORSE; BERNER, 1979; PLUMMER; PARKHURST; WIGLEY, 1979; PLUMMER; WIGLEY; PARKHURST, 1978).

Na Região 1 da Tabela 2.3, a velocidade de dissolução da calcita é controlada pelo transporte de íons $\mathrm{H}^{+}$da solução para a interface calcita/solução e pelo contra-

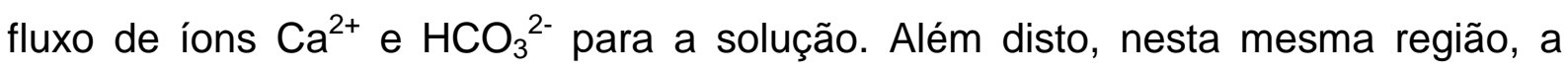
velocidade de dissolução é independente de $\mathrm{pCO}_{2}$ e, consequentemente, do sistema de reações do ácido carbônico (BERNER; MORSE, 1974; PLUMMER; PARKHURST; WIGLEY, 1979; PLUMMER; WIGLEY; PARKHURST, 1978). A Região 3 da Tabela 2.3 é caracterizada pelo controle da cinética de dissolução por reações superficiais. Sendo assim, não há influência do pH, no entanto, a velocidade 
aumenta linearmente com a pressão parcial de $\mathrm{CO}_{2}$ no sistema (PLUMMER; WIGLEY; PARKHURST, 1978).

A Região 2 da Tabela 2.3 é caracterizada por uma transição entre um mecanismo de controle cinético estritamente relacionado ao $\mathrm{pH}$ e outro que é governado por reações superficiais, cuja dependência em relação à $\mathrm{pCO}_{2}$ é acentuada. Os valores de $\mathrm{pH}$ que limitam essa região dependem da temperatura, da composição da solução e de $\mathrm{pCO}_{2}$. Para $\mathrm{pCO}_{2}=1,0$ atm, por exemplo, essa região se estende de $\mathrm{pH} 3,5$ a 5,5, ao passo que, para a $\mathrm{pCO}_{2}=0,03$ atm este intervalo de pH está entre 4,5 e 6,5 (PLUMMER; WIGLEY; PARKHURST, 1978).

Tabela 2.3 - Controle da velocidade de dissolução da calcita em função dos parâmetros $\mathrm{pH}$ e $\mathrm{pCO}_{2}$ (BERNER; MORSE, 1974; PLUMMER; WIGLEY, PARKHURST, 1978).

\begin{tabular}{cccc}
\hline Região & Faixa de pH & $\begin{array}{c}\text { Parâmetros que influenciam } \\
\text { a velocidade de dissolução }\end{array}$ & $\begin{array}{c}\text { Controle da } \\
\text { velocidade }\end{array}$ \\
\hline 1 & $\mathrm{pH}<3,5$ & $\mathrm{pH}$ & Transporte \\
\hline 2 & $3,5<\mathrm{pH}<5,5$ & $\mathrm{pH} \mathrm{e} \mathrm{pCO}_{2}$ & $\begin{array}{c}\text { Transporte e } \\
\text { reações de } \\
\text { superfície }\end{array}$ \\
\hline 3 & & & Reações de \\
& $\mathrm{pH}>5,5$ & $\mathrm{pCO}_{2}$ & superfície \\
\hline
\end{tabular}

Vários estudos abordam a influência do grau de saturação da solução na dissolução da calcita. De maneira geral, o que se observa é que o controle por transporte diminui em detrimento do controle por reações superficiais, na medida em que o grau de saturação aumenta (BERNER, 1978; BERNER; MORSE, 1974; MORSE; ARVIDSON, 2002).

Vale ressaltar que a gênese e as condições geológicas as quais o mineral foi submetido antes da dissolução podem resultar em heterogeneidade superficial, que influencia o tipo e a extensão das interações químicas na interface sólido/líquido 
(COMPTON; DALY; HOUSE, 1986; MORSE, 1986; PLUMMER; PARKHURST; WIGLEY, 1979). Neste contexto, a densidade de sítios ativos superficiais, que está diretamente relacionada à ocorrência de imperfeições, parece ser um parâmetro relevante para estimar a quantidade de espécies disponíveis para sofrer reações. Assim, cristais menos perfeitos tendem a se dissolver mais rapidamente em detrimento dos mais perfeitos (COMPTON; DALY; HOUSE, 1986; PLUMMER; PARKHURST; WIGLEY, 1979). Esta tese se propõe a verificar se tal tendência é valida para calcitas de diferentes depósitos.

A técnica de Microscopia de Força Atômica (MFA) vem sendo utilizada para a análise superficial de calcitas, objetivando complementar os estudos de dissolução realizados em tanques agitados e também em discos rotatórios. Tal técnica permite resolução vertical ou lateral e escolha de planos preferenciais de clivagem. Estes trabalhos fazem uso de células fluidizadas conectadas ao microscópio, o que permite a coleta de uma sequência de imagens em diversos tempos de reação com o meio aquoso. Como resultado, podem ser observadas mudanças na topografia dos minerais, como formato e altura de pites (orifício na superfície, tradução do inglês para a palavra pit) e degraus, além da velocidade de sua movimentação ao longo da superfície (HILLNER et al., 1992; LIANG et al., 1996).

Hillner et al. (1992) observaram, por meio da técnica de MFA, que a dissolução da calcita ocorre pela combinação de movimentação de degraus e expansão de pites. A movimentação de degraus acontece ao longo de um determinado plano de clivagem, o que indica que a velocidade deste processo deve variar com a orientação cristalográfica. Os autores observaram que a expansão de pites na amostra utilizada ocorreu com a velocidade de $0,37 \mathrm{~nm} \mathrm{~s}{ }^{-1}$, com a preservação do formato romboédrico (HILLNER et al., 1992). Liang et al. (1996) reportaram que a dissolução da calcita, ocorre pela remoção de "camada por camada", por meio da criação e desaparecimento de pites rasos nos primeiros estágios da reação. Após algumas horas de reação, no entanto, a superfície mineral apresenta pites mais profundos e distorcidos atingindo até 40 camadas (LIANG et al., 1996).

Outro aspecto que deve ser considerado é o efeito de espécies em solução na dissolução da calcita. A presença de íons estranhos influencia a dissolução dos minerais semi-solúveis por três processos: aumento na força iônica, efeito de íons 
comuns, efeito do par iônico e adsorção na interface sólido/líquido (BERNER, 1978). De acordo com Berner (1978), a adsorção de inibidores de dissolução na interface sólido/líquido pode causar uma inversão no mecanismo de controle de dissolução da calcita, de uma cinética controlada pelo transporte para outra controlada por reações superficiais. É importante ressaltar que tais inibidores de dissolução podem estar presentes em águas naturais que são utilizadas nos processos de flotação industriais.

A influência de íons $\mathrm{Mg}^{2+}$ é bastante estudada devido à sua presença em águas naturais e em minerais como dolomita e silicatos que ocorrem naturalmente com a calcita. No entanto, existe uma discordância entre os resultados dos trabalhos a respeito do efeito deste íon. Alguns autores reportam que a presença de íons $\mathrm{Mg}^{2+}$ aumenta a velocidade de dissolução da calcita na região neutra e básica, em meio aquoso com força iônica constante. Tal efeito é explicado pela interação entre $\mathrm{Mg}^{2+}$ e $\mathrm{CO}_{3}{ }^{2-}$, resultando na diminuição da concentração de $\mathrm{CO}_{3}{ }^{2-} \mathrm{e}$, consequente, no favorecimento da reação de dissolução (BERNER, 1978; MUCCI; MORSE, 1984; PLUMMER; MACKENZIE, 1974). Mucci e Morse (1984) sugerem ainda que o aumento na razão $\mathrm{Mg}^{2+} / \mathrm{Ca}^{2+}$ pode induzir a formação de fases ricas em calcitas magnesianas que são mais instáveis do que a calcita pura.

Não obstante, outros autores reportam a diminuição da dissolução da calcita devido à presença de íons $\mathrm{Mg}^{2+}$. É geralmente aceito que a inibição da dissolução da calcita ocorre pela adsorção de íons $\mathrm{Mg}^{2+}$ em sítios superficiais específicos (ALKATTAN et al., 2002; ARVIDSON et al., 2006). Arvidson et al. (2006) estudaram o efeito inibitório de íons $\mathrm{Mg}^{2+}$ na dissolução da calcita por MFA, com base no modelo de movimentação de degraus e expansão de pites proposto por Hillner et al. (1992). Tais autores observaram que os íons $\mathrm{Mg}^{2+}$ interferem na movimentação de degraus que é aproximadamente nula numa concentração de íons $\mathrm{Mg}^{2+}$ da ordem de $0,8 \times 10^{-5} \mathrm{~mol} \mathrm{~L}^{-1}$ (ARVIDSON et al., 2006). Tal concentração crítica de magnésio $(\mathrm{pMg}=5,1)$ é muito inferior à concentração de magnésio $(\mathrm{pMg})$ presente nas polpas de flotação das usinas brasileiras (Tabela 2.1), implicando que, nelas, a dissolução da calcita estaria sujeita ao processo de inibição. Segundo Alkattan et al. (2002), a inibição por $\mathrm{Mg}$ ocorreria apenas em meio básico porque, em meio ácido, a dissolução da calcita é tão rápida que a presença de íons $\mathrm{Mg}^{2+}$ deveria ser irrelevante. 


\section{Capítulo 3}

\section{Materiais e Métodos}

Neste capítulo os procedimentos adotados para a execução do trabalho experimental são apresentados. O trabalho consistiu na condução de ensaios para a determinação da cristalinidade, dissolução e flotação dos minerais apatita e calcita de diferentes gêneses e origens. A Seção 3.1 contém a caracterização das amostras utilizadas, bem como particularidades a respeito de identificação, preparação, purificação, análise química e determinação de densidade, área superficial e porosidade das amostras. As seções seguintes abrangem a metodologia aplicada na determinação da cristalinidade (Seção 3.2) e nos ensaios de dissolução (Seção 3.3) e flotação (Seção 3.4). 


\subsection{Amostras minerais}

\subsubsection{Identificação}

Quatro classes de minerais foram utilizadas nos ensaios de dissolução, cristalinidade e flotação. A Tabela 3.1 contém a descrição dos tipos de minerais empregados neste trabalho.

Tabela 3.1 - Descrição dos tipos de amostras minerais utilizadas no trabalho.

Tipo de mineral

Purificados

\section{Descrição}

Concentrados* minerais já existentes no Laboratório de

Previamente purificados Físico-Química de Interfaces e Fenômenos de Transporte (LFQI).

Naturalmente puros

Amostras puras catadas nas minas.

Amostras de coleção

Cristais perfeitos.

* Purificados na década de 1990.

Os minérios que foram submetidos à purificação que visou à obtenção de concentrados de apatita e calcita são provenientes das minas de Cajati-SP, AraxáMG, Santa Quitéria-CE (Brasil) e de Sra Ouertane (Tunísia). Este último depósito é localizado em El Kef (noroeste da Tunísia) e será lavrado em 2013 (SMITH; GRIFFITHS, 2010). Os minerais purificados de cada minério, bem como as 
características relacionadas a sua gênese e localização estão apresentados na Tabela 3.2.

Tabela 3.2 - Informação sobre os minérios de fosfato que foram utilizados para a concentração dos minerais apatita e calcita.

\section{Origem}

\begin{tabular}{|c|c|c|c|c|c|}
\hline & & & Gôn & Em & \\
\hline Município & País & Estado & & & \\
\hline Araxá & Brasil & $\begin{array}{l}\text { Minas } \\
\text { Gerais }\end{array}$ & Ígneo & Vale & apatita \\
\hline Cajati & Brasil & $\begin{array}{l}\text { São } \\
\text { Paulo }\end{array}$ & Ígneo & Vale & $\begin{array}{c}\text { apatita e } \\
\text { calcita }\end{array}$ \\
\hline $\begin{array}{c}\text { Santa } \\
\text { Quitéria }\end{array}$ & Brasil & Ceará & Metamórfico & $\begin{array}{c}\text { Indústrias } \\
\text { Nucleares no } \\
\text { Brasil }\end{array}$ & $\begin{array}{c}\text { apatita e } \\
\text { calcita }\end{array}$ \\
\hline Sra Ouertane & Tunísia & - & Sedimentar & $\begin{array}{c}\text { Groupe Chimique } \\
\text { Tunisien }\end{array}$ & apatita \\
\hline
\end{tabular}

Observa-se na Tabela 3.2 que os concentrados de apatita foram obtidos a partir de todos os depósitos contemplados pelo estudo. Além disso, concentrados de calcita foram gerados a partir dos minérios de Cajati-SP e Santa Quitéria-CE (Tabela 3.2).

As amostras previamente purificadas (Tabela 3.3) são apatitas das minas brasileiras de Anitápolis-SC e Tapira-MG. Tais amostras foram purificadas em estudos anteriores realizados no LFQI. 
Tabela 3.3 - Características das apatitas previamente purificadas no LFQI.

\section{Origem}

\begin{tabular}{cccc}
\hline Município & Estado & Gênese & Empresa \\
\hline \multirow{2}{*}{ Anitápolis } & $\begin{array}{c}\text { Santa } \\
\text { Catarina }\end{array}$ & (manto de intemperismo) & Norsk Hydro Brasil \\
& Minas Gerais & Ígnea & Vale \\
\hline Tapira & & & \\
\hline
\end{tabular}

Os minerais naturalmente puros foram catados em afloramentos cuidadosamente selecionados. Tais minerais exibiram pureza muito próxima à necessária para serem empregados nesta tese. Desse modo, sua purificação foi conduzida por meio de um menor número de etapas, comparando-se com os minerais concentrados a partir de minérios, como será visto na Seção 3.1.3. A identificação dos minerais naturalmente puros é apresentada na Tabela 3.4.

Tabela 3.4 - Características dos minerais naturalmente puros.

\begin{tabular}{|c|c|c|c|c|}
\hline \multirow{2}{*}{ Mineral } & \multicolumn{2}{|c|}{ Origem } & \multirow{2}{*}{ Gênese } & \multirow{2}{*}{ Empresa } \\
\hline & Município & Estado & & \\
\hline Apatita & Ipirá & Bahia & Ígnea & - \\
\hline \multirow{2}{*}{ Calcita } & $\begin{array}{l}\text { Cachoeiro do } \\
\text { Itapemirim }\end{array}$ & $\begin{array}{l}\text { Espirito } \\
\text { Santo }\end{array}$ & Sedimentar & Imerys \\
\hline & Amorinópolis & Goiás & Sedimentar & - \\
\hline
\end{tabular}

Por fim, duas amostras de coleção (Figura 3.1) foram utilizadas: romboedros opaco e transparente de calcita. 


\section{Romboedro Opaco}

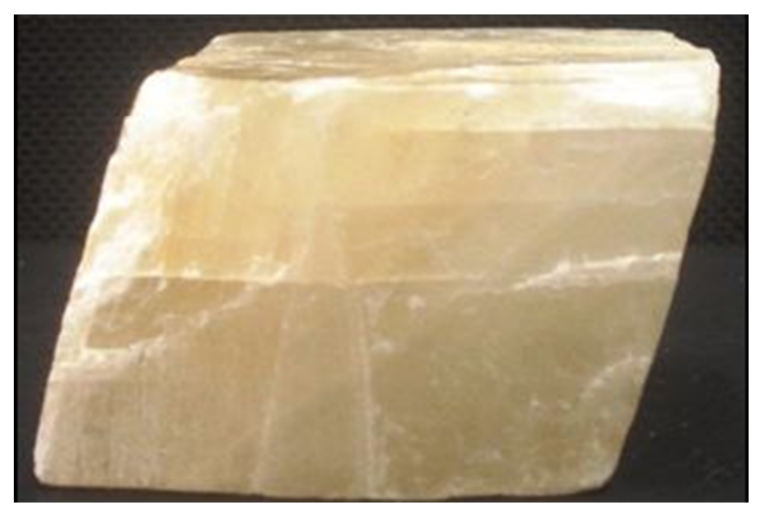

Romboedro Transparente

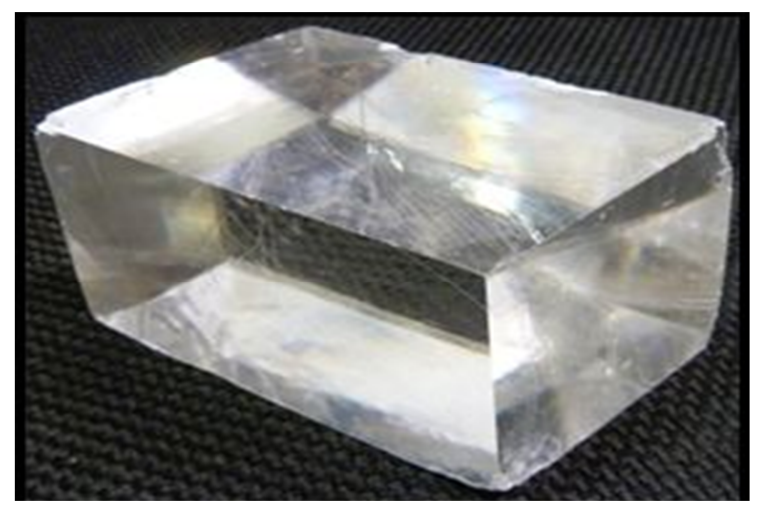

Figura 3.1- Imagens das amostras de coleção.

Uma visão genérica da localização dos depósitos que originaram as amostras brasileiras utilizadas neste trabalho é ilustrada no mapa da Figura 3.2.

Para indicar de modo claro a origem dos minerais abordadas nesta tese, identificaram-se as amostras por três letras. Amostras de apatita são identificadas com A na primeira letra, enquanto as calcitas são identificadas com C. As duas últimas letras, por sua vez, dizem respeito à origem das amostras. Na Tabela 3.5 encontra-se a forma como os minerais são identificadas ao longo do texto. 


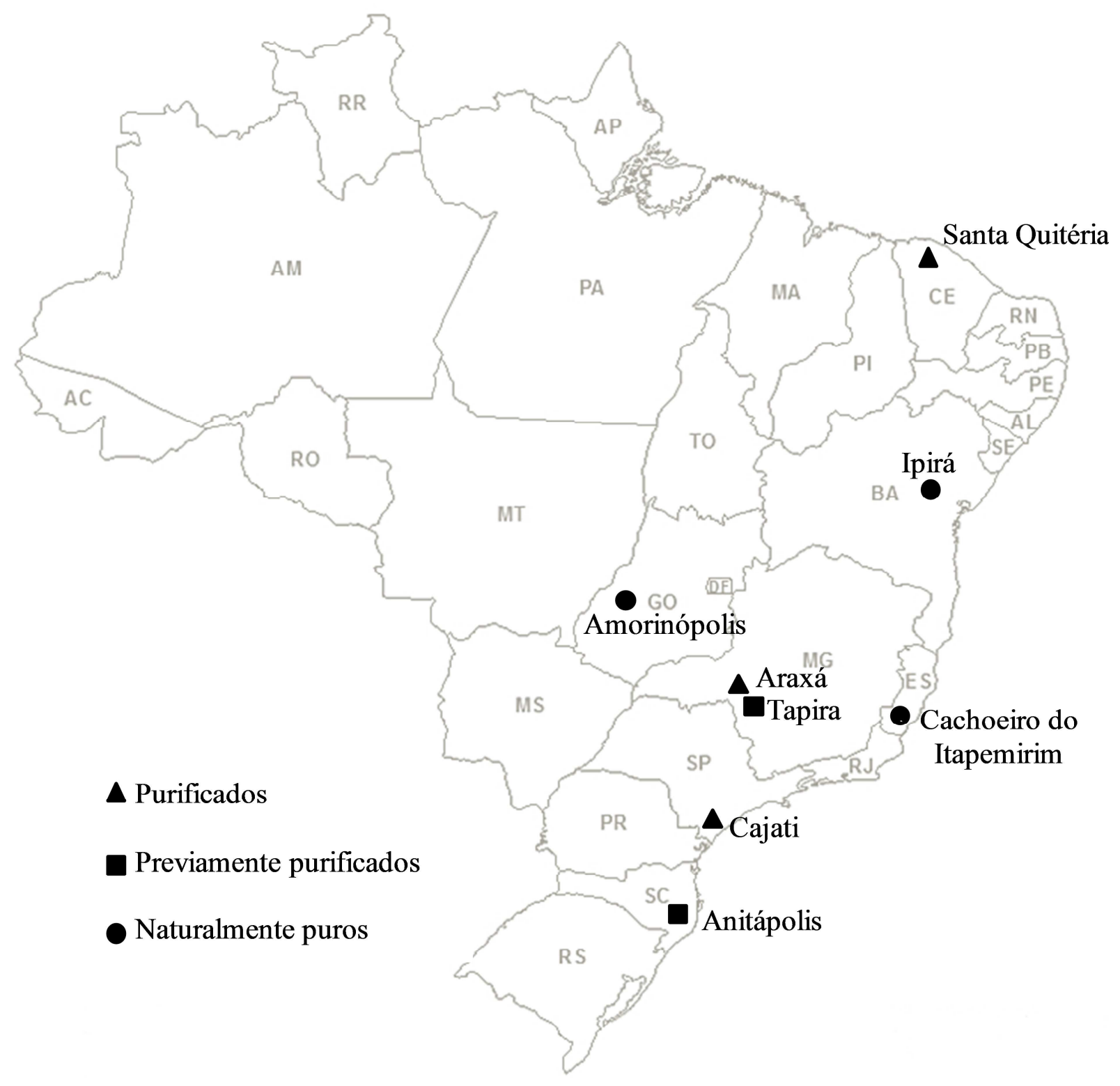

Figura 3.2 - Localização dos depósitos brasileiros que originaram as amostras contempladas neste trabalho. 
Tabela 3.5 - Identificação das amostras ao longo do texto.

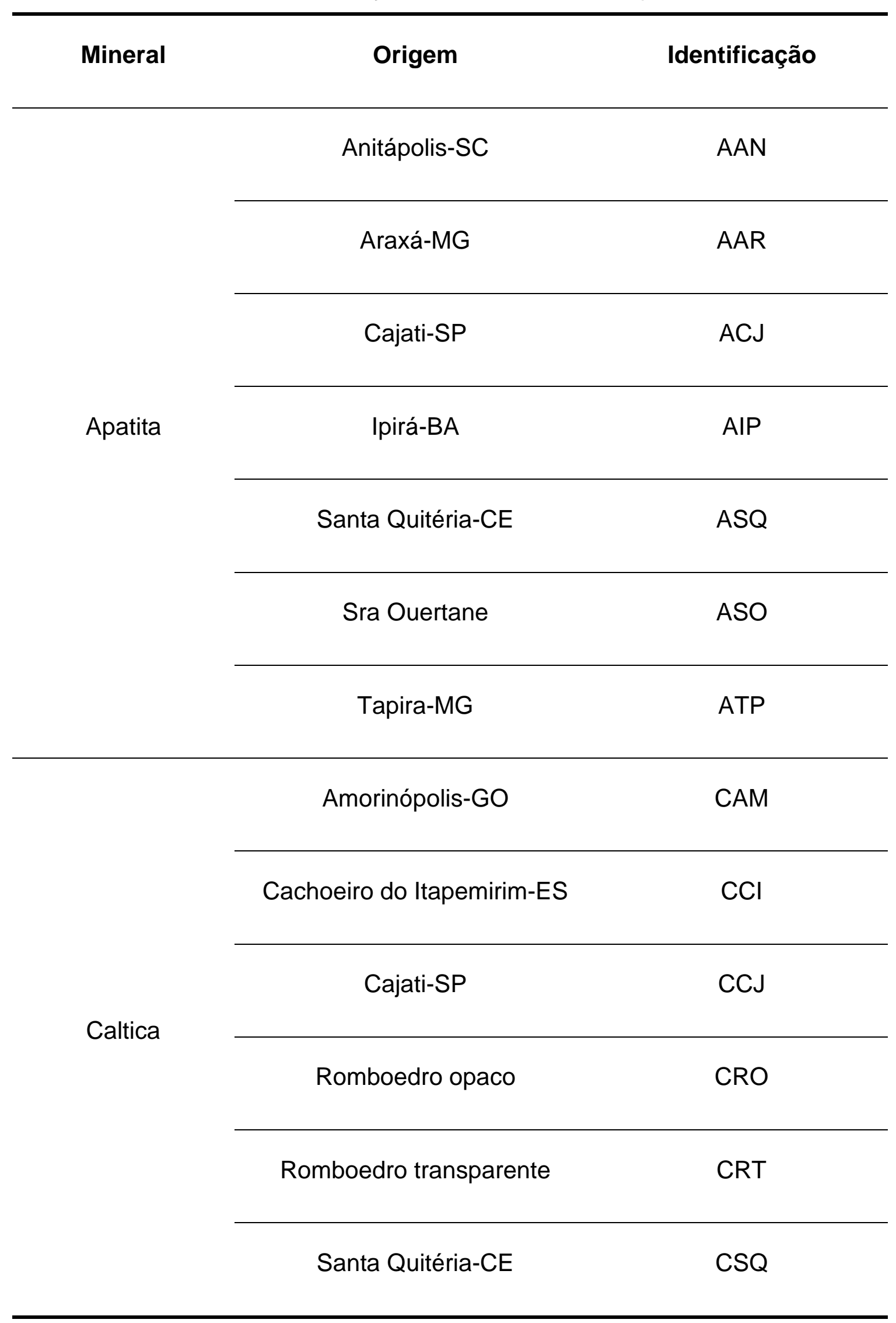




\subsubsection{Preparação}

Para serem utilizadas nos ensaios de flotação e dissolução, todas as amostras foram cominuídas até a faixa granulométrica em que as partículas são passantes em peneira de $103 \mu \mathrm{m}$ e ficam retidas em peneira de $43 \mu \mathrm{m}$. Os minerais previamente purificados (AAN e ATP) já se encontravam na faixa granulométrica desejada. O minério de Sra Ouertane também foi recebido na faixa granulométrica entre 103 e $43 \mu \mathrm{m}$. As amostras de coleção (CRO e CRT) foram moídas manualmente, a seco, em almofariz, para atingir granulometria inferior a $103 \mu \mathrm{m}$, e em seguida, deslamadas em peneira de $43 \mu \mathrm{m}$. Todas as etapas de deslamagem foram realizadas, a úmido, seguidas de secagem a $40^{\circ} \mathrm{C}$.

A cominuição das demais amostras (minérios de Cajati-SP, Araxá-MG e Santa Quitéria-CE; amostras naturalmente puras AIP e CCI) começou em britador de mandíbulas até que as partículas fossem 100\% passantes em peneira de 6,35 mm. Em seguida, o material foi moído, a seco, em moinho de bolas de cerâmica. A britagem e a moagem foram conduzidas no Laboratório de Tratamento de Minérios (LTM) do Departamento de Engenharia de Minas e Petróleo da Escola Politécnica da Universidade de São Paulo.

A primeira etapa de moagem foi conduzida até que as amostras passassem em peneira de $212 \mu \mathrm{m}$. Em seguida, os produtos desta etapa foram deslamados em peneira de $43 \mu \mathrm{m}$. As amostras resultantes da primeira etapa de moagem, que continham partículas na faixa granulométrica entre 212 e $43 \mu \mathrm{m}$, foram submetidas à separação magnética, que foi a etapa inicial do processo de purificação descrito na próxima seção. Após a separação magnética, as amostras de minério foram separadas, por meio de peneiramento a úmido, em três frações granulométricas: entre 212 e $140 \mu \mathrm{m}$, entre 140 e $103 \mu \mathrm{m}$ e entre 103 e $43 \mu \mathrm{m}$. Estas frações foram submetidas à primeira etapa de separação por meio denso (Seção 3.1.3). Os produtos desta etapa que estavam nas faixas entre 212 e $140 \mu \mathrm{m}$ e entre 140 e 103 $\mu \mathrm{m}$ foram, então, moídos a seco em almofariz e deslamados para a faixa entre $103 \mathrm{e}$ $43 \mu \mathrm{m}$. A conclusão do processo de purificação foi conduzida com partículas nesta última faixa granulométrica. 


\subsubsection{Purificação}

O processo de purificação dos minerais a partir dos minérios de Araxá-MG, Cajati-SP, Santa Quitéria-CE e Sra Ouertane foi conduzido mesclando-se etapas de separação magnética e separação por meio denso, como ilustrado no diagrama da Figura 3.3. A evolução da purificação foi acompanhada por análises químicas de Fluorescência de raios-X (FRX).

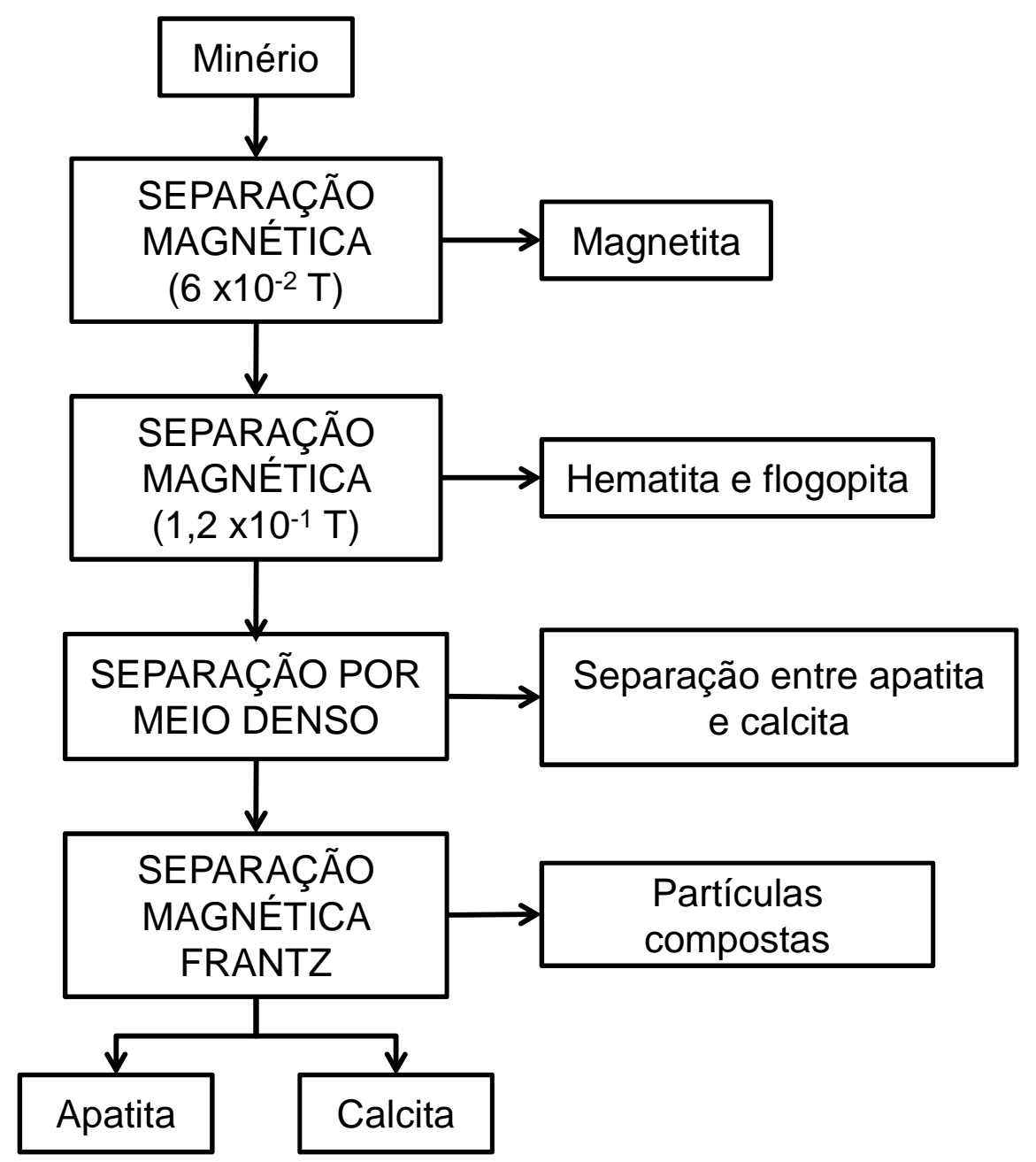

Figura 3.3 - Etapas do processo de purificação de minerais a partir de minérios.

Na primeira fase de separação magnética, os minérios foram submetidos à separação em campo baixo $\left(6,0 \times 10^{-2} \mathrm{~T}\right)$ para a remoção de magnetita (equipamento Inbras, HFP RE-Ø15”x12). Em seguida, conduziu-se separação magnética em 
campo alto $\left(1,2 \times 10^{-1} \mathrm{~T}\right)$ para a remoção de hematita e flogopita (equipamento Inbras, RE-05/04-1) como observado na Figura 3.3. No caso do minério de Santa Quitéria$\mathrm{CE}$, a apatita permaneceu na fase magnética porque contém ferro. Dessa forma, a separação magnética foi útil para a separação entre apatita e calcita, pois este último mineral não apresenta propriedades magnéticas. Posteriormente, conduziu-se a separação entre os minerais apatita e calcita por sucessivas etapas de meio denso. Finalmente, os minerais foram passados em separador magnético Frantz de Barreira (modelo LB-1) para retirada de partículas compostas (Figura 3.3).

A separação por meio denso foi realizada utilizando-se bromofórmio $\left(\mathrm{CHBr}_{3}\right)$ e diiodometano $\left(\mathrm{CH}_{2} \mathrm{I}_{2}\right)$ de pureza analítica (marca Synth). As densidades dos minerais (DANNA, 1969) e dos líquidos densos utilizados estão apresentadas na Tabela 3.6. Quando foi necessário que o líquido denso apresentasse densidade inferior à do bromofórmio ou do diiodometano, estes foram diluídos com etanol $\left(\mathrm{C}_{2} \mathrm{H}_{6} \mathrm{O}\right)$ e propanona $\left(\mathrm{C}_{3} \mathrm{H}_{6} \mathrm{O}\right)$, de pureza analítica (Synth), respectivamente. A separação por meio denso também foi útil para remover silicatos dos concentrados de calcita e minerais "pesados" dos concentrados de apatitas.

Tabela 3.6 - Densidade dos minerais e líquidos utilizados na separação densitária.

Espécie Densidade $\left(\mathrm{g} \mathrm{cm}^{-3}\right)$

\section{Minerais}

Apatita

$3,16-3,22$

Calcita

2,71

\section{Líquidos densos}

Bromofórmio

$2,81-2,84$

Diiodometano 
Cada batelada de separação por meio denso foi conduzida pela centrifugação de 1 a 5 gramas da amostra, com $25 \mathrm{~mL}$ do líquido denso na densidade desejada, a 1.500 rpm por 5 minutos (centrífuga FANEN, Excelsa II). Após cada centrifugação, flutuado e afundado foram filtrados, lavados com etanol e água, e secos a $40^{\circ} \mathrm{C}$.

Um esquema geral contendo as etapas de purificação de apatitas e calcitas por meio denso está ilustrado na Figura 3.4. Os minérios foram passados em meio de densidade $2,8 \mathrm{~g} \mathrm{~cm}^{-3}$ (bromofórmio) para uma primeira separação entre produto intermediário de apatita-1 (afundado) e produto intermediário de calcita-1 (flutuado) (Figura 3.4).

Após a primeira etapa de separação por meio denso (exceto o minério de Sra Ouertane), os produtos intermediários, nas faixas granulométricas entre 212 e $140 \mu \mathrm{m}$ e entre 140 e $103 \mu \mathrm{m}$, foram moídos em almofariz (a seco) e deslamados (a úmido) para granulometria compreendida entre $103 \mu \mathrm{m}$ e $43 \mu \mathrm{m}$, como visto na Seção 3.1.2. O produto intermediário apatita-1 foi, então, repassado sucessivas vezes em meio com densidade $2,8 \mathrm{~g} \mathrm{~cm}^{-3}$ (bromofórmio) para a remoção dos carbonatos remanescentes como se observa na Figura 3.4. O afundado desse processo, produto intermediário de apatita-2, foi passado várias vezes em meio com densidade $3,3 \mathrm{~g} \mathrm{~cm}^{-3}$ (diiodometano) para retirada de minerais mais pesados como barita, sulfetos e minerais ferrosos (Figura 3.4).

De maneira similar, o produto intermediário de calcita-1 foi repassado diversas vezes em meio com densidade $2,8 \mathrm{~g} \mathrm{~cm}^{-3}$ (bromofórmio), para remoção da apatita remanescente. Posteriormente, o flutuado desse processo, chamado produto intermediário de calcita-2, foi passado em meio com densidade $2,6 \mathrm{~g} \mathrm{~cm}^{-3}$ (bromofórmio diluído) para a remoção de silicatos (Figura 3.4).

Para o minério de Santa Quitéria-CE, a separação por meio denso começou na segunda etapa do diagrama da Figura 3.4, porque a separação inicial entre apatia e calcita se deu durante a separação magnética. O mesmo ocorreu com os minerais naturalmente puros AIP, CAM e CCI que já apresentavam pureza suficiente para que a primeira etapa de separação por meio denso fosse transposta. 


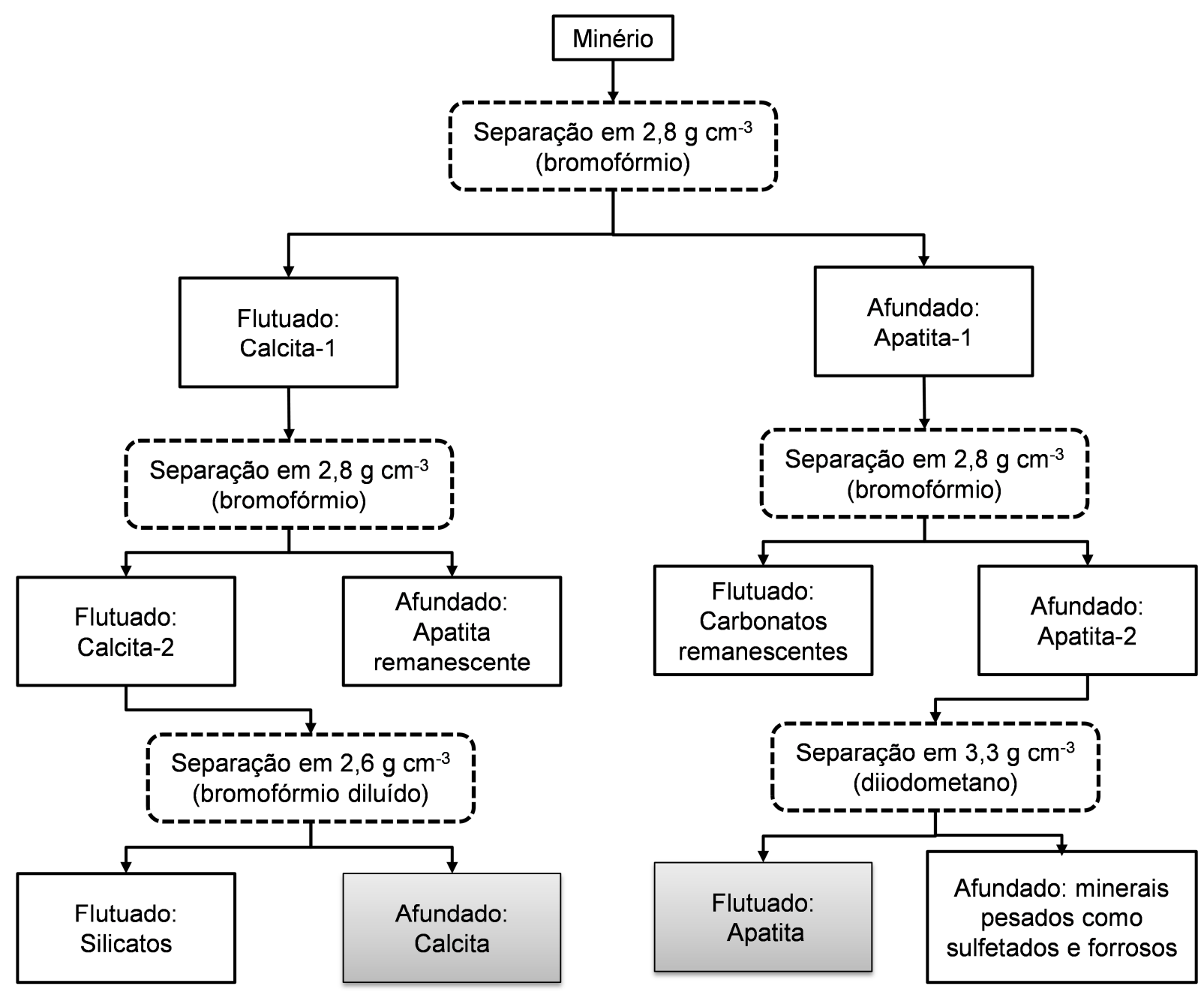

Figura 3.4 - Esquema geral das etapas de purificação por separação densitária.

Uma vez separados os minerais apatita e calcita por meio denso, estes foram passados, sucessivas vezes, em separador magnético Frantz de Barreira para a remoção de partículas compostas e fracamente magnéticas. O separador magnético Frantz, que realiza separação a seco, é composto por uma calha vibratória com inclinações longitudinal e lateral variáveis $\left(0-90^{\circ}\right)$ situada entre os polos de um eletroímã gerador de campo magnético (BRUMATTI, 2008). As inclinações lateral e

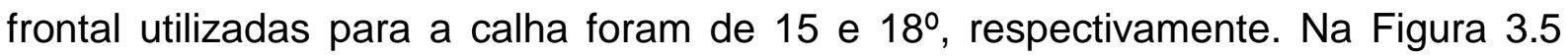
ilustra-se a variação do campo magnético com a intensidade de corrente para o separador magnético Frantz de Barreira (BRUMATTI, 2008). Nos ensaios conduzidos no separador Frantz, utilizou-se corrente de 0,5 a $1,5 \mathrm{~A}$, o que corresponde a um campo magnético de 0,6 a 1,5 T, como observado na Figura 3.5. 


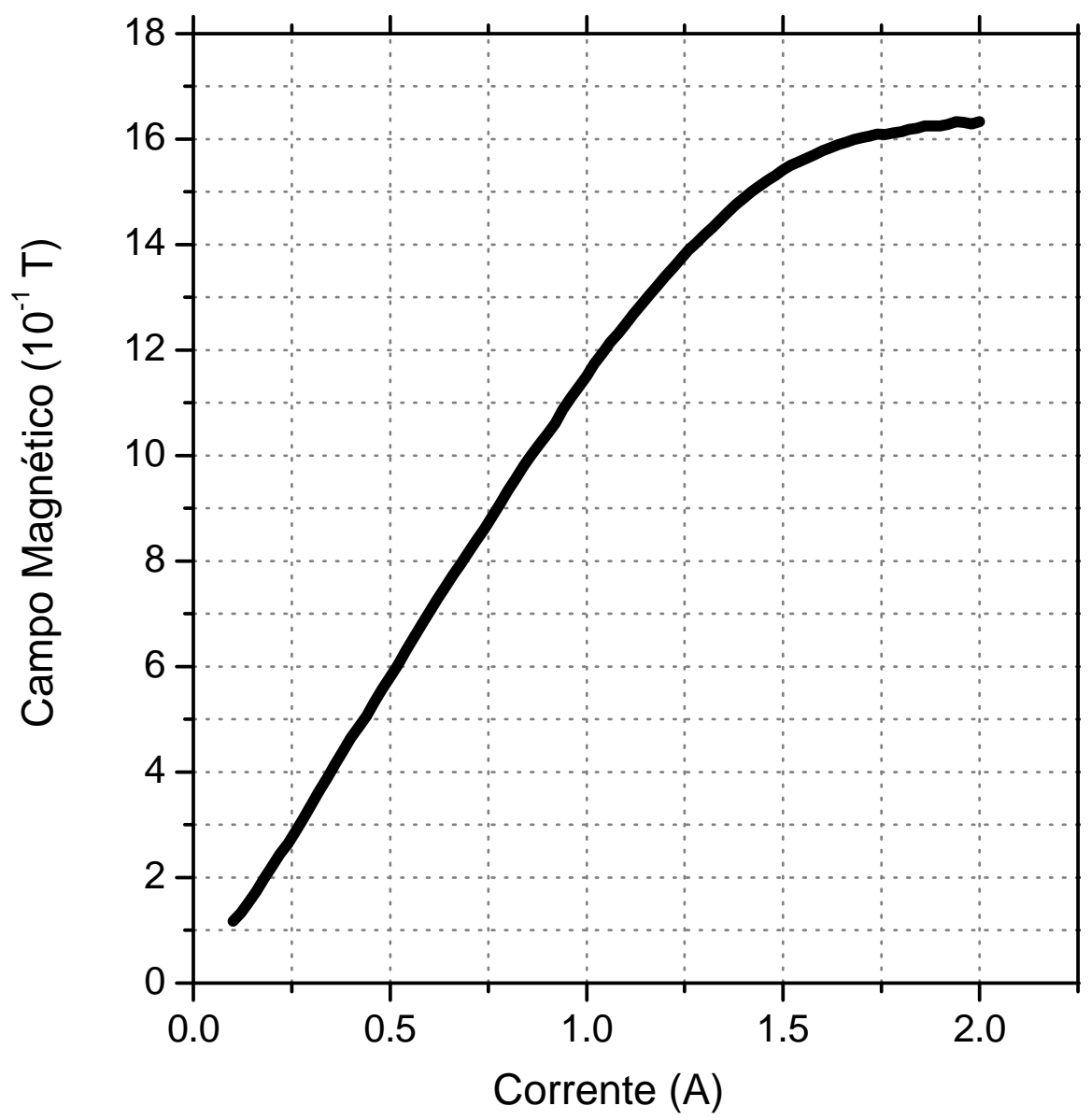

Figura 3.5 - Variação do Campo magnético (em T) com a corrente aplicada (em A) para o separador magnético Frantz de Barreira (BRUMATTI, 2008 - modificado).

\subsubsection{Caracterização}

Os concentrados de apatita e calcita foram analisados por Fluorescência de raios-X (FRX) e por análise mista de espectroscopia de dispersão de comprimento de onda (WDS-Wavelength Dispersive $X$-ray Spectroscopy) e espectroscopia de dispersão de energia (EDS-Energy Dispersive $X$-ray Spectrocopy). As amostras também foram submetidas à análise de perda ao fogo, densidade, área superficial e porosidade. Todas as análises foram conduzidas no Laboratório de Caracterização Tecnológica (LCT) do Departamento de Engenharia de Minas e Petróleo da USP. 
As análises de FRX foram realizadas em amostra fundida com tetraborato de lítio anidro por comparação com materiais certificados de referência Fosfato TBL. Utilizou-se o espectrômetro de fluorescência de raios-X marca PANanalytical, modelo Axios Advanced. Os elementos analisados foram: $\mathrm{Ca}, \mathrm{Mg}, \mathrm{Si}, \mathrm{P}, \mathrm{Fe}, \mathrm{Al}, \mathrm{Na}$, $\mathrm{K}, \mathrm{Ti}, \mathrm{Sr}, \mathrm{Mn}$, Ba e $\mathrm{S}$, na forma de óxidos. A análise de FRX é conduzida em um conjunto de partículas, dessa forma, os elementos tanto do mineral de interesse como da ganga residual são quantificados.

A análise semi-quantitativa WDS/EDS foi conduzida com detectores EDS e WDS marca Oxford, modelos INCA X-act e WDX-600, respectivamente. Os analisadores são acoplados a um microscópio eletrônico de varredura marca LEO, modelo Stereoscan 440. As análises foram realizadas por meio do programa analisador INCA, sendo que de quatro a cinco partículas de cada amostra foram analisadas. A Tabela 3.7 contém os elementos analisados por WDS e EDS para as apatitas e calcitas. As análises por WDS são realizadas com base nas quantidades do elemento analisado em amostras referência (Padrões marca MAC-Micro-Analysis Consultants Ltda). Os padrões utilizados para cada elemento são encontrados na Tabela 3.8.

Tabela 3.7 - Elementos analisados por WDS e EDS.

\begin{tabular}{lll}
\hline Mineral & $\begin{array}{l}\text { Elementos analisados } \\
\text { WDS }\end{array}$ & $\begin{array}{l}\text { por } \\
\text { EDS }\end{array}$ \\
\hline Apatita & $\mathrm{F}, \mathrm{P}, \mathrm{Cl}, \mathrm{Ca}, \mathrm{Sr}$ e $\mathrm{Fe}$ & $\mathrm{Na}, \mathrm{Mg}, \mathrm{Al}, \mathrm{Si}, \mathrm{S}, \mathrm{K}, \mathrm{Ti}, \mathrm{U}$ e $\mathrm{Mn}$ \\
\hline Carbonatos & $\mathrm{Na}, \mathrm{Mg}, \mathrm{Ke} \mathrm{Ca}$ & $\mathrm{Al}, \mathrm{Si}, \mathrm{P}, \mathrm{S}, \mathrm{Ti}, \mathrm{Mn}, \mathrm{Fe}$ e $\mathrm{Sr}$ \\
\hline
\end{tabular}

As análises de perda ao fogo (PF) foram conduzidas por calcinação em mufla efetuada a $1.050^{\circ} \mathrm{C}$ por $1 \mathrm{~h}$. A perda ao fogo mede a variação de massa da amostra após calcinação. 
Tabela 3.8 - Características dos padrões utilizados nas análises por WDS.

\begin{tabular}{|c|c|c|c|}
\hline \multirow{2}{*}{$\begin{array}{l}\text { Elemento } \\
\text { analisado }\end{array}$} & \multicolumn{2}{|c|}{ Padrão } & \multirow{2}{*}{$\begin{array}{c}\text { Porcentagem, em } \\
\text { massa, do } \\
\text { elemento analisado }\end{array}$} \\
\hline & Nome & Fórmula & \\
\hline $\mathrm{F}$ & Fluoreto de cálcio & $\mathrm{CaF}_{2}$ & 48,0 \\
\hline $\mathrm{Na}$ & Jadeita & $\mathrm{Na}(\mathrm{Al}, \mathrm{Fe}) \mathrm{Si}_{2} \mathrm{O}_{6}$ & 11,0 \\
\hline $\mathrm{Mg}$ & Olivina & $\left(\mathrm{Mg}, \mathrm{Fe}_{2}\right)\left(\mathrm{SiO}_{4}\right)$ & 30,1 \\
\hline$P$ & Apatita & $\mathrm{Ca}_{5}\left(\mathrm{PO}_{4}\right)_{3}(\mathrm{~F}, \mathrm{Cl}, \mathrm{OH})$ & 17.9 \\
\hline $\mathrm{Cl}$ & $\begin{array}{l}\text { Cloreto de } \\
\text { potássio }\end{array}$ & $\mathrm{KCl}$ & 47,6 \\
\hline $\mathrm{K}$ & Ortoclásio & $\mathrm{KAISi}_{3} \mathrm{O}_{8}$ & 9,5 \\
\hline $\mathrm{Ca}$ & Calcita & $\mathrm{CaCO}_{3}$ & 40,0 \\
\hline $\mathrm{Sr}$ & $\begin{array}{c}\text { Fluoreto de } \\
\text { estrôncio }\end{array}$ & $\mathrm{SrF}_{2}$ & 69,8 \\
\hline $\mathrm{Fe}$ & Magnetita & $\mathrm{Fe}_{3} \mathrm{O}_{4}$ & 70,4 \\
\hline
\end{tabular}

A densidade das apatitas foi determinada por picnometria de hélio (Picnômetro marca Micromeritics, modelo AccuPyc II 1340). Antes das análises as amostras foram secas a $60^{\circ} \mathrm{C}$ por 24 horas. O picnômetro de hélio é constituído por duas câmaras de volumes conhecidos (por calibração prévia): a câmara onde se coloca a amostra e câmara de expansão (ligadas por uma válvula de expansão). Para a análise as amostras foram quarteadas de modo que ocupassem $3 / 4$ do volume da 
câmara $\left(10,0 \mathrm{~cm}^{3}\right)$ onde se coloca a amostra. Em seguida, o sistema foi levado à pressão atmosférica, a câmara de expansão foi isolada pelo fechamento da válvula de expansão, e a câmara que contém a amostra foi pressurizada com hélio até uma pressão $P_{1}=134,5 \mathrm{kPa}$. Posteriormente, a válvula de expansão foi aberta, o que conduz à redução da pressão de $\mathrm{P}_{1}$ para $\mathrm{P}_{2}$. Admitindo-se o comportamento ideal do hélio, o volume do sólido pode ser calculado a partir da seguinte equação:

$$
P_{1}\left(V_{a}-V_{s}\right)=P_{2}\left(V_{a}-V_{s}+V_{e}\right)
$$

Em que $V_{a}$ é o volume da câmara que contém a amostra, $V_{e}$ é o volume da câmara de expansão e $V_{s}$ é o volume do sólido. A densidade é calculada pela razão entre a massa de mineral introduzida no sistema e $V_{s}$.

A área superficial e a porosidade das amostras foram determinadas por porosimetria de mercúrio em porosímetro marca Micromeritics (modelo Auto Pore IV). Antes das medidas as amostras foram secas a $60^{\circ} \mathrm{C}$ por 24 horas. Para a análise, as amostras foram quarteadas para que ocupassem $1 / 2$ do volume do recipiente em que se conduz a medida $\left(3,0 \mathrm{~cm}^{3}\right)$, chamado penetrômetro. Em seguida, o mercúrio foi introduzido ao penetrômetro a diferentes pressões (138 a $2.103 \mathrm{kPa}$ ). A área superficial e a porosidade dos minerais foram determinadas por meio da curva de volume cumulativo de mercúrio em função dos sucessivos aumentos de pressão. Estes cálculos, realizados pelo programa do equipamento, utilizam o ângulo de contato $(\theta)$ entre o mercúrio e os minerais, além da tensão superficial $(\gamma)$ do mercúrio. O valor de ângulo de contato utilizado para apatitas e calcitas foi aquele medido entre o mercúrio e AIP $\left(\theta=50 \pm 5^{\circ}\right)$ e $\mathrm{CRO}\left(\theta=147 \pm 5^{\circ}\right)$, respectivamente. As medidas de ângulo de contato foram realizadas a $20^{\circ} \mathrm{C}$, pelo método da gota em goniômetro marca Attension, modelo Theta no LFQI. O valor de tensão superficial de mercúrio utilizado foi de $\gamma=0,485 \mathrm{~N} \mathrm{~m}^{-1}$.

As apatitas também foram submetidas à análise FTIRpara a identificação dos grupos $\mathrm{OH}^{-}$e $\mathrm{CO}_{3}{ }^{2-}$. As análises foram realizadas com pastilhas de apatita pulverizada (granulometria 100\% inferior a $20 \mu \mathrm{m}$ ) misturadas a $100 \mathrm{mg}$ de $\mathrm{KBr}$ (marca Merck, grau Uvasol). As pastilhas foram confeccionadas sob pressão de 4 
toneladas por 4 minutos em prensa marca Marconi, modelo MA098. As análises de FTIR foram conduzidas em espectrômetro marca BOMEM, modelo MB, na Central Analítica do Instituto de Química da USP.

\subsection{Determinação da cristalinidade}

O método de Rietveld, aplicado a análises de difração de raios- $X$, foi utilizado para a determinação da cristalinidade das amostras de apatita e calcita. Antes de serem submetidas às varreduras de raios- $X$ as amostras foram moídas em almofariz até granulometria 100\% inferior a $20 \mu \mathrm{m}$. Em seguida $20 \%$, em massa, do padrão interno NIST (National Institute of Standards and Technology) alumina, $\mathrm{Al}_{2} \mathrm{O}_{3}-\mathrm{SRM}$ 676a (SRM- Stantard Reference Material), cuja quantidade de material amorfo é conhecida $(1,96 \%)$, foi inserido na amostra. Tal medida teve como objetivo possibilitar a determinação do grau de cristalinidade como será visto a seguir, nesta seção.

As varreduras foram realizadas no equipamento PANanalytical (modelo Empyrean) no laboratório da PANanalytical em Santo Amaro. As condições de aquisição de dados foram:

- Radiação de Cu ( $\gamma=1,54 \AA$ A $)$;

- Fenda de divergência automática com área irradiada de 15 mm;

- Passo = 0,013;

$-\Delta 2 \theta=8$ a $140^{\circ}$

Os perfis de difração coletados foram submetidos a refinamentos do método de Rietveld conduzidos no programa TOPAS Academic V.4.1 no Laboratório Computacional de Análises Cristalográficas e Cristalinas (LabCACC) do Instituto de Química da Universidade Estadual Paulista, Campus de Araraquara. 
O refinamento de estrutura cristalina consiste no cálculo de um perfil de difração com base na estrutura cristalográfica das fases. A intensidade calculada $\left(\mathrm{y}_{\mathrm{ci}}\right)$ em cada ponto $\left.\mathrm{(}_{\mathrm{i}}\right)$ é determinada pela soma das contribuições de todos os picos de Bragg (b) para todas as fases (Ø) presentes, segundo a Equação 3.2.

$$
\gamma_{c i}=\emptyset_{r s i} \sum_{\varnothing} S_{\emptyset}^{\prime} \sum_{b \emptyset} J_{b \varnothing} L_{p_{b \emptyset}}\left|F_{b \emptyset}^{\prime}\right|^{2} G_{b \emptyset i} F_{a_{b \emptyset i}} P_{b \emptyset}^{\prime}+\gamma_{l i}^{\prime}
$$

Em que $\varnothing_{\text {rsi }}$ é a rugosidade superficial, S' é o fator de escala, J é o fator de multiplicidade do b-ésimo pico de Bragg, $L_{p}$ é o fator de polarização de Lorentz, F' é o fator de estrutura, $G$ é a função de perfil de reflexão, $F_{a}$ é a função assimétrica, $P$ ' é a função orientação preferencial e $y^{\prime}{ }_{i i}$ é o refinamento da linha base (PAIVASANTOS, 2009).

O refinamento dos parâmetros da Equação 3.2 é conduzido com o objetivo de minimizar as diferenças entre os perfis de difração calculado e observado, ponto a ponto. A aproximação é realizada por meio do método dos mínimos quadrados (YOUNG, 1993; PAIVA-SANTOS, 2009). Assim, o refinamento é finalizado quando a convergência é atingida, ou seja, os valores dos parâmetros da Equação 3.2 não se alteram com os ciclos de refinamento, e a função dos mínimos quadrados atinge um valor mínimo (PAIVA-SANTOS, 2009). Na Figura 3.6 observa-se um exemplo de um gráfico de Rietveld que contém o ajuste entre os perfis de difração calculado e observado.

Embora a comparação entre perfis calculado e observado por análise visual dos gráficos de Rietveld seja considerada a melhor maneira de determinar-se a qualidade dos refinamentos, também são utilizados os índices $R$ ou fatores de concordância, ou ainda, resíduos. Os resíduos mais utilizados são o $R$ padrão ponderado $\left(R_{p p}\right)$, e o seu valor estatisticamente esperado $\left(R_{\text {exp }}\right)$. Idealmente, o valor final de $R_{p p}$ deve atingir o valor estatisticamente esperado $R_{\text {exp }}$. A razão entre $R_{p p} e$ $R_{\exp }$ (Equação 3.3) é chamada goodness of fit, ou valor GOF (ANTONIO, 2010; PAIVA-SANTOS, 2009; YOUNG, 1993). 


$$
G O F=R_{p p} / R_{\text {exp }}
$$

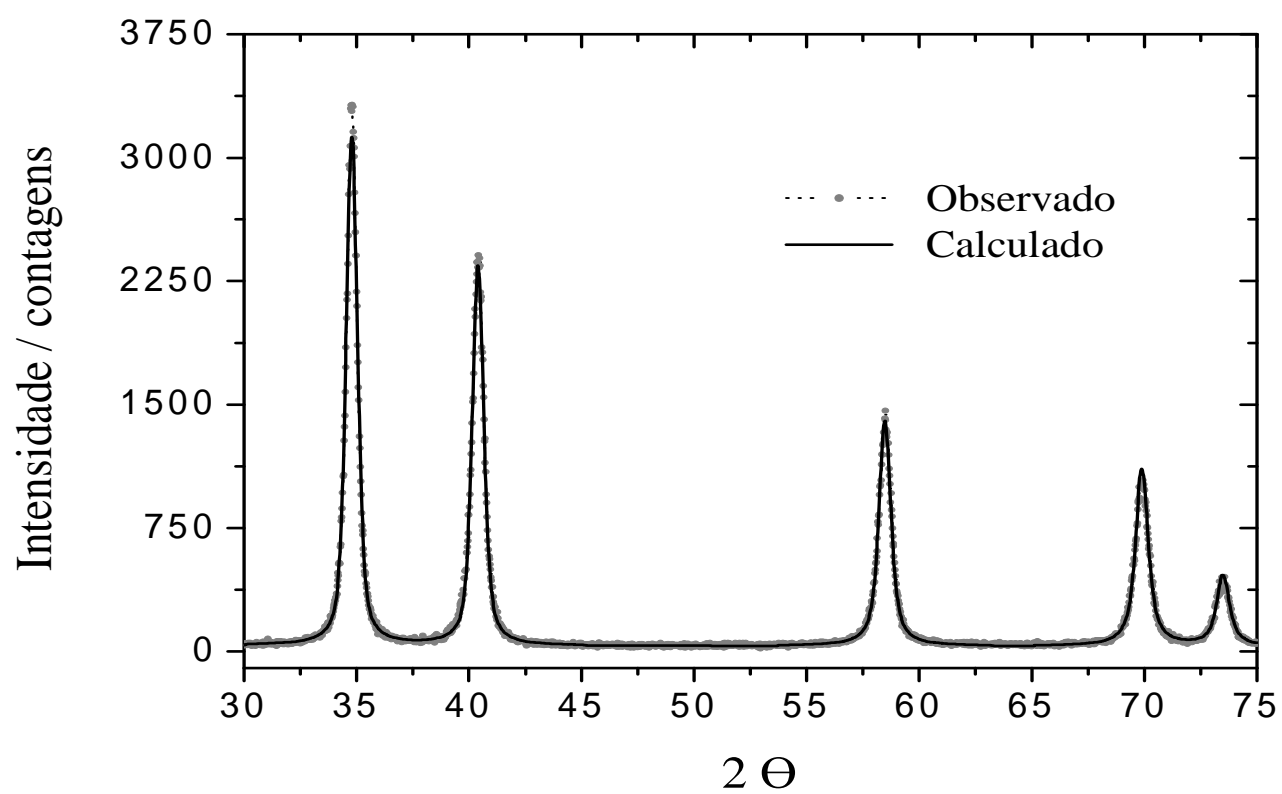

Figura 3.6 - Gráfico de Rietveld: comparação entre perfis de difração observado e calculado após o refinamento.

O valor GOF foi o índice indicador da qualidade do refinamento do método de Rietveld utilizado neste trabalho. Quanto mais satisfatório é o refinamento, mais próximo de 1 é o valor GOF (COELHO, 2007; PAIVA-SANTOS, 2009; YOUNG, 1993). De acordo com Young (1993) valores ideais do número GOF são aqueles menores ou iguais a 1,3. No entanto, deve-se ressaltar, na análise da qualidade dos refinamentos, a importância da avaliação visual da concordância entre perfis calculado e observado no gráfico de Rietveld (PAIVA-SANTOS, 2009).

Os parâmetros determinados por meio dos refinamentos do método de Rietveld, que foram utilizados nesta tese foram:

- Parâmetros microestruturais: tamanho médio de cristalito (TC); microdeformação (MD) ou deformação de rede;

- Parâmetros de rede a e $c$, e o volume da cela unitária $\left(\mathrm{V}_{\mathrm{cu}}\right)$;

- Porcentagem de material amorfo que foi utilizada para a determinação do grau de cristalinidade (GC), que é dado pela razão entre massa de material 
cristalino e massa de material total (amorfo mais cristalino). A determinação da porcentagem de material amorfo foi possível graças à mistura do padrão alumina, cuja quantidade de material amorfo é conhecida (1,96\%), à amostra.

A determinação dos parâmetros microestruturais (TC e MD) é possível devido a sua influência no alargamento dos picos de difração de raios-X. Entretanto, características instrumentais também contribuem para o alargamento dos picos. Estas características constituem particularidades do difratômetro tais como distribuição do comprimento de onda e aberrações geométricas relacionadas, por exemplo, ao tamanho de fendas e à posição do filamento do tubo. Dessa forma, é necessário separar o alargamento físico, causado pelas dimensões do cristalito e pela microdeformação, do alargamento instrumental causado pelo equipamento (BALZAR, 1999; PAIVA-SANTOS, 2009).

Neste trabalho, a remoção do alargamento instrumental foi realizada com 0 uso do padrão NIST hexaborato de lantânio ( LaB $\left._{6}-S R M-660 a\right)$. O padrão é caracterizado por possuir tamanho de cristalito e microdeformação suficientes para que haja apenas o alargamento instrumental. A varredura de raios- $X$ do padrão foi realizada nas mesmas condições utilizadas para as amostras de apatita e calcita. Uma vez definidos os valores para os parâmetros instrumentais, por meio do refinamento do padrão, estes foram considerados nos refinamentos das amostras de apatita e calcita.

\subsection{Ensaios de dissolução}

Os ensaios de dissolução das apatitas e calcitas foram realizados no reator químico Atlas Potassium (marca Syrris), cuja representação esquemática está ilustrada na Figura 3.7. O equipamento é constituído por um vaso de reação de $250 \mathrm{~mL}$ fechado com tampa desenhada de forma a permitir a entrada de quatro sensores. A agitação é promovida por agitador mecânico, cuja haste do rotor é 
verticalmente introduzida no centro do vaso de reação, o qual é envolvido por um compartimento de vidro percorrido por um óleo térmico (Julabo, JL40) proveniente do banho termostático circulante (Julabo, CF 30). A dosagem de até dois reagentes pode ser conduzida por uma bomba injetora (Syrris, ASP-020). Dois capilares de 1 $\mathrm{mm}$ (diâmetro interno), por onde passam as soluções dosadas, conectam a bomba ao vaso de reação. Um fluxômetro (AALBORG, RS 232), conectado ao cilindro de gás, é responsável pelo controle do fluxo de adição de até um gás à reação, que é introduzido por meio de um tubo de vidro de ponta porosa (Figura 3.7).

1 - Fluxômetro

2 - Rotor

3 - Capilares
4 - Tubo de entrada de gás

5 - Sensor de temperatura

6 - Eletrodo de $\mathrm{pH}$

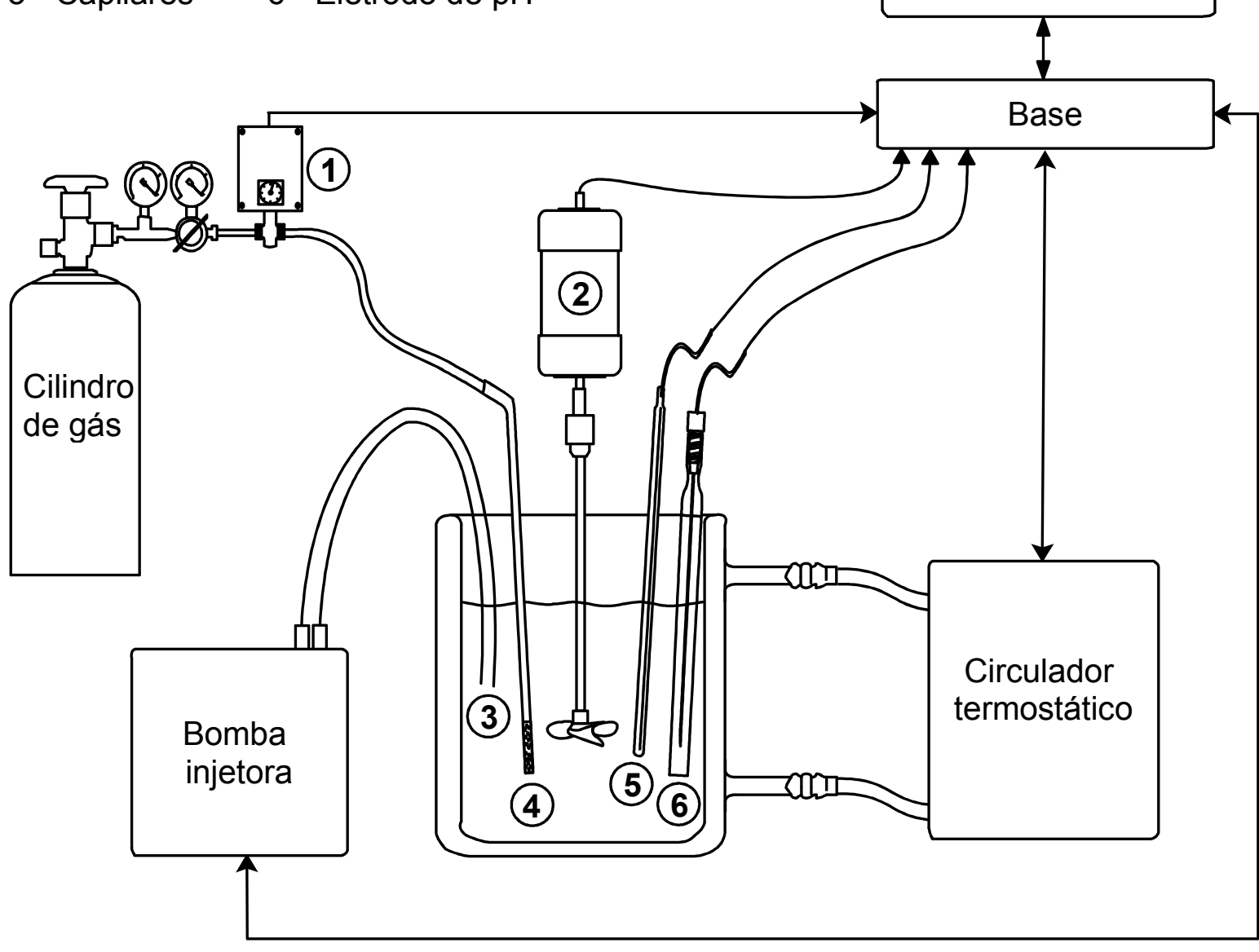

Figura 3.7 - Representação esquemática do reator Atlas Potassium utilizado nos ensaios de dissolução de apatitas e calcitas (elaboração própria). 
Deste modo, o reator permite o controle e monitoramento de $\mathrm{pH}$ e temperatura além da introdução de um gás. $\mathrm{O}$ controle de $\mathrm{pH}$ é realizado pela dosagem de soluções ácida e básica por meio da bomba injetora. O controle de temperatura, por sua vez, é executado pela circulação do óleo térmico proveniente do banho termostático no compartimento que circunda o vaso de reação. $O$ equipamento é automatizado e os comandos são transmitidos por meio do programa Atlas-Syrris.

Todos os ensaios de dissolução foram realizados com água ultra-pura (18,2 $\mathrm{M} \Omega \mathrm{cm}$ em $25^{\circ} \mathrm{C}$ ). A temperatura utilizada nos experimentos foi de $25^{\circ} \mathrm{C}$. Para $\mathrm{O}$ ajuste de $\mathrm{pH}$ foram utilizadas soluções padrão de ácido clorídrico $(\mathrm{HCl})$ e hidróxido d sódio $(\mathrm{NaOH})$ nas concentrações de 0,005 e 0,01 $\mathrm{mol} \mathrm{L}^{-1}$, pureza analítica, marca Synth. A agitação de 500 rpm foi utilizada, pois corresponde ao valor suficiente para manter os sólidos em suspensão. Os ensaios de dissolução foram conduzidos na ausência $\mathrm{CO}_{2}$, condição obtida pela constante adição de gás $\mathrm{N}_{2}$ ultra-puro a um fluxo de $100 \mathrm{~mL} \mathrm{~min}^{-1}$.

Os ensaios de dissolução foram conduzidos em três etapas representadas na Figura 3.8. A primeira etapa consistiu no ajuste da temperatura da água $(150,0 \mathrm{~mL})$ para $25^{\circ} \mathrm{C}$ durante 10 minutos. Na segunda etapa, o pH da água foi ajustado pela introdução de soluções ácida e básica, também durante 10 minutos. As concentrações e fluxos de adição das soluções de ajuste $(\mathrm{HCl}$ e $\mathrm{NaOH})$ em função do pH são exibidas na Tabela 3.9. Na segunda etapa, paralelamente ao ajuste de $\mathrm{pH}$, realizou-se a adição de $\mathrm{N}_{2}$ (Figura 3.8).

A terceira etapa consistiu na dissolução propriamente dita, que se iniciou com a adição de $1,5 \mathrm{~g}$ de apatita ou calcita ao vaso de reação. A dissolução foi acompanhada pelo controle de temperatura e adição de gás (Figura 3.8). Esta etapa difere para apatitas e calcitas como será detalhado nos parágrafos que seguem. 


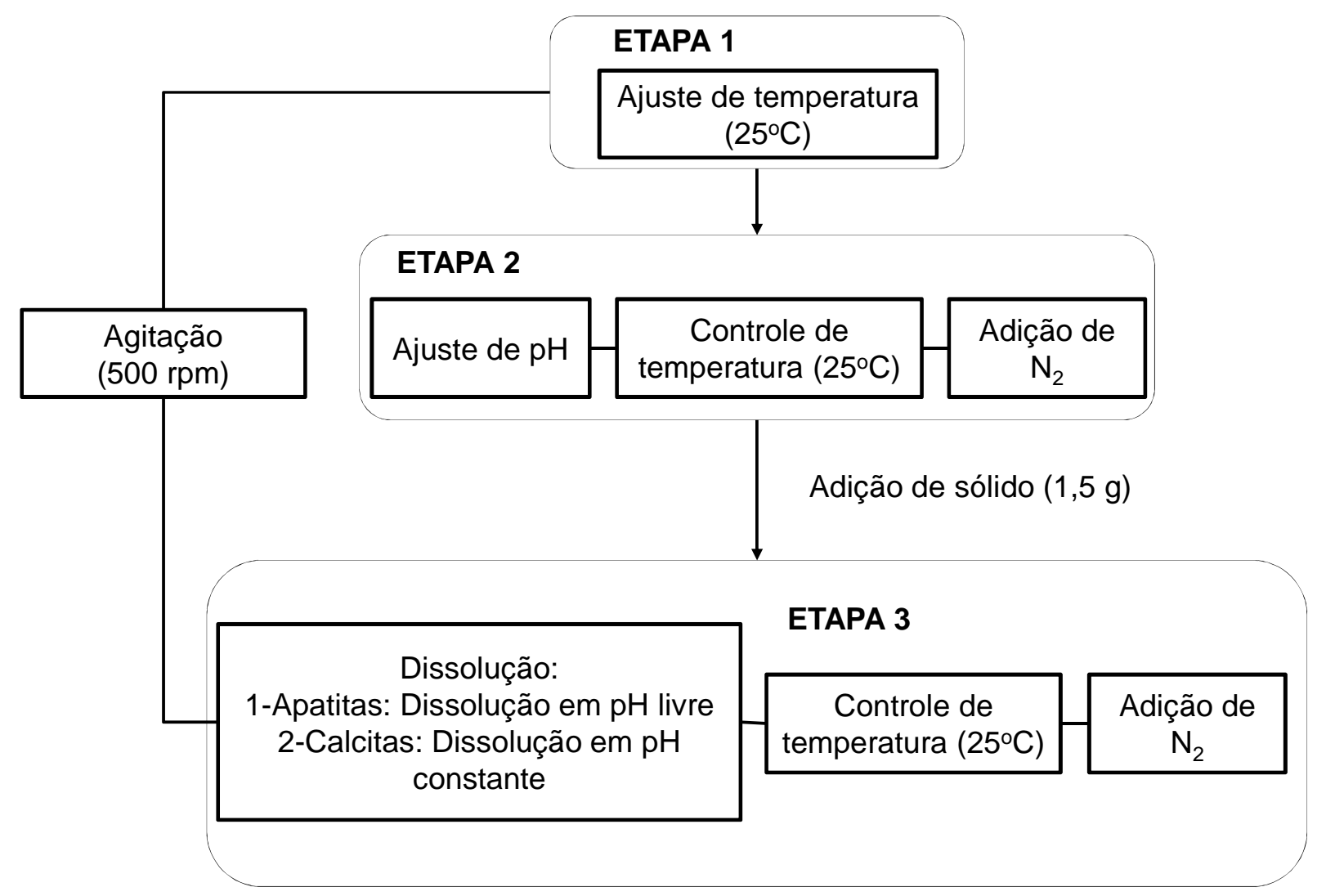

Figura 3.8 - Diagrama representativo das etapas dos ensaios de dissolução.

Tabela 3.9 - Concentrações e fluxos de adição das soluções ácida e básica utilizadas no ajuste de $\mathrm{pH}$ (Etapa 2 da Figura 3.8).

\begin{tabular}{ccc}
\hline pH & Concentração $\left(\mathbf{m o l} / \mathbf{L}^{-1}\right)$ & Fluxo de adição $\left(\mathbf{m l ~ m i n}^{-1}\right)$ \\
\hline 8 & 0,010 & 0,2 \\
\hline 10 & 0,005 & 0,4 \\
\hline
\end{tabular}

Todas as calcitas abordadas nesta tese foram submetidas aos ensaios de dissolução que foram realizados em triplicata. Os ensaios de dissolução das calcitas foram conduzidos por meio do método de pH constante (MORSE, 1974; BERNER, 1978; PLUMMER, 1976; MORSE, 1986; MORSE, ARVIDSON, 2002). Nesses ensaios, o aumento de $\mathrm{pH}$ devido à dissolução de calcita foi contraposto pela adição de solução ácida $(\mathrm{HCl})$ nas concentrações exibidas na Tabela 3.9. O fluxo de adição de solução ácida durante a dissolução foi de $6,7 \times 10^{-3} \mathrm{~cm}^{3} \mathrm{~s}^{-1}$ independentemente do 
pH. A dissolução das calcitas foi conduzida durante 40 min e os ensaios foram realizados em pH 8 e 10 (Tabela 3.9).

A quantidade em mol de íons $\mathrm{Ca}^{2+}$ dissolvidos $\left(\mathrm{nCa}^{2+} \mathrm{em} \mathrm{mol} \mathrm{cm}^{-2}\right.$ ) num determinado tempo $t$, foi calculada por meio da Equação 3.4.

$$
n C a^{2+}=\frac{V_{a c} C_{a c}}{2 A m}
$$

Em que $V_{\mathrm{ac}}$ (em L) é o volume acumulado de solução ácida adicionada, $\mathrm{C}_{\mathrm{ac}}$ (em mol L ${ }^{-1}$ ) é a concentração da solução ácida utilizada (Tabela 3.9), A (em cm $\mathrm{cg}^{-1}$ ) é a área superficial do mineral e $\mathrm{m}$ (em g) é a massa de mineral dissolvido. O fator 2 no denominador da fração da Equação 3.4 corrige a relação estequiométrica entre íons $\mathrm{Ca}^{2+}$ e H$^{+}$(Reação 2.12). A quantidade de íons $\mathrm{Ca}^{2+}$ dissolvida foi normalizada em relação à área superficial para possibilitar a comparação entre a dissolução de minerais com diferentes áreas superficiais.

No caso das apatitas, os ensaios de dissolução foram conduzidos com as amostras AAR, ACJ, AIP, ASO e ASQ. Neste caso, os ensaios foram realizados em duplicata. As demais apatitas (AAN e ATP) não foram submetidas a tais ensaios devido ao fato de a quantidade de amostra disponível não ser suficiente.

Os ensaios de dissolução de apatitas foram conduzidos em pH livre. Nestes experimentos o $\mathrm{pH}$ é ajustado antes da introdução do sólido, em seguida a dissolução ocorre sem controle de pH (CHAÏRAT et al., 2007b; HAROUIYA et al., 2007; GUIDRY; MACKENZIE, 2003). A dissolução em pH livre das apatitas foi interrompida após diferentes tempos (5, 10, 25 e 40 minutos) e a solução foi filtrada em filtro Millex HV com 0,45 $\mu \mathrm{m}$ de poro e $33 \mathrm{~mm}$ de diâmetro para a separação entre sólido e líquido. $O$ filtrado $(50 \mathrm{~mL})$ foi acidificado com ácido nítrico $\left(\mathrm{HNO}_{3}\right)$ concentrado (duas gotas), grau analítico (Synth), e em seguida, encaminhado para análise da concentração de íons $\mathrm{Ca}^{2+}$. Tal análise era conduzida por espectrometria de emissão óptica por plasma acoplado individualmente (ICP-OES, Inductively Coupled Plasma-Atomic Emission Spectrometry) no Laboratório de Fluorescência de raios-X e ICP do Departamento de Mineralogia e Geotectônica do Instituto de 
Geociências da USP. A quantidade de íons $\mathrm{Ca}^{2+}$ dissolvida das apatitas também foi normalizada em relação à área superficial das amostras, determinada por meio de porosimetria de mercúrio.

Testes de envelhecimento das amostras foram realizados por meio da repetição da análise de íons $\mathrm{Ca}^{2+}$, por ICP-OES, após 12, 24 e 48 horas decorridas do ensaio de dissolução. Observou-se que variações nas concentrações de $\mathrm{Ca}^{2+}$ ocorriam após 24 horas da coleta das soluções de dissolução. Dessa forma, as análises de ICP-OES foram realizadas em no máximo 24 horas após os ensaios. A concentração de íons $\mathrm{Ca}^{2+}$ no reator antes da adição de sólido $(\mathrm{t}=0$ ) era nula de acordo com análise por ICP-OES conduzida na água ultra-pura. Concentração de íons $\mathrm{Ca}^{2+}$ nula também foi encontrada nas soluções de ajuste de $\mathrm{pH}(\mathrm{HCl}$ e $\mathrm{NaOH})$ e na água ultra-pura passada pelo filtro Millex HV.

O fato de a dissolução de calcitas e apatitas ter sido determinada por metodologias experimentais diferentes não invalida as discussões geradas por este trabalho, uma vez que o objetivo é comparar o comportamento de minerais de diferentes origens entre si (calcitas entre si e apatitas entre si), e não, comparar diferentes minerais (calcitas com apatitas). O motivo por ter-se utilizado o método do $\mathrm{pH}$ constante, em detrimento das análises de ICP-OES, para o estudo da dissolução das calcitas foi a tentativa de se adotar uma técnica de análise rápida e de baixo custo. Além destas vantagens, o método de $\mathrm{pH}$ constante fornece uma grande quantidade de pontos em função do tempo, o que facilita o tratamento matemático dos dados.

Os resultados dos ensaios de dissolução são as curvas de variação da quantidade acumulada de íons $\mathrm{Ca}^{2+}$ dissolvidos $\left(\mathrm{mol} \mathrm{cm}^{-2}\right)$ em relação ao tempo $(\mathrm{t})$, denominadas curva de dissolução. Estas curvas exibiram perfil exponencial para todos os ensaios realizados, como se observa na Figura 3.9, o que está de acordo com uma reação de primeira ordem em relação aos íons $\mathrm{Ca}^{2+}$. Tais curvas foram ajustadas à Equação 3.5, o que permitiu o cálculo da quantidade máxima de íons $\mathrm{Ca}^{2+}$ dissolvida $\left(\mathrm{Ca}^{2+}{ }_{\mathrm{MAX}}\right)$, bem como da constante cinética $(\mathrm{k})$.

$$
n C a^{2+}=C a_{M A X}^{2+}\left(1-e^{-k t}\right)
$$


O parâmetro $\mathrm{Ca}^{2+}$ MAX informa a quantidade de íons $\mathrm{Ca}^{2+}$ dissolvida após 0 alcance do estado estacionário, que corresponde ao patamar da curva de dissolução (Figura 3.9). A constante cinética, por sua vez, expressa quão rapidamente o estado estacionário é atingido.

A velocidade de dissolução de íons $\mathrm{Ca}^{2+}$ é dada pela variação da quantidade de íons $\mathrm{Ca}^{2+}$ acumulada com o tempo de reação $\left(\mathrm{dCa}{ }^{2+} / \mathrm{dt}\right)$. Esta velocidade diminui na medida em que a dissolução prossegue e o estado estacionário se aproxima (Figura 3.9). A curva de dissolução foi dividida em duas etapas caracterizadas por velocidades de dissolução constantes, mas de diferentes magnitudes como observado na Figura 3.9. Ambas as etapas são caracterizadas por um segmento de reta na curva de dissolução, cuja inclinação corresponde à velocidade de dissolução.

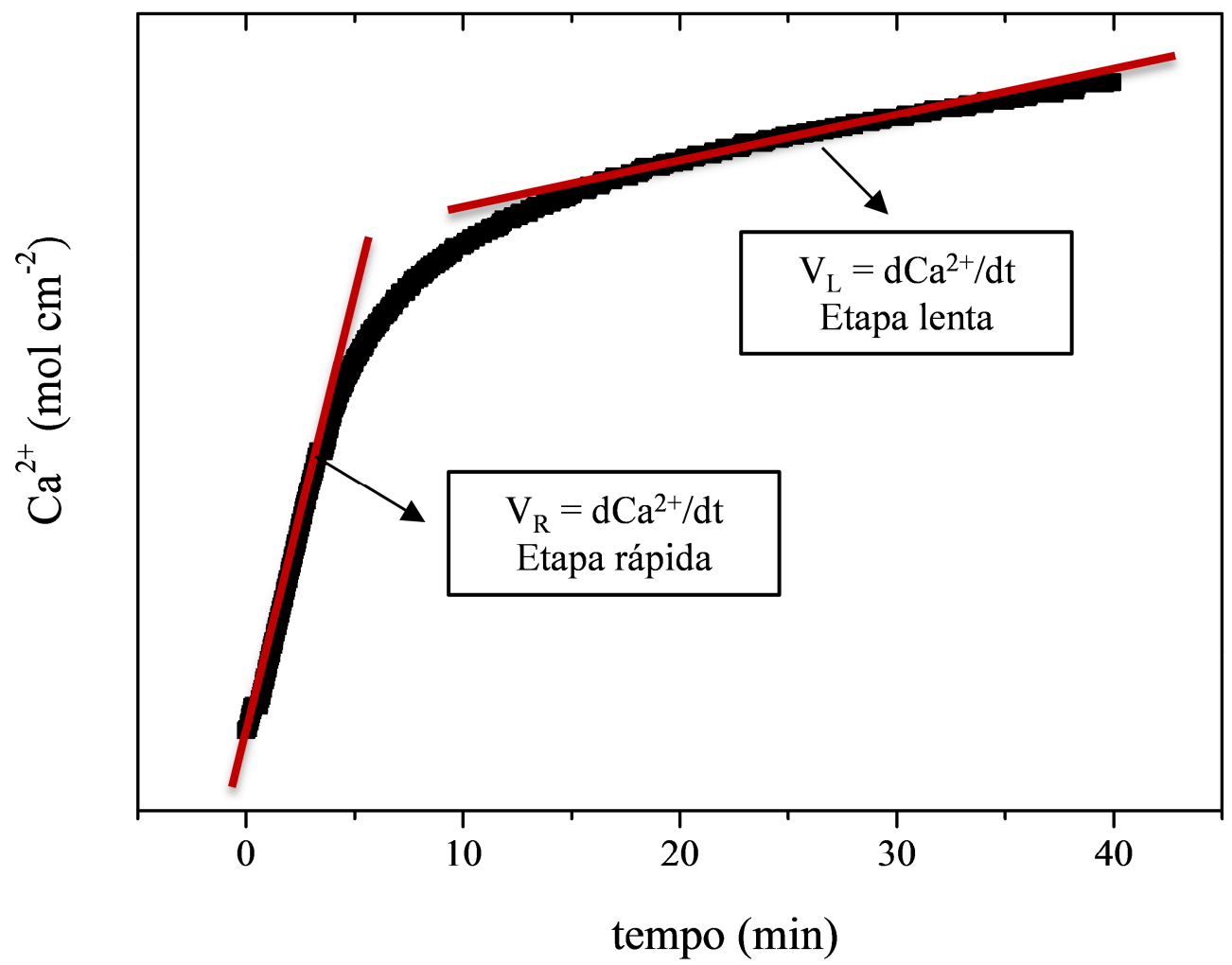

Figura 3.9 - Representação das velocidades de dissolução calculadas a partir do gráfico de dissolução.

A primeira etapa de dissolução ocorre durante os primeiros minutos de ensaio em que a dissolução é muito rápida. A velocidade determinada nesta etapa é identificada como Velocidade na etapa rápida $\left(V_{R}\right)$. A segunda etapa é caracterizada 
por um segmento de reta com menor inclinação correspondendo, portanto, à dissolução mais lenta (Figura 3.8). A velocidade de dissolução da segunda etapa é identificada como Velocidade na etapa lenta $\left(\mathrm{V}_{\mathrm{L}}\right)$.

A Tabela 3.10 contém um resumo dos parâmetros de dissolução determinados a partir das curvas de dissolução.

Tabela 3.10 - Parâmetros de dissolução.

\begin{tabular}{ccc}
\hline $\begin{array}{c}\text { Parâmetro de } \\
\text { dissolução }\end{array}$ & Significado & Unidade \\
\hline $\mathrm{Ca}^{2+}{ }_{\mathrm{MAX}}$ & $\begin{array}{c}\text { Quantidade de íons } \mathrm{Ca}^{2+} \text { dissolvido no estado } \\
\text { estacionário. }\end{array}$ & $\mathrm{mol} \mathrm{cm}^{-2}$ \\
\hline $\mathrm{k}$ & $\begin{array}{c}\text { Constante cinética que pode ser interpretada } \\
\text { como quão rapidamente o estado estacionário é } \\
\text { atingido. }\end{array}$ & $\mathrm{s}^{-1}$ \\
\hline $\mathrm{V}_{\mathrm{R}}$ & $\begin{array}{c}\text { Velocidade de dissolução dada pela inclinação } \\
\text { da curva de Ca }{ }^{2+}=\mathrm{f}(\mathrm{t}) \text { na etapa rápida. }\end{array}$ & $\mathrm{mol} \mathrm{s}^{-1} \mathrm{~cm}^{-2}$ \\
\hline $\mathrm{V}_{\mathrm{L}}$ & $\begin{array}{r}\text { Velocidade de dissolução dada pela inclinação } \\
\text { da curva de } \mathrm{Ca}^{2+}=\mathrm{f}(\mathrm{t}) \text { na etapa lenta. }\end{array}$ & $\mathrm{mol} \mathrm{s}^{-1} \mathrm{~cm}^{-2}$ \\
\hline
\end{tabular}

\subsection{Ensaios de microflotação}

A resposta dos minerais à flotação foi determinada por meio de ensaios de microflotação realizados em aparato experimental que está representado na Figura 3.10. Os ensaios foram conduzidos em uma micro célula de flotação com forma e geometria (diâmetro de $32,2 \mathrm{~cm}$ e altura de 92,2 $\mathrm{mm}$ ) que se assemelham ao tradicional tubo de Hallimond. A agitação de 1.380 rpm foi promovida por agitador mecânico com controlador de velocidade conectado a um impelidor de 1,3 mm (Figura 3.10). 
Todos os ensaios de microflotação foram realizados em triplicata e as soluções preparadas com água ultra-pura $\left(18,2 \mathrm{M} \Omega \mathrm{cm}\right.$ em $\left.25^{\circ} \mathrm{C}\right)$. Os valores de $\mathrm{pH}$ das soluções foram inicialmente ajustados para 8 e 10 com soluções de $\mathrm{NaOH}$ e $\mathrm{HCl}$ (padronizadas, marca Synth). A temperatura das soluções foi ajustada para $25^{\circ} \mathrm{C} \mathrm{em}$ banho-maria. Como agente coletor utilizou-se oleato de sódio preparado a partir da saponificação de ácido oleico com $\mathrm{NaOH}$, ambos grau analítico (Synth). As concentrações de oleato de sódio utilizadas nos ensaios de microflotação de apatitas e calcitas foram de $1,42 \times 10^{-5}$ e $7,11 \times 10^{-6} \mathrm{~mol} \mathrm{~L}^{-1}$, respectivamente.

Cada ensaio de microflotação foi iniciado pelo o condicionamento de $1,0 \mathrm{~g}$ de mineral com $60 \mathrm{~mL}$ de solução de oleato de sódio, na concentração desejada, durante 1 minuto. Em seguida, a flotação foi conduzida também por 1 minuto, por meio da adição de $\mathrm{N}_{2}$ ultra-puro a um fluxo de $50,0 \mathrm{~mL} \mathrm{~min}^{-1}$, controlado por um fluxômetro (AALBORG, RS 232). Durante a flotação a micro célula foi alimentada com solução do agente coletor por meio de uma bureta, e o sólido flutuado foi removido por uma pá. Os produtos de flotação (flutuado e afundado) foram, então, filtrados e secos a $40^{\circ} \mathrm{C}$. Após a secagem, a massa dos produtos foi medida para 0 cálculo da flotabilidade (F) de acordo com a Equação 3.6.

$$
F=\frac{m_{F L}}{m_{F L}+m_{A F}}
$$

Em que $m_{F L}$ e $m_{A F}$ são as massas do flutuado e do afundado, respectivamente. 
1 - Fluxômetro (AALBORG, RS 232)

2 - Agitador Mecânico

3 - Rotor

4 - Microcélula de Flotação

5 - Bureta de alimentação do reagente de flotação

6 - Pá de retirada do material flutuado

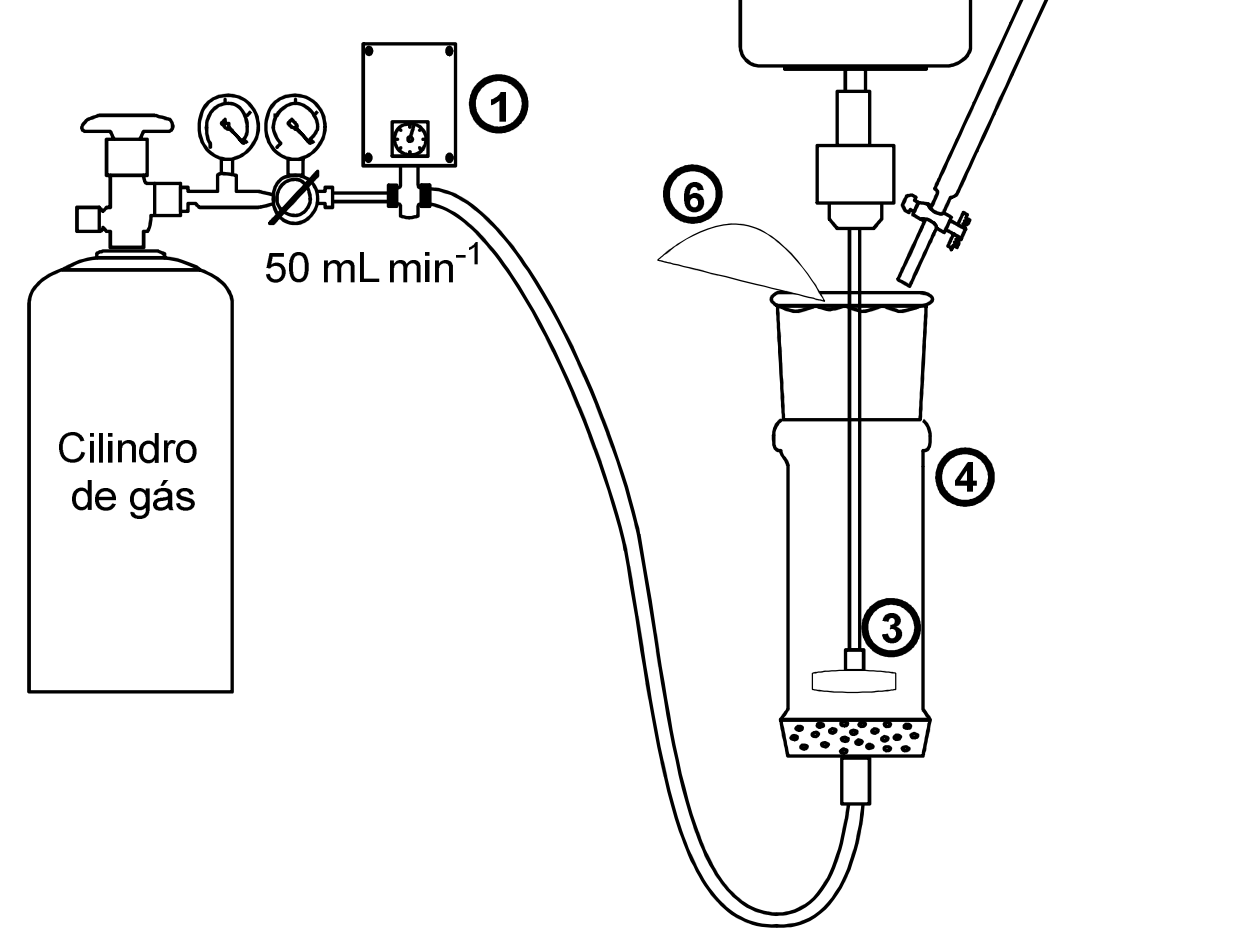

Figura 3.10 - Representação esquemática do aparato experimental utilizado nos ensaios de microflotação (elaboração própria).

\subsection{Tratamento dos resultados}

Para verificar se existe relação de causa-efeito entre características intrínsecas (parâmetros de rede, de cristalinidade e físicos) das apatitas e calcitas, sua cinética de dissolução e flotabilidade, os resultados foram tratados por meio de correlações lineares simples e múltiplas no programa Statistica 8.0. 


\section{Capítulo 4}

\section{Resultados e Discussão}

Neste capítulo são apresentados e discutidos os resultados obtidos nos experimentos conduzidos com as amostras de apatita e calcita. A caracterização dos minerais é exibida na Seção 4.1. Em seguida, os resultados dos estudos de cristalinidade (Seção 4.2), dissolução (Seção 4.3) e flotação (Seção 4.4) são analisados. Finalmente, na Seção 4.5, faz-se uma análise das relações de causa e efeito entre flotabilidade, dissolução e características intrínsecas (parâmetros de rede, de cristalinidade e físicos) dos minerais. 


\subsection{Caracterização das amostras de apatita e calcita}

Amostras de apatita e calcita (Figura 4.1) de diversas origens e gêneses (ígnea, sedimentar e metamórfica) foram caracterizadas quanto a sua composição química (por meio de FRX, WDS/EDS e FTIR) e parâmetros físicos (densidade, área superficial, porosidade). Uma vez que todas as amostras são de origem natural, nenhuma delas apresenta $100 \%$ da fase de interesse (apatita ou calcita) porque algumas impurezas não são passíveis de remoção pelos processos físicos empregados para a sua concentração (separação por densidade e/ou susceptibilidade magnética). O teor dos concentrados utilizados corresponde, assim, ao máximo que foi possível de ser alcançado após sucessivas etapas de purificação.

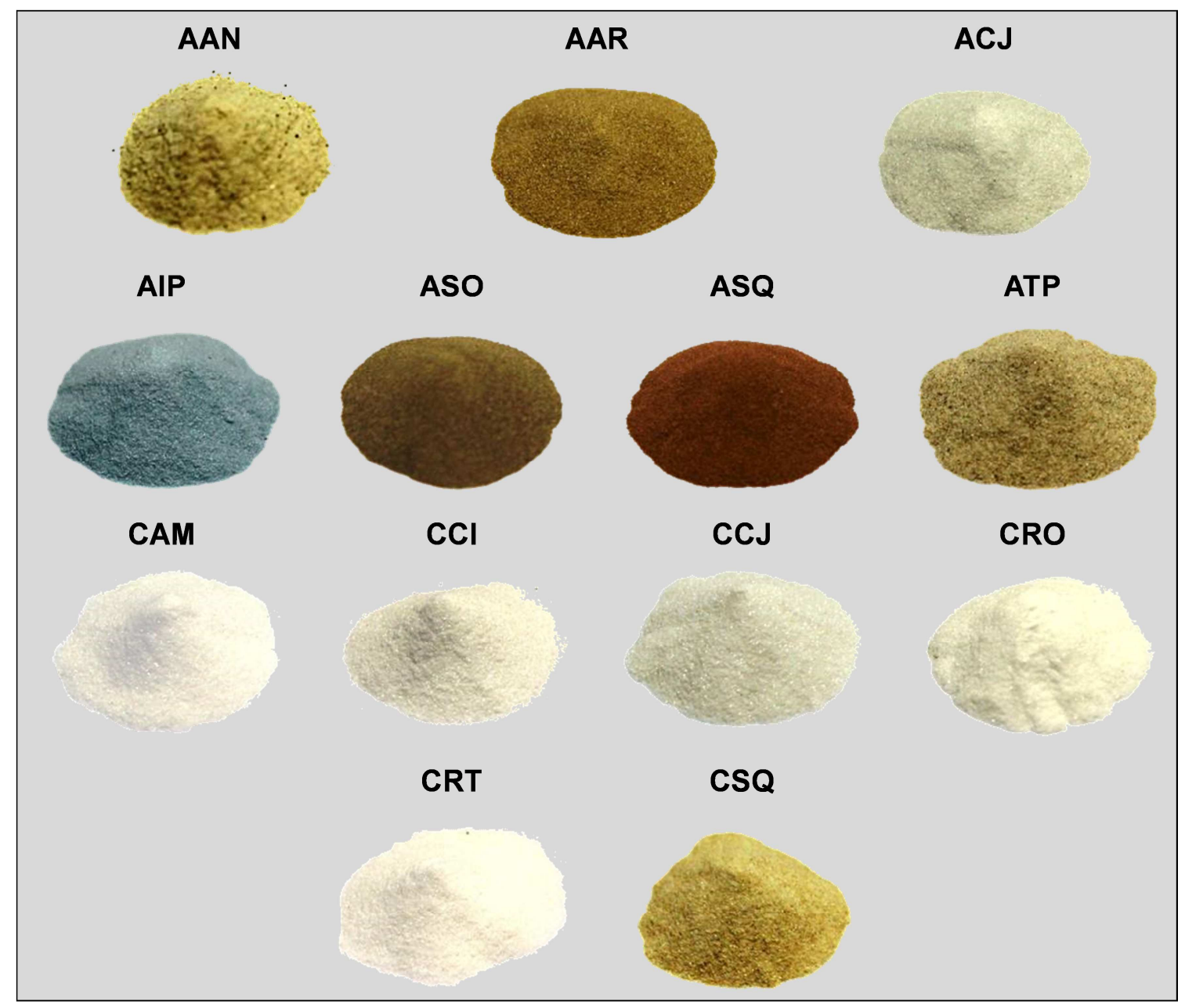

Figura 4.1 - Imagem dos minerais utilizados, na forma de pó (entre 103 e 43 m). 


\subsubsection{Caracterização das apatitas}

Nas Tabelas 4.1 e 4.2 são apresentados os resultados das análises químicas das apatitas por FRX e WDS/EDS, respectivamente. Na Figura 4.2 estão ilustradas as imagens de MEV de uma das partículas analisadas por WDS/EDS para cada amostra, selecionadas para compor esta seção. Exemplos de espectros das análises mistas WDS/EDS e as demais imagens das partículas analisadas são encontrados no Apêndice A.

As análises de FRX (Tabela 4.1) são realizadas com um grupo de partículas, portanto, os elementos identificados podem pertencer tanto à apatita como às partículas de impurezas remanescentes. Sendo assim, os resultados apresentados na Tabela 4.1 indicam que:

- A impureza mais evidente na composição química do concentrado AAN é a sílica $\left(1,1 \%\right.$ de $\left.\mathrm{SiO}_{2}\right)$, indicando a possível ocorrência de silicatos;

- O concentrado AAR se destaca pelo conteúdo de $\mathrm{BaO}(3,7 \%)$ e $\mathrm{SO}_{3}(2,1 \%)$, provavelmente relacionado à presença de barita $\left(\mathrm{BaSO}_{4}\right)$. A perda ao fogo (PF $=1,2 \%$ ) sugere a presença de carbonatos;

- A ACJ é a amostra mais pura, segundo as análises de FRX, apresentando apenas traços de $\mathrm{SrO}(0,4 \%)$;

- $\mathrm{Na}$ apatita AIP o valor de $0,6 \%$ de PF, acompanhado de relação $\mathrm{CaO} / \mathrm{P}_{2} \mathrm{O}_{5}$ de 1,38 sugere contaminação por calcita;

- O concentrado ASQ se destaca dos demais por apresentar elevado teor de $\mathrm{Fe}_{2} \mathrm{O}_{3}(3,2 \%)$, que será mais adequadamente abordado após a discussão dos resultados exibidos na Tabela 4.2. Além disso, esta amostra exibe elevado conteúdo de $\mathrm{SiO}_{2}(2,1 \%)$, valor elevado de $\mathrm{PF}(1,9 \%)$, e relação $\mathrm{CaO} / \mathrm{P}_{2} \mathrm{O}_{5}$ de 1,36. Tais valores indicam a presença de silicatos e calcita;

- A ASO apresenta o maior valor de PF $(7,4 \%)$, o que sugere a contaminação por carbonatos ou substituição de $\mathrm{PO}_{4}{ }^{-3}$ por $\mathrm{CO}_{3}{ }^{2-}$ na estrutura da apatita.

- O concentrado ATP exibe teor de $\mathrm{SiO}_{2}$ de 1,2\%, acompanhado de baixos teores de $\mathrm{Al}_{2} \mathrm{O}_{3}(<0,1 \%)$ e $\mathrm{MgO}(<0,1 \%)$, o que sugere a presença de quartzo e não de outros silicatos. 
Tabela 4.1 - Análise química das apatitas por FRX.

\begin{tabular}{|c|c|c|c|c|c|c|c|}
\hline $\begin{array}{l}\text { Espécie } \\
\text { Química }\end{array}$ & AAN & $\operatorname{AAR}^{(*)}$ & ACJ & AIP & ASQ & ASO & ATP \\
\hline $\mathrm{Na}_{2} \mathrm{O}$ & 0,3 & $<0,1$ & $<0,1$ & $<0,1$ & 0,6 & 0,6 & 0,2 \\
\hline $\mathrm{MgO}$ & $<0,1$ & 0,1 & $<0,1$ & $<0,1$ & 0,1 & 0,4 & $<0,1$ \\
\hline $\mathrm{Al}_{2} \mathrm{O}_{3}$ & $<0,1$ & $<0,1$ & $<0,1$ & $<0,1$ & 0,1 & $<0,1$ & $<0,1$ \\
\hline $\mathrm{SiO}_{2}$ & 1,1 & 0,5 & $<0,1$ & 1,6 & 2,1 & 0,9 & 1,2 \\
\hline $\mathrm{P}_{2} \mathrm{O}_{5}$ & 40,2 & 37,2 & 42,3 & 39,4 & 38,7 & 35,5 & 39,6 \\
\hline $\mathrm{SO}_{3}$ & $<0,1$ & 2,1 & $<0,1$ & 0,6 & 0,4 & 0,5 & 0,1 \\
\hline $\mathrm{K}_{2} \mathrm{O}$ & $<0,1$ & $<0,1$ & $<0,1$ & $<0,1$ & $<0,1$ & $<0,1$ & $<0,1$ \\
\hline $\mathrm{CaO}$ & 53,2 & 50,8 & 55,4 & 54,4 & 52,6 & 52,9 & 53,3 \\
\hline $\mathrm{TiO}_{2}$ & $<0,1$ & $<0,1$ & $<0,1$ & $<0,1$ & $<0,1$ & $<0,1$ & 0,3 \\
\hline $\mathrm{MnO}$ & $<0,1$ & $<0,1$ & $<0,1$ & $<0,1$ & $<0,1$ & $<0,1$ & $<0,1$ \\
\hline $\mathrm{Fe}_{2} \mathrm{O}_{3}$ & 0,3 & 0,4 & $<0,1$ & $<0,1$ & 3,2 & 0,2 & 0,4 \\
\hline $\mathrm{SrO}$ & 0,5 & 0,9 & 0,4 & $<0,1$ & 0,3 & 0,2 & 0,8 \\
\hline $\mathrm{PF}^{(*)}$ & 0,2 & 1,2 & 0,3 & 0,6 & 1,9 & 7,4 & 0,4 \\
\hline $\mathrm{CaO} / \mathrm{P}_{2} \mathrm{O}_{5}$ & 1,32 & 1,37 & 1,31 & 1,38 & 1,36 & 1,49 & 1,35 \\
\hline
\end{tabular}

(*) $\mathrm{PF}=$ Perda de fogo

$\left.{ }^{* *}\right)$ AAR também contém $\mathrm{BaO}$, cujo teor é de 3,7\%. 
As análises por WDS/EDS (Tabela 4.2) são realizadas em regiões selecionadas das partículas observadas ao microscópio eletrônico de varredura. Nesta análise mista (WDS/EDS), os elementos mais importantes para a caracterização de cada mineral foram analisados por WDS, enquanto os demais foram analisado por EDS. Na Tabela 3.7 (Capítulo 3) encontram-se discriminados os elementos analisados por cada tipo de detector. A escolha da análise mista se deve ao fato de a análise por WDS demandar tempo, durante o qual pode ocorrer a fusão da região analisada da amostra e sua consequente degradação. Assim, o número de elementos analisados por WDS foi limitado por este cuidado.

Os resultados referentes ao conteúdo de $\mathrm{F}$ e Cl, apresentados na Tabela 4.2, são provenientes de análise elementar, enquanto os demais resultados estão expressos na forma de óxidos para possibilitar a comparação entre FRX (Tabela 4.1) e WDS/EDS (Tabela 4.2). Os resultados exibidos na Tabela 4.4 são valores médios (média aritmética de aprox. 5 análises), cujos valores mínimos e máximos correspondentes são encontrados no Apêndice A. A respeito das análises por WDS/EDS, é importante ressaltar que:

- Todas as apatitas são portadoras de flúor, seja em maior $(5,8 \%)$ ou menor $(1,6 \%)$ extensão. Deste modo, elas podem ser classificadas como fluorapatitas;

- As apatitas AAN e ACJ apresentam composição semelhante, caracterizada por teor de $\mathrm{SiO}_{2}$ de $0,5 \%$, e $\mathrm{SrO}$ na faixa de $0,4-0,5 \%$. A relação $\mathrm{CaO} / \mathrm{P}_{2} \mathrm{O}_{5}$ de 1,27-1,29 é inferior à estequiométrica (1,31) apontada por Dana (1969) e também por Betejtin (1977), possivelmente devido à substituição de Ca por Sr;

- A apatita AAR apresenta o maior conteúdo de $\mathrm{SrO}$ (1,0\%), acompanhado de 0,5\% de $\mathrm{SiO}_{2}$. A relação $\mathrm{CaO} / \mathrm{P}_{2} \mathrm{O}_{5}$ de 1,26 está muito abaixo da estequiométrica, sugerindo substituição do Ca pelo $\mathrm{Sr}$ ou de $\mathrm{PO}_{4}{ }^{2-}$ por outros ânions;

- A apatita AIP apresenta o menor teor de $\mathrm{P}_{2} \mathrm{O}_{5}(40,1 \%)$ do que AAR, ACJ e AAN, e maior conteúdo de $\mathrm{SiO}_{2}(0,8 \%)$. Esta apatita é a mais rica em cloro $(0,3 \%)$ entre todas as amostras abordadas nesta tese; 
Tabela 4.2 - Análise química das apatitas por WDS/EDS.

\begin{tabular}{|c|c|c|c|c|c|c|c|c|}
\hline $\begin{array}{l}\text { Espécie } \\
\text { Química }\end{array}$ & AAN & AAR & ACJ & AIP & $\mathbf{A S Q} \mathbf{Q}^{(*)}$ & ASO-1 & ASO-2 & ATP \\
\hline $\mathrm{F}$ & 2,1 & 2,5 & 1,6 & 3,0 & 3,4 & 5,7 & 5,8 & 2,0 \\
\hline $\mathrm{Cl}$ & $<0,1$ & $<0,1$ & $<0,1$ & 0,3 & $<0,1$ & $<0,1$ & 0,1 & $<0,1$ \\
\hline $\mathrm{Na}_{2} \mathrm{O}$ & 0,2 & 0,1 & 0,2 & 0,1 & 0,5 & 0,5 & 0,6 & 0,1 \\
\hline $\mathrm{MgO}$ & $<0,1$ & $<0,1$ & $<0,1$ & $<0,1$ & $<0,1$ & 0,3 & 0,2 & 0,1 \\
\hline $\mathrm{Al}_{2} \mathrm{O}_{3}$ & 0,1 & $<0,1$ & 0,1 & 0,1 & 0,3 & 0,3 & 0,2 & $<0,1$ \\
\hline $\mathrm{SiO}_{2}$ & 0,5 & 0,5 & 0,5 & 0,8 & 2,1 & 1,1 & 0,6 & 1,0 \\
\hline $\mathrm{P}_{2} \mathrm{O}_{5}$ & 42,1 & 42,4 & 42,8 & 40,1 & 39,2 & 35,9 & 35,9 & 41,4 \\
\hline $\mathrm{SO}_{3}$ & $<0,1$ & 0,1 & 0,1 & 0,4 & 0,2 & 1,3 & 1,0 & 0,1 \\
\hline $\mathrm{K}_{2} \mathrm{O}$ & $<0,1$ & $<0,1$ & $<0,1$ & $<0,1$ & $<0,1$ & $<0,1$ & $<0,1$ & $<0,1$ \\
\hline $\mathrm{CaO}$ & 54,5 & 53,3 & 54,3 & 55,0 & 51,8 & 54,5 & 54,0 & 54,5 \\
\hline $\mathrm{TiO}_{2}$ & $<0,1$ & $<0,1$ & $<0,1$ & $<0,1$ & 0,1 & 0,1 & $<0,1$ & $<0,1$ \\
\hline $\mathrm{MnO}$ & $<0,1$ & $<0,1$ & $<0,1$ & $<0,1$ & $<0,1$ & $<0,1$ & $<0,1$ & $<0,1$ \\
\hline $\mathrm{Fe}_{2} \mathrm{O}_{3}$ & 0,1 & 01 & $<0,1$ & $<0,1$ & 2,1 & 0,5 & 0,5 & $<0,1$ \\
\hline SrO & 0,5 & 1,0 & 0,4 & $<0,1$ & 0,3 & 0,3 & 0,1 & 0,9 \\
\hline $\mathrm{CaO} / \mathrm{P}_{2} \mathrm{O}_{5}$ & 1,29 & 1,26 & 1,27 & 1,34 & 1,32 & 1,52 & 1,54 & 1,32 \\
\hline $\mathrm{F} / \mathrm{P}_{2} \mathrm{O}_{5}$ & 0,05 & 0,06 & 0,04 & 0,08 & 0,09 & 0,16 & 0,16 & 0,05 \\
\hline
\end{tabular}

(*) ASQ contém $\mathrm{UO}_{2}$, cujo teor é de $0,3 \%$ 
- Os altos teores de $\mathrm{Fe}_{2} \mathrm{O}_{3}(2,1 \%), \mathrm{SiO}_{2}(2,1 \%), \mathrm{Na}_{2} \mathrm{O}(0,5 \%)$ e $\mathrm{Al}_{2} \mathrm{O}_{3}(0,3 \%)$ fazem com que as partículas da apatita $A S Q$ se destaquem com relação às demais. Além disso, a ASQ contém urânio em sua estrutura cristalina $\left(\mathrm{UO}_{2}=\right.$ $0,3 \%)$.

- Quando se analisou a apatita ASO foi possível identificar dois tipos de partículas (Figura 4.2): um mais escuro (ASO-1) e outro mais claro (ASO-2), cuja composição química foi analisada individualmente. $\mathrm{O}$ que diferencia tais partículas é o fato de a ASO-1 conter mais $\mathrm{MgO}(0,3 \%$ versus $0,2 \%), \mathrm{Al}_{2} \mathrm{O}_{3}$ $(0,3 \%$ versus $0,2 \%)$ e $\mathrm{SiO}_{2}(1,1 \%$ versus $0,6 \%)$;

- A apatita ASO exibe o menor teor de $\mathrm{P}_{2} \mathrm{O}_{5}(35,9 \%)$ e o maior teor de flúor $\left(\mathrm{F} / \mathrm{P}_{2} \mathrm{O}_{5}=0,16\right)$, se comparada às demais. Esta apatita também apresenta a relação $\mathrm{CaO} / \mathrm{P}_{2} \mathrm{O}_{5}$ mais alta $(1,52-1,54)$.

- Partículas da apatita ATP exibem alto conteúdo de $\mathrm{SiO}_{2}(1,0 \%)$ e $\mathrm{SrO}(0,9 \%)$. A relação $\mathrm{CaO} / \mathrm{P}_{2} \mathrm{O}_{5}$ aproxima-se do valor estequiométrico $(1,32)$.

Os valores teóricos para $\% \mathrm{CaO}$ e $\% \mathrm{P}_{2} \mathrm{O}_{5}$ na fluorapatita são de $55,6 \%$ e $42,3 \%$, respectivamente, cuja razão $\mathrm{CaO} / \mathrm{P}_{2} \mathrm{O}_{5}$ resulta em 1,31 (DANA, 1969). No entanto, as várias substituições possíveis (Seção 2.5.1) conduzem a modificações nestes valores observados na Tabela 4.2. (BORN; LENHARO; KAHN, 1996; McCLELLAN, 1980; TOLEDO et al., 2004; TOLEDO; PEREIRA, 2001). O teor de $\mathrm{P}_{2} \mathrm{O}_{5}$ das apatitas ígneas abordadas por esta tese são superiores aos da sedimentar (ASO) e metamórfica (ASQ). Nas apatitas ígneas, o teor de $\mathrm{P}_{2} \mathrm{O}_{5}$ varia de um valor mínimo de 40,1\% (na amostra AIP) a um valor máximo de 42,8\% (na amostra ACJ) como observado na Tabela 4.2. A apatita sedimentar (ASO) exibe o menor teor de $\mathrm{P}_{2} \mathrm{O}_{5}(35,9 \%)$, provavelmente devido à substituição de íons $\mathrm{PO}_{4}{ }^{3-}$ por $\mathrm{CO}_{3}{ }^{2-}$. Já a apatita metamórfica (ASQ) apresenta um valor intermediário $(39,2 \%)$ de teor de $\mathrm{P}_{2} \mathrm{O}_{5}$.

A análise de MEV (Figura 4.2) permite comparar as amostras no que diz respeito ao aspecto da superfície de suas partículas. Nesta abordagem, observa-se que as apatitas de gênese ígnea (AAR, ACJ, AIP, ATP) apresentam superfícies aparentemente lisas e uniformes. A apatita metamórfica (ASQ), por outro lado, exibe superfície mais heterogênea, que parece conter inclusões de outras fases. Conforme comentado anteriormente, a apatita sedimentar ASO é composta por partículas de 
dois tipos que diferem no que diz respeito às características superficiais e à composição química. O primeiro tipo de partícula, denominada ASO-1, é mais escura e apresenta rugosidade superficial mais pronunciada, enquanto ASO-2 tem cor mais clara e superfície menos rugosa.

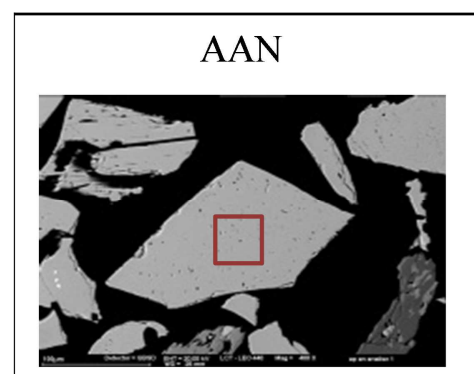

ACJ

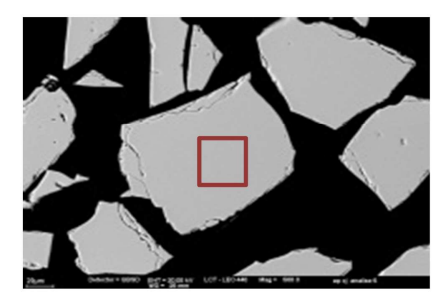

ASQ

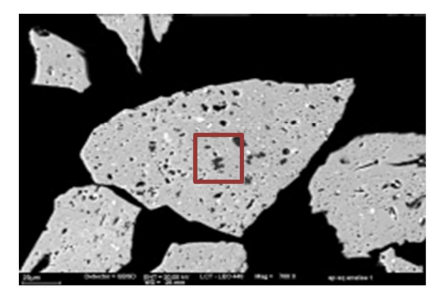

ASO-2

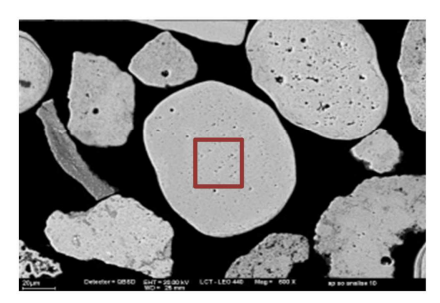

AAR

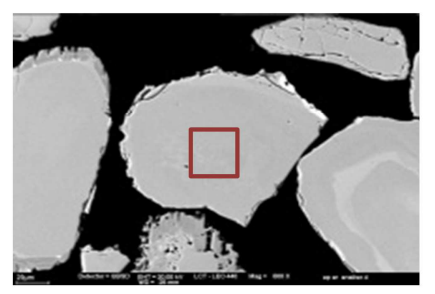

AIP

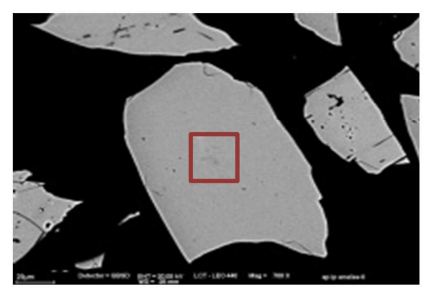

ASO-1

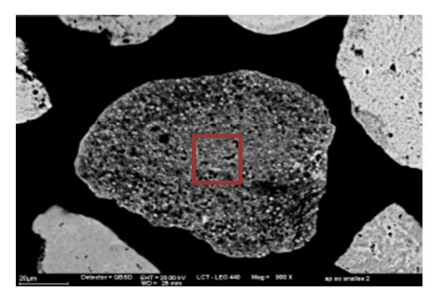

ATP

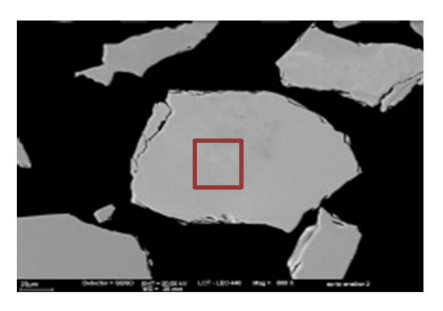

Figura 4.2 - Imagens de MEV com exemplos de partículas de apatitas analisadas por WDS/EDS. O quadro vermelho indica o local da análise.

Uma comparação entre o teor de flúor das apatitas contempladas por este estudo (Tabela 4.2), com aqueles reportados por outros autores para amostras de mesma origem, é apresentada na Tabela 4.3. De acordo com tal comparação, os 
teores de flúor obtidos neste trabalho estão dentro da faixa reportada pela literatura (Tabela 4.3).

Tabela 4.3 - Teores de flúor determinados nesta tese e reportados por trabalhos da literatura para apatitas de mesma origem.

\begin{tabular}{cccc}
\hline & \multicolumn{2}{c}{ Teor de flúor } & \\
\cline { 2 - 3 } Apatita & Tabela 4.2 & Literatura & \\
\cline { 2 - 4 } & 2,1 & $1,8-2,2$ & Ferrari (2000) \\
\hline AAN & 2,5 & $1,9-3,1$ & Lenharo (1994) \\
\hline AAR & 1,6 & $1,5-2,0$ & Lenharo (1994) \\
\hline ACJ & & & Lenharo (1994) \\
\hline ATP & 2,0 & $1,2-1,7$ & Ferrari (2000) \\
\hline
\end{tabular}

A pureza dos concentrados de apatita foi estimada por análise semiquantitativa utilizando-se o método de Rietveld, cujos resultados estão ilustrados na Tabela 4.4. Os resultados da análise de pureza indicam que:

- As amostras podem ser organizadas de acordo com a ordem decrescente de sua pureza (teor de apatita): ACJ (cerca de 100\%) > AAN, AIP, ASQ, ASO, $\operatorname{ATP}(99 \%)$ > AAR $(97 \%)$;

- Via de regra, os principais contaminantes das amostras são calcita, dolomita e quartzo, o que está de acordo com a análise dos resultados de FRX (Tabela 4.1);

- A apatita AAR se destaca por apresentar barita como impureza, cuja presença também foi sugerida pela análise química por FRX. 
Tabela 4.4 - Pureza dos concentrados de apatita determinada por análise semiquantitativa do método de Rietveld.

\begin{tabular}{ccc} 
& \multicolumn{2}{c}{ Composição Mineralógica das Amostras } \\
\cline { 2 - 3 } Apatita & Apatita (\%) & Impurezas \\
\hline AAN & 99 & Calcita \\
\hline AAR & 97 & Barita, calcita, dolomita \\
\hline ACJ & $>99$ & n.d \\
\hline AIP & 99 & Quartzo, calcita \\
\hline ASQ & 99 & Calcita \\
\hline ASO & 99 & Calcita \\
\hline ATP & 99 & Quartzo, calcita \\
\hline
\end{tabular}

n.d. = não detectado.

Os concentrados de apatita também foram analisados por espectroscopia no infravermelho por transformada de Fourier (FTIR) para detectar a presença de espécies $\mathrm{OH}^{-}$e $\mathrm{CO}_{3}{ }^{2-}$. Os espectros obtidos (Figura 4.3) são caracterizados por exibir as vibrações correspondentes aos grupos $\mathrm{PO}_{4}, \mathrm{CO}_{3}$ e $\mathrm{OH}$. $\mathrm{Na}$ Tabela 4.5 estão compiladas as informações da literatura relativas ao intervalo de número de onda em que ocorrem tais vibrações (LEGEROS et al., 1970; ROSS, 1974; SANTOS; CLAYTON, 1995). Os números de onda relativos às vibrações inerentes aos grupos $\mathrm{PO}_{4}, \mathrm{CO}_{3}$ e $\mathrm{OH}$ (Tabela 4.5), que foram identificadas nos espectros obtidos (Figura 4.3), são apresentados na Tabela 4.6. 
Tabela 4.5 - Números de onda das vibrações das espécies de apatita determinadas por FTIR.

Espécie Vibração Número de onda $\left(\mathrm{cm}^{-1}\right)$

Referência

\begin{tabular}{|c|c|c|c|}
\hline \multirow{4}{*}{$\mathrm{PO}_{4}$} & $v_{1}$ & $930-980$ & \multirow{4}{*}{ Ross (1974) } \\
\hline & $v_{2}$ & $360-420$ & \\
\hline & $v_{3}$ & $1.010-1.080$ & \\
\hline & $v_{4}$ & $515-570$ & \\
\hline \multirow{3}{*}{$\mathrm{CO}_{3}$} & $v_{2}$ & $860-885$ & \multirow{3}{*}{ Legeros et al. (1970) } \\
\hline & \multirow{2}{*}{$v_{3}$} & $1.465-1.542$ & \\
\hline & & $1.430-1.460$ & \\
\hline \multirow{2}{*}{$\mathrm{OH}$} & $v_{f}$ & $\sim 3.537$ & \multirow{2}{*}{ Santos e Clayton (1995 } \\
\hline & $v_{a}$ & $\sim 746$ & \\
\hline
\end{tabular}

A presença do grupo $\mathrm{OH}$ nos concentrados de apatita foi indicada pelas vibrações: Fundamental $\left(v_{t}\right)$, observada em aproximadamente $3.537 \mathrm{~cm}^{-1}$, e associada $\left(v_{a}\right)$, observada na região de $746 \mathrm{~cm}^{-1}$, de acordo com as Tabela 4.5 e 4.6 (ARAUJO, 1990; LENHARO, 1994; SANTOS; CLAYTON, 1995). Nos espectros das apatitas contempladas neste estudo (Figura 4.3 e Tabela 4.6), se observa que as vibrações características do $\mathrm{OH}$ não ocorrem no concentrado ASO. Deste modo, as apatitas AAN, AAR, ACJ, AIP, ASQ e ATP, por apresentarem as duas vibrações características do $\mathrm{OH}$, podem ser classificadas como hidroxi-fluorapatitas. Born, Lenharo e Kahn (1996) observaram que as hidroxi-fluorapatitas primárias apresentam a razão $\mathrm{F} / \mathrm{P}_{2} \mathrm{O}_{5} \leq 0,90$. Os resultados obtidos por meio de análises de FTIR e WDS/EDS nesta tese estão de acordo com a condição reportada por Born, 
Lenharo e Kahn (1996), uma vez que a relação $\mathrm{F} / \mathrm{P}_{2} \mathrm{O}_{5}$ das apatitas classificadas como hidroxi-fluorapatitas é menor ou igual a 0,90 (Tabela 4.2).

Entre as vibrações de $\mathrm{CO}_{3}$, a $v_{3}$ presente como banda dupla entre $1.467 \mathrm{e}$ $1.418 \mathrm{~cm}^{-1}$, é a mais evidente nos espectros de FTIR das apatitas abordadas neste estudo (Figura 4.3). No entanto, a análise de tal vibração deve ser realizada com cautela, pois, esta região de número de onda também corresponde às vibrações de carbonatos (BÖTTCHER; GEHLKEN; STEELE, 1997; FLEET, 2009; GUNASEKARAN; ANBALAGAN, 2007) que constituem as impurezas das apatitas, como constatado nas análises de FRX (Tabela 4.1) e semi-quantitativa pelo método de Rietveld (Tabela 4.4).

Como se observa nas Figuras 4.3 (espectro de FTIR de todas as apatitas) e 4.4 (espectro de ASO), o concentrado de ASO foi o único a exibir todas as vibrações do $\mathrm{CO}_{3}$ com alta intensidade e definição. Dessa forma, com base nestes resultados, apenas a apatita ASO pode ser classificada como carbonato-fluorapatita.

As posições das vibrações $v_{3}$ da carbonato-fluorapatita ASO (1.430 e $1.456 \mathrm{~cm}^{-1}$ ) indicam a presença de estiramento do tipo $\mathrm{B}$, caracterizado pela substituição de $\mathrm{PO}_{4}{ }^{2-}$ por $\mathrm{CO}_{3}{ }^{2-}$. Estiramentos do tipo $\mathrm{A}$ ocorrem quando $0 \mathrm{CO}_{3}{ }^{2-}$ substitui os íons $\mathrm{F}^{-}$nos canais (ANTONAKOS; LIAROKAPIS; LEVENTOURI, 2007; ROSS, 1974). A substituição de íons $\mathrm{PO}_{4}{ }^{3-}$ por $\mathrm{CO}_{3}{ }^{2-}$ pode levar à incorporação de $\mathrm{F}^{-}$ ou $\mathrm{OH}^{-}$, ou à deficiência de $\mathrm{Ca}^{2+}$, para que as cargas sejam compensadas (FLEET, 2009; TOLEDO; PEREIRA, 2001). De fato, na Tabela 4.2 se observa que o conteúdo de $F(5,71 \%$ em média), identificada por WDS/EDS na apatita ASO é superior àquele encontrado para as demais apatitas estudadas.

Na Figura 4.3, a vibração observada em aproximadamente $3.450 \mathrm{~cm}^{-1}$, bem como a vibração em aproximadamente $1.636 \mathrm{~cm}^{-1}$, correspondem às moléculas de água adsorvidas no $\mathrm{KBr}$ (utilizado na confecção da pastilha que contém a amostra) ou nos concentrados de apatita (AGOUGUI; AISSA; DEBBABI, 2012; MARKOVIC; FOWLER; TUNG, 2004; HUI et al., 2010; TROMMER; SANTOS; BERGMANN, 2007). 


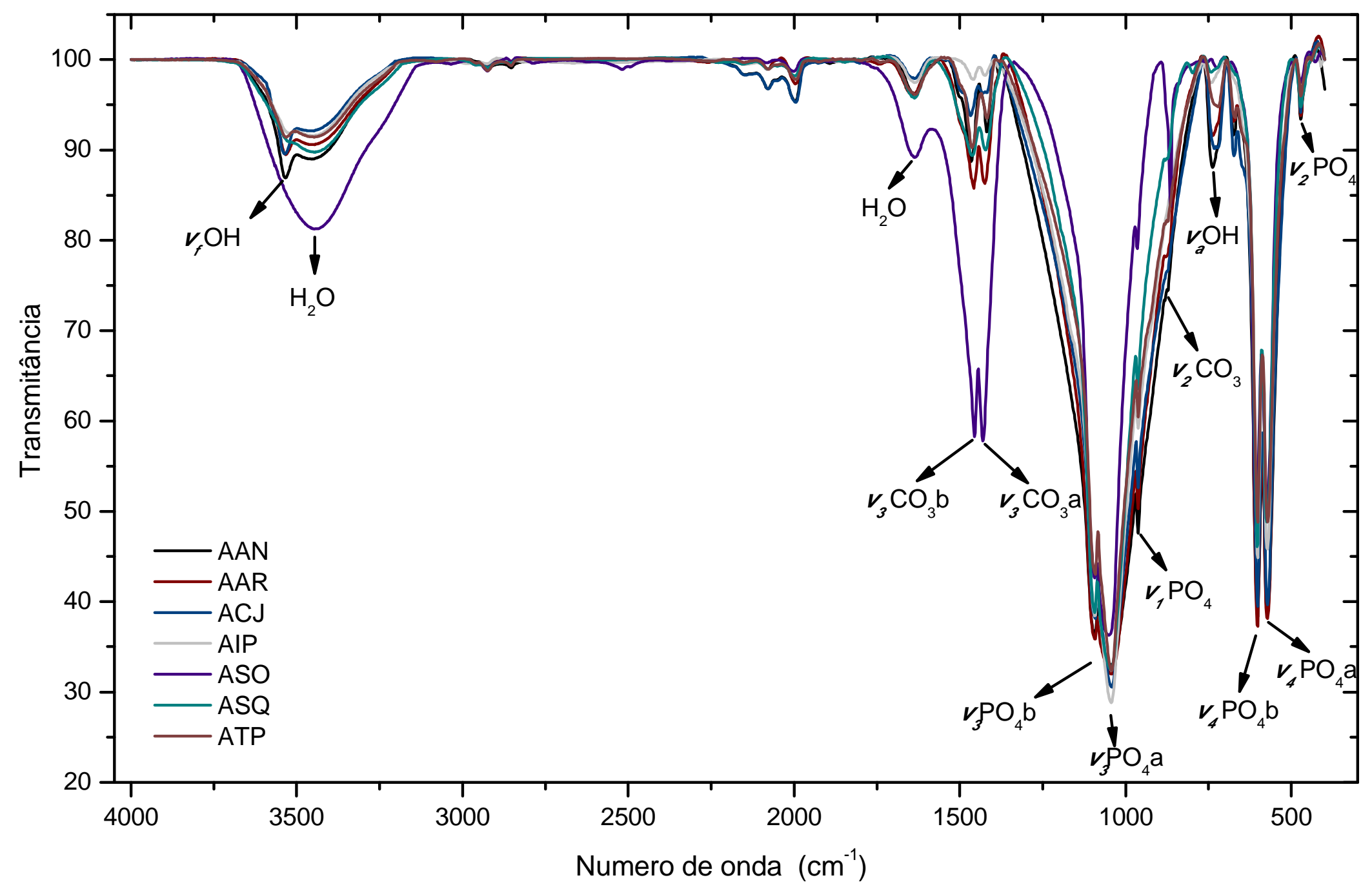

Figura 4.3 - Espectros de FTIR (número de onda entre 4.000 e $400 \mathrm{~cm}^{-1}$ ) das apatitas. 
Tabela 4.6 - Número de onda das vibrações encontradas nos espectros de FTIR das apatitas.

\begin{tabular}{|c|c|c|c|c|c|c|c|c|c|c|c|c|}
\hline Apatitas & $v_{1} \mathrm{PO}_{4}$ & $v_{2} \mathrm{PO}_{4}$ & $v_{3} \mathrm{PO}_{4} \mathrm{a}$ & $v_{3} \mathrm{PO}_{4} \mathrm{~b}$ & $v_{4} \mathrm{PO}_{4} \mathrm{a}$ & $v_{4} \mathrm{PO}_{4} \mathrm{~b}$ & $v_{2} \mathrm{CO}_{3}$ & $v_{3} \mathrm{CO}_{3} \mathrm{a}$ & $v_{3} \mathrm{CO}_{3} \mathrm{~b}$ & $v_{f} \mathrm{OH}$ & $v_{a} \mathrm{OH}$ & $\mathrm{OH}-\mathrm{F}$ \\
\hline AAN & 962,50 & 471,79 & $1.042,13$ & $1.092,48$ & 573,17 & 602,52 & 873,36 & $1.418,60$ & $1.466,70$ & $3.453,87$ & 737,64 & $3.534,25$ \\
\hline AAR & 962,43 & 471,65 & $1.042,62$ & $1.092,57$ & 573,22 & 602,64 & 879,41 & $1.425,42$ & $1.458,55$ & $3.446,84$ & 737,28 & $3.533,14$ \\
\hline ACJ & 962,19 & 472,19 & $1.042,44$ & $1.092,32$ & 572,31 & 602,35 & $-\left(^{*}\right)$ & $1.424,19$ & $1.467,15$ & $3.448,84$ & 731,86 & $3.535,94$ \\
\hline AIP & 961,98 & 471,75 & $1.044,05$ & $1.092,73$ & 573,40 & 602,50 & - & $1.424,15$ & $1.458,98$ & $3.453,42$ & 743,57 & $3.521,83$ \\
\hline ASQ & 963,27 & 471,67 & 1044,71 & 1093,78 & 574,08 & 602,90 & 880,33 & $1.422,69$ & $1.462,89$ & $3.444,96$ & 742,16 & $3.527,00$ \\
\hline ASO & 965,12 & 471,48 & $1.050,47$ & $1.094,17$ & 573,41 & 605,39 & 865,03 & $1.430,30$ & $1.455,78$ & $3.447,24$ & - & - \\
\hline ATP & 961,83 & 471,75 & $1.042,67$ & $1.092,21$ & 571,92 & 602,38 & 873,22 & $1.418,38$ & $1.463,22$ & $3.446,91$ & 721,71 & $3.532,39$ \\
\hline
\end{tabular}

(*) Vibrações não identificadas. 


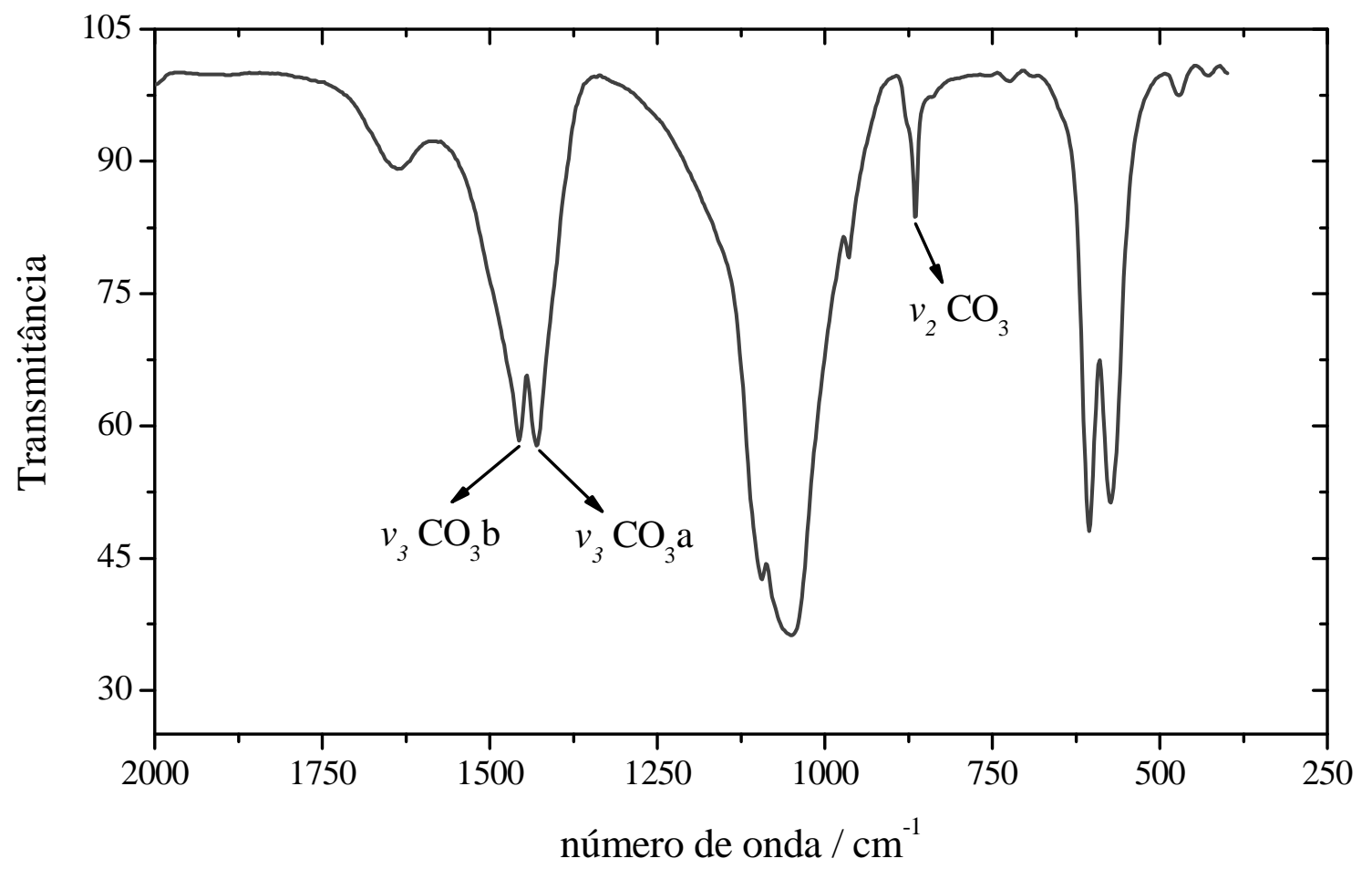

Figura 4.4 - Espectro de FTIR da apatita ASO (número de onda entre $=2.000 \mathrm{e}$ $400 \mathrm{~cm}^{-1}$ ) com a identificação das vibrações do $\mathrm{CO}_{3}$.

Com base nas análises FTIR apresentadas, as apatitas de gênese ígnea (AAN, AAR, ACJ, AIP e ATP) e metamórfica (ASQ) foram classificadas como hidroxifluorapatitas, enquanto a apatita sedimentar (ASO) foi classificada como carbonatofluorapatita.

Os valores encontrados para as propriedades físicas, densidade (d), área superficial $(S)$ e porosidade $(P)$, dos concentrados de apatita são apresentados na Tabela 4.7. A densidade dos concentrados de apatita varia de 3,024 a $3,221 \mathrm{~g} \mathrm{~cm}^{-3}$, obedecendo à seguinte lógica inerente à gênese: sedimentar < metamórfica < ígnea (Tabela 4.7). O valor teórico de densidade para a fluorapatita é de $3,16-3,22 \mathrm{~g} \mathrm{~cm}^{-3}$ segundo Dana (1969). De acordo com Toledo e Pereira (2001), variações na densidade das apatitas estão relacionadas a sua variabilidade de composição devida às diversas substituições passíveis de ocorrer em sua estrutura cristalina.

Embora a faixa granulométrica dos concentrados de apatita estudados seja a mesma (entre 103 e $43 \mu \mathrm{m}$ ), sua área superficial varia largamente, como se observa na Tabela 4.7. A apatita sedimentar ASO exibe área superficial $\left(S=85.520 \mathrm{~cm}^{2} \mathrm{~g}^{-1}\right)$ muito superior às demais, que se situaram na faixa de $60 \leq S \leq 2.710 \mathrm{~cm}^{2} \mathrm{~g}^{-1}$. A apatita metamórfica (ASQ) apresenta $S$ com valor intermediário $\left(2.710 \mathrm{~cm}^{2} \mathrm{~g}^{-1}\right)$, 
enquanto as amostras de gênese ígnea exibem as menores áreas $\left(<570 \mathrm{~cm}^{2} \mathrm{~g}^{-1}\right)$. Os valores de $S$ foram utilizados para normalizar os resultados dos ensaios de dissolução que foram expressos por unidade de área.

Tabela 4.7 - Propriedades físicas das apatitas.

\begin{tabular}{cccc}
\hline Apatita & $\begin{array}{c}\text { Densidade } \\
\left(\mathbf{g ~ c m}^{-3}\right)\end{array}$ & $\begin{array}{c}\text { Área superficial } \\
\left(\mathbf{c m}^{2} \mathbf{g}^{-1}\right)\end{array}$ & $\begin{array}{c}\text { Porosidade } \\
(\%)\end{array}$ \\
\hline AAN & $3,212 \pm 0,004$ & 570 & 4,00 \\
\hline AAR & $3,221 \pm 0,003$ & 320 & 2,44 \\
\hline ACJ & $3,205 \pm 0,007$ & 60 & 2,46 \\
\hline AIP & $3,202 \pm 0,004$ & 60 & 2,12 \\
\hline ASO & $3,024 \pm 0,001$ & 85.520 & 12,72 \\
\hline ASQ & $3,139 \pm 0,001$ & 2.710 & 3,82 \\
\hline ATP & $3,207 \pm 0,002$ & 570 & \\
\hline
\end{tabular}

No que diz respeito à porosidade $(\mathrm{P})$, os resultados da Tabela 4.7 apontam maior porosidade nas amostras que exibiram maior área superficial (S). Deste modo, as apatitas ASO ( $\left.\mathrm{S}=85.520 \mathrm{~cm}^{2} \mathrm{~g}^{-1} ; \mathrm{P}=12,72 \%\right)$ e ASQ $\left(\mathrm{S}=2.710 \mathrm{~cm}^{2} \mathrm{~g}^{-1}\right.$; $P=4,82 \%)$ foram aquelas que apresentaram maior área superficial e porosidade. Coincidentemente, tais amostras são as únicas de origem não ígnea. 


\subsubsection{Caracterização das calcitas}

A análise da composição química das calcitas contempladas nesta tese foi realizada por FRX e WDS/EDS, cujos resultados estão ilustrados nas Tabelas 4.8 e 4.9 , respectivamente. Imagens de partículas de calcita obtidas por meio de MEV, e cuja composição foi analisada por WDS/EDS, estão ilustradas na Figura 4.5.

Com base na análise de FRX (Tabela 4.8), é possível avaliar quais são as principais fases contaminantes das calcitas:

- As calcitas CAM e CRO podem ser consideradas como sendo de alta pureza, visto que exibem conteúdo de contaminantes analisados $\leq 0,1 \%$;

- As calcitas CCI e CSQ apresentam traços de apatita, o que é indicado pela presença de $0,2 \%$ e $0,3 \%$ de $\mathrm{P}_{2} \mathrm{O}_{5}$, respectivamente;

- Elevados teores de $\mathrm{MgO}(3,2 \%)$ e $\mathrm{SiO}_{2}(3,9 \%)$ são observados na calcita $\mathrm{CCI}$, o que indica a presença de dolomita e quartzo;

- A presença de dolomita também é evidente na calcita CCJ devido ao conteúdo de $\mathrm{MgO}(1,3 \%)$;

- A presença de $\mathrm{MgO}$ na composição das calcitas CCl e CCJ também pode estar relacionada à substituição de cálcio por magnésio na estrutura das calcitas, o que as classificaria como calcitas magnesianas. Tal hipótese será comprovada pela análise por WDS/EDS apresentada a seguir;

- A calcita CRT, apesar de ser uma amostra de coleção (romboedro perfeito), exibe algum nível de contaminação: $0,8 \%$ de $\mathrm{Al}_{2} \mathrm{O}_{3}$ e $0,5 \%$ de $\mathrm{SiO}_{2}$;

- A calcita CSQ se destaca por exibir 4,5\% de $\mathrm{SiO}_{2}$. Uma vez que ela foi concentrada a partir de minério de fosfato, este teor indica a presença de quartzo como contaminante, pois calcita e quartzo apresentam densidade próxima, o que dificulta a seletividade na separação densitária em bromofórmio. 
Tabela 4.8 - Análise química das calcitas por FRX.

\begin{tabular}{|c|c|c|c|c|c|c|}
\hline Espécie/Química & CAM & $\mathrm{CCl}$ & CCJ & CRO & CRT & CSQ \\
\hline $\mathrm{Na}_{2} \mathrm{O}$ & $<0,1$ & 0,1 & $<0,1$ & 0,1 & $<0,1$ & $<0,1$ \\
\hline $\mathrm{MgO}$ & $<0,1$ & 3,2 & 1,3 & 0,1 & $<0,1$ & $<0,1$ \\
\hline $\mathrm{Al}_{2} \mathrm{O}_{3}$ & $<0,1$ & $<0,1$ & 0,1 & $<0,1$ & 0,8 & $<0,1$ \\
\hline $\mathrm{SiO}_{2}$ & $<0,1$ & 3,9 & 0,3 & 0,1 & 0,5 & 4,5 \\
\hline $\mathrm{P}_{2} \mathrm{O}_{5}$ & $<0,1$ & 0,2 & $<0,1$ & $<0,1$ & $<0,1$ & 0,3 \\
\hline $\mathrm{SO}_{3}$ & $<0,1$ & $<0,1$ & $<0,1$ & $<0,1$ & $<0,1$ & $<0,1$ \\
\hline $\mathrm{K}_{2} \mathrm{O}$ & $<0,1$ & $<0,1$ & $<0,1$ & $<0,1$ & $<0,1$ & $<0,1$ \\
\hline $\mathrm{CaO}$ & 55,7 & 51,2 & 53,8 & 55,8 & 55,8 & 54,0 \\
\hline $\mathrm{TiO}_{2}$ & $<0,1$ & $<0,1$ & $<0,1$ & $<0,1$ & $<0,1$ & $<0,1$ \\
\hline $\mathrm{MnO}$ & $<0,1$ & $<0,1$ & 0,1 & $<0,1$ & $<0,1$ & 0,1 \\
\hline $\mathrm{Fe}_{2} \mathrm{O}_{3}$ & $<0,1$ & $<0,1$ & 0,1 & $<0,1$ & $<0,1$ & 0,2 \\
\hline $\mathrm{SrO}$ & $<0,1$ & $<0,1$ & 0,7 & $<0,1$ & $<0,1$ & 0,2 \\
\hline $\operatorname{PF}\left({ }^{*}\right)$ & 43,6 & 41,6 & 43,0 & 43,6 & 42,8 & 39,6 \\
\hline
\end{tabular}

$\left(^{\star}\right)$ PF = Perda ao fogo. 
Tabela 4.9 - Análise química das calcitas por WDS/EDS.

\begin{tabular}{|c|c|c|c|c|c|c|}
\hline Espécie/Química & CAM & $\mathrm{CCl}$ & CCJ & CRO & CRT & $\mathrm{CSQ}$ \\
\hline $\mathrm{Na}_{2} \mathrm{O}$ & $<0,1$ & $<0,1$ & $<0,1$ & $<0,1$ & $<0,1$ & $<0,1$ \\
\hline $\mathrm{MgO}$ & $<0,1$ & 0,6 & 0,3 & $<0,1$ & $<0,1$ & $<0,1$ \\
\hline $\mathrm{Al}_{2} \mathrm{O}_{3}$ & 0,1 & $<0,1$ & $<0,1$ & $<0,1$ & $<0,1$ & $<0,1$ \\
\hline $\mathrm{SiO}_{2}$ & $<0,1$ & 0,1 & 0,1 & 0,1 & 0,1 & 0,1 \\
\hline $\mathrm{P}_{2} \mathrm{O}_{5}$ & $<0,1$ & $<0,1$ & $<0,1$ & $<0,1$ & $<0,1$ & $<0,1$ \\
\hline $\mathrm{SO}_{3}$ & $<0,1$ & $<0,1$ & $<0,1$ & $<0,1$ & $<0,1$ & $<0,1$ \\
\hline $\mathrm{K}_{2} \mathrm{O}$ & $<0,1$ & $<0,1$ & $<0,1$ & $<0,1$ & $<0,1$ & $<0,1$ \\
\hline $\mathrm{CaO}$ & 56,7 & 55,0 & 56,9 & 57,4 & 56,8 & 55,6 \\
\hline $\mathrm{TiO}_{2}$ & $<0,1$ & $<0,1$ & 0,1 & $<0,1$ & $<0,1$ & $<0,1$ \\
\hline $\mathrm{MnO}$ & $<0,1$ & $<0,1$ & $<0,1$ & $<0,1$ & $<0,1$ & 0,1 \\
\hline $\mathrm{Fe}_{2} \mathrm{O}_{3}$ & $<0,1$ & $<0,1$ & 0,1 & 0,1 & $<0,1$ & $<0,1$ \\
\hline $\mathrm{SrO}$ & $<0,1$ & $<0,1$ & 0,7 & $<0,1$ & $<0,1$ & 0,1 \\
\hline
\end{tabular}


Os resultados das análises WDS/EDS (Tabela 4.9) revelam a presença de contaminantes nas partículas de calcita liberadas:

- O teor de $\mathrm{MgO}$ nas calcitas $\mathrm{CCl}(0,6 \%)$ e CCJ (0,3\%), indica serem calcitas magnesianas;

- A maioria das calcitas (CCI, CCJ, CRO, CRT e CSQ) apresenta contaminação por sílica $\left(\mathrm{SiO}_{2}=0,1 \%\right)$;

- A calcita CAM apresenta traços de $\mathrm{Al}_{2} \mathrm{O}_{3}(0,1 \%)$;

- A calcita CCJ se destaca pela presença de SrO (0,7\%). Além disso, a CCJ apresenta traços de $\mathrm{Fe}_{2} \mathrm{O}_{3}(0,1 \%)$;

- A calcita CRO exibe traços de $\mathrm{Fe}_{2} \mathrm{O}_{3}(0,1 \%)$;

- A calcita CSQ exibe traços de $\mathrm{MnO}(0,1 \%)$.

Avaliando-se as imagens de MEV das calcitas (Figura 4.5), observa-se que todas as amostras exibem superfícies lisas, sem rugosidade pronunciada ou inclusões de outras fases.

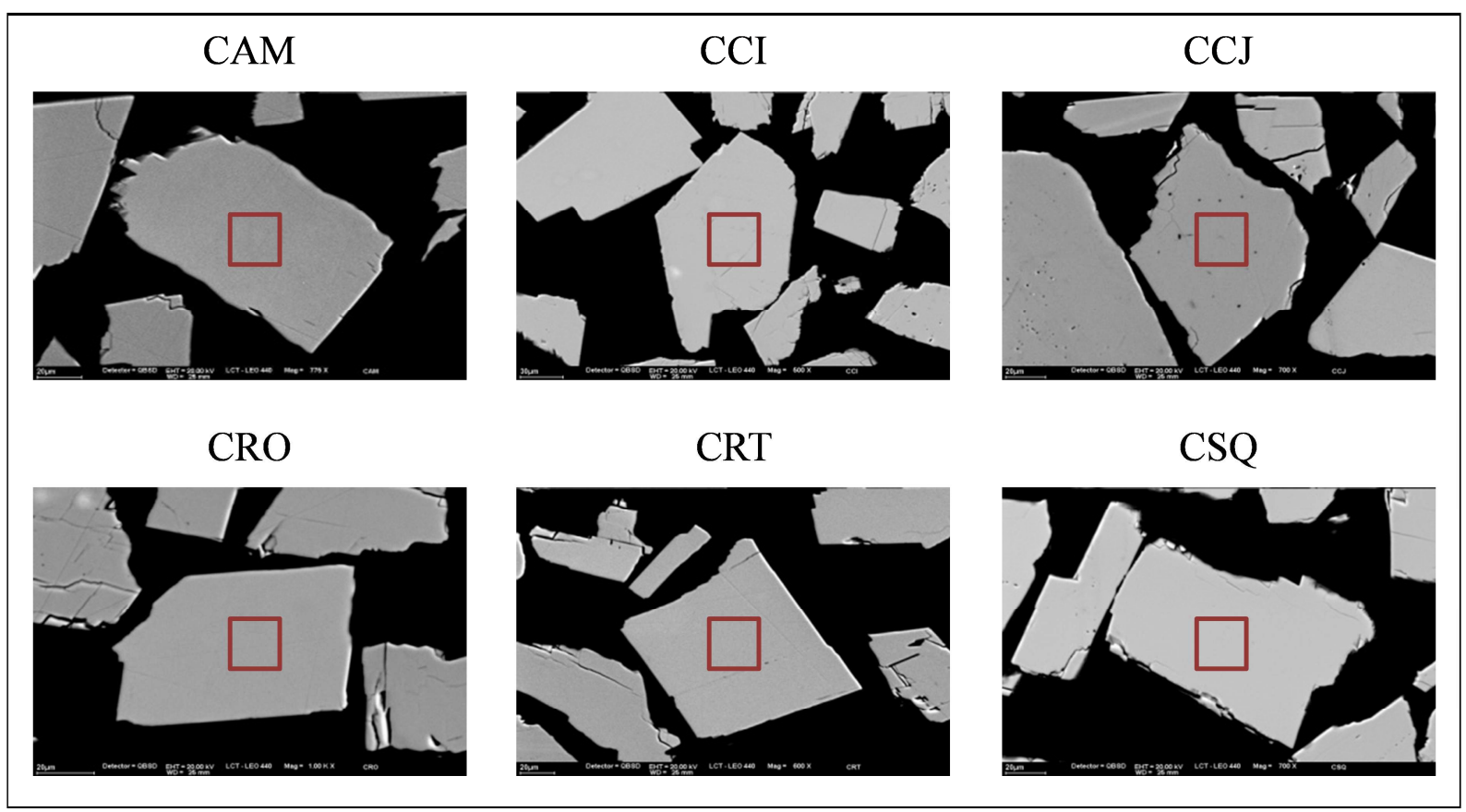

Figura 4.5 - Imagens de MEV com exemplos de partículas de calcitas analisadas por WDS/EDS. O quadro vermelho indica o local da análise. 
A pureza das calcitas abordadas nesta tese também foi determinada por meio de análise semi-quantitativa pelo método de Rietveld, cujos resultados estão ilustrados na Tabela 4.10. De acordo com a análise de pureza das calcitas, apresentada na Tabela 4.10, se observa que:

- As calcitas podem ser organizadas em ordem decrescente de acordo com sua pureza: CAM, CRO, CRT, ( 100\%) > CSQ $(98 \%)>$ CCJ $(97 \%)>>C C I(91 \%)$;

- As principais fases contaminantes das calcitas são quartzo e dolomita, o que está de acordo com as análises de FRX (Tabela 4.8);

- A calcita $\mathrm{CCl}$ exibe a menor pureza (91\%), devido à presença de dolomita e quartzo. As principais impurezas determinadas pelo método de Rietveld corroboram com os elevados teores de $\mathrm{MgO}(3,2 \%)$ e $\mathrm{SiO}_{2}$ (3,9\%) determinados por FRX (Tabela 4.8).

Tabela 4.10 - Pureza dos concentrados de calcita determinada por análise semiquantitativa do método de Rietveld.

Composição mineralógica das amostras

\section{Calcitas}

Calcita (\%)

CAM

$\mathrm{CCl}$

CCJ

CRO

$>99$

$>99$

n.d.

CSQ
99

91

97

Dolomita, quartzo

\section{Impurezas}

Quartzo

\begin{tabular}{ccl}
\hline CRT & $>99$ & n.d. \\
\hline CSQ & 98 & Quartzo \\
\hline
\end{tabular}

n.d. = não detectado. 
Os valores obtidos para as propriedades físicas (d, S e P) das calcitas estudadas são apresentados na Tabela 4.11, em que se verifica que os valores de densidade estão na faixa de 2,732 a 2,766 $\mathrm{g} \mathrm{cm}^{-3}$, que diferem ligeiramente do valor teórico de 2,72 $\mathrm{g} \mathrm{cm}^{-3}$ reportado por Dana (1969). As amostras mais densas $(2,766 \mathrm{~g}$ $\mathrm{cm}^{-3}$ para $\mathrm{CCl}$ e $2,756 \mathrm{~g} \mathrm{~cm}^{-3}$ para CCJ) são as mais contaminadas por dolomita e apatita, cujos valores de densidade são superiores aos da calcita (Tabela 4.11).

Tabela 4.11 - Propriedades físicas das calcitas.

\begin{tabular}{cccc}
\hline Calcita & $\begin{array}{c}\text { Densidade } \\
\left(\mathbf{g ~ c m} \mathbf{~}^{-3}\right)\end{array}$ & $\begin{array}{c}\text { Área superficial } \\
\left(\mathbf{c m}^{\mathbf{2}} \mathbf{g}^{-1}\right)\end{array}$ & Porosidade \\
\hline CAM & $2,737 \pm 0,007$ & 260 & 3,35 \\
\hline CCJ & $2,756 \pm 0,010$ & 310 & 2,78 \\
\hline CCI & $2,766 \pm 0,005$ & 260 & 2,99 \\
\hline CRO & $2,742 \pm 0,002$ & 510 & 3,55 \\
\hline CRT & $2,732 \pm 0,004$ & 340 & 3,76 \\
\hline CSQ & $2,742 \pm 0,003$ & 210 & 3,14 \\
\hline
\end{tabular}

$\mathrm{Na}$ Tabela 4.11, os valores de área superficial $\left(210 \leq \mathrm{S} \leq 510 \mathrm{~cm}^{2} \mathrm{~g}^{-1}\right) \mathrm{e}$ porosidade $(2,78 \leq P \leq 3,76 \%)$ das calcitas não variam tanto quanto os valores obtidos para as apatitas (Tabela 4.7), dentro do conjunto de amostras estudadas. 


\subsection{Cristalinidade}

A determinação da cristalinidade das apatitas e calcitas foi conduzida por meio do refinamento de perfis de difração, utilizando-se o método de Rietveld. Tal abordagem forneceu:

- Parâmetros microestruturais: tamanho de cristalito (TC) e microdeformação (MD);

- Parâmetros de rede: distâncias $a, c$ da cela unitária e seu volume $\left(\mathrm{V}_{\mathrm{CU}}\right)$;

- Quantidade de material amorfo, que foi utilizada para a determinação do grau de cristalinidade (GC).

O padrão $\mathrm{LaB}_{6}$ foi empregado na remoção do alargamento instrumental em todos os refinamentos. O gráfico de Rietveld do refinamento do padrão, que ilustra a comparação entre os perfis de difração calculado e observado, é apresentado na Figura 4.6.

A qualidade dos refinamentos do método de Rietveld pode ser avaliada por meio dos índices de ajuste e do gráfico de Rietveld. O índice utilizado neste trabalho foi o número GOF (goodness of fit), sendo que, quanto mais próximo de 1 é o valor assumido por GOF, mais satisfatório é o ajuste entre os perfis de difração calculado e observado (PAIVA-SANTOS, 2009; YOUNG, 1993). No refinamento do padrão, o número GOF obtido foi 1,3. O número GOF de aproximadamente 1 e o bom ajuste entre perfis de difração observado e calculado (Figura 4.6), indicam que o padrão é adequado para a sua finalidade. Os gráficos de Rietveld do refinamento de todas as amostras contempladas nesta tese são encontrados no Apêndice B. 


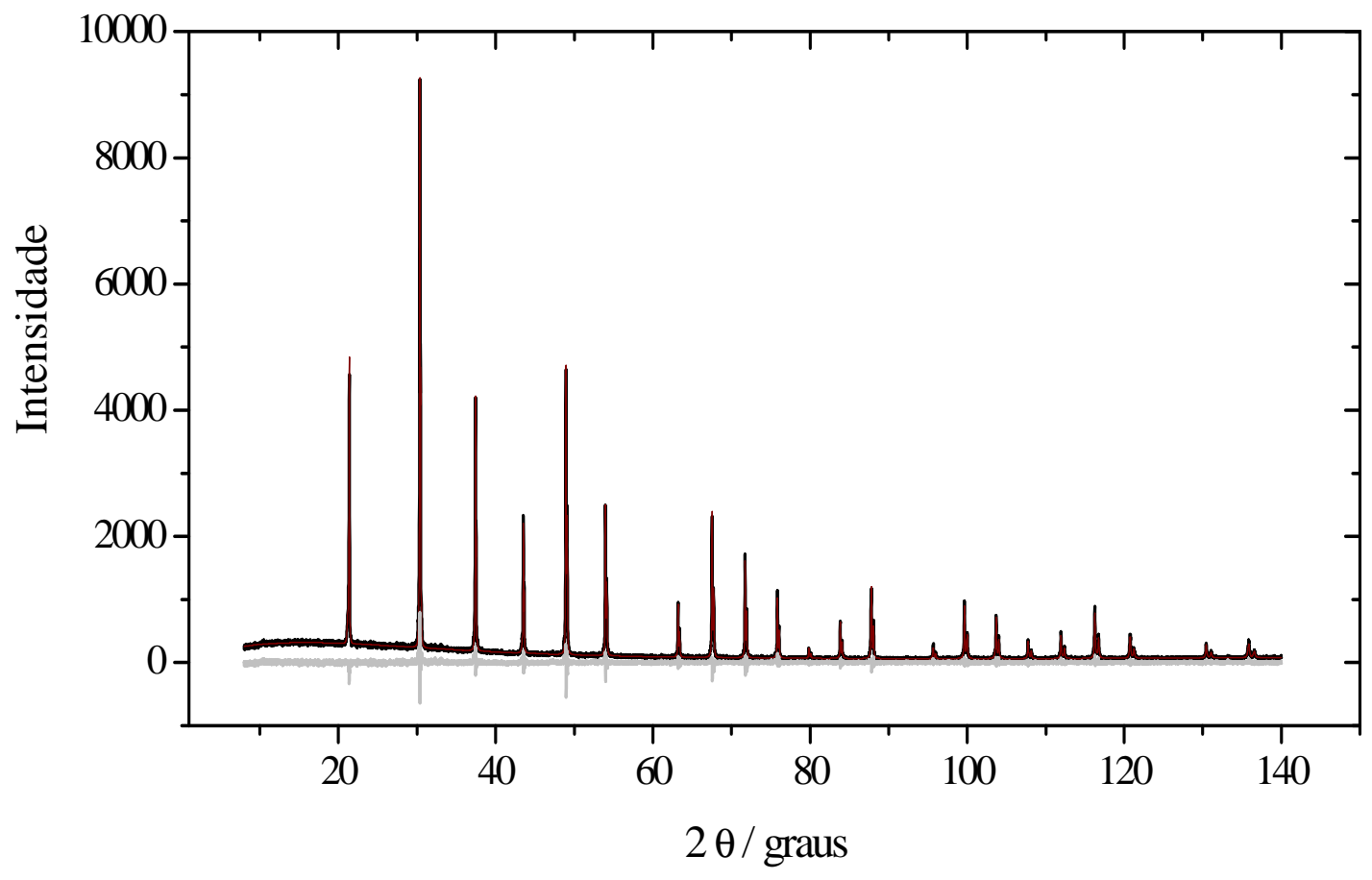

Figura 4.6 - Gráfico de Rietveld do padrão $\operatorname{LaB}_{6}$. Comparação entre perfis de difração: - observado e - calculado (- resíduo).

\subsubsection{Cristalinidade das apatitas}

No que concerne às apatitas, seu tamanho de cristalito (TC) foi refinado de forma anisotrópica por meio de uma rotina (denominada de "macro") que foi incluída no programa TOPAS Academic (ANTONIO, 2010). Por conta disto, o TC foi refinado para cada uma das três orientações cristalográficas (h00), (0k0) e (00\%). Os parâmetros de cristalinidade (GC, TC e MD) e os parâmetros de rede $\left(a, c\right.$ e $\mathrm{V}_{\mathrm{CU}}$ ) obtidos para as apatitas são apresentados na Tabela 4.12.

Para facilitar a comparação entre os tamanhos de cristalito das amostras de apatita, calculou-se um tamanho de cristalito médio $\mathrm{TC}_{\mathrm{M}}$, que constitui na média geométrica entre $\mathrm{TC}_{(\mathrm{h} 00)}, \mathrm{TC}_{(0 \mathrm{k} 0)}$ e $\mathrm{TC}_{(00)}$ (Tabela 4.12). O $\mathrm{TC}_{(00)}$ das apatitas AIP e ASQ não foi determinado por possuir valor superior ao limite de detecção da técnica, como se observa na Tabela 4.12. Para tais amostras adotou-se $\mathrm{TC}_{(00)}=1.000 \mathrm{~nm}$ no cálculo de $\mathrm{TC}_{\mathrm{M}}$, pois este foi o valor máximo de $\mathrm{TC}_{(00)}(\mathrm{AAN})$ determinado. 
Com base nos valores de GOF da Tabela $4.12(\leq 1,5)$, e nos ajustes dos gráficos de Rietveld (Figura 4.7 para AAR e Apêndice B para as demais apatitas), pode-se concluir que os refinamentos das apatitas foram adequados para a determinação dos parâmetros de rede e de cristalinidade.

Tabela 4.12 - Parâmetros de rede e de cristalinidade das apatitas.

\begin{tabular}{|c|c|c|c|c|c|c|c|c|c|c|}
\hline \multirow{2}{*}{ Apatitas } & \multirow{2}{*}{$\begin{array}{l}\text { GC } \\
(\%)\end{array}$} & \multicolumn{3}{|c|}{$\mathrm{TC}(\mathrm{nm})$} & \multirow{2}{*}{$\begin{array}{c}\left.\mathrm{TC}_{\mathrm{M}}{ }^{(\star *}\right) \\
(\mathrm{nm})\end{array}$} & \multirow{2}{*}{$\begin{array}{c}\text { MD } \\
\left(10^{-4}\right)\end{array}$} & \multirow{2}{*}{$\begin{array}{l}a^{(+)} \\
(\AA)\end{array}$} & \multirow{2}{*}{$\begin{array}{l}c^{(++)} \\
(\AA)\end{array}$} & \multirow{2}{*}{$\begin{array}{c}\mathrm{V}_{\mathrm{Cu}}^{(\#)} \\
\left(\AA^{3}\right)\end{array}$} & \multirow{2}{*}{ GOF } \\
\hline & & (h00) & (0k0) & $(00)$ & & & & & & \\
\hline AAN & 74 & 109 & 941 & 1.001 & 468 & 0,6 & 9,396 & 6,889 & 526,8 & 1,5 \\
\hline AAR & 71 & 73 & 156 & 248 & 141 & 0,4 & 9,400 & 6,891 & 527,3 & 1,4 \\
\hline ACJ & 73 & 108 & 556 & 573 & 325 & 0,6 & 9,402 & 6,886 & 526,7 & 1,5 \\
\hline AIP & 75 & 109 & 172 & n.d..$^{(*)}$ & 266 & 160 & 9,404 & 6,886 & 527,5 & 1,4 \\
\hline ASO & 70 & 109 & 43 & 56 & 64 & 600 & 9,340 & 6,896 & 520,9 & 1,3 \\
\hline ASQ & 78 & 81 & 936 & n.d. & 423 & 460 & 9,387 & 6,893 & 526,0 & 1,3 \\
\hline ATP & 72 & 109 & 607 & 563 & 334 & 10 & 9,404 & 6,892 & 527,8 & 1,4 \\
\hline
\end{tabular}

(*) Tamanho superior ao limite de detecção da técnica. $\left(^{* \star}\right) \mathrm{TC}_{\mathrm{M}}=$ Média geométrica dos tamanhos de cristalito assumindo-se que $\mathrm{TC}_{(00)}$ de AIP e ASQ é igual ao valor máximo obtido (1.000 nm). (+) desvio padrão $(\mathrm{dp})<0,0003 .(++) \mathrm{dp}<0,0002$. (\#) $\mathrm{dp}<0,2$. 


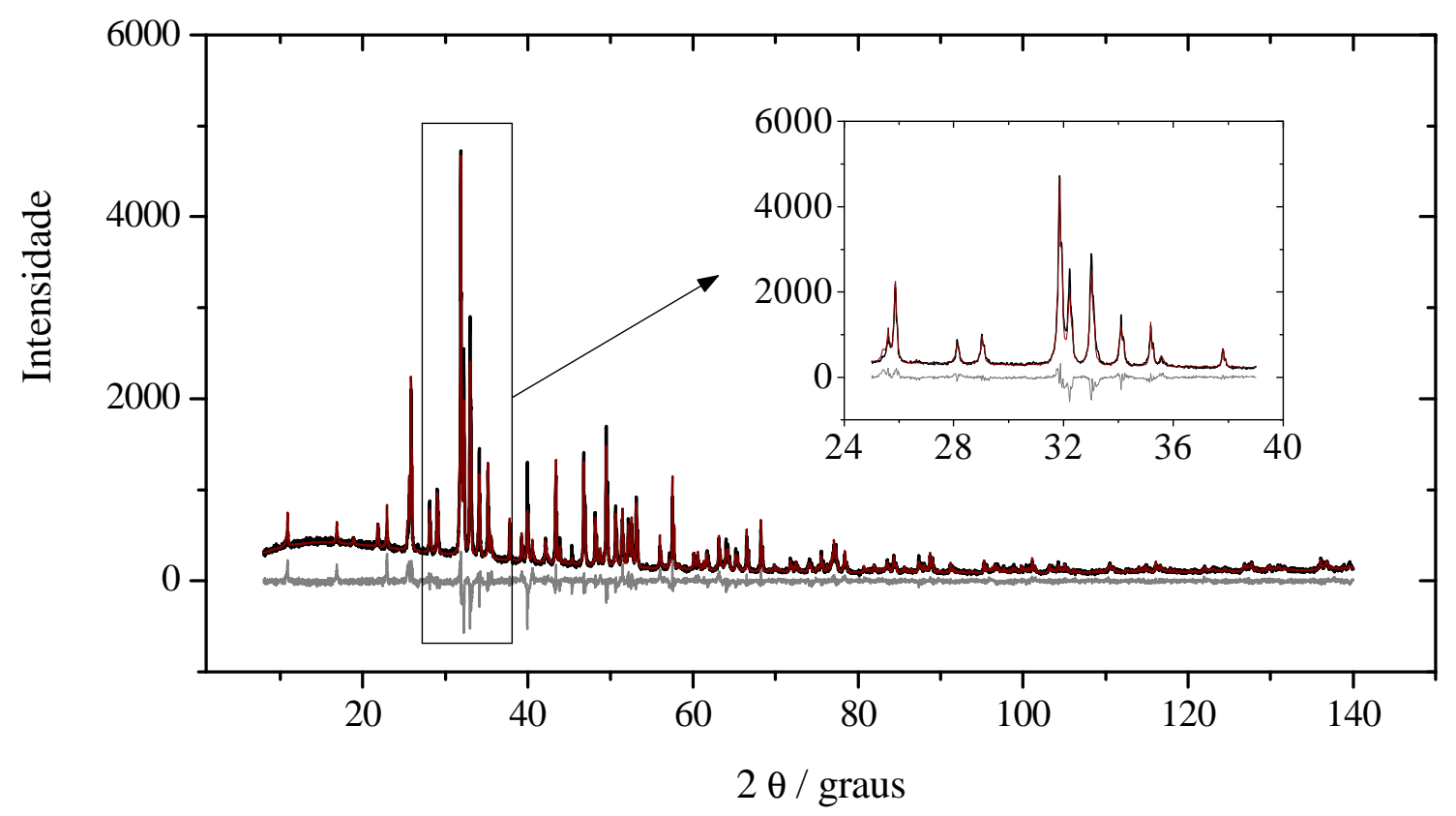

Figura 4.7 - Exemplo de gráfico de Rietveld da apatita AAR. Comparação entre perfis de difração: - observado e - calculado (- resíduo). O quadro interno exibe a região $25^{\circ}<2 \theta<38^{\circ}$.

Na Figura 4.8 está ilustrada a variação de $\mathrm{GC}, \mathrm{TC}_{\mathrm{M}}$ e $\mathrm{MD}$ dentro do grupo de amostras estudadas. A análise dos parâmetros da Tabela 4.12 e da Figura 4.8 indica que:

- A apatita com menor grau de cristalinidade é a de origem sedimentar ASO (70\%), enquanto o maior valor deste parâmetro corresponde à apatita de origem metamórfica ASQ (78\%);

- O parâmetro, que corresponde ao tamanho de cristalito medido na direção (h00), exibe valores menores que $109 \mathrm{~nm}$ para todas as amostras estudadas. Os valores de $\mathrm{TC}_{(\mathrm{ho0})}$, via de regra, são inferiores à magnitude de $\mathrm{TC}_{(\mathrm{ok} 0)} \mathrm{e}$ $\mathrm{TC}_{(00)}$;

- Elevados valores de TC $\mathrm{T}_{(\mathrm{ok})}$ são apresentados pelas apatitas AAN (941 nm), ASQ (936 nm), ATP (607 nm) e ACJ (556 nm). Resultados intermediários são exibidos por, AAR (156 nm) e AIP (172 nm), enquanto que o menor valor é apresentado por ASO (43 nm);

- Elevados valores de $\mathrm{TC}_{(00)}(>1.000 \mathrm{~nm})$ são exibidos pelas apatitas AAN, AIP e ASQ. Resultados intermediários $\left(200 \mathrm{~nm}<\mathrm{TC}_{(00)}<600 \mathrm{~nm}\right)$ foram 
observados para AAR, ACJ, ATP. A apatita ASO é caracterizada pelo menor valor deste parâmetro (56 $\mathrm{nm})$;

- Considerando os valores de $\mathrm{TC}_{\mathrm{M}}$, é possível organizar amostras na seguinte ordem decrescente: AAN > ASQ > ACJ, ATP > AIP > AAR > ASO;

- A microdeformação (MD) varia em larga extensão: de $0,4 \times 10^{-4}$ (AAR) a $600 \times 10^{-4}$ (ASO). A ordem decrescente que organiza as apatitas conforme seu valor de MD é: ASO $\left(600 \times 10^{-4}\right)>$ ASQ $\left(460 \times 10^{-4}\right)>>$ AIP $\left(160 \times 10^{-4}\right)>>$ ATP $\left(10 \times 10^{-4}\right)>>$ AAN, ACJ $\left(0,6 \times 10^{-4}\right)>\operatorname{AAR}\left(0,4 \times 10^{-4}\right)$;

- Com relação aos parâmetros de rede a e $c$, verifica-se que $c$ varia entre $6,886 \AA$ e $6,896 \AA$, enquanto a varia entre 9,340 A e 9,404 $\mathrm{A}$. As mudanças nas dimensões de a e $c$ serão discutidas à luz da literatura nos próximos parágrafos;

- No que concerne ao volume da célula unitária $\left(\mathrm{V}_{\mathrm{CU}}\right)$, verifica-se a seguinte ordem decrescente: ATP $\left(527,8 \AA^{3}\right)>\operatorname{AIP}\left(527,5 \AA^{3}\right)>\operatorname{AAR}\left(527,3 \AA^{3}\right)>$ AAN $\left(526,8 \AA^{3}\right)>\operatorname{ACJ}\left(526,7 \AA^{3}\right)>\operatorname{ASQ}\left(526,0 \AA^{3}\right)>>$ ASO $\left(520,9 \AA^{3}\right)$.

A comparação entre os parâmetros de cristalinidade obtidos neste trabalho (Tabela 4.12 e Figura 4.8) e aqueles reportados pela literatura não é uma tarefa fácil devido à escassez de informações levantadas para apatitas naturais. Com relação à microdeformação, Papangkorn et al. (2008) reportaram valores na faixa de 0,1-0,6 para carbonatoapatitas sintéticas, e tais valores são da ordem de 10 vezes superiores àquele determinado neste trabalho para a carbonato-fluorapatita ASO $(0,06)$ que é natural. Baig et al. (1999) encontraram, para carbonatoapatitas, valores de TC entre 25 e $181 \mathrm{~nm}$ e MD entre $0,4 \times 10^{-4}$ e $31 \times 10^{-4}$, que se encontram dentro da faixa de valores determinados neste trabalho (Tabela 4.12)

Baig et al. (1996) observaram que quanto maior é o grau de substituição de íons $\mathrm{PO}_{4}{ }^{3-}$ por íons $\mathrm{CO}_{3}{ }^{2-}$, menor é o tamanho de cristalito e maior é a microdeformação. Os resultados obtidos neste trabalho estão de acordo com os reportados por tais autores, uma vez que a carbonatoapatita ASO apresenta o maior valor de $\mathrm{MD}\left(600 \times 10^{-4}\right)$ e o menor valor de $\mathrm{TC}_{\mathrm{M}}(64 \mathrm{~nm})$ como se observa na Tabela 4.12 e Figura 4.8. Yao, Legeros e Legeros (2009) também observaram a redução do tamanho de cristalito com o aumento do grau de substituição de $\mathrm{PO}_{4}{ }^{3-}$ por íons $\mathrm{CO}_{3}{ }^{2-}$. 


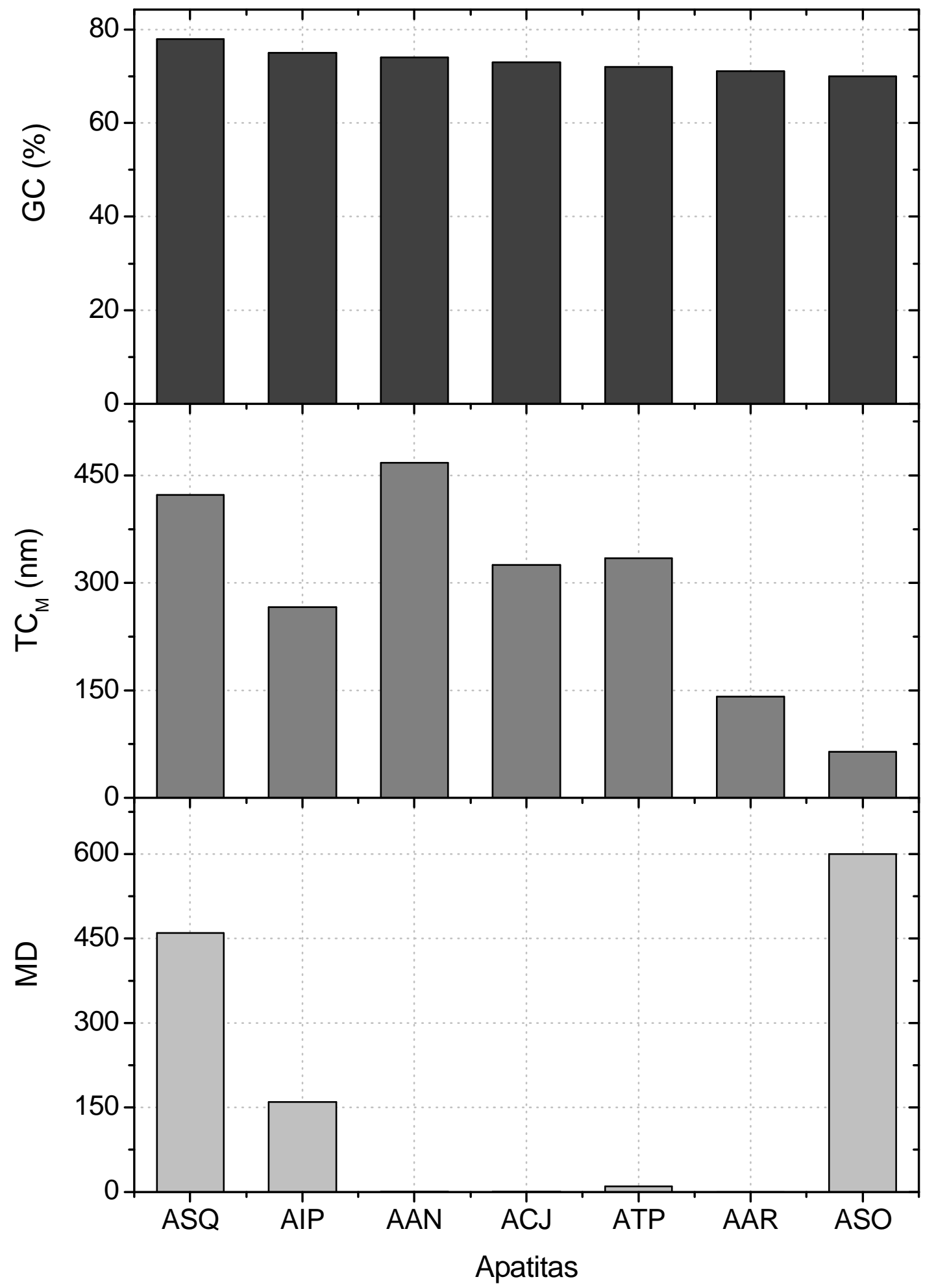

Figura 4.8 - Variação dos parâmetros de cristalinidade das apatitas com a origem das amostras. 
No que diz respeito aos parâmetros de rede ( $a, c$ e $\left.\mathrm{V}_{\mathrm{CU}}\right)$, todavia, existem valores reportados pela literatura que permitem alguma comparação e discussão, que seguem nos próximos parágrafos.

Toledo e Pereira (2001) fizeram um apanhado dos valores de a e c reportados para diferentes tipos de apatita. Dentro do grupo de resultados compilados pelos

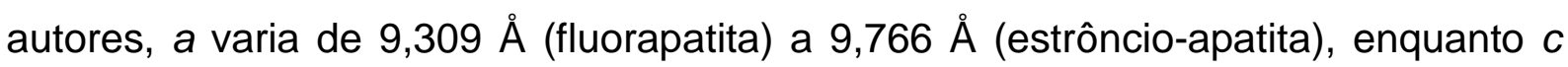
varia de 6,851 $\AA$ (cloro-hidroxiapatita) a 7,276 ̊ (estrôncio-apatita). O comprimento dos eixos a e $c$ exibidos na Tabela 4.12, encontram-se dentro da faixa de valores reportados por Toledo e Pereira (2001).

Rodrigues e Brandão (1993) e Born, Lenharo e Kahn (1996) também determinaram os parâmetros de rede de algumas das apatitas brasileiras contempladas nesta tese. A comparação entre os resultados reportados por estes autores e aqueles obtidos neste trabalho é apresentada na Tabela 4.13, em que se observa que os valores de $c$ e $V_{C U}$ determinados são muito próximos daqueles reportados por tais autores. Por outro lado, com exceção para a apatita ATP, a magnitude do parâmetro a determinado para as apatitas deste estudo é ligeiramente superior aos reportados pela literatura como se observa por Rodrigues e Brandão (1993) e Born, Lenharo e Kahn (1996) como se observa na Tabela 4.13.

Vários trabalhos se dedicam à investigação do efeito das substituições que ocorrem na estrutura cristalina das apatitas nos parâmetros de cela unitária. Lenharo (1994), sintetizando as informações da bibliografia, observou que a partir da fluorapatita com parâmetros cristalográficos $a=9,37 \AA$ e $c=6,88 \AA$ :

- A substituição do Ca por um cátion maior (Sr, Ba, Ce, La) provoca o aumento simultâneo de a e $c$;

- A substituição de $\mathrm{F}^{-}$por um ânion maior, como $\mathrm{OH}^{-}$, ocasiona a expansão do eixo a e contração do eixo $c$;

- A substituição de $\mathrm{PO}_{4}{ }^{3-}$ por $\mathrm{CO}_{3}{ }^{2-}$ causa uma diminuição de a e um aumento de $c$. 
Tabela 4.13 - Comparação entre os parâmetros de rede das apatitas determinados nesta tese e encontrados em trabalhos da literatura.

Tabela 4.12

Trabalhos da literatura

Apatitas

$$
a(\AA ̊) \quad c(\AA) \quad V_{C U}\left(\AA^{3}\right) \quad a(\AA) \quad c(\AA) \quad V_{C U}\left(\AA^{3}\right) \quad \text { Referência }
$$

\begin{tabular}{|c|c|c|c|c|c|c|c|}
\hline AAR & 9,400 & 6,891 & 527,3 & 9,340 & 6,890 & 527,2 & $\begin{array}{c}\text { Born, Lenharo e } \\
\text { Kahn (1996) }\end{array}$ \\
\hline ACJ & 9,402 & 6,886 & 526,7 & 9,340 & 6,887 & 527,0 & $\begin{array}{c}\text { Born, Lenharo e } \\
\text { Kahn (1996) }\end{array}$ \\
\hline \multirow{2}{*}{ ATP } & \multirow{2}{*}{9,404} & \multirow{2}{*}{6,592} & \multirow{2}{*}{527,8} & 9,402 & 6,893 & 527,6 & $\begin{array}{c}\text { Rodrigues e } \\
\text { Brandão (1993) }\end{array}$ \\
\hline & & & & 9,406 & 6,892 & 528,0 & $\begin{array}{c}\text { Born, Lenharo e } \\
\text { Kahn (1996) }\end{array}$ \\
\hline
\end{tabular}

Comparando-se a análise de Lenharo (1994) com os parâmetros de cela unitária da Tabela 4.12, verifica-se que as hidroxi-fluorapatitas (AAN, AAR, ACJ, ASQ e ATP), apresentam os maiores valores de a $(9,387-9,404 \AA)$, e menores valores de $c(6,886-6,893 \AA)$, em comparação à carbonato-apatita ASO que exibe $a$ $=9,340 \AA$ e $c=6,896 \AA$ (Tabela 4.12). A contração do eixo a e expansão do eixo $c$ da carbonato-fluorapatita ASO estão de acordo com as observações feitas por Lenharo (1994).

A cristalinidade da apatita metamórfica ASQ é peculiar porque, enquanto seus elevados valores de GC $(78 \%)$ e TC $\left(\mathrm{TC}_{(\mathrm{h} 00)}=81 \mathrm{~nm}, \mathrm{TC}_{(0 \mathrm{k} 0)}=936 \mathrm{~nm}\right.$, $\mathrm{TC}_{(00))}>1.000 \mathrm{~nm}$ ) indicam alta cristalinidade, a magnitude da microdeformação $\left(M D=460 \times 10^{-4}\right)$ também é alta, o que caracteriza materiais menos cristalinos (Tabela 4.12). Em termos de composição química, o que diferencia a ASQ das demais apatitas é a presença de ferro $\mathrm{Fe}_{2} \mathrm{O}_{3}$ observada tanto na análise por $\mathrm{FRX}$ (3,2\%-Tabela 4.1) como por WDS/EDS (2,1\%-Tabela 4.2). No entanto, não se sabe se o ferro da ASQ é um substituinte na estrutura cristalina da apatita ou se participa de pequenas inclusões observadas nas partículas por MEV (Figura 4.2). Caso a 
primeira opção seja verdadeira, a presença de ferro seria uma possível explicação para a disparidade (GC e TC versus MD) encontrada na cristalinidade da ASQ. Além disso, $A S Q$ contém urânio identificado por WDS/EDS $\left(\mathrm{UO}_{2}=0,3 \%\right)$.

A análise estatística da correlação existente entre os parâmetros de rede, de cristalinidade e físicos gerou os coeficientes de correlação $(R)$ que são exibidos na Tabela 4.14. Os valores marcados $\left(^{*}\right)$ são aqueles considerados significativos dentro de um intervalo de confiança de 95\%. De acordo com esta análise, observa-se que as relações que se destacam são:

- Os parâmetros de rede estão relacionados entre si: c é inversamente proporcional a a $(R=-0,75)$ e a $V_{C U}(R=-0,68)$. O parâmetro a e $V_{c u}$ são diretamente proporcionais $(R=0,99)$;

- Os parâmetros físicos também apresentam inter-relação: $P$ aumenta com 0 aumento de $S(R=0,97)$, e d diminui com o aumento de $S(R=-0,94)$ e $P$ $(R=-0,96)$. Isto indica que o aumento da porosidade $(P)$ conduz ao aumento da área superficial (S), e redução da densidade;

- Apatitas com maior MD apresentam menor densidade (d), haja vista que d diminui com MD $(R=-0,93)$;

- Amostras com maior MD também apresentam maior porosidade $(P)$ e área superficial (S), corroborados por $R=0,82$ e $R=0,76$, respectivamente;

- MD aumenta com o aumento de $c(R=0,69)$ e diminui com o aumento de $a$ $(R=-0,85)$. Como visto anteriormente, Lenharo (1994) observou que a incorporação de $\mathrm{CO}_{3}{ }^{2-}$ na estrutura cristalina das apatitas conduz à expansão do eixo $c$, e contração do eixo a. De acordo com esta abordagem, a substituição de $\mathrm{PO}_{4}{ }^{3-}$ por $\mathrm{CO}_{3}{ }^{2-}$ conduziria a um aumento da deformação de rede (MD). Isto explicaria o valor elevado de $\mathrm{MD}$ exibido pela apatita sedimentar ASO $\left(600 \times 10^{-4}\right)$, que apresenta substituição de $\mathrm{PO}_{4}{ }^{3-}$ por $\mathrm{CO}_{3}{ }^{2-}$ de acordo com as análises por FTIR da Seção 4.1.1. 
Tabela 4.14 - Coeficientes de correlação linear (R) entre os parâmetros de rede (a, c e $\left.\mathrm{V}_{\mathrm{Cu}}\right)$, de cristalinidade (GC, TC e MD) e físicos (d, S e P) para as apatitas.

\begin{tabular}{|c|c|c|c|c|c|c|c|c|c|c|c|c|}
\hline Parâmetros & $\begin{array}{l}\text { GC } \\
(\%)\end{array}$ & $\begin{array}{c}\mathrm{TC}_{(\mathrm{h} 00)} \\
(\mathrm{nm})\end{array}$ & $\begin{array}{c}\mathrm{TC}_{(0 \mathrm{k} 0)} \\
(\mathrm{nm})\end{array}$ & $\begin{array}{c}\mathrm{TC}_{(0 \mathrm{k} 0)} \\
(\mathrm{nm})\end{array}$ & $\begin{array}{l}\mathrm{TC}_{\mathrm{M}} \\
(\mathrm{nm})\end{array}$ & MD & $\begin{array}{c}a \\
(\AA)\end{array}$ & $\begin{array}{c}c \\
(\AA)\end{array}$ & $\begin{array}{l}V_{C U} \\
\left(\AA^{3}\right)\end{array}$ & $\begin{array}{c}d \\
\left(\mathrm{~g} \mathrm{~cm}^{-3}\right)\end{array}$ & $\begin{array}{c}S \\
\left(\mathrm{~cm}^{2} \mathrm{~g}^{-1}\right)\end{array}$ & $\begin{array}{c}P \\
(\%)\end{array}$ \\
\hline GC (\%) & $-* *$ & $-0,20$ & 0,66 & $0,88^{*}$ & 0,69 & 0,11 & 0,36 & $-0,28$ & 0,37 & 0,21 & $-0,52$ & $-0,39$ \\
\hline $\mathrm{TC}_{(\mathrm{h} 00)}(\mathrm{nm})$ & $-0,20$ & - & $-0,02$ & 0,10 & 0,14 & $-0,06$ & $-0,12$ & $-0,25$ & $-0,17$ & $-0,12$ & 0,25 & 0,21 \\
\hline $\mathrm{TC}_{(0 \mathrm{k} 0)}(\mathrm{nm})$ & 0,67 & $-0,02$ & - & 0,68 & $0,94^{*}$ & $-0,19$ & 0,36 & $-0,11$ & 0,37 & 0,31 & $-0,51$ & $-0,31$ \\
\hline $\mathrm{TC}_{(00 \mathrm{l})}(\mathrm{nm})$ & $0,88^{*}$ & 0,10 & 0,68 & - & $0,84^{*}$ & $-0,21$ & 0,55 & $-0,53$ & 0,56 & 0,46 & $-0,65$ & $-0,55$ \\
\hline MD & 0,69 & 0,14 & 0,94 & $0,84^{*}$ & - & $-0,36$ & 0,53 & $-0,37$ & 0,53 & 0,49 & $-0,64$ & $-0,48$ \\
\hline $\mathrm{TC}_{\mathrm{M}}(\mathrm{nm})$ & 0,11 & $-0,06$ & $-0,19$ & $-0,21$ & $-0,36$ & - & $-0,85^{*}$ & 0,69 & $-0,83^{*}$ & $-0,93^{*}$ & $0,76^{*}$ & $0,82^{*}$ \\
\hline$a(\AA)$ & 0,36 & $-0,12$ & 0,36 & 0,55 & 0,53 & $-0,85^{\star}$ & - & $-0,75$ & $0,99^{*}$ & $0,97^{*}$ & $-0,97^{\star}$ & $-0,99$ * \\
\hline$c(\AA)$ & $-0,28$ & $-0,25$ & $-0,11$ & $-0,53$ & $-0,37$ & 0,69 & $-0,75$ & - & $-0,68$ & $-0,74$ & 0,68 & $0,78^{*}$ \\
\hline $\mathrm{V}_{\mathrm{CU}}\left(\AA^{3}\right)$ & 0,37 & $-0,17$ & 0,37 & 0,56 & 0,53 & $-0,83^{*}$ & $0,99^{*}$ & $-0,68$ & - & $0,97^{*}$ & $-0,97^{\star}$ & $-0,97^{*}$ \\
\hline$d\left(\mathrm{~g} \mathrm{~cm}^{-3}\right)$ & 0,21 & $-0,12$ & 0,31 & 0,46 & 0,49 & $-0,93^{*}$ & $0,97^{*}$ & $-0,74$ & $0,97^{*}$ & - & $-0,94^{*}$ & $-0,96^{*}$ \\
\hline $\mathrm{S}\left(\mathrm{cm}^{2} \mathrm{~g}^{-1}\right)$ & $-0,52$ & 0,25 & $-0,51$ & $-0,65$ & $-0,64$ & $0,76^{*}$ & $-0,97^{\star}$ & 0,68 & $-0,97^{*}$ & $-0,93^{*}$ & - & $0,97^{*}$ \\
\hline $\mathbf{P}(\%)$ & $-0,39$ & 0,21 & $-0,31$ & $-0,55$ & $-0,48$ & $0,82^{*}$ & $-0,99^{*}$ & $0,78^{*}$ & $-0,97^{*}$ & $-0,96^{*}$ & $0,97^{*}$ & - \\
\hline
\end{tabular}

$\left({ }^{*}\right)$ Correlação significativa, dentro de um intervalo de confiança de $95 \%$.

$\left.{ }^{* \star}\right)$ Correlação entre valores de uma mesma variável. 


\subsubsection{Cristalinidade das calcitas}

No que diz respeito às calcitas, seus parâmetros de rede $\left(a, c, V_{C U}\right)$ e de cristalinidade (GC, TC, MD), determinados por meio do método de Rietveld, são apresentados na Tabela 4.15 e Figura 4.9. O tamanho de cristalito (TC) das calcitas foi refinado de forma isotrópica, portanto, apenas um valor médio de TC foi determinado.

Um exemplo de gráfico de Rietveld, correspondente à calcita $\mathrm{CCl}$, está ilustrado na Figura 4.10. Números GOF com valores menores ou iguais 2,4 (Tabela 4.15), além da concordância entre os perfis de difração calculados e observados (Figura 4.9 para CCl e Apêndice B para demais calcitas) são um indicativo de que os refinamentos foram adequados para a determinação dos parâmetros de rede e de cristalinidade das calcitas.

Tabela 4.15 - Parâmetros de rede e de cristalinidade das calcitas.

\begin{tabular}{cccccccc}
\hline Calcita & GC (\%) & TC $(\mathbf{n m})$ & MD & $a^{(*)}(\AA)$ & $c^{(* *}(\AA)$ & $V_{\mathbf{C u}^{(+)}\left(\AA^{3}\right)}$ & GOF \\
\hline CAM & 88 & 134 & 0,06 & 4,989 & 17,061 & 367,7 & 2,2 \\
\hline CCI & 89 & 164 & 0,13 & 4,981 & 17,021 & 365,7 & 2,4 \\
\hline CCJ & 84 & 164 & 0,16 & 4,978 & 17,015 & 365,2 & 1,8 \\
\hline CRO & 82 & 152 & 0,08 & 4,986 & 17,049 & 367,1 & 1,6 \\
\hline CRT & 88 & 122 & 0,08 & 4,989 & 17,060 & 367,7 & 2,1 \\
\hline CSQ & 87 & 161 & 0,08 & 4,987 & 17,055 & 367,3 & 2,2 \\
\hline
\end{tabular}

$\left(^{*}\right)$ desvio padrão $\left.(\mathrm{dp})<0,0007 .{ }^{* *}\right) \mathrm{dp}<0,005 .(+) \mathrm{dp}<0,2$ 


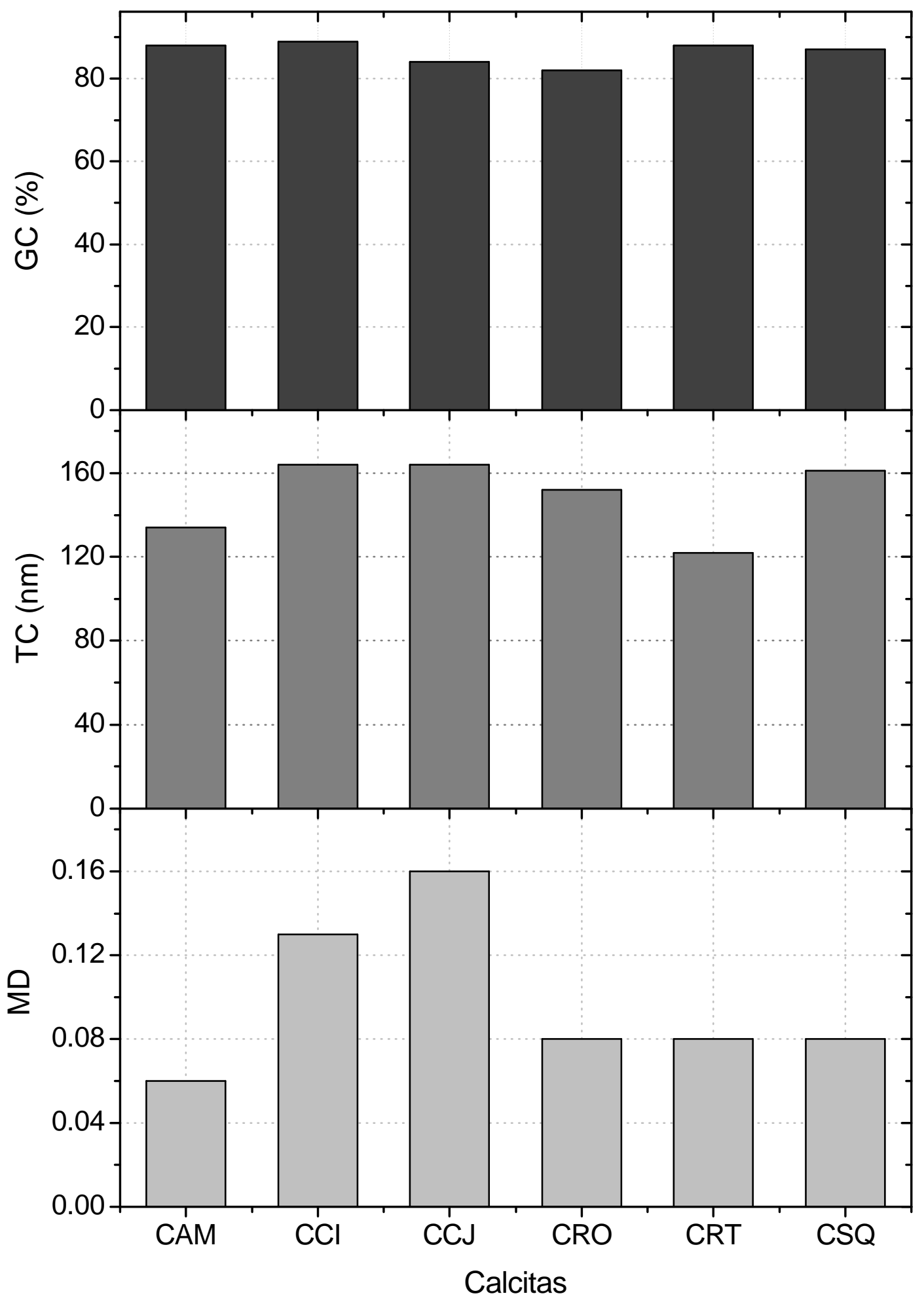

Figura 4.9 - Variação dos parâmetros de cristalinidade das calcitas com a origem das amostras. 


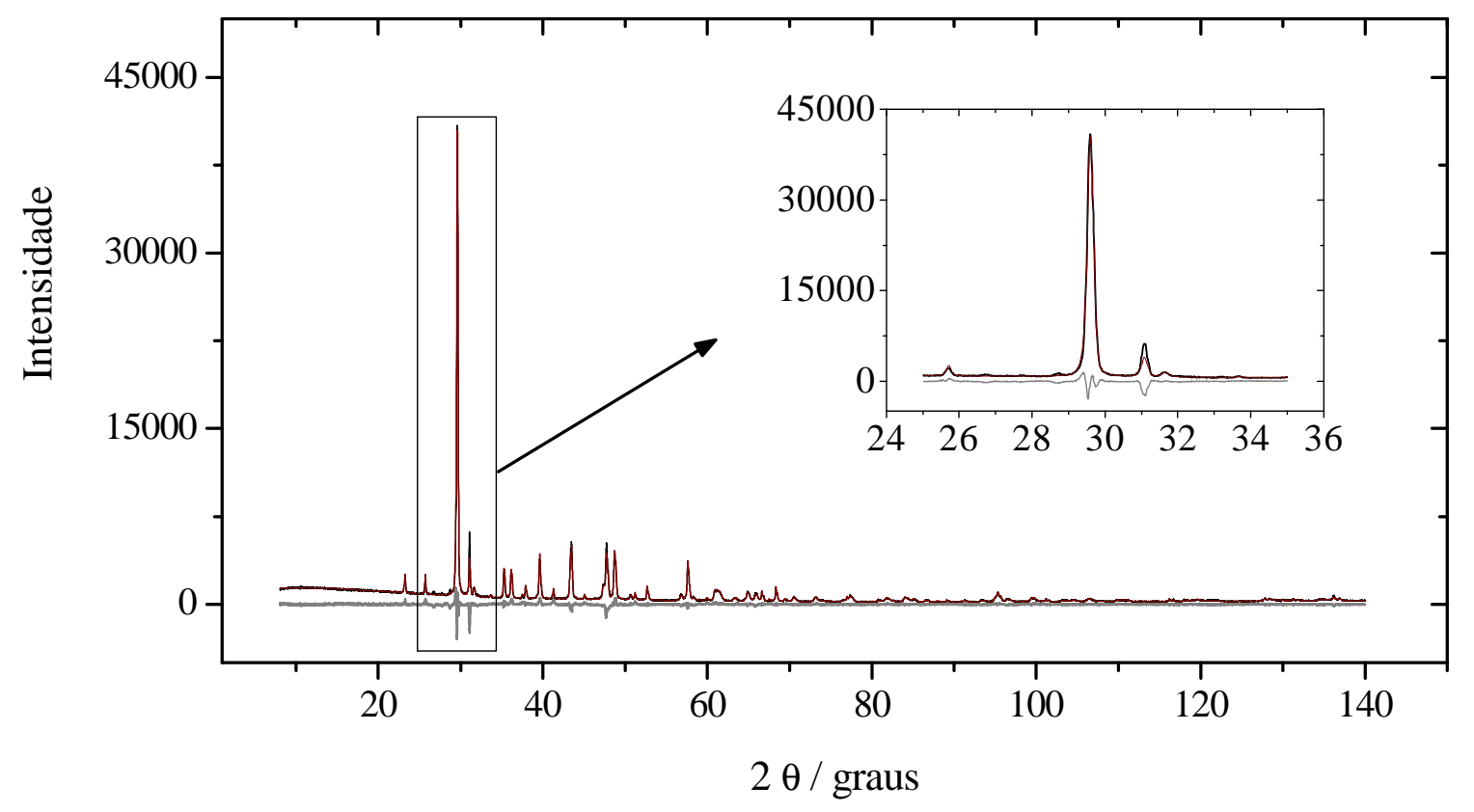

Figura 4.10 - Exemplo de gráfico de Rietveld da calcita CCI. Comparação entre perfis de difração: - observado e - calculado ( - resíduo). O quadro interno exibe a região $25^{\circ}<2 \Theta<38^{\circ}$.

Os dados apresentados da Tabela 4.15 e na Figura 4.9 indicam que:

- Tanto o grau de cristalinidade (82-89\%) como o tamanho de cristalito (122$164 \mathrm{~nm}$ ) variam muito pouco com a origem das amostras de calcita;

- A calcita CCl é aquela que apresenta o maior valor de GC (89\%), enquanto o menor valor obtido para este parâmetro corresponde à calcita CRO (82\%);

- As calcitas CCl e CCJ apresentam o maior TC (164 nm), e a calcita CRT exibe o menor valor de TC (122 nm);

- A magnitude da microdeformação, por outro lado, varia amplamente dentro do grupo de calcitas analisadas (de 0,06 para CAM a 0,16 para CCJ). A ordem decrescente de MD das calcitas é: $\mathrm{CCJ}>\mathrm{CCl}>\mathrm{CRO}, \mathrm{CRT}, \mathrm{CSQ}>\mathrm{CAM}$.

Osawaro, Orumwense e Forssberg (1991) determinaram o tamanho de cristalito e a microdeformação de calcitas após diferentes tempos de moagem. Os autores encontraram tamanho de cristalito entre 46 e $311 \mathrm{~nm}$ e microdeformação entre 0,17 e 0,41 . Os valores de TC encontrados na Tabela 4.15 se encontram dentro do intervalo de valores reportados por Osawaro, Orumwense e Forssberg (1991). As calcitas analisadas por tais autores, por outro lado, apresentaram valores 
de microdeformação superiores àqueles apresentados na Tabela 4.15. Não se encontrou trabalho na literatura que tenha se dedicado em determinar o grau de cristalinidade de calcitas.

Skalá e Jakes (1999) determinaram os parâmetros de rede de calcitas de diferentes origens por meio do método de Rietveld (refinamento pelo programa FullProf). Tais autores encontraram: $a=0,982-0,989 \AA ; c=17,04-17,06 \AA \mathrm{e}$ $V_{\mathrm{CU}}=366,3-367,4 \AA^{3}$. Tais resultados estão em concordância com aqueles obtidos neste trabalho (Tabela 4.15).

Os coeficientes de correlação $(R)$ linear entre os parâmetros de rede, de cristalinidade e físicos das calcitas contempladas neste trabalho estão ilustrados na Tabela 4.16. A análise destes coeficientes indica que:

- Os parâmetros de rede exibem correlação entre si: a e $c$ são diretamente proporcionais $(R=0,99)$, e o volume da cela unitária aumenta com o aumento das dimensões a $(R=0,99)$ e $c(R=0,99)$;

- $\mathrm{P}$ é inversamente proporcional a TC $(R=-0,83)$, o que indica que quanto maior é o tamanho de cristalito (TC) das calcitas menor sua porosidade (P);

- O parâmetro de cristalinidade MD diminui com o aumento de $a(R=-0,98)$ de $c(R=-0,97)$ e $V_{C U}(R=-0,98)$, ou seja, quanto menores as dimensões da rede cristalina, maior sua deformação;

- $d$ aumenta com MD $(R=0,95)$ e, diminui com a $(R=-0,99), c(R=-0,97), V_{C U}$ $(R=-0,98)$. 
Tabela 4.16 - Coeficientes de correlação linear $(\mathrm{R})$ entre os parâmetros de rede $\left(a, c\right.$ e $\left.\mathrm{V}_{\mathrm{cu}}\right)$, de cristalinidade (GC, TC e MD) e físicos (d, S e P.) para as calcitas.

\begin{tabular}{|c|c|c|c|c|c|c|c|c|c|}
\hline Parâmetros & GC (\%) & $\mathrm{TC}(\mathrm{nm})$ & MD & $a(\AA)$ & $c(\AA)$ & $V_{C u}\left(\AA^{3}\right)$ & $d\left(\mathrm{~g} \mathrm{~cm}^{-3}\right)$ & $\mathrm{S}\left(\mathrm{cm}^{2} \mathrm{~g}^{-1}\right)$ & $\mathbf{P}(\%)$ \\
\hline GC (\%) & $-* *$ & $-0,29$ & $-0,17$ & 0,26 & 0,17 & 0,19 & $-0,25$ & $-0,59$ & $-0,20$ \\
\hline $\mathrm{TC}(\mathrm{nm})$ & $-0,29$ & - & 0,65 & $-0,77$ & $-0,74$ & $-0,76$ & 0,81 & $-0,15$ & $-0,83^{*}$ \\
\hline MD & $-0,17$ & 0,65 & - & $-0,98^{*}$ & $-0,97^{*}$ & $-0,98^{*}$ & $0,95^{*}$ & $-0,18$ & $-0,69$ \\
\hline$a(\AA ̊)$ & 0,26 & $-0,77$ & $-0,98^{*}$ & - & $0,99^{*}$ & $0,99^{*}$ & $-0,99^{*}$ & 0,11 & 0,76 \\
\hline$c(\AA)$ & 0,17 & $-0,74$ & $-0,97^{*}$ & $0,99^{*}$ & - & $0,99^{*}$ & $-0,97^{*}$ & 0,09 & 0,77 \\
\hline$V_{C U}\left(\AA^{3}\right)$ & 0,19 & $-0,76$ & $-0,98^{*}$ & $0,99^{*}$ & $0,99^{*}$ & - & $-0,98^{*}$ & 0,13 & 0,78 \\
\hline$d\left(\mathrm{~g} \mathrm{~cm}^{-3}\right)$ & $-0,25$ & 0,81 & $0,95^{*}$ & $-0,99^{*}$ & $-0,97^{*}$ & $-0,98^{*}$ & - & $-0,20$ & $-0,81$ \\
\hline$S\left(\mathrm{~cm}^{2} \mathrm{~g}^{-1}\right)$ & $-0,59$ & $-0,15$ & $-0,18$ & 0,11 & 0,09 & 0,13 & $-0,20$ & - & 0,49 \\
\hline P (\%) & $-0,20$ & $-0,83^{*}$ & $-0,69$ & 0,76 & 0,77 & 0,78 & $-0,81$ & 0,49 & - \\
\hline
\end{tabular}

${ }^{*}$ ) Correlação significativa dentro de um intervalo de confiança de $95 \%$.

$\left.{ }^{* *}\right)$ Correlação entre valores de uma mesma variável. 


\subsection{Dissolução}

De acordo com o experimentalmente observado, todas as curvas de dissolução apresentam a mesma tendência. Dessa forma, na Figura 4.11, estão ilustrados exemplos de curvas de dissolução da apatita AAR e da calcita CRO em $\mathrm{pH} 8$ e 10,

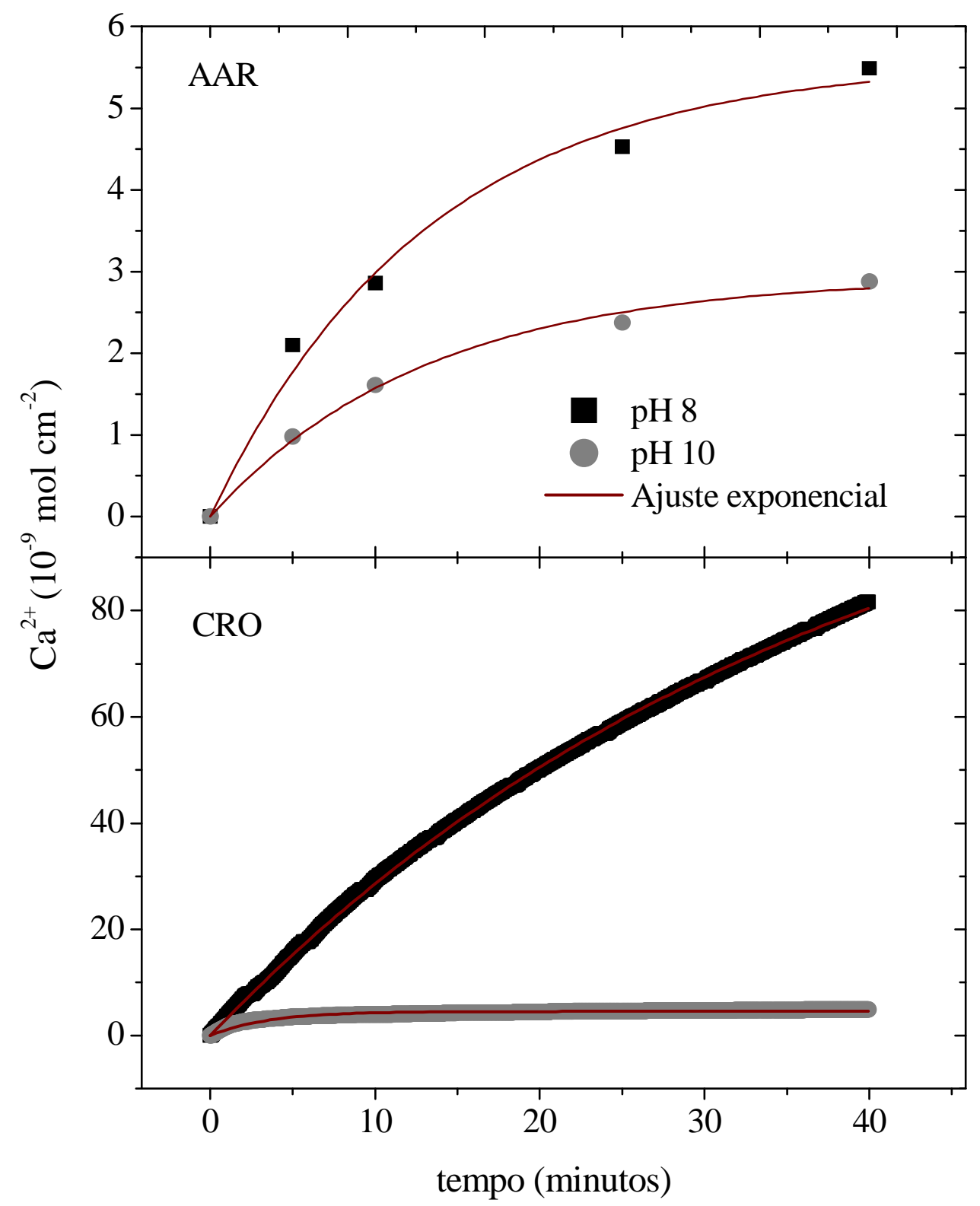

Figura 4.11 - Exemplo de curvas de dissolução em pH 8 e 10: apatita AAR e calcita CRO. 
As curvas de dissolução das calcitas foram obtidas por meio do método do $\mathrm{pH}$ constante, cujas condições experimentais permitiram a aquisição de um ponto por segundo, durante o monitoramento da introdução de solução ácida à reação. Com isto, foi possível obter curvas de dissolução com uma grande quantidade de pontos, como se observa na Figura 4.11 para CRO. Os ensaios de dissolução das apatitas, por outro lado, foram realizados por meio de análise da concentração de íons $\mathrm{Ca}^{2+}$ na solução, após diferentes intervalos de tempo de dissolução. Sendo assim, as curvas de dissolução das apatitas exibem cinco pontos que correspondem à quantidade de íons $\mathrm{Ca}^{2+}$ dissolvidos após $0,5,10,25$ e 40 minutos.

Os perfis de dissolução tanto das apatitas como das calcitas (Figura 4.11) exibem duas etapas de dissolução distintas: uma etapa inicial rápida, caracterizada por um parâmetro denominado de velocidade na etapa rápida $\left(\mathrm{V}_{\mathrm{R}}\right)$. Tal etapa é seguida de outra etapa, caracterizada por uma velocidade de dissolução lenta $\left(V_{L}\right)$. Além disso, como foi visto no Capítulo 3 (Seção 3.3), baseando-se na premissa de que a dissolução desses minerais obedece a um modelo de $1^{\text {a }}$ ordem, pode-se calcular a quantidade de íons $\mathrm{Ca}^{2+}$ máxima $\left(\mathrm{Ca}^{2+}{ }_{\text {MAX }}\right)$ que pode ser liberada para a solução, assim como a constante cinética $(\mathrm{k})$ do processo de dissolução.

\subsubsection{Dissolução das apatitas}

Os valores obtidos para os parâmetros de dissolução $\left(\mathrm{V}_{\mathrm{R}}, \mathrm{V}_{\mathrm{L}}, \mathrm{Ca}^{2+}{ }_{\mathrm{MAX}} \mathrm{e} \mathrm{k}\right)$ correspondentes às apatitas são exibidos na Tabela 4.17 e Figura 4.12. Entre as amostras de apatitas de diferentes origens existem diferenças significativas no que concerne aos parâmetros de dissolução, principalmente $\mathrm{Ca}^{2+}{ }_{\mathrm{MAX}}, \mathrm{V}_{\mathrm{R}}$ e $\mathrm{V}_{\mathrm{L}}$. Por exemplo, enquanto $A C J$ dissolve com velocidade na etapa rápida $\left(V_{R}\right)$ igual a $4,4 \times 10^{-11} \mathrm{~mol} \mathrm{~s}^{-1} \mathrm{~cm}^{-2}$, ASO apresenta $V_{R}$ mais de duzentas vezes inferior $\left(1,3 \times 10^{-13}\right.$ $\left.\mathrm{mol} \mathrm{s} \mathrm{cm}^{-2}\right)$. 
Tabela 4.17 - Parâmetros de dissolução das apatitas.

\begin{tabular}{|c|c|c|c|c|c|c|c|c|}
\hline \multirow[b]{2}{*}{ Apatita } & \multicolumn{4}{|c|}{ pH 8} & \multicolumn{4}{|c|}{ pH 10} \\
\hline & $\begin{array}{c}\mathrm{V}_{\mathrm{R}} \\
10^{-13} \\
\mathrm{~mol} \mathrm{~s}^{-1} \mathrm{~cm}^{-2}\end{array}$ & $\begin{array}{c}\mathrm{V}_{\mathrm{L}} \\
10^{-13} \\
\mathrm{~mol} \mathrm{~s}^{-1} \mathrm{~cm}^{-2}\end{array}$ & $\begin{array}{c}\mathrm{Ca}^{2+}{ }_{\text {MAX }} \\
10^{-10} \\
\mathrm{~mol} \mathrm{~cm}\end{array}$ & $\begin{array}{c}k \\
10^{-3} \\
s^{-1}\end{array}$ & $\begin{array}{c}\mathrm{V}_{\mathrm{R}} \\
10^{-13} \\
\mathrm{~mol} \mathrm{~s}^{-1} \mathrm{~cm}^{-2}\end{array}$ & $\begin{array}{c}\mathrm{V}_{\mathrm{L}} \\
10^{-13} \\
\mathrm{~mol} \mathrm{~s}^{-1} \mathrm{~cm}^{-2}\end{array}$ & $\begin{array}{c}\mathrm{Ca}^{2+}{ }_{\mathrm{MAX}} \\
10^{-10} \\
\mathrm{~mol} \mathrm{~cm}\end{array}$ & $\begin{array}{c}k \\
10^{-3} \\
s^{-1}\end{array}$ \\
\hline AAR & 47,7 & 14,6 & 55,9 & 1,3 & 26,8 & 7,1 & 29,3 & 1,3 \\
\hline ACJ & 442,4 & 66,1 & 355,8 & 2,6 & 245,4 & 43,7 & 218,5 & 1,8 \\
\hline AIP & 343,7 & 87,3 & 490,6 & 2,1 & 209,7 & 21,4 & 167,1 & 2,1 \\
\hline ASO & 1,3 & 0,2 & 1,1 & 2,4 & 0,8 & 0,1 & 0,8 & 2,3 \\
\hline ASQ & 129,5 & 20,4 & 109,1 & 2,5 & 102,7 & 6,7 & 73,3 & 3,5 \\
\hline
\end{tabular}



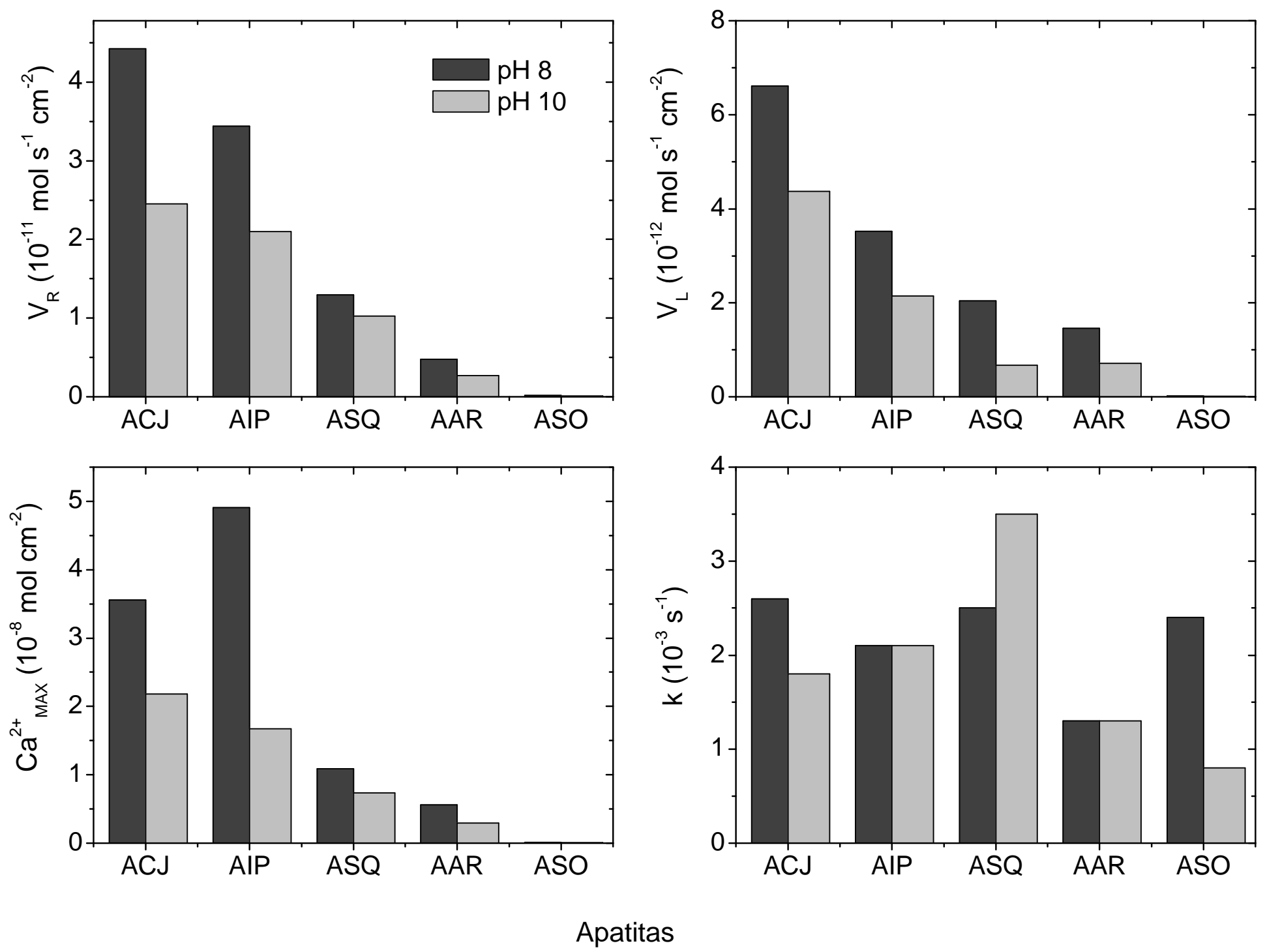

Figura 4.12 - Variação dos parâmetros de dissolução das apatitas com a origem da amostra e com o pH da reação. 
A análise do comportamento das apatitas nos ensaios de dissolução (Tabela 4.17 e Figura 4.12) indica que:

- Os valores de $\mathrm{V}_{\mathrm{R}}, \mathrm{V}_{\mathrm{L}}$ e $\mathrm{Ca}^{2+}{ }_{\mathrm{MAX}}$ são maiores em $\mathrm{pH} 8$ do que em $\mathrm{pH} 10$, o que indica que em pH 8 a dissolução é mais rápida e disponibiliza mais íons $\mathrm{Ca}^{2+}$ para a solução após o alcance do estado estacionário;

- ACJ e AIP são as apatitas que dissolvem com maior velocidade e disponibilizam mais íons $\mathrm{Ca}^{2+}$ para a solução;

- $A A R$ e $A S Q$ apresentaram dissolução intermediária. ASQ atinge o estado estacionário mais rapidamente do que AAR devido ao seu valor mais elevado de $\mathrm{k}$;

- ASO dissolve muito lentamente em comparação com as demais apatitas.

Com relação ao tipo de apatita, as hidroxi-fluorapatitas (AAR, ACJ, AIP e ASQ) dissolvem mais rapidamente em comparação à carbonato-fluorapatita (ASO). Guidry e Mackenzie (2003) também observaram que a velocidade de dissolução da fluorapatita é superior à da carbonatoapatita quando os resultados são normalizados em relação à área superficial na faixa de $\mathrm{pH}$ entre 4 e 7.

\subsubsection{Dissolução das calcitas}

Os parâmetros de dissolução obtidos para as calcitas são apresentados na Tabela 4.18 e estão organizados na Figura 4.13. O erro relativo percentual $\left(\varepsilon_{\%}\right)$ exibido na Tabela 4.18 foi calculado a partir de três repetições de ensaios de dissolução. Ele representa o quociente entre o desvio padrão e a média aritmética, multiplicado por 100 .

Como observado no caso das apatitas, as velocidades de dissolução $\left(\mathrm{V}_{\mathrm{R}} \mathrm{e}\right.$ $\mathrm{V}_{\mathrm{L}}$ ) e a quantidade máxima de íons $\mathrm{Ca}^{2+}$ dissolvidos $\left(\mathrm{Ca}^{2+}{ }_{\mathrm{MAX}}\right)$ diminuem quando $\mathrm{O}$ pH da solução aumenta de 8 para 10. Uma tendência oposta é verificada com 
relação à constante cinética, o que indica que o estado estacionário é atingido mais rapidamente em $\mathrm{pH} 10$ do que em pH 8 (Tabela 4.18 e Figura 4.13).

Comparando-se os valores de velocidade de dissolução na etapa rápida $\left(\mathrm{V}_{\mathrm{R}}\right)$ com os da etapa lenta $\left(\mathrm{V}_{\mathrm{L}}\right)$ versus $\mathrm{pH}$, observa-se que $\mathrm{V}_{\mathrm{L}}$ em $\mathrm{pH} 10$ é muito menor do que em pH 8. Todavia, tal diferença é menos acentuada quando se observa a variação de $\mathrm{V}_{\mathrm{R}}$ com o $\mathrm{pH}$ da solução (Tabela 4.18 e Figura 4.13).

$\mathrm{Na}$ Tabela 4.18 e Figura 4.13, observa-se a seguinte ordem decrescente de $\mathrm{V}_{\mathrm{R}}$ : CRT > CCJ, CAM, CCI > CRO > CRQ, que é independente do $\mathrm{pH}$. Por outro lado, a ordem decrescente de $\mathrm{V}_{\mathrm{L}}$ depende do $\mathrm{pH}$ :

- $\mathrm{Em} \mathrm{pH}=8, \mathrm{~V}_{\mathrm{L}}$ decresce de acordo com a seguinte ordem: CRT, CAM > CCJ, $\mathrm{CCl}, \mathrm{CRO}>\mathrm{CSQ}$;

- $\mathrm{Em} \mathrm{pH}=10, \mathrm{~V}_{\mathrm{L}}$ decresce de acordo com a seguinte ordem: CCJ > CAM, CCI $>\mathrm{CRT}>\mathrm{CRO}>\mathrm{CSQ}$.

Considerando a quantidade máxima de íons $\mathrm{Ca}^{2+}$ que as calcitas são capazes de colocar em solução ( $\mathrm{Ca}^{2+}{ }_{\mathrm{MAX}}$ ), observa-se na Tabela 4.18 e Figura 4.13 que:

- $\mathrm{Em}$ pH 8, a seguinte sequência decrescente é observada: CAM > CRT > CRO $>\mathrm{CCJ}, \mathrm{CCl}>\mathrm{CSQ}$;

- Em pH 10, observa-se a seguinte ordem decrescente: $\mathrm{CCl}>\mathrm{CCJ}>\mathrm{CRO}>$ $\mathrm{CRT}, \mathrm{CAM}>\mathrm{CSQ}$.

Enfocando a constante cinética $(k)$ da dissolução, observa-se na Tabela 4.18 e Figura 4.12 que:

- $\mathrm{Em} \mathrm{pH}$ 8, ordenando os valores de $\mathrm{k}$ de modo decrescente, tem-se: CRO > $\mathrm{CRT}>\mathrm{CAM}, \mathrm{CCI}, \mathrm{CSQ}>\mathrm{CCJ}$;

- $\mathrm{Em}$ pH 10, tal sequência é: CCJ, CCI, CSQ > CRT, CRO > CAM; 
Tabela 4.18 - Parâmetros de dissolução das calcitas.

\begin{tabular}{|c|c|c|c|c|c|c|c|c|c|}
\hline $\mathrm{pH}$ & Calcita & $\begin{array}{c}V_{R} \\
10^{-13} \mathrm{~mol} \mathrm{~cm}^{-2} \mathrm{~s}^{-1}\end{array}$ & $\begin{array}{c}\varepsilon_{\%} \\
\left(V_{R}\right)\end{array}$ & $\begin{array}{c}\mathrm{V}_{\mathrm{L}} \\
10^{-13} \mathrm{~mol} \mathrm{~cm}^{-2} \mathrm{~s}^{-1}\end{array}$ & $\begin{array}{c}\varepsilon_{\%} \\
\left(V_{L}\right)\end{array}$ & $\begin{array}{c}\mathrm{Ca}^{2+}{ }_{\text {MAX }} \\
10^{-9} \mathrm{~mol} \mathrm{~cm}^{-2}\end{array}$ & $\begin{array}{c}\varepsilon_{\%} \\
\left(\mathrm{Ca}^{2+}{ }_{\mathrm{MAX}}\right)\end{array}$ & $\begin{array}{c}k \\
10^{-4} \mathrm{~s}^{-1}\end{array}$ & $\begin{array}{l}\varepsilon_{\%} \\
(k)\end{array}$ \\
\hline \multirow{6}{*}{8} & CAM & 694,5 & 0,8 & 417,1 & 3,9 & 201,0 & 5,2 & 3,8 & 5,7 \\
\hline & $\mathrm{CCl}$ & 669,7 & 1,7 & 219,7 & 0,8 & 86,6 & 0,5 & 8,0 & 1,2 \\
\hline & CCJ & 728,0 & 5,1 & 240,2 & 3,3 & 90,8 & 4,8 & 7,7 & 2,6 \\
\hline & CRO & 519,7 & 5,0 & 265,2 & 4,5 & 115,0 & 6,1 & 4,7 & 6,5 \\
\hline & CRT & 880,7 & 0,6 & 417,3 & 1,4 & 178,0 & 4,9 & 5,6 & 3,7 \\
\hline & $\mathrm{CSQ}$ & 345,5 & 2,5 & 86,1 & 3,7 & 31,5 & 2,9 & 8,3 & 1,9 \\
\hline \multirow{6}{*}{10} & CAM & 292,5 & 3,2 & 8,2 & 6,1 & 8,27 & 3,3 & 40,1 & 5,5 \\
\hline & $\mathrm{CCl}$ & 260,0 & 3,8 & 7,5 & 1,3 & 8,28 & 6,1 & 41,1 & 6,0 \\
\hline & CCJ & 261,1 & 0,5 & 8,3 & 6,0 & 6,1 & 1,9 & 31,3 & 5,7 \\
\hline & CRO & 202,6 & 1,0 & 4,2 & 5,4 & 4,3 & 4,6 & 51,9 & 5,6 \\
\hline & CRT & 406,4 & 5,8 & 5,8 & 2,9 & 10,6 & 2,5 & 47,4 & 5,8 \\
\hline & $\mathrm{CSQ}$ & 167,4 & 2,0 & 4,6 & 1,6 & 4,8 & 2,4 & 41,6 & 6,3 \\
\hline
\end{tabular}



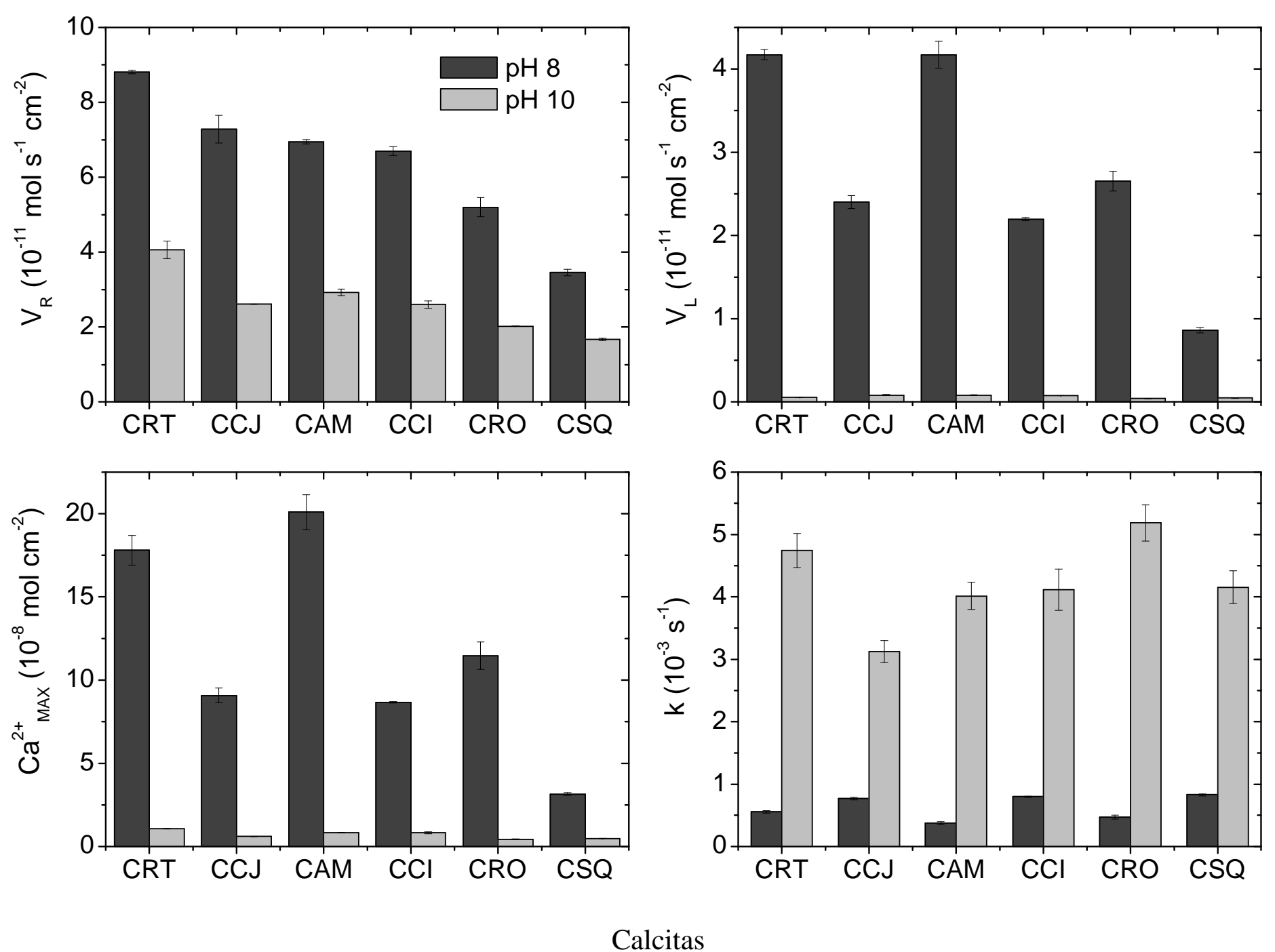

Figura 4.13 - Variação dos parâmetros de dissolução das calcitas com a origem da amostra e o com o pH da reação. 


\subsection{Flotação com oleato de sódio}

A resposta à flotação dos minerais foi determinada por meio de ensaios de microflotação realizados em Tubo de Hallimond modificado. Eles fornecem um valor de recuperação em massa que pode ser chamado de flotabilidade. Como reagente coletor, utilizou-se oleato de sódio em concentrações que assegurassem valores nem muito altos e nem muito baixos de flotabilidade, para permitir a comparação entre a resposta à flotação das diferentes amostras. As concentrações de coletor mais adequadas para que tal condição fosse atingida foram de $1,42 \times 10^{-5}$ para as apatitas e, $7,11 \times 10^{-6} \mathrm{~mol} \mathrm{~L}^{-1}$ para as calcitas.

O fato de a concentração de coletor necessária para alcançar os valores desejados de flotabilidade ser maior para as apatitas do que para as calcitas pode ser explicado com base nos resultados de dissolução. Como as calcitas dissolvem mais rapidamente do que as apatitas, as primeiras disponibilizam maior quantidade de íons $\mathrm{Ca}^{2+}$ para interagir com o coletor dentro do intervalo de 1 minuto, que corresponde ao tempo de condicionamento do coletor. Sendo assim, a flotabilidade das calcitas é maior em comparação com a flotabilidade das apatitas para uma mesma dosagem de coletor. Portanto, maior quantidade de coletor $\left(1,42 \times 10^{-5} \mathrm{~mol} \mathrm{~L}^{-1}\right)$ foi necessária nos ensaios de microflotação das apatitas, para que se obtivessem valores de flotabilidade similares aos das calcitas com uma menor concentração de oleato $\left(7,11 \times 10^{-6} \mathrm{~mol} \mathrm{~L}^{-1}\right)$.

\subsubsection{Flotabilidade das apatitas}

Os resultados de ensaios de microflotação com oleato de sódio $\left(1,42 \times 10^{-5} \mathrm{~mol} \mathrm{~L}^{-1}\right)$ em $\mathrm{pH} 8$ versus $\mathrm{pH} 10$, a que foram submetidas as apatitas, são apresentados na Tabela 4.19 e Figura 4.14. O erro relativo percentual $\left(\varepsilon_{\%}\right)$ obtido 
para a flotabilidade (F) das apatitas variou na faixa de $1 \%$ a $7 \%$ quando a flotação foi executada em $\mathrm{pH} 8$, e de $3 \%$ e $10 \%$ quando foi conduzida em $\mathrm{pH} 10$.

Tabela 4.19 - Flotabilidade das apatitas com oleato de sódio $\left(1,42 \times 10^{-5} \mathrm{~mol} \mathrm{~L}^{-1}\right)$.

pH 8

$\mathrm{pH} 10$

Apatita

Flotabilidade (\%)

$\varepsilon \% \quad$ Flotabilidade (\%)

$\boldsymbol{\varepsilon} \%$

\begin{tabular}{lcccc}
\hline AAN & 93 & 1 & 76 & 3 \\
\hline AAR & 33 & 3 & 30 & 6 \\
\hline ACJ & 97 & 1 & 72 & 3 \\
AIP & 95 & 2 & 91 & 10 \\
\hline ASO & 5 & 7 & 4 & 9 \\
\hline ASQ & 20 & 3 & 17 & 1 \\
\hline ATP & 64 & 2 & 42 & \\
\hline
\end{tabular}

A análise da variação da flotabilidade das apatitas de acordo com sua origem e com o pH do ensaio indica que (Tabela 4.19 e Figura 4.14):

- A sequência de flotabilidade em pH 8 é: $A C J>A I P>A A N>A T P>A A R>$ ASQ > ASO. Tal sequência pode ser expressa em termos da gênese das amostras: ígneo > metamórfico > sedimentar, que esta de acordo com a sequência encontrada por Rodrigues e Brandão (1993) ao investigarem a relação flotabilidade versus cristalinidade de apatitas brasileiras. 
- A sequência de flotabilidade em $\mathrm{pH} 10$ é a mesma que a observada para pH 8, exceção feita para AIP, que apresenta maior flotabilidade do que ACJ;

- Independentemente de sua origem, todas as apatitas apresentaram maior flotabilidade em $\mathrm{pH} 8$ do que em $\mathrm{pH} 10$.

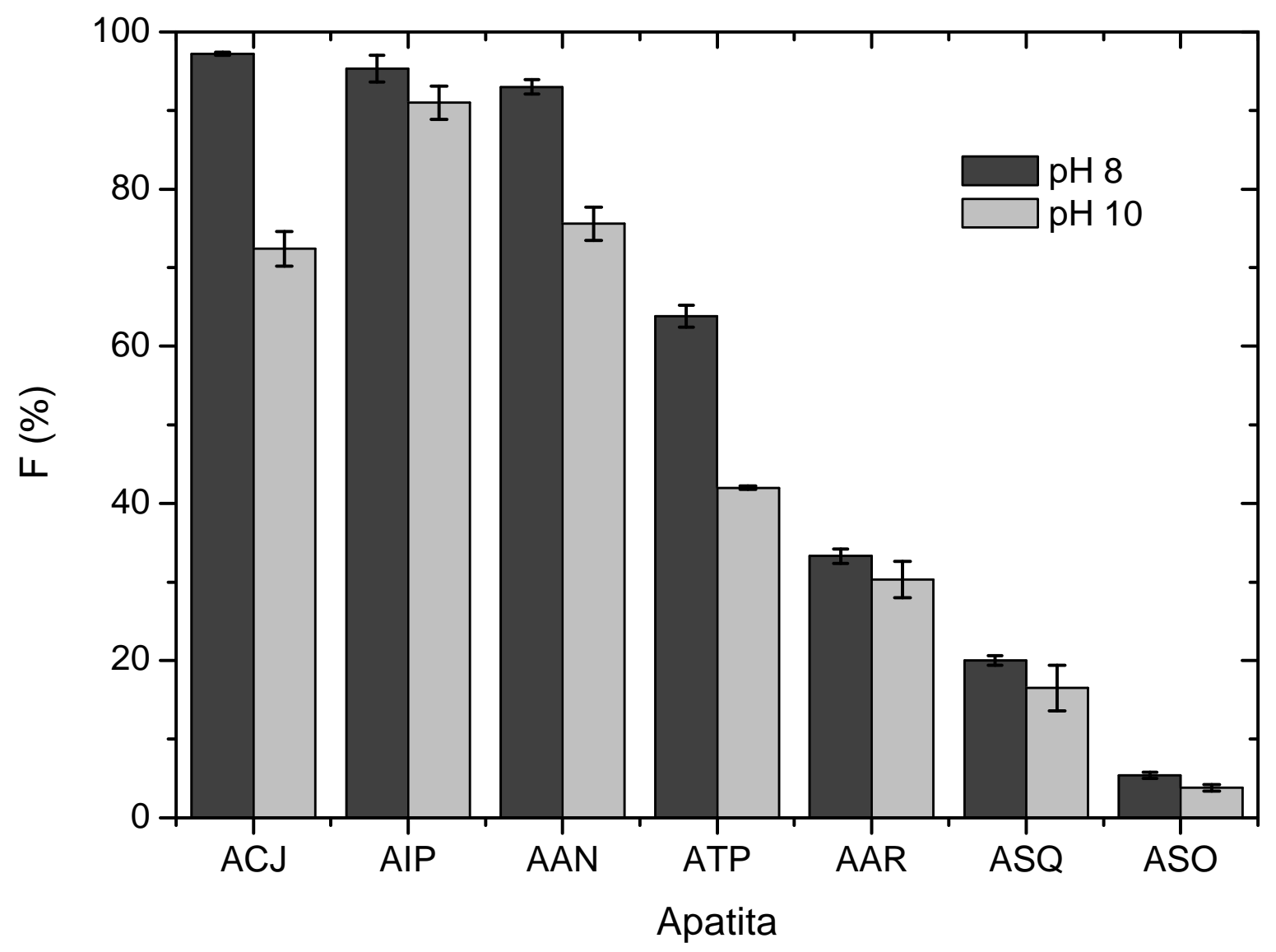

Figura 4.14 - Flotabilidade das apatitas em função de sua origem e do pH de flotação.

$\mathrm{O}$ fato de as apatitas apresentarem maior flotabilidade em $\mathrm{pH} 8$ do que em $\mathrm{pH}$ 10 demanda discussão. Considerando-se a amostra oriunda de Cajati-SP (ACJ) e com base nas informações sobre as variáveis que controlam a interação apatita/coletor (Tabela 4.20), observa-se que:

- Após 1 minuto de contato com o meio aquoso, a apatita é capaz de colocar em solução maior quantidade de cálcio em $\mathrm{pH} 8\left(3,2 \times 10^{-7} \mathrm{~mol} \mathrm{~L}^{-1}\right)$ do que em $\mathrm{pH} 10\left(1,33 \times 10^{-7} \mathrm{~mol} \mathrm{~L}^{-1}\right)$. Deste modo, em $\mathrm{pH} 8$, o produto $\left[\mathrm{Ca}^{2+}\right] \times$ [oleato] ${ }^{2}$, que é de $6,45 \times 10^{-16}$, é superior àquele calculado para $\mathrm{pH} 10\left(2,67 \times 10^{-16}\right)$. 
Conclui-se, assim, que as condições termodinâmicas para formação do oleato de cálcio são mais favoráveis em $\mathrm{pH} 8$ do que em $\mathrm{pH} 10$, visto que: $6,45 \times 10^{-16}>2,67 \times 10^{-16}$

Tabela 4.20 - Variáveis de controle da precipitação de oleato de cálcio em suspensões aquosas que contêm 1 grama da apatita ACJ.

Variáveis de controle da

interação coletor/apatita

pH 8

Velocidade rápida de dissolução

$\left(\mathrm{V}_{\mathrm{R}}\right)$

$4,42 \times 10^{-11}$

$2,45 \times 10^{-11}$

$\left(\mathrm{mol} \mathrm{s} \mathrm{cm}^{-2}\right)$

Concentração de $\left.\mathrm{Ca}^{2+}{ }^{*}\right)$

$\left(\mathrm{mol} \mathrm{L}^{-1}\right)$

$3,20 \times 10^{-7} \quad 1,33 \times 10^{-7}$

Concentração do ânion oleato

$\left(\mathrm{mol} \mathrm{L}^{-1}\right)$

$1,42 \times 10^{-5} \quad 1,42 \times 10^{-5}$

$\left[\mathrm{Ca}^{2+}\right] \times[\text { oleato }]^{2} \quad 6,45 \times 10^{-16} \quad 2,67 \times 10^{-16}$

${ }^{*}$ ) Após 1 minuto de dissolução que corresponde ao tempo de condicionamento com o agente coletor.

- Os valores do produto $\left[\mathrm{Ca}^{2+}\right] \times$ [oleato $^{2}$ que são reportados na Tabela 4.20 são superiores à magnitude da constante do produto de solubilidade $\left(\mathrm{K}_{\mathrm{PS}}\right)$ do oleato de cálcio, cuja magnitude é de $3,98 \times 10^{-16}$ (DU RIETZ, 1975). Deste modo, é de se esperar que oleato de cálcio precipite na interface apatita/solução;

- Do ponto de vista cinético, a velocidade com que a apatita libera íons $\mathrm{Ca}^{2+}$ para a solução é maior em $\mathrm{pH} 8$ do que em $\mathrm{pH} 10$, visto que $4,42 \times 10^{-11}$ mol s $\mathrm{cm}^{-2}>2,45 \times 10^{-11} \mathrm{~mol} \mathrm{~s}^{-1} \mathrm{~cm}^{-2}$. Deste modo, a precipitação do oleato de cálcio na interface apatita/solução ocorre mais prontamente em $\mathrm{pH} 8$ do que em pH 10, corroborando a maior flotabilidade dessa amostra em pH 8. 
As mesmas considerações de cunho termodinâmico e cinético que foram desenvolvidas com a apatita ACJ para explicar a sua maior flotabilidade em $\mathrm{pH} 8$ versus $\mathrm{pH} 10$ podem ser generalizadas para as demais apatitas abordadas nesta tese. Tais informações não foram aqui reproduzidas pelo fato de serem redundantes.

\subsubsection{Flotabilidade das calcitas}

A flotabilidade das calcitas com oleato de sódio em pH 8 e 10 é apresentada na Tabela 4.21 em função do $\mathrm{pH}$. O erro relativo percentual $\left(\varepsilon_{\%}\right)$ possui valor inferior a $3 \%$ para os experimentos realizados em $\mathrm{pH} 8$, e menor do que $4 \%$ para os experimentos conduzidos em $\mathrm{pH}$ 10. Tais erros são muito inferiores àqueles observados com a flotação das apatitas. A variação da flotabilidade das calcitas em função da sua origem e do pH de flotação pode ser melhor visualizada por meio dos resultados apresentados na Figura 4.15. A análise da Tabela 4.21 e Figura 4.15 indica que:

- $\mathrm{Em}$ pH 8, a sequência de flotabilidade que se observa é: CRT > CAM > CCI > $\mathrm{CRO}>\mathrm{CCJ}>\mathrm{CSQ}$;

- $\mathrm{Em}$ pH 10, no entanto, a diferença entre a flotabilidade das calcitas de diferentes origens é menos evidente, embora a ordem de decrescente de flotabilidade não se altere: CRT > CAM, CCI, CRO, CCJ > CSQ. 
Tabela 4.21 - Flotabilidade das calcitas com oleato de sódio $\left(7,11 \times 10^{-6} \mathrm{~mol} \mathrm{~L}^{-1}\right)$.

\begin{tabular}{ccccc}
\hline & \multicolumn{2}{c}{ pH 8} & \multicolumn{2}{c}{ pH 10 } \\
Amostra & 53 & $\varepsilon_{\%}$ & Flotabilidade (\%) & $\varepsilon_{\%}$ \\
\cline { 2 - 5 } & Flotabilidade (\%) & 3 & 77,3 & 2 \\
\hline CAM & 38 & 1 & 74,6 & 2 \\
\hline CCJ & 23 & 2 & 74,5 & 2 \\
\hline CRO & 28 & 1 & 74,6 & 1 \\
\hline CRT & 57 & 3 & 90,3 \\
\hline CSQ & 7 & $<1$ & 44,0 & 4 \\
\hline
\end{tabular}

Na Tabela 4.21 e na Figura 4.15 se observa que a flotabilidade obtida nos experimentos realizados em $\mathrm{pH} 8$ foi inferior àquela produzida pelo experimentos realizados em pH 10, apesar de fatores cinéticos (velocidade rápida de dissolução) e termodinâmicos (produto $\left[\mathrm{Ca}^{2+}\right] \times$ [oleato] ${ }^{2}$ ) exibidos na Tabela 4.22 indiquem que a calcita deveria apresentar maior flotabilidade em $\mathrm{pH} 8$ do que em $\mathrm{pH}$ 10. Esta contradição demanda esclarecimentos:

- Ensaios de dissolução apresentados nesta tese foram realizados na ausência de $\mathrm{CO}_{2}$, embora o Projeto AMIRA P260F preveja a realização de ensaios de dissolução na presença de $\mathrm{CO}_{2}$ (400 e 800 ppm);

- Os ensaios de flotabilidade, cujos resultados são apresentados na Tabela 4.21 e Figura 4.15, foram executados sob uma concentração de $\mathrm{CO}_{2}$ no ar que variou na faixa de 400 a 500 ppm, que caracteriza a composição do ar atmosférico num recinto confinado ( $8 \mathrm{~m}^{2}$ de área e $4 \mathrm{~m}$ de altura) na presença 
de duas pessoas, cuja respiração contribui para o aumento da concentração de $\mathrm{CO}_{2}$ no ar;

- Nos ensaios de dissolução, por terem sido realizados na ausência de $\mathrm{CO}_{2}$, a presença dos íons carbonato/bicarbonato na solução é devida somente à dissolução da calcita. Por outro lado, nos ensaios de microflotação, que foram realizados na presença de $\mathrm{CO}_{2}$, a solução foi alimentada com íons carbonato/bicarbonato oriundos também do ar e não somente da dissolução da calcita. Deste modo, os resultados apresentados na Tabela 4.22 não reproduzem as condições sob as quais a microflotação foi conduzida.

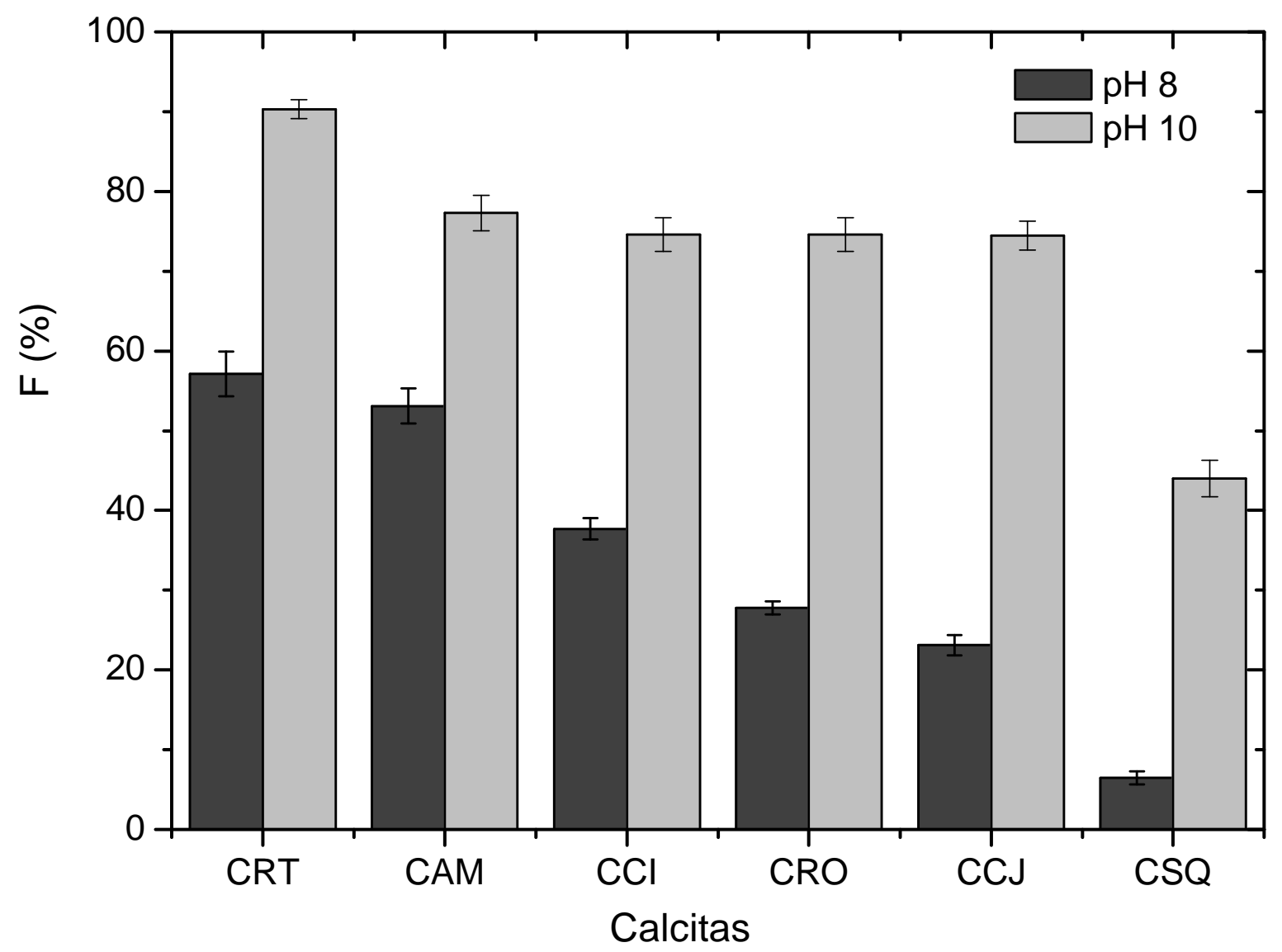

Figura 4.15 - Flotabilidade das calcitas em função de sua origem e do pH de flotação. 
As questões acima discutidas podem ser mais bem esclarecidas pelos resultados de flotabilidade da calcita de Cajati-SP (CCJ) e de Cachoeiro do Itapemerim-ES (CCl) que foram obtidos por meio de experimentos de microflotação reportados por Horta e Leal Filho (2012). Tais ensaios foram conduzidos após ter-se borbulhado nitrogênio contendo diferentes quantidades de $\mathrm{CO}_{2}(0,400$ e 800 ppm) na água antes e durante os ensaios de microflotação com oleato de sódio $\left(7,11 \times 10^{-6}\right.$ $\left.\mathrm{mol} \mathrm{L}^{-1}\right)$. Os resultados são apresentados na Figura 4.16, em que se observa que a flotabilidade das calcitas $\mathrm{CCJ}$ e $\mathrm{CCl}$ aumenta com o aumento da concentração de $\mathrm{CO}_{2}$. Deste modo, fica evidente que íons carbonato/bicarbonato oriundos não somente da dissolução da calcita, mas também do gás carbônico presente no ar influenciam o desempenho da flotação. Por outro lado, a flotabilidade de $\mathrm{CCl}$ foi superior à de $\mathrm{CCJ}$ sob quaisquer concentrações de $\mathrm{CO}_{2}$ estudadas, corroborando a tendência que se verifica na Tabela 4.21 e Figura 4.15.

Tabela 4.22 - Variáveis de controle da precipitação de oleato de cálcio em suspensões aquosas que contêm 1 grama da calcita CCJ.

\begin{tabular}{|c|c|c|}
\hline $\begin{array}{l}\text { Variáveis de controle da } \\
\text { interação coletor/apatita }\end{array}$ & pH 8 & pH 10 \\
\hline $\begin{array}{c}\text { Velocidade rápida de dissolução } \\
\qquad\left(\mathrm{V}_{\mathrm{R}}\right) \\
\left(\mathrm{mol} \mathrm{s}^{-1} \mathrm{~cm}^{-2}\right)\end{array}$ & $7,3 \times 10^{-11}$ & $2,6 \times 10^{-11}$ \\
\hline $\begin{array}{c}\text { Concentração de } \mathrm{Ca}^{2+}\left(^{*}\right) \\
\left(\mathrm{mol} \mathrm{L}^{-1}\right)\end{array}$ & $1,3 \times 10^{-5}$ & $4,7 \times 10^{-6}$ \\
\hline $\begin{array}{l}\text { Concentração do ânion oleato } \\
\qquad\left(\mathrm{mol} \mathrm{L}^{-1}\right)\end{array}$ & $7,0 \times 10^{-6}$ & $7,1 \times 10^{-6}$ \\
\hline$\left[\mathrm{Ca}^{2+}\right] \times$ [oleato $^{2}$ & $6,4 \times 10^{-16}$ & $2,3 \times 10^{-16}$ \\
\hline
\end{tabular}

$\left({ }^{*}\right)$ Após 1 minuto de dissolução que também corresponde ao tempo de condicionamento com o agente coletor. 


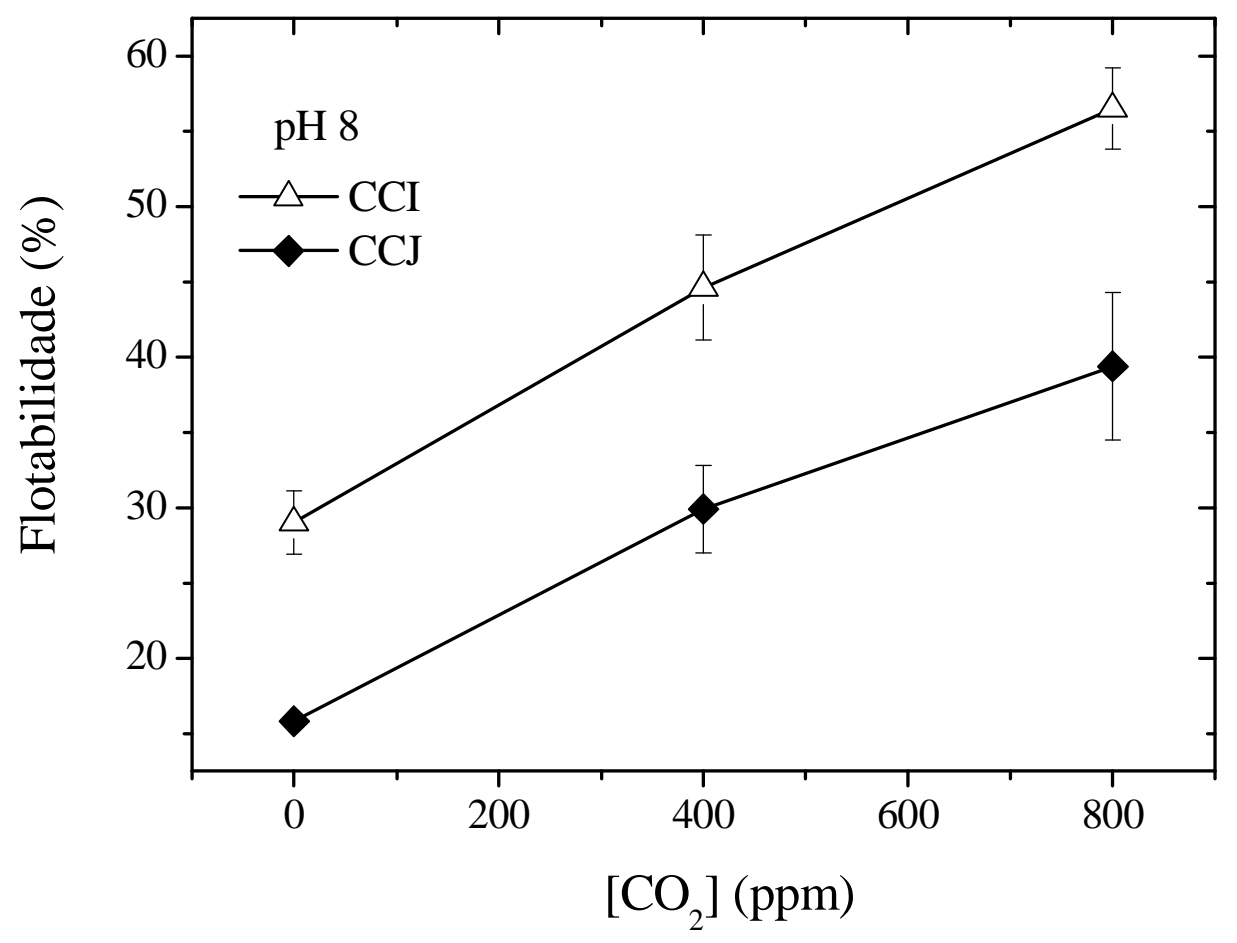

Figura 4.16 - Flotabilidade de calcitas com oleato de sódio $\left(7,11 \times 10^{-6} \mathrm{~mol} \mathrm{~L}^{-1}\right) \mathrm{em} \mathrm{pH}$ 8 na presença de gases contendo diferentes concentrações de gás carbônico (HORTA; LEAL FILHO, 2012).

\subsection{Relações de causa e efeito entre características intrínsecas, dissolução e flotabilidade}

O mecanismo predominante de adsorção do coletor aniônico (oleato) na superfície dos minerais semi-solúveis (calcita e apatita) é a precipitação na interface mineral/solução. De acordo com este mecanismo, a formação do oleato de cálcio em tal interface é o produto da interação entre o ânion coletor e os cátions $\left(\mathrm{Ca}^{2+}\right)$ que saem do retículo cristalino, migram para a fase aquosa e, muito próximos à superfície, encontram os ânions do coletor (FINKELSTEIN, 1989; LU; DRELICH; MILLER, 1998; YOUNG; MILLER, 2000). A este fato se deve a importância dos parâmetros de dissolução dos minerais no seu desempenho na flotação. 


\subsubsection{Apatitas}

A influência dos parâmetros de dissolução $\left(\mathrm{V}_{\mathrm{R}}, \mathrm{V}_{\mathrm{L}}, \mathrm{Ca}^{2+}{ }_{\mathrm{MAX}} \mathrm{e} \mathrm{k}\right)$ das apatitas sobre a sua flotabilidade com oleato de sódio em $\mathrm{pH} 8$ e pH 10 foi analisada por meio de correlação linear simples, obtendo-se os coeficientes de correlação (R) exibidos na Tabela 4.23.

Tabela 4.23 - Coeficientes de correlação linear $(R)$ entre flotabilidade e parâmetros de dissolução $\left(\mathrm{V}_{\mathrm{R}}, \mathrm{V}_{\mathrm{L}}, \mathrm{Ca}^{2+}{ }_{\mathrm{MAX}}\right.$ e $\left.\mathrm{k}\right)$ das apatitas em $\mathrm{pH} 8$ e 10.

\begin{tabular}{|c|c|c|c|c|c|}
\hline & pH & $\begin{array}{c}\mathrm{V}_{\mathrm{R}} \\
\left(10^{-11} \mathrm{~mol} \mathrm{~s}^{-1} \mathrm{~cm}^{-2}\right)\end{array}$ & $\begin{array}{c}\mathrm{V}_{\mathrm{L}} \\
\left(\mathrm{mol} 10^{-11} \mathrm{~s}^{-1} \mathrm{~cm}^{-2}\right)\end{array}$ & $\begin{array}{c}k \\
\left(10^{-4} \mathrm{~s}^{-1}\right)\end{array}$ & $\begin{array}{c}\mathrm{Ca}^{2+}{ }_{\text {MAX }} \\
\left(\mathrm{mol} 10^{-10} \mathrm{~cm}^{-2}\right)\end{array}$ \\
\hline & 8 & 0,95 & 0,88 & 0,16 & 0,95 \\
\hline & 10 & 0,89 & 0,79 & $-0,36$ & 0,89 \\
\hline
\end{tabular}

De acordo com os resultados apresentados na Tabela 4.23, observa-se que:

- As correlações mais significativas são aquelas obtidas entre $F$ e os parâmetros $\mathrm{V}_{\mathrm{R}}$ e $\mathrm{Ca}^{2+}{ }_{\mathrm{MAX}}$ em $\mathrm{pH} 8$ e 10;

- $F$ aumenta com $V_{R}$ tanto em pH $8(R=0,95)$ como em pH $10(R=0,89)$, o que indica que as apatitas que dissolvem mais rapidamente (na etapa rápida) exibem maior desempenho na microflotação;

- $F$ também aumenta com $\mathrm{Ca}^{2+}{ }_{\mathrm{MAx}}$ em $\mathrm{pH} 8(\mathrm{R}=0,95)$ e $10(\mathrm{R}=0,89)$, o que sugere que a flotabilidade é tanto maior quanto maior é a quantidade máxima de íons $\mathrm{Ca}^{2+}$ dissolvidos;

- k parece não se relacionar à flotabilidade dos concentrados de apatita estudados, uma vez que os coeficientes de correlação entre este parâmetro e a flotabilidade encontrados são baixos $(\mathrm{R}=0,16$ em $\mathrm{pH} 8$ e $\mathrm{R}=-0,36 \mathrm{em} \mathrm{pH}$ 10); 
- A etapa lenta de dissolução se refere ao que ocorre após intervalos de tempo (> $10 \mathrm{~min}$ ) superiores ao tempo de condicionamento com o coletor (1 minuto) e de flotação (1 minuto). Deste modo, o parâmetro $V_{L}$ não demanda maior atenção no estudo da influência que a dissolução exerce sobre a flotabilidade.

Na Figura 4.17 está ilustrada a relação linear entre a flotabilidade das apatitas e seus parâmetros de dissolução, $V_{R}$ e $\mathrm{Ca}^{2+}{ }_{\mathrm{MAX}}$, em pH 8 e 10 . Os coeficientes de correlação foram apresentados na Tabela 4.23. O efeito que a dissolução exerce na resposta à flotação das apatitas com oleato de sódio elucida a relevância do mecanismo de precipitação na superfície (FINKELSTEIN, 1989; LU; DRELICH; MILLER, 1998; FA et al., 2003; FA et al., 2006). Os resultados exibidos na Tabela 4.23 e Figura 4.17 sugerem que as apatitas que liberam íons $\mathrm{Ca}^{2+}$ para a solução, com maior velocidade $\left(V_{R}\right)$ e extensão $\left(\mathrm{Ca}^{2+}{ }_{\mathrm{MAX}}\right)$, são aquelas que apresentam maior resposta à flotação.

Na Figura 4.17 é possível agrupar as apatitas de alta flotabilidade (ACJ, AIP) e as de baixa flotabilidade (AAR, ASO, ASQ). Os dois grupos se diferenciam com relação à dissolução (Tabela 4.17) e ao desempenho nos ensaios de microflotação (Tabela 4.19). Neste ponto, uma questão merece aprofundamento e discussão: o que diferencia as apatitas que dissolvem mais e flotam mais daquelas que dissolvem menos e flotam menos? Para encontrar resposta para esta pergunta, investigou-se a influência dos parâmetros de rede $\left(a, c, V_{C U}\right)$, de cristalinidade $(G C, T C, M D)$ e físicos (d, S, P) dos concentrados de apatita na sua dissolução, realizando-se análise de correlação linear múltipla.

Para realizar a análise de correlação linear múltipla, foi necessário selecionar os parâmetros mais relevantes em cada um dos grupos de variáveis. Esta medida foi tomada devido ao pequeno número de amostras de apatita $(n=5)$ com as quais os ensaios de cristalinidade e dissolução foram conduzidos. Entre os parâmetros de dissolução, adotou-se apenas a velocidade na etapa rápida $\left(V_{R}\right)$. Tal parâmetro foi selecionado por caracterizar a dissolução no intervalo de tempo relevante para os ensaios de flotabilidade, que é de dois minutos ( 1 minuto de condicionamento +1 minuto de flotação). Esta abordagem considera que os fenômenos relacionados à 
dissolução, que ocorrem nos minutos iniciais de contato dos minerais com o meio aquoso, são adequadamente representados por $V_{R}$.

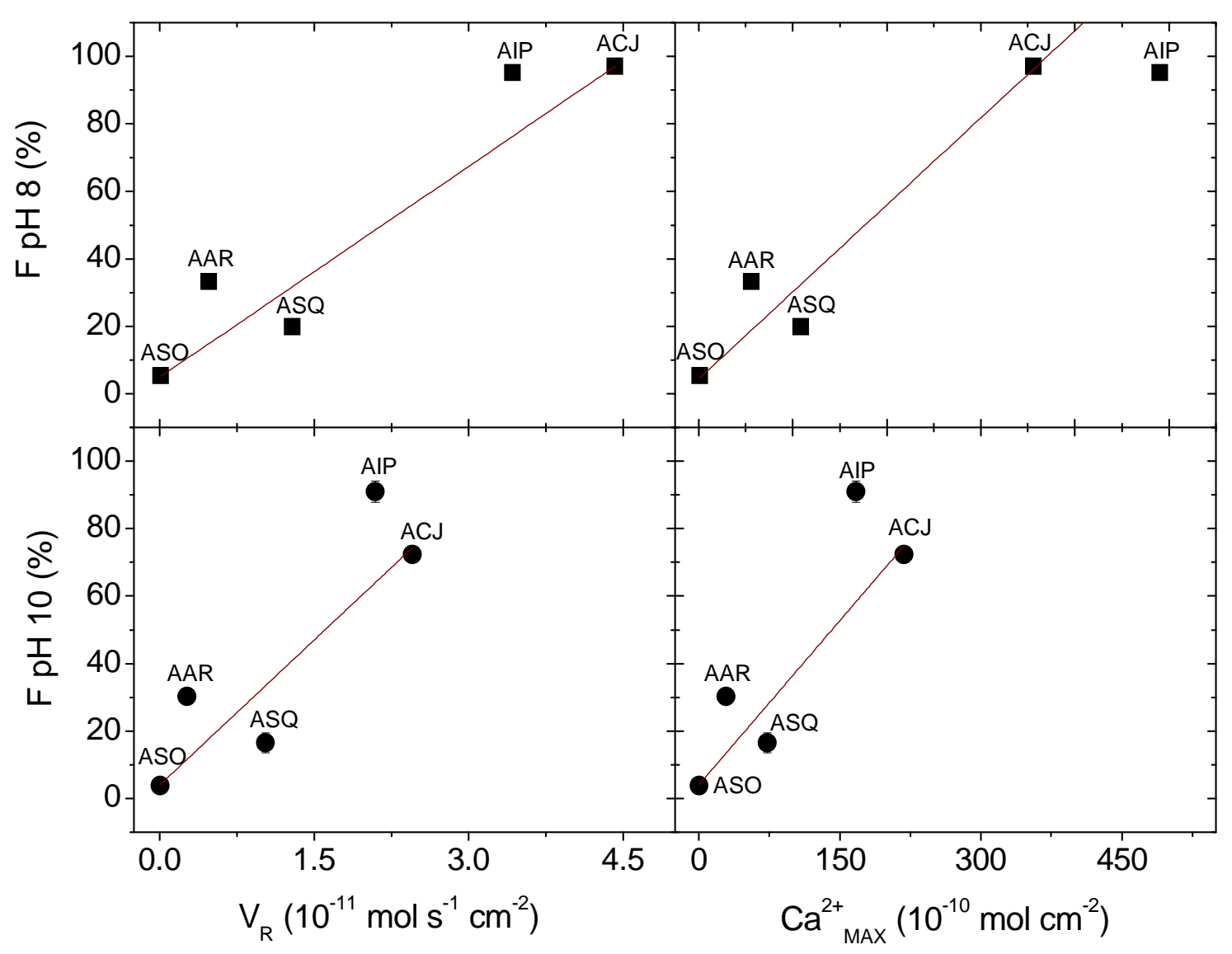

Figura 4.17 - Variação da flotabilidade das apatitas com os parâmetros de dissolução $\mathrm{V}_{\mathrm{R}}$ e $\mathrm{Ca}^{2+}{ }_{\mathrm{MAX}}$ em $\mathrm{pH} 8$ e 10.

A relação linear da flotabilidade $(F)$ em função de $V_{R}$ é dada pelas Equações 4.1 e 4.2 .

$$
\begin{gathered}
F_{p H 8}=8,9+21,5 V_{R-p H 8}\left(10^{-11}\right) \\
(R=0,95) \\
F_{p H 10}=7,1+30,5 V_{R-p H 10}\left(10^{-11}\right) \\
(R=0,89)
\end{gathered}
$$


Em que $\mathrm{F}_{\mathrm{pH} 8}$ é a flotabilidade em $\mathrm{pH} 8, \mathrm{~F}_{\mathrm{pH} 10}$ é a flotabilidade em $\mathrm{pH} 10, \mathrm{~V}_{\mathrm{R} \text {-pH8 }}$ é a velocidade na etapa rápida em pH 8 e $\mathrm{V}_{\mathrm{R} \text {-pH10 }}$ é a velocidade na etapa rápida em $\mathrm{pH}$ 10. As constantes das Equações 4.1 e 4.2 exibem valores similares (mesma ordem de grandeza), o que indica que o $\mathrm{pH}$ é um parâmetro com potencial para ser introduzido no modelo de flotabilidade versus $V_{R}$. Para tanto, experimentos de flotabilidade e dissolução devem ser conduzidos em um maior número de valores de $\mathrm{pH}$.

A seleção dos parâmetros de rede, de cristalinidade e físicos relevantes foi fundamentada na análise estatística de correlação entre $V_{R}$ e estes parâmetros. Tal análise gerou os coeficientes de correlação que estão ilustrados na Tabela 4.24,os quais fornecem as seguintes informações:

- Entre os parâmetros de rede, as maiores correlações com $V_{R}$ foram obtidas para $c(\mathrm{R}=-0,90$ em $\mathrm{pH} 8$ e $\mathrm{R}=-0,89 \mathrm{em} \mathrm{pH} \mathrm{10).} \mathrm{Tal} \mathrm{correlação} \mathrm{estabelece}$ que $V_{R}$ é maior quanto menor for o comprimento do parâmetro $c$;

- No que concerne aos parâmetros de cristalinidade, as maiores correlações são exibidas para $\mathrm{TC}_{(00)}(\mathrm{R}=0,55 \mathrm{em} \mathrm{pH} 8$ e $\mathrm{R}=0,52$ em $\mathrm{pH} 10), \mathrm{TC}_{\mathrm{M}}(\mathrm{R}=$ 0,47 em pH 8 e $\mathrm{R}=0,54$ em pH 10) e $M D(R=-0,58$ em pH 8 e $R=-0,59$ em $\mathrm{pH}$ 10). Estas correlações sugerem que $\mathrm{V}_{\mathrm{R}}$ aumenta com o aumento do tamanho de cristalito (TC) e diminui com a deformação de rede (MD). Sendo assim, os resultados são um indicativo de que as amostras mais cristalinas exibem maior dissolução tanto em pH 8 como em pH 10. Baig et al. (1999) observaram que a solubilidade de carbonatoapatitas sintéticas também diminui com o aumento da microdeformação (determinada pelo método de Rietveld). No entanto, os autores não encontraram influência do tamanho de cristalito na solubilidade das amostras por eles estudadas;

- $V_{R}$ também parece aumentar com o aumento do grau de cristalinidade dos concentrados de apatita $(\mathrm{R}=0,34$ em $\mathrm{pH} 8$ e $\mathrm{R}=0,46$ em $\mathrm{pH} 10)$. 
Tabela 4.24 - Coeficientes de correlação linear $(R)$ entre $V_{R}$ e os parâmetros de rede, de cristalinidade, e físicos das apatitas.

\begin{tabular}{|c|c|c|}
\hline \multirow{2}{*}{$\begin{array}{l}\text { Parâmetros de } \\
\text { dissolução }\end{array}$} & \multicolumn{2}{|c|}{ pH } \\
\hline & 8 & 10 \\
\hline GC (\%) & 0,34 & 0,46 \\
\hline $\mathrm{TC}_{(\mathrm{h} 00)}(\mathrm{nm})$ & 0,50 & 0,46 \\
\hline $\mathrm{TC}_{(0 \mathrm{k} 0)}(\mathrm{nm})$ & 0,26 & 0,34 \\
\hline $\mathrm{TC}_{(00))}(\mathrm{nm})$ & 0,56 & 0,66 \\
\hline $\mathrm{TC}_{\mathrm{M}}(\mathrm{nm})$ & 0,56 & 0,65 \\
\hline MD & $-0,57$ & $-0,52$ \\
\hline$a(\AA)$ & 0,65 & 0,67 \\
\hline$c(\AA)$ & $-0,92$ & $-0,90$ \\
\hline $\mathrm{V}_{\mathrm{CU}}\left(\AA^{3}\right)$ & 0,57 & 0,59 \\
\hline $\mathrm{d}\left(\mathrm{g} \mathrm{cm}^{-3}\right)$ & 0,58 & 0,58 \\
\hline $\mathrm{S}\left(\mathrm{cm}^{2} \mathrm{~g}^{-1}\right)$ & $-0,57$ & $-0,61$ \\
\hline $\mathrm{P}(\%)$ & $-0,63$ & $-0,64$ \\
\hline
\end{tabular}


Com base nos coeficientes de correlação ilustrados na Tabela 4.14 (características intrínsecas entre si) e na Tabela $4.24\left(\mathrm{~V}_{\mathrm{R}}\right.$ versus características intrínsecas), os parâmetros escolhidos para compor o modelo velocidade de dissolução $\left(\mathrm{V}_{\mathrm{R}}\right)$ versus características intrínsecas foram:

- O parâmetro de rede $c$, que foi eleito devido ao elevado coeficiente de correlação exibido entre $c$ e $V_{R}(R=-0,92$ em pH 8 e $R=-0,90$ em pH 10). Outro fator que justifica a escolha de $c$ é a sua correlação com os parâmetros a, $\mathrm{V}_{\mathrm{CU}}, \mathrm{d}, \mathrm{S}, \mathrm{P}$ e MD. Sendo assim, sua participação no modelo carrega as informações de vários parâmetros de rede $\left(a, V_{C U}\right)$, de cristalinidade (MD) e das variáveis físicas $(\mathrm{d}, \mathrm{S}, \mathrm{P})$;

- O parâmetro de cristalinidade $\mathrm{TC}_{\mathrm{M}}$, que foi escolhido por apresentar correlação com $\mathrm{V}_{\mathrm{R}}(\mathrm{R}=0,56$ em $\mathrm{pH} 8$ e $\mathrm{R}=0,65$ em pH 10), além de conter informação a respeito de $\mathrm{TC}_{(0 k 0)}(R=0,94)$ e $\mathrm{TC}_{(00)}(\mathrm{R}=0,84)$;

- O parâmetro GC que apresenta coeficientes de correlação com $V_{R}$ de $\mathrm{R}=0,34$ em $\mathrm{pH} 8$ e $\mathrm{R}=0,46 \mathrm{em} \mathrm{pH} 10$. Embora os coeficientes de correlação entre $V_{R}$ e $M D(R=-0,57$ em $\mathrm{pH} 8$ e $R=-0,52$ em $\mathrm{pH} 10)$ sejam superiores àqueles obtidos entre $\mathrm{V}_{\mathrm{R}} \mathrm{e} \mathrm{GC}, \mathrm{GC}$ foi escolhido em detrimento de $\mathrm{MD}$, pois, as informações a respeito de MD são trazidas pelo parâmetro $c$.

O número de variáveis dependentes utilizado para compor um modelo de correlação não trivial de $V_{R}$ em função das características intrínsecas foi igual a 3 , visto que o número de amostras analisadas é igual a 5 . O diagrama de autovalores da matriz de correlação provenientes de uma análise de fatores sobre os parâmetros de rede, de cristalinidade e físicos (Figura 4.18) indica que as informações contidas nesses parâmetros podem ser representadas pela escolha de três variáveis. De acordo com o diagrama da Figura 4.18, a utilização de três variáveis confere ao modelo perda de aproximadamente $11 \%$ da informação a respeito das características intrínsecas das apatitas. Embora a análise de fatores não tenha sido integralmente aplicada neste trabalho (porque se deu preferência em preservar o sentido físico das variáveis), o diagrama da Figura 4.18 traz informações aproximadas a respeito da perda de informação que acompanha a escolha das variáveis. 


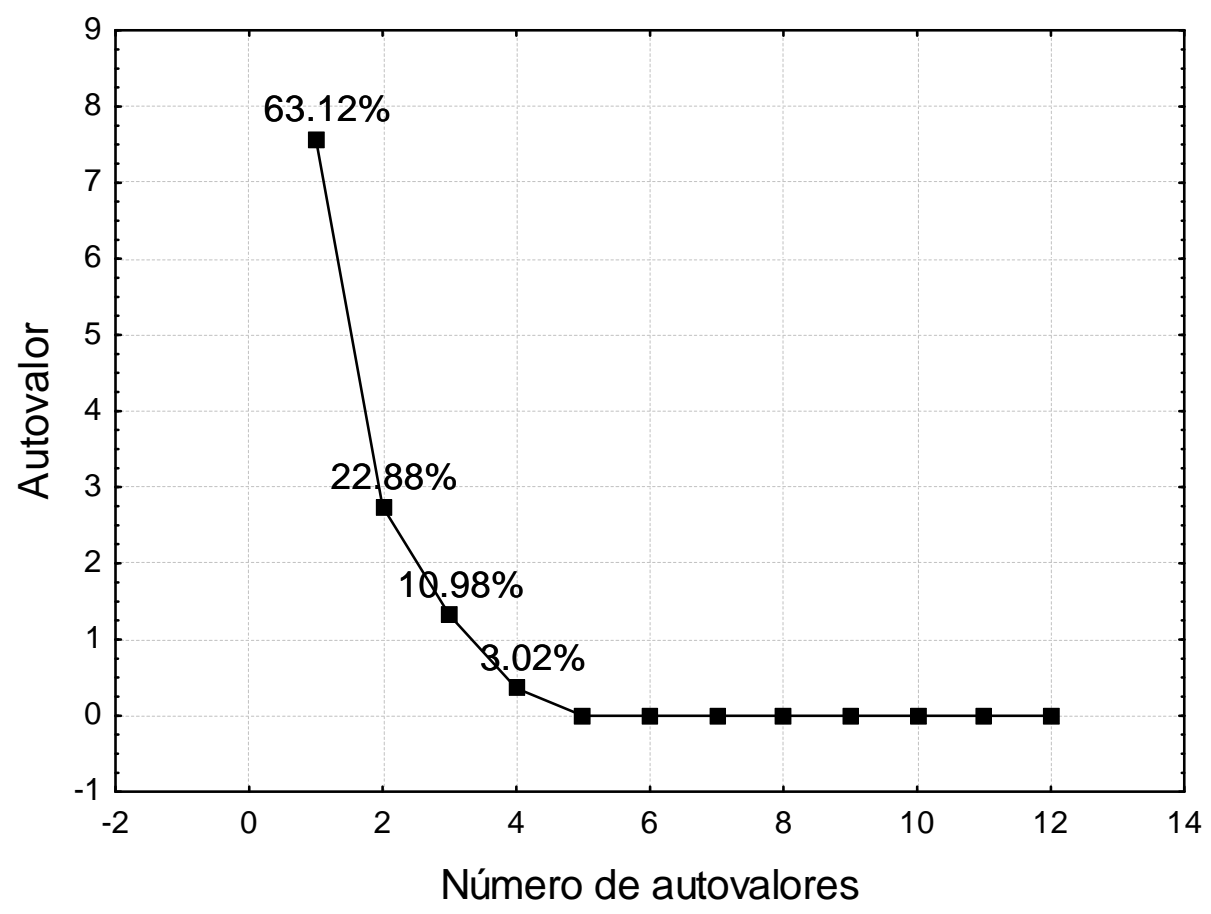

Figura 4.18 - Diagrama de autovalores da matriz de correlação dos parâmetros de rede, de cristalinidade e físicos das apatitas.

As equações que descrevem o comportamento de $V_{R}$ em função dos parâmetros de cristalinidade e de rede selecionados (GC, $\mathrm{TC}_{\mathrm{M}} \mathrm{e} c$ ) estão ilustradas a seguir:

$$
\begin{gathered}
V_{R-p H 8}\left(10^{-11}\right)=2,3 \times 10^{3}-0,2 G C+8,0 \times 10^{-3} T C_{M}-331 c \\
(R=0,95) \\
V_{R-p H 10}\left(10^{-11}\right)=1,3 \times 10^{3}-0,1 G C+3,7 \times 10^{-3} T C_{M}-182 c \\
(R=0,95)
\end{gathered}
$$

A comparação entre os valores observados (experimentais) e aqueles que são previstos pelas Equações 4.3 e 4.4, dentro de um intervalo de confiança de $95 \%$, está ilustrada na Figura 4.19. Os coeficientes de correlação obtidos $(R=0,95$ em $\mathrm{pH} 8$ e 10) e o ajuste entre valores observados e previstos (Figura 4.19) 
corroboram a aderência dos valores previstos pelo modelo aos resultados experimentais (reais).
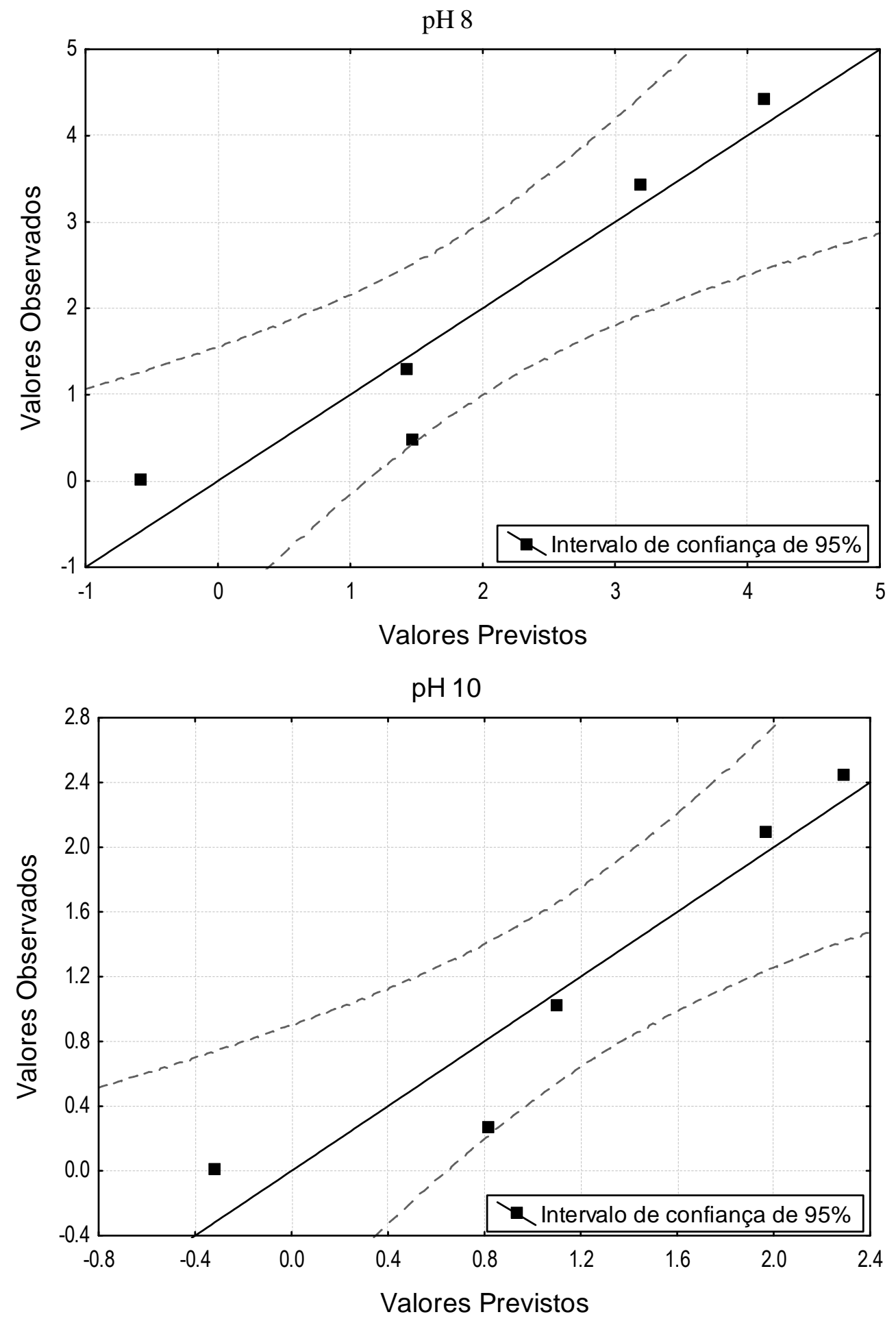

Figura 4.19 - Valores observados versus calculados pelo modelo regressão linear múltipla de $\mathrm{V}_{\mathrm{R}}$ em função de $\mathrm{GC}, \mathrm{TC}_{\mathrm{M}}$ e $c$ para as apatitas. 
O modelos que relacionam $F$ com $V_{R}$ (Equações 4.1 e 4.2 ) e $V_{R}$ com as características intrínsecas GC, $\mathrm{TC}_{\mathrm{M}}$ e $c$ (Equações 4.3 e 4.4) foram utilizados para prever a flotabilidade das apatitas AAN e ATP, com as quais não foram conduzidos ensaios de dissolução. Os valores de F previstos (Equações 4.1 a 4.4) e observados (Tabela 4.19) são bastante similares como se observa na Tabela 4.25. A flotabilidade prevista para a ATP, em pH 8 por exemplo, tem valor de $61 \%$, enquanto a experimentalmente observada é de $63 \%$. Este resultado indica que o modelo proposto é adequado para prever a flotabilidade das apatitas com base em suas características intrínsecas $\left(\mathrm{GC}, \mathrm{TC}_{\mathrm{M}}\right.$ e c), dentro do universo de amostras contempladas neste trabalho.

Tabela 4.25 - Comparação entre valores previstos (Equações 4.1 a 4.4) e experimentalmente obtidos da flotabilidade de concentrados de apatita.

pH 8

$V_{R}$

Apatita $\quad\left(10^{-11} \mathrm{~mol} \mathrm{~s}^{-1}\right.$

$\mathrm{F}(\%)$

$F(\%)$

$\mathrm{cm}^{-2}$ ) previsto

Equação 4.1 previsto observado

Equação Tabela

4.3

4.19

$V_{R}$

$F(\%)$

$F(\%)$

pH 10

$\left(10^{-11} \mathrm{~mol} \mathrm{~s}^{-1}\right.$

previsto observado $\mathrm{cm}^{-2}$ ) previsto Equação Tabela

4.4

4.19

Equação 4.2 


\subsubsection{Calcitas}

A mesma abordagem utilizada na Seção 4.5.1 para comparar os parâmetros de rede, de cristalinidade, físicos, de dissolução e flotabilidade das apatitas, foi também empregada no tratamento dos resultados obtidos com as calcitas. Os coeficientes de correlação entre flotabilidade e parâmetros de dissolução para as calcitas em pH 8 e 10 são apresentados na Tabela 4.26. A análise da influência dos parâmetros de dissolução na flotabilidade das calcitas estudadas indica que:

- Os parâmetros de dissolução que exibem maior correlação com a flotabilidade são $V_{R}\left(R=0,62\right.$ em pH 8 e $R=0,66$ em pH 10) e $\mathrm{Ca}^{2+}{ }_{\text {MAX }}(R=0,63$ em pH 8 e $\mathrm{R}=0,60$ em $\mathrm{pH} 10$ );

- $V_{L}$ parece afetar a flotabilidade das calcitas estudadas apenas em $\mathrm{pH} 8$ $(R=0,63)$, haja vista o baixo coeficiente de correlação obtido pela relação linear entre $V_{L}$ e $F(R=0,36)$ em $\mathrm{pH} 10$.

- k não influencia a flotabilidade das calcitas, o que é indicado pelos baixos valores dos coeficientes de correlação entre $\mathrm{F}$ e $\mathrm{k}(\mathrm{R}=-0,23$ em $\mathrm{pH} 8 \mathrm{e}$ $\mathrm{R}=-0,38$ em $\mathrm{pH} 10)$;

- Os coeficientes de correlação obtidos para a relação entre flotabilidade versus $\mathrm{V}_{\mathrm{R}}$ e $\mathrm{Ca}^{2+}{ }_{\text {MAX }}$ para as calcitas $(0,62<\mathrm{R}<0,70$ - Tabela 4.23) são menores em relação àqueles observados para as apatitas $(0,89<R<0,95$ - Tabela 4.26). Tal comparação indica que a influência da dissolução na flotabilidade das apatitas é mais acentuada do que nas calcitas.

As informações a respeito da variação de $\mathrm{F}$ com $\mathrm{V}_{\mathrm{R}}$ e $\mathrm{Ca}^{2+}{ }_{\mathrm{MAX}}$ contidas na Tabela 4.26 estão ilustradas na Figura 4.20. O aumento da flotação com o aumento dos parâmetros de dissolução $\left(\mathrm{V}_{\mathrm{R}}\right.$ e $\left.\mathrm{Ca}^{2+}{ }_{\mathrm{MAX}}\right)$ sugere que as calcitas que liberam íons $\mathrm{Ca}^{2+}$ para a solução, com maior velocidade $\left(\mathrm{V}_{\mathrm{R}}\right)$ e extensão $\left(\mathrm{Ca}^{2+}{ }_{\mathrm{MAX}}\right)$, são aquelas que apresentam maior resposta à flotação. De maneira similar ao que foi observado para as apatitas na Seção 4.5.1, a influência da dissolução na resposta à flotação das calcitas com oleato de sódio ilustra a relevância do mecanismo de precipitação na superfície. 
Tabela 4.26 - Coeficiente de correlação linear $(R)$ entre flotabilidade e parâmetros de dissolução $\left(\mathrm{V}_{\mathrm{R}}, \mathrm{V}_{\mathrm{L}}, \mathrm{Ca}^{2+}{ }_{\text {MAX }} \mathrm{e} \mathrm{k}\right)$ das calcitas em $\mathrm{pH} 8$ e 10.

\begin{tabular}{|c|c|c|c|c|c|}
\hline & pH & $\begin{array}{c}\mathrm{V}_{\mathrm{R}} \\
\left(10^{-11} \mathrm{~mol} \mathrm{~s}^{-1} \mathrm{~cm}^{-2}\right)\end{array}$ & $\begin{array}{c}\mathrm{V}_{\mathrm{L}} \\
\left(\mathrm{mol} 10^{-11} \mathrm{~s}^{-1} \mathrm{~cm}^{-2}\right)\end{array}$ & $\begin{array}{c}k \\
\left(10^{-4} \mathrm{~s}^{-1}\right)\end{array}$ & $\begin{array}{c}\mathrm{Ca}^{2+}{ }_{\text {MAX }} \\
\left(\mathrm{mol} 10^{-10} \mathrm{~cm}^{-2}\right)\end{array}$ \\
\hline $\mathbf{F}$ & 8 & 0,62 & 0,63 & $-0,23$ & 0,63 \\
\hline (\%) & 10 & 0,66 & 0,36 & $-0,38$ & 0,70 \\
\hline
\end{tabular}
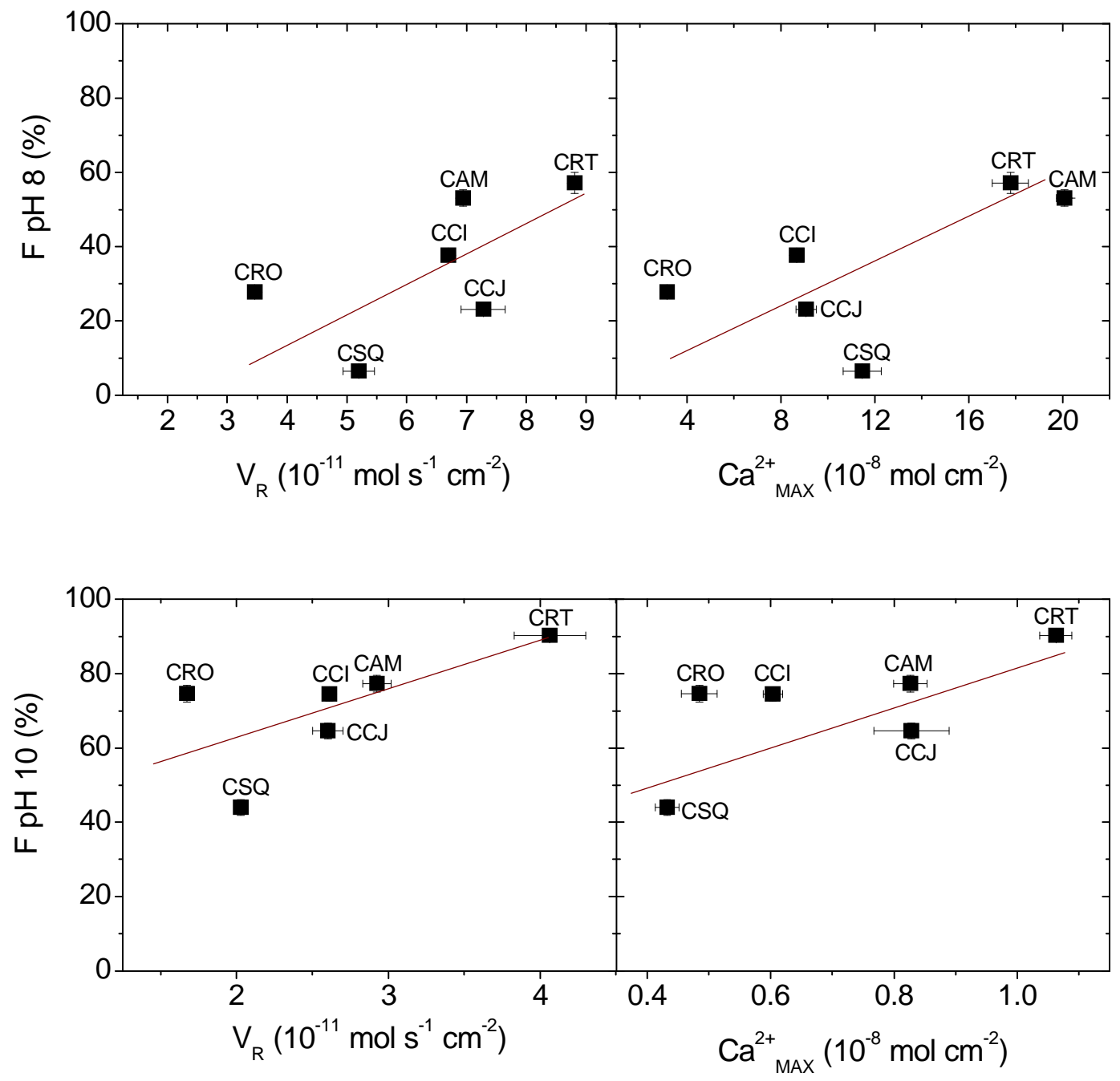

Figura 4.20 - Variação da flotabilidade das calcitas com os parâmetros de dissolução $\mathrm{V}_{\mathrm{R}}$ e $\mathrm{Ca}^{2+}{ }_{\text {MAX }}$ em $\mathrm{pH} 8$ e 10. 
As equações de correlação linear simples que descrevem o comportamento de $\mathrm{F}$ em função de $\mathrm{V}_{\mathrm{R}}$ para as calcitas em pH 8 e 10 são exibidas abaixo.

$$
\begin{gathered}
F_{p H 8}=-20,5+8,6 V_{R-p H 8}\left(10^{-11}\right) \\
(R=0,62) \\
F_{p H 10}=31,6+15,4 V_{R-p H 10}\left(10^{-11}\right) \\
(R=0,66)
\end{gathered}
$$

A escolha das variáveis mais relevantes para serem introduzidas no modelo de $V_{R}$ versus características intrínsecas das amostras de calcita foi feita com base nos coeficientes de correlação ente $V_{R}$ e parâmetros de rede, de cristalinidade $e$ físicos apresentados na Tabela 4.27. Os coeficientes de correlação entre $V_{R}$ e os parâmetros que definem as características intrínsecas das calcitas são inferiores àqueles obtidos para as apatitas (Tabela 4.16). Tais resultados sugerem que a influência das características intrínsecas na velocidade de dissolução das calcitas é menos pronunciada em comparação às apatitas.

O número de variáveis dependentes utilizado para compor um modelo de correlação não trivial de $V_{R}$ em função das características intrínsecas foi igual a 4, uma vez que o número de amostras com as quais foram conduzidos ensaios de dissolução é igual a 5. A escolha das variáveis também se baseou na inter-relação dos parâmetros que definem as características intrínsecas das calcitas apresentada na Tabela 4.16. Os parâmetros escolhidos foram:

- TC, GC e P, pois, exibem os maiores coeficientes de correlação com $V_{R}$ (Tabela 4.27);

- d porque carrega informação a respeito de MD e os parâmetros de rede $(a, c$ e $\mathrm{V}_{\mathrm{CU}}$ ) como se observa na Tabela 4.16.

O diagrama de autovalores da matriz de correlação proveniente de uma análise de fatores sobre os parâmetros de rede, de cristalinidade e físicos das 
calcitas está ilustrado na Figura 4.21. De acordo com este diagrama, a utilização de quatro variáveis confere ao modelo perda de aproximadamente $3 \%$ da informação a respeito das características intrínsecas das calcitas.

Tabela 4.27 - Coeficientes de correlação linear $(R)$ entre $V_{R}$ e os parâmetros de rede, de cristalinidade e físicos das calcitas.

\begin{tabular}{|c|c|c|}
\hline \multirow{2}{*}{ Parâmetro } & \multicolumn{2}{|c|}{$\mathrm{pH}$} \\
\hline & 8 & 10 \\
\hline GC (\%) & 0,27 & 0,43 \\
\hline $\mathrm{TC}(\mathrm{nm})$ & $-0,58$ & $-0,78$ \\
\hline MD & 0,21 & $-0,07$ \\
\hline$a(\AA)$ & $-0,06$ & 0,25 \\
\hline$c(\AA)$ & $-0,12$ & 0,19 \\
\hline $\mathrm{V}_{\mathrm{CU}}\left(\AA^{3}\right)$ & $-0,09$ & 0,22 \\
\hline $\mathrm{d}\left(\mathrm{g} \mathrm{cm}^{-3}\right)$ & $-0,01$ & $-0,33$ \\
\hline $\mathrm{S}\left(\mathrm{cm}^{2} \mathrm{~g}^{-1}\right)$ & 0,06 & 0,01 \\
\hline P (\%) & 0,26 & 0,47 \\
\hline
\end{tabular}




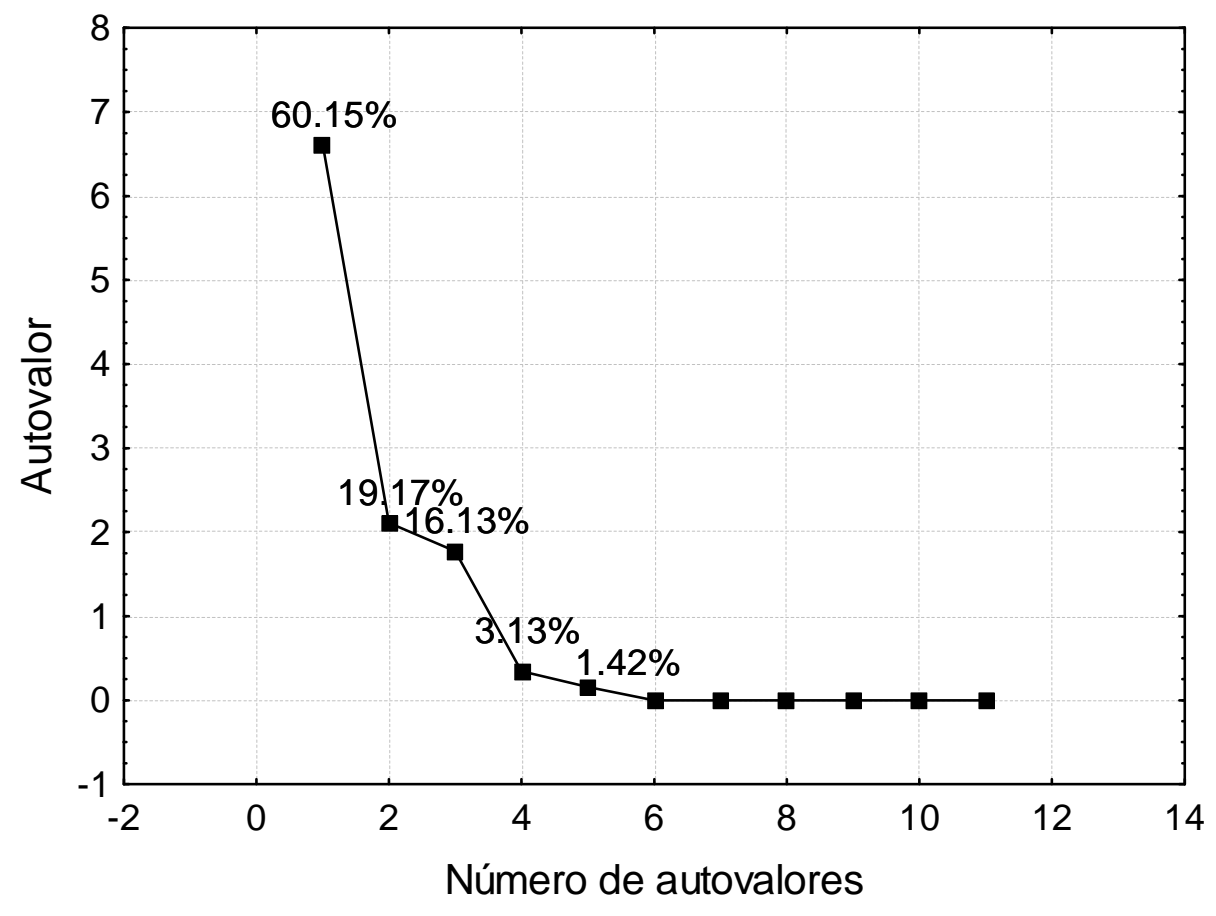

Figura 4.21 - Diagrama de autovalores da matriz de correlação dos parâmetros de rede, de cristalinidade e físicos das calcitas.

As Equações 4.7 e 4.8 foram obtidas por meio de regressão linear múltipla de $V_{R}$ em função de GC, TC, d e $\mathrm{P}$ em $\mathrm{pH} 8$ e $\mathrm{pH} 10$, respectivamente.

$$
\begin{gathered}
V_{R-p H 8}\left(10^{-11}\right)=-647,8+0,3 G C-0,1 T C+230,6 d+3,5 P \\
(R=0,98) \\
V_{R-p H 10}\left(10^{-11}\right)=-284,11+0,27 G C-3,0 \times 10^{-2} T C+93,8 d+3,1 P \\
(R=0,99)
\end{gathered}
$$

De acordo com os coeficientes de correlação das Equações $4.7(R=0,98)$ e $4.8(R=0,99$ 
), e com o ajuste entre valores observados e previstos (Figura 4.22), pode-se concluir que tais equações são adequadas para prever o comportamento de $V_{R}$ em função de GC, TC, d e P do grupo de calcitas estudadas.
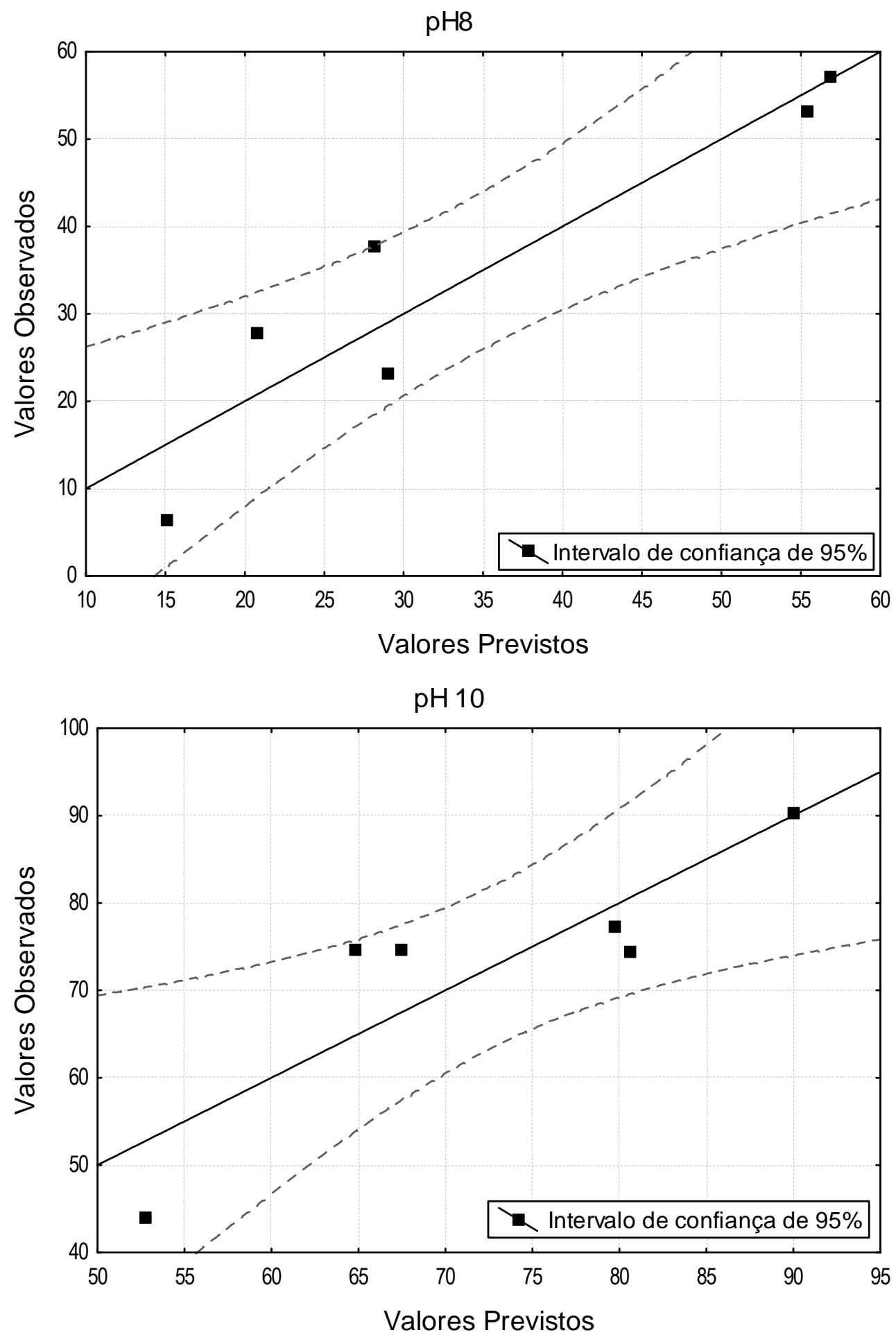

Figura 4.22 - Valores observados versus calculados pelo modelo de regressão linear múltipla de $V_{R}$ em função de GC, TC, d e P para as calcitas. 
É importante ressaltar que os modelos propostos nesta seção são adequados para prever 0 comportamento de flotabilidade versus $V_{R}$ versus características intrínsecas, do grupo de amostras contempladas nesta tese. Com tais modelos se pretendeu avaliar, dentro do conjunto de parâmetros experimentalmente determinados (parâmetros de dissolução, de rede, de cristalinidade e físicos), quais são aqueles que exercem maior influência sobre a resposta à flotação das apatitas e calcitas com oleato de sódio. Não faz parte dos objetivos deste trabalho estender os modelos sugeridos para a determinação da flotabilidade de outras apatitas e calcitas. Para que tal trabalho seja executado, faz-se necessário investigar as características intrínsecas e o comportamento da dissolução e da flotabilidade de um maior número de amostras. $\mathrm{O}$ aumento da base de dados poderia validar ou corrigir os modelos propostos neste estudo. 


\section{Capítulo 5}

\section{Conclusões}

Este capítulo contém as principais conclusões a respeito dos estudos conduzidos com as apatitas e calcitas. 
As conclusões relativas ao estudo com as apatitas e calcitas são apresentadas nas seções 5.1 e 5.2 , respectivamente.

\subsection{Conclusões relativas ao estudo com as apatitas}

Dentro do universo desta investigação, é possível concluir:

1. Amostras de apatita oriundas de Anitápolis-SC (AAN), Araxá-MG (AAR), Cajati-SP (ACJ), Ipirá-BA (AIP), Sra Ouertane-Tunísia (ASO), Santa Quitéria-CE (ASQ) e Tapira-MG (ATP) foram obtidas de minérios de fosfato por meio de separação densitária e magnética, o que gerou concentrados com pureza (determinada por análise semi-quantitativa do método de Rietveld) superior a 95\%: AAN (99\%), AAR (97\%), ACJ (>99\%), AIP (99\%), ASQ (99\%), ASO (99\%) e ATP (99\%). Traços de calcita, dolomita e quartzo constituem as impurezas mais frequentes dos concentrados de apatita.

2. No que diz respeito à composição química, a AAR se destaca por exibir um teor de $\mathrm{BaO}$ de 3,7\% (determinado por $\mathrm{FRX}$ ) e 97\% de apatita (método de Rietveld), o que indica a presença de barita. A ASQ, apesar da pureza de 99\%, apresenta teores de ferro $\left(3,2 \%\right.$ de $\mathrm{Fe}_{2} \mathrm{O}_{3}$ determinado por $\left.\mathrm{FRX}\right)$ e urânio $\left(0,3 \%\right.$ de $\left.\mathrm{UO}_{2}\right)$ determinado por WDS/EDS) que correspondem a fases intimamente ligadas à apatita.

3. De acordo com análises por WDS/EDS e FTIR, apatitas ígneas (AAN, AAR, ACJ, AIP e ATP) e metamórfica (ASQ) são classificadas como hidroxi-fluorapatitas, enquanto a apatita sedimentar (ASO) é classificada como carbonato-fluorapatita.

4. A densidade (d) das amostras, sua área superficial (S) e porosidade (P) constituem os parâmetros físicos escolhidos para complementar a caracterização das propriedades intrínsecas das apatitas. Elas exibem densidade na faixa de 3,024 a $3,221 \mathrm{~g} \mathrm{~cm}^{-3}$; área superficial (S) que varia em grande extensão (60 a $85.520 \mathrm{~cm}^{2} \mathrm{~g}^{-1}$ ) e valores de porosidade $(P)$ que se situam entre 2,12 a $12,72 \%$. Via de regra, as apatitas de maior área superficial apresentam os maiores valores de porosidade. 
5. Os parâmetros de rede ( $a, c$, volume da célula unitária) e de cristalinidade (grau de cristalinidade, tamanho de cristalito, microdeformação) foram determinados pelo método de Rietveld, que produziu resultados aceitáveis, haja vista o ajuste obtido entre os perfis de difração calculados versus observados, assim como a magnitude do parâmetro GOF que exibiu valores $\leq 1,5$. Os parâmetros de rede medidos por tal método encontram-se dentro da faixa prevista pela literatura: 9,340 $\AA<a<9,404 \AA$; $6,886 \AA<c<6,896 \AA$ e $520,9 \AA^{3}<$ volume da célula unitária $<527,8$ $\AA^{3}$. Todas as apatitas apresentam elevado conteúdo de matéria cristalina (grau de cristalinidade), que varia entre 70\% (ASO) e 78\% (ASQ). O tamanho médio de cristalito $\left(\mathrm{TC}_{\mathrm{M}}\right)$, abrangendo as orientações cristalográficas (h00), (0k0) e (00), pode ser colocado na seguinte ordem decrescente de magnitude: AAN (468 nm) $>$ ASQ $(423 \mathrm{~nm})>\operatorname{ATP}(334 \mathrm{~nm})>\operatorname{ACJ}(325 \mathrm{~nm})>\operatorname{AIP}(266 \mathrm{~nm}) \operatorname{AAR}(141 \mathrm{~nm})>$ ASO $(64 \mathrm{~nm})$. A microdeformação (MD) varia em larga extensão: de $0,4 \times 10^{-4}$ (AAR) a $600 \times 10^{-4}$ (ASO). Ela pode ser apresentada de acordo com a seguinte ordem decrescente de valores: ASO $\left(600 \times 10^{-4}\right)>$ ASQ $\left(460 \times 10^{-4}\right)>$ AIP $\left(160 \times 10^{-4}\right)>$ ATP $\left(10 \times 10^{-4}\right)>>$ AAN, ACJ $\left(0,6 \times 10^{-4}\right)>\operatorname{AAR}\left(0,4 \times 10^{-4}\right)$.

6. As amostras AAR, AIP, ACJ, ASO e ASQ foram submetidas a ensaios de dissolução em meio básico ( $\mathrm{pH} 8$ e pH 10), obtendo-se um perfil de variação da quantidade de cálcio (mol) que foi liberada para a solução $\left(\mathrm{Ca}^{2+}\right)$ versus tempo $(\mathrm{t})$ de reação. Tal perfil pode ser representado por uma curva exponencial do tipo $\mathrm{Ca}^{2+}=\mathrm{Ca}^{2+} \operatorname{MAx}\left(1-\mathrm{e}^{-\mathrm{kt}}\right)$, indicando que o fenômeno obedece a um modelo de $1^{\text {a }}$ ordem. Deste modo, nos momentos iniciais, a dissolução ocorre por meio de uma etapa rápida (caracterizada pela velocidade rápida de dissolução - $V_{R}$ ) que é seguida de outra lenta (representada pela velocidade lenta de dissolução $-\mathrm{V}_{\mathrm{L}}$ ). A curva exponencial permitiu a determinação da constante cinética $(k)$ e a quantidade máxima de cálcio $\left(\mathrm{Ca}^{2+}{ }_{\mathrm{MAX}}\right)$ colocada em solução quando se atinge o estado estacionário. Este se mostrou ser, no mínimo, 15 vezes superior ao tempo de realização de um ensaio de microflotação ( 1 minuto de condicionamento +1 minuto de flotação). Deste modo, a velocidade de dissolução na etapa rápida $\left(V_{R}\right)$ foi escolhida como o parâmetro mais indicado para se avaliar a influência da dissolução dos minerais na resposta à flotação. A seguinte sequência decrescente de $V_{R}$ é observada: $A C J$ > AIP > ASQ > AAR > ASO, independentemente do $\mathrm{pH}$.

7. A flotabilidade das apatitas foi avaliada em meio básico ( $\mathrm{pH} 8$ e pH 10), na presença de $1,42 \times 10^{-5} \mathrm{~mol} \mathrm{~L}^{-1}$ de oleato de sódio. Independentemente do $\mathrm{pH}$, 
verifica-se a seguinte ordem decrescente de flotabilidade: ACJ, AIP > AAN > ATP > $\mathrm{AAR}>\mathrm{ASQ}>\mathrm{ASO}$. A flotabilidade em $\mathrm{pH} 8$ é superior à obtida em $\mathrm{pH} 10$.

8. Com base nas características intrínsecas das apatitas (parâmetros de rede, de cristalinidade e físicos), comportamento da dissolução $\left(V_{R}\right)$ e flotabilidade $(F)$, as seguintes relações de causa-efeito merecem ser destacadas:

a) Por correlação linear simples, observa-se que a flotabilidade das apatitas aumenta com a magnitude de $V_{R}$. $O$ coeficiente de correlação $(R)$ é de $R=0,95$ para $\mathrm{pH} 8$ e $\mathrm{R}=0,89$ para $\mathrm{pH} 10$;

b) Por meio de correlação linear múltipla para um mesmo nível de $\mathrm{pH}(\mathrm{pH} 8$ ou $\mathrm{pH}$ 10), verifica-se relação de causa-efeito entre $V_{R}$ e três variáveis que correspondem a características intrínsecas das apatitas: grau de cristalinidade (GC), tamanho médio de cristalito $\left(\mathrm{TC}_{\mathrm{M}}\right)$, e o parâmetro de rede $c$. Quanto maior a magnitude de $\mathrm{GC}$ e $\mathrm{TC}_{\mathrm{M}}$, maior o valor de $\mathrm{V}_{\mathrm{R}}$. Por outro lado, o valor de $V_{R}$ diminui com o aumento da magnitude do parâmetro de rede $c$. Os valores experimentais de $V_{R}$ se ajustam àqueles calculados pelo modelo de correlação múltipla, dentro de um intervalo de confiança de $95 \%$.

c) Os modelos propostos foram utilizados para calcular a flotabilidade das apatitas AAN e ATP. Os valores calculados de $F$ são muito próximos dos experimentais, dando suporte à validação do modelo.

\subsection{Conclusões relativas ao estudo com as calcitas}

Dentro do universo desta investigação, é possível concluir:

1. Amostras de calcita provenientes de Amorinópolis-(GO), Cachoeiro do Itapemirim (ES), Cajati-SP e Santa-Quitéria (CE) foram concentradas por meio de separação por meio denso e magnética a fim de que fossem empregadas neste estudo. Também foram utilizados cristais perfeitos de calcita: romboedro opaco (CRO) e transparente (CRT). A pureza (determinada por análise semi-quantitativa do método de Rietveld) das calcitas utilizadas foi superior a 91\%: CRO, CRT, CAM 
$(\sim 100 \%)>\operatorname{CSQ}(98 \%)>\operatorname{CCJ}(97 \%)>\mathrm{CCl}(91 \%)$. As principais impurezas encontradas nas calcitas foram dolomita e quartzo. A calcita de $\mathrm{CCl}$ se destaca por seu elevado teor de $\mathrm{MgO}$ (3,2\%-FRX). As calcitas CCl e CCJ foram classificadas como calcitas magnesianas por apresentarem $\mathrm{MgO}(0,6 \%$ em $\mathrm{CCl}$ e $0,3 \%$ em CCJ) detectado por WDS/EDS.

2. As calcitas estudadas exibem densidade na faixa de 2,732 a $3,766 \mathrm{~g} \mathrm{~cm}^{-3}$; área superficial de 210 a $510 \mathrm{~cm}^{2} \mathrm{~g}^{-1}$ e porosidade de 2,99 a 3,76\%.

3. $O$ método de Rietveld foi utilizado para a determinação dos parâmetros de rede e de cristalinidade das amostras de calcita. Os refinamentos foram adequados para esta finalidade, haja vista os ajustes obtidos entre os perfis de difração calculados versus observados e o número GOF que assumiu valores $\leq 2,4$. Os parâmetros de rede determinados por este método variaram dentro da faixa prevista pela literatura: 4,978 $\AA$ < $a<4,989 \AA ; 17,015 \AA<c<17,061 \AA$ e $565,2 \AA^{3}<$ volume da célula unitária $<567,7 \AA^{3}$. O grau de cristalinidade das calcitas varia entre $82 \%$ (CRO) a $89 \%(\mathrm{CCl})$. As amostras podem ser organizadas de acordo com a seguinte ordem decrescente de tamanho de cristalito (TC): CCI, CCJ (164 nm) > CSQ $(161 \mathrm{~nm})>\operatorname{CRO}(152 \mathrm{~nm})>\operatorname{CAM}(134 \mathrm{~nm})>\mathrm{CRT}(122 \mathrm{~nm})$. A magnitude da microdeformação varia amplamente dentro do grupo de calcitas analisadas: de 0,06 (CAM) para 0,16 (CCJ).

4. A cinética de dissolução das amostras foi investigada por meio de ensaios em $\mathrm{pH}$ constante. As curvas de dissolução exibem um perfil exponencial que pode ser representado por uma curva do tipo $\mathrm{nCa}^{2+}=\mathrm{Ca}^{2+} \operatorname{MAX}\left(1-\mathrm{e}^{-k t}\right)$. Os mesmos parâmetros de dissolução determinados para as apatitas foram calculados no estudo de dissolução das calcitas: quantidade máxima de íons $\mathrm{Ca}^{2+}$ dissolvidos $\left(\mathrm{Ca}^{2+}{ }_{\mathrm{MAX}}\right)$, constante cinética $(k)$, velocidade de dissolução na etapa rápida $\left(V_{R}\right)$ e velocidade de dissolução na etapa lenta $\left(\mathrm{V}_{\mathrm{L}}\right)$. $\mathrm{V}_{\mathrm{R}}$ foi eleito como o parâmetro de dissolução mais adequado para se avaliar a influência da dissolução dos minerais na resposta à flotação, por contemplar intervalo de tempo correspondente aos ensaios de microflotação (2 minutos iniciais). A seguinte ordem decrescente de $V_{R}$ é encontrada para o grupo de calcitas estudada tanto em pH 8 como em pH 10: CRT > CCJ, CAM, $\mathrm{CCl}>\mathrm{CRO}>\mathrm{CSQ}$.

5. A flotabilidade das calcitas, na presença de $7,11 \times 10^{-6} \mathrm{~mol} \mathrm{~L}^{-1}$ de oleato de sódio, em pH 8 e 10 foi estudada. $\mathrm{Em} \mathrm{pH} \mathrm{8,} \mathrm{a} \mathrm{sequência} \mathrm{de} \mathrm{flotabilidade} \mathrm{que} \mathrm{se}$ observa é: CRT > CAM > CCI > CRO > CCJ > CSQ. Em pH 10 a diferença entre a 
flotabilidade das calcitas de diferentes origens é menos evidente, embora a ordem decrescente de flotabilidade não se altere: CRT > CAM, CCI, CRO, CCJ > CSQ. A flotabilidade em $\mathrm{pH} 10$ é superior à obtida em $\mathrm{pH} 8$.

6. As relações de causa-efeito encontradas entre as características intrínsecas das calcitas (parâmetros de rede, de cristalinidade e físicos) e o seu comportamento na dissolução $\left(V_{R}\right)$ e na flotabilidade $(F)$ são:

a) A flotabilidade aumenta com a magnitude de $V_{R}$. Os coeficientes de correlação (R) são de $\mathrm{R}=0,62$ para $\mathrm{pH} 8$ e $\mathrm{R}=0$,66 para $\mathrm{pH} 10$;

b) Por meio de correlação linear múltipla para um mesmo nível de $\mathrm{pH}(\mathrm{pH} 8$ ou $\mathrm{pH} 10$ ), observa-se relação de causa-efeito entre $\mathrm{V}_{\mathrm{R}}$ e grau de cristalinidade (GC), tamanho de cristalito (TC), densidade (d) e porosidade (P). A magnitude de $V_{R}$ aumenta com GC e com $P$, no entanto, $V_{R}$ diminui com o aumento de TC e de $\mathrm{d}$. Observou-se que os valores experimentais de $V_{R}$ se ajustam aos valores calculados pelo modelo de correlação múltipla, dentro de um intervalo de confiança de $95 \%$. 


\section{REFERÊNCIAS}

ABDEL-KHALEK, N. S. A. Evaluation of flotation strategies for sedimentary phosphates with siliceous and carbonates gangues. Minerals Engineering, v. 13, p. 789-793, 2000.

ABOUZEID, A. Z. M. Physical and thermal treatment of phosphate ores - An overview. International Journal of Mineral Processing, v. 85, p. 59-84, 2008.

ABOUZEID, A. Z. M.; EL-JALLAD, I. S.; ORPHY, M. K. Calcareous phosphates and their calcined products. Minerals Science and Engineering, v. 12, p. 73-83, 1980.

ABOUZEID, A. Z. M.; NEGM, A. T.; ELGILLANI. D. A. Upgrading of calcareous phosphate ores by flotation: Effect of ore characteristics. International Journal of Mineral Processing, v. 90, p. 81-89, 2009.

AGOUGUI, H.; AISSA, A.; DEBBABI, M. Synthesis and characterization of calcium hydroxy and fluorapatita functionalized with methyl phosphonic dichloride. Applied Surface Science, v. 261, p. 182-188. 2012.

ALKATTAN, M.; OELKERS, E. H.; DANDURAND, J. L.; SCHOTT, J. An experimental study of calcite dissolution rates at acid conditions and $25^{\circ} \mathrm{C}$ in the presence of $\mathrm{NaPO}_{3}$ and $\mathrm{MgCl}_{2}$. Chemical Geology, v. 190, p. 291-302, 2002.

AMANKONAH J. O.; SOMASUNDARAN, P.; ANANTHAPADMANABHAN, K. P. Effects of dissolved mineral species on the dissolution/precipitation characteristics of calcite and apatite. Colloids and Surfaces, v. 15, p. 295-307, 1985.

ANANTHAPADMANABHAN, K. P.; SOMASUNDARAN, P. Acid-soap formation in aqueous oleate solutions. Journal of Colloid and Interface Science, v. 122, p. 104110, 1988.

ANTONAKOS, A. A.; LIAROKAPIS, E.; LEVENTOURI, T. Micro-Raman and FTIR studies of synthetic and natural apatites. Biomaterials, v. 28, p. 3043-3054, 2007. 
ANTONIO, S. G. Aplicação da difração de raios X por policristais e do método de Rietveld de refinamento de estruturas cristalinas no estudo de polimorfos cristalinos de fármacos. 2010. 161 p. Tese (Doutorado) - UNESP, Araraquara, 2010. (2010).

ARAUJO, A. C.; GUIMARÃES, R. C.; PERES, A. E. C.; POLING, G. W. Selective adsorption of starches onto Ca-bearing surfaces. In: ZHANG, P.; MILLER, J.; ELSHALL, H.; STANA, R. Beneficiation of Phosphates IV: Technology and Sustainability. Florida: The Society of Mining, Metallurgy, and Exploration Inc., 2006. p. 15-24.

ARAUJO, A. C. Espectofotometria no infravermelho aplicada à caracterização de apatitas. In: ENCONTRO NACIONAL DE ROCHA FOSFÁTICA, 5., 1990, São Paulo. Anais. Brasilia: IBRAFOS, 1990. p. 201-211.

ARVIDSON, R. S.; ERTAN, I. E.; AMONETTE, J. E.; LUTTGE A. Variation in calcite dissolution rates: A fundamental problem?. Cheochimica et Cosmochimica Acta, v. 67, p. $1623-1634,2002$.

ARVIDSON, R. S.; COLLIER, M.; DAVIS, K. J.; VINSON, M. D.; AMONETTE, J. E.; LUTTGE, A. Magnesium inhibition of calcite dissolution kinetics. Cheochimica et Cosmochimica Acta, v. 70, p. 583-594, 2006.

ASSIS, S. M.; MAIA, G. S.; COELHO, E. M.; SILVA, J. M. Contribuição à interpretação das características de flutuabilidade do sistema calcita/apatita. In: ENCONTRO NACIONAL DE TRATAMENTO DE MINÉRIO E MINERALOGIA EXTRATIVA, 11, 1985, Natal. Anais... Natal: URRGN, 1985. p. 87-101.

ASSIS, S. M.; VIANA S. M.; SILVA, J. M. Calcitas, dolomitas e apatitas. Algumas características inerentes X microflotção. In: ENCONTRO NACIONAL DE TRATAMENTO DE MINÉRIOS E HIDROMETALURIA, 12, 1987, Rio de Janeiro. Anais... Rio de Janeiro: S.n.t., 1987. p. 265-280.

BAIG, A. A.; FOX, J. L.; HSU, J.; WANG, Z.; OTSUKA, M.; HIGUCHI, W.; LEGEROS, R. Z. Effect of carbonate content and crystallinity on the metastable equilibrium solubility behavior of carbonated apatites. Journal of Colloid and Interface Science, v. 179, p. 608-617, 1996.

BAIG, A. A.; FOX, J. L. J.; YOUNG, R. A.; WANG, Z.; HSU.J.; HIGUCHI, W. I.; CHHETTRY, A.; ZHUANG, H.; OTSUKA, M. Relationships among carbonated apatite solubility, crystallite size, and microstrain parameters. Calcified Tissue International, v. 64, p. $437-449,1999$. 
BALZAR, D., Voight-function model in diffraction line-froadening analysis, In: SNYDER, R. L.; BUNGE, H. J.; FIALA, J. Microstructure Analysis from Diffraction. Boulder: International Union of Crystallography, 1999. p. 1-44.

BARROS, L. A. F.; FERREIRA, E. E.; PERES, A. E. C. Floatability of apatites and gangue minerals of an igneous phosphate ore. Minerals Engineering, v. 21, p. 994-999, 2008.

BARROS, L. A. F.; LEAL FILHO, L. S.; PERES, A. E. C. Plant practice innovations in a phosphate concentrator. Minerals Engineering, v. 14, p. 117-121, 2001.

BAUDET, G.; SAVE, M. Phosphoric esters as carbonate collectors in the flotation of sedimentary phosphate ores. In: ZHANG, P., EL-SHALL, H., WIEGEL, R.

Beneficiation of Phosphates: Advances in Research and Practice. Littleton: The Society of Mining, Metallurgy, and Exploration Inc., 1999. p. 763-185.

BERNER, R. A. Rate control of mineral dissolution under earth surface conditions. American Journal of Science, v. 278, p. 1235-1252, 1978.

BERNER, R. A.; MORSE, J. W. Dissolution kinetics of calcium carbonate in sea water IV: Theory of calcite dissolution. American Journal of Science, v. 174, p. 108-134, 1974.

BETEJTIN, A. Curso de Mineralogia. 3르 ed. Moscou: Mir, 1977. 461 p.

BORN, H.; LENHARO, S. L. R.; KAHN, H. Mineralogical characterization of apatites from brazillian phosphate deposits. Transactions Institution of Mining and Metallurgy, v. B1001, p. 117-126, 1996.

BÖTTCHER, M. GEHLKEN, P. L.; STEELE, D. F. Characterization of inorganic and biogenic magnesian calcites by Fourier transform infrared spectroscopy. Solid State lonics, v. 101-103, p. 1379-1385, 1997.

BRUMATTI, M. Mineralogia aplicada ao beneficiamento das zonas de xenólitos, mina de Cajati. 2008. 160 p. Tese (Doutorado) - Escola Politécnica, Universidade de São Paulo, 2008. 
CHAÏRAT, C.; OELKERS, E. H.; SCHOTT, J.; LARTIGUE, J. E. Fluorapatite surface composition in aqueous solution deduced from potentiometric, electrokinetic, and solubility measurements, and spectroscopic observations. Geochimica et Cosmochimica Acta, v. 71, p. 5888-5900, 2007a.

CHAÏRAT, C.; SCHOTT, J.; OELKERS, E. H.; LARTIGUE, J. E.; HAROUIYA, N. Kinetics and mechanism of natural fluorapatite dissolution at $25^{\circ} \mathrm{C}$ and $\mathrm{pH}$ from 3 to 12. Geochimica et Cosmochimica Acta, v. 71, p. 5901-5912, 2007b.

CHAVES, A. P. Teoria e Prática do Tratamento de Minérios. São Paulo: Signus, 2006. v. 4, 484 p.

CHAVES, A. P.; LEAL FILHO, L. S.; BRAGA, P. F. A. Flotação. In: LUZ, A. B.; SAMPAIO, J. A.; FRANÇA, S. C. A. Tratamento de Minérios. Rio de Janeiro: CETEM - Centro de Tecnologia Mineral, 2010. p. 468-513.

CHHETTRY, A.; WANG, Z.; HSU, J.; FOX, J. L.; BAIG, A. A.; BARRY, A. M.; ZHUANG, H.; OTSUKA, M.; HIGUCHI, W. I. Metastable equilibrium solubility distribution of carbonated apatite as a function of solution composition. Journal of Colloid and Interface Science, v. 218, p. 57-67, 1999.

CHRISTOFFERSEN, J.; CHRISTOFFERSEN, M. R.; KJAERGAARD, N. The kinetics of dissolution of calcium hydroxyapatite in water at constant $\mathrm{pH}$. Journal of Crystal Growth, v. 43, p. 501-511, 1978.

CISSE, L; MRABET, T. World phosphate production: Overview and prospects. Phosphorus Research Bulletin, v. 15, p. 21-25, 2004.

COELHO, A. Users Manual, Topas Academic, Version 4.1. Brisbane: 2007, 34 p.

COMPTON, R. F.; DALY, P. J. The dissolution/precipitation kinetics of calcium carbonate: An assessment of various kinetic equations using a rotating disk method. Journal of Colloid and Interface Science, v. 115. p. 493-498, 1987.

COMPTON, R. F.; DALY, P. J.; HOUSE W. A. The dissolution of Iceland spar crystals: The effect of surface morphology. Journal of Colloid and Interface Science, v. 113, p. 12-20, 1986.

CRAGO, A. Process of concentrating phosphate minerals. USA 2,2936404. p.4, 1942. 
DANA, J. D. Manual de Mineralogia. 1aㅡ ed. Rio de Janeiro: Rio de Janeiro Livros técnicos e científicos, 1969. 643 p.

DOROZHKIN, S. V. Acidic dissolution mechanism of natural fluorapatite I. Mili and microlevels of investigation. Journal of Crystal Growth, v. 182, p. 125-132, 1997a.

DOROZHKIN, S. V. Acidic dissolution mechanism of natural fluorapatite II. Nanolevel of investigation. Journal of Crystal Growth, v. 182, p. 133-140, 1997b.

DU RIETZ, C. Chemisorption of collectors in flotation. In. INTERNATIONAL MINERAL PROCESSING CONGRESS, 11., 1975, Cagliari. Proceedings... Cagliari: Instituto di Arte Mineraria, 1975. p. 27-29.

ELGILLANI, D. A.; ABOUZEID, A. Z. M. Flotation of carbonates from phosphate ores in acidic media. International Journal of Mineral Processing, v. 38, p. 235-258, 1993.

EL-MIDANY, A.; EL-SHALL, H.; STANA, R. Mechanisms involved in reactive flotation of dolomite. Minerals and Metallurgical Processing, v. 26, p. 94-100, 2009.

FA, K.; JIANG, T.; NALASKOWSKI, J.; MILLER. J. D. Interaction between a calcium dioleate sphere and calcite/fluorite surfaces and their significance in flotation. Langmuir, v. 19, p. 10523-10530, 2003.

FA, K.; NGUYEN, A. V.; MILLER, J. D. Interaction of calcium dioleate collector colloids with calcite and fluorite surfaces as revealed by AFM force measurements and molecular dynamics simulation. International Journal of Mineral Processing, v. 81 , p. 166-177, 2006.

FERRARI, V. C. Fosfatos primários e secundários nos perfis de intemperismo sobre os maciços de Juquiá (SP), Anitápolis (SC) e Tapira (MG). 2000, 241 p. Tese (Doutorado) - Instituto de Geociências, Universidade de São Paulo, 2000.

FINKELSTEIN, N. P. Review of the interactions in flotation of sparingly soluble calcium minerals with anionic collectors. Transactions of the institution of mining and metallurgy C, v. 988, p. 157-78, 1989.

FLEET, M. E. Infrared spectra of carbonate apatites: v2-Region bands. Biomaterials, v. 30, p. 1473-1481, 2009. 
FONSECA, D. S.; SILVA, T. H. C. S. Fosfato, Sumário mineral 2012. DNPM (departamento nacional de produção mineral), 2012. 2 p.

FRANCISCO JUNIOR, W. E. Carboidratos: estrutura, propriedades e funções, Química Nova na Escola, v. 29, p. 8-13, 2008.

FREE, M. L.; MILLER, J. D. The significance of collector colloid adsorption phenomena in the fluorite/oleate flotation system as revealed by FTIR/IRS and solution chemistry analysis. International Journal of Mineral Processing, v. 48, p. 197-216, 1996.

FUERSTENAU, M. C. "Where are we in flotation chemistry after 70 years of research". In: IXI INTERNATIONAL MINERALS PROCESSING CONGRESS, v. 3, p. 3-18, 1995.

GAO, Z.; ZHENG, S.; GU, Z. Review of beneficiation technology for Florida high dolomite pebble, In: ZHANG, P.; EL-SHALL, H.; SOMASUNDARAN, P.; STANA, R. Beneficiation of Phosphates: Fundamentals and Technology. Littleton: The Society of Mining, Metallurgy, and Exploration Inc., 2002. p. 247-259.

GRUBER, G. A.; ZHENG, S. HWANG, C. A pilot-scale demonstration of the IMC/CLDRI/FIPR flotation process for Florida high-MgO pebble. Florida: Florida Institute of Phosphate Research, 2001. 100p. (Report).

GUAN, C. Theoretical background of the Crago Phosphate flotation process. Minerals \& Metallurgical Processing, v. 26, p. 55-64, 2009.

GUIDRY, M. W.; MACKENZIE, F. T. Experimental study of igneous and sedimentary apatite dissolution: Control of $\mathrm{pH}$, distance from equilibrium, and temperatures on dissolution rates. Geochimica et Cosmochimica Acta, v. 67, p. 2249-2963, 2003.

GUimarÃES, R. C., ARAUJO, A. C., PERES, A. E. C. Reagents in igneous phosphate ores flotation. Minerals Engineering, v. 18, p. 199-204, 2005.

GUNASEKARAN, S.; ANBALAGAN, G. Spectroscopic characterization of natural calcite minerals. Spectrochimica Acta Part A, v. 68, p. 656-664, 2007.

HANNA, H. S.; SOMASUNDARAN, P. Flotation of salt-type minerals In:

FUERSTENAU, M. C. Flotation: Gaudin Memorial Volume. New York: American Institute of Mining, Metallurgical, and Petroleum Engineers, Inc., 1976. p.197-272. 
HAROUIYA, N.; CHAÏRAT, C.; KÖHLER, J.; GOUT, R.; OELKERS, E. H. The dissolution kinetics and apparent solubility of natural apatite in closed reactors at temperatures from 5 to $50^{\circ} \mathrm{C}$ and $\mathrm{pH}$ from 1 to 6 . Chemical Geology, v. 244, p. 554-568, 2007.

HILLNER, P.E.; MANNE, S.; GRATZ, A.J.; HANSMA, P.K. AFM images of dissolution and growth on a calcite crystal. Ultramicroscopy, v. 42-44, p. 1387-1393, 1992.

HORTA, D. G.; LEAL FILHO, L. S. Separation between phosphates and carbonates. Melbourne: AMIRA P260F, November 2012. p 59-73 (Progress report confidential).

HUI, P.; MEENA, S. L.; SINGH, G.; AGARAWAL, R. D.; PRAKASH, A. S. Synthesis of hydroxyapatite bio-ceramic powder by bydrothermal method. Journal of Minerals \& Materials Characterization \& Engineering, v. 9, p. 683-692, 2010.

JENKINS, R.; SNYDER, R. Introduction to X-ray powder diffractometry. $1^{\text {st }}$ ed. Canada: Jonh Wiley \& Sons, 1996. 403 p.

KANAZAWA, T. Inorganic Phosphate Materials. Amsterdan: Kodansha,1989. $290 \mathrm{p}$.

KHOSLA, N. K.; BISWAS, A. K. Mineral-collector-starch constituent interactions. Colloids and Surfaces, v. 9, p. 219-235, 1984.

KIRWAN, L. J.; DEENEY, F. A.; CROKE, G. M.; HODNETT, K. Characterization of various Jamaican bauxite ores by quantitative Rietveld $X$-ray powder diffraction and Mossbauer spectroscopy. International Journal of Mineral Processing, v. 91, p. 14-18, 2009.

LAWENDY, T. A. B.; McCLELLAN, G. H. Flotation of dolomitic and calcareous phosphate ores In: EL-SHALL, H.; MOUDGIL, B. M.; WIEGEL, R. Beneficiation of Phosphates: Theory and Practice. Littleton: Society of Mining, Metallurgy, and Exploration, Inc., 1993. p. 29-43.

LEAL FILHO, L.S. Aspectos relevantes na separação apatita/minerais de ganga via processo Serrana. 1991. 266 p. Tese (Doutorado) - Escola Politécnica, Universidade de São Paulo, São Paulo, 1991. 
LEAL FILHO, L. S. A seletividade na separação apatita/silicatos por flotação: Subsídios para a solução de problemas tipicamente brasileiros. 1999. 160 p. Tese (Livre-Docência) - Escola Politécnica, Universidade de São Paulo, São Paulo, 1999a.

LEAL FILHO, L. S. The influence of modifier agents on the separation apatite/silicates by flotation. In: ZHANG, P.; EL-SHALL, H.; WIEGEL, R.

Beneficiation of Phosphates: Advances in Research and Practice. Littleton: The Society of Mining, Metallurgy, and Exploration Inc., 1999b. p. 53-62.

LEAL FILHO, L. S.; ASSIS, S. M.; BARROS, L. A. F.; PERES, A. E. C. Activation and depression of silicates during anionic flotation of igneous apatites, In: ZHANG, P.; EL-SHALL, H.; SOMASUNDARAN, P.; STANA, R. Beneficiation of Phosphates: Fundamentals and Technology. Littleton: The Society of Mining, Metallurgy, and Exploration Inc., 2002. p. 55-65.

LEAL FILHO, L. S.; MARTINS, M.; HORTA, D. G. Concentration of igneous phosphate ores via froth flotation: Challenges and developments. In: INTERNATIONAL MINERAL PROCESSING CONGRESS, 25, 2010, Brisbane. Proceedings... Brisbane: IMPC, p. 3-13.

LEAL FILHO, L. S.; SEIDL, P. R.; CORREIA, J. C. G.; CERQUEIRA, L. C. K. Molecular modeling of reagents of flotation processes. Minerals Engineering, v. 13, p. 1495-1503, 2000.

LEGEROS, R. Z.; LEGEROS, J. P.; TRAUTZ, O. R.; KLEIN, E. Spectral properties of carbonate in carbonate-containing apatites. Developments in Applied Spectroscopy, v. 7 B, p. 3-12, 1970.

LENHARO, S. L. R. Caracterização mineralógica/tecnológica das apatitas de alguns depósitos brasileiros de fosfato. 1994. 196 p. Tese (Doutorado) Escola Politécnica, Universidade de São Paulo, São Paulo, 1994.

LIANG, Y. et al. Dissolution kinetics at the calcite-water interface. Geochimica et Cosmochimica Acta, v. 60, p. 4883-4887, 1996.

LINDSAY, W. L. Chemical Equilibria in soils. $1^{\underline{a}}$ ed. Canada: John Wiley \& Sons, 1979. $449 \mathrm{p}$. 
LU, Y.; DRELICH, J.; MILLER, D. Oleate adsorption at an apatite surface studied by ex-situ FTIR internal reflection spectroscopy. Journal of Colloid and Interface Science, v. 202, p. 462-476, 1998.

MALTESH, C.; SOMASUNDARAN, P.; GRUBER, G. A. Fundamentals of oleic acid adsorption on phosphate flotation feed during anionic conditioning. Minerals and Metallurgical Processing, v. 13, p. 156-160, 1996.

MARKOVIC, M.; FOWLER, B. O.; TUNG, M. S. Preparation and comprehensive characterization of a calcium hydroxyapatite reference material. Journal of Research of the National Institute of Standards and Technology, v. 109, p. 553-568, 2004.

MARINAKIS, K. I.; SHERGOLD, H. L. The mechanism of adsorption in the presence of fluorite, calcite and barite. International Journal of Mineral Processing, v. 14, p. 161-176, 1985.

MATHUR, S.; MOUDGIL, B. M. Application of infrared spectroscopy in solid-solid separation process. Colloids and Surfaces A: Physicochemical and Engineering Aspects, v. 93, p. 137-147, 1994.

McCLELLAN, G. H. Mineralogy of carbonate fluorapatita. Journal of the Geological Society, v. 137, p. 675-681, 1980.

MENEGHINI, C.; DALCONI, M. C.; NUZZO, S.; MOBILIO, S.; WENK, R. H. Rietveld refinement on X-ray diffraction patterns of bioapatite in human fetal bones.

Biophysical Journal, v. 84, p. 2021-2029, 2003.

MIELCZARSKI, J. A.; CASES, J. M.; BOUQUET, E.; BARRES, O.; DELON, J. F. Nature and structure of adsorption layer on apatite contacted with oleate solution 1 : Adsorption and Fourier Transform Infrared Reflection Studies. Langmuir, v. 9, p p. 2370-2382, 1993.

MIELCZARSKI, E.; DONATO, P; MIELCZARSKI, J. A.; CASES, J. M.; BARRES, O.; BOUQUET, E. Solution chemistry in adsorption layer formation of oleate on fluorite. Journal of Colloid and Interface Science, v. 226, p. 269-276, 2000.

MORSE, J. W. Dissolution kinetics of calcium carbonate in sea water V: Effects of natural inhibitors and the position of the chemical lysocline. American Journal of Science, v. 274, p. 338-347, 1974. 
MORSE, J. W. The kinetics of calcium carbonate dissolution and precipitation. In: REEDER, R. Carbonates: Mineralogy and Chemistry. Chelsea: Mineralogical Society of America, 1983. p. 227-264.

MORSE, J. W. The surface chemistry of calcium carbonate minerals in natural waters: An overview. Marine Chemistry, v. 20, p. 91-112, 1986.

MORSE, J. W.; ARVIDSON, R. S. The dissolution kinetics of major sedimentary carbonate minerals. Earth-Science Reviews, v. 58, p. 51-84, 2002.

MORSE, J. W.; BERNER, R. A. Dissolution kinetics of calcium carbonate in seawater: II. A kinetic origin for lysocline. American Journal of Science, v. 272, p. 840-852, 1972.

MORSE, J. W.; BERNER, R. A. Chemistry of calcium carbonate in the deep oceans. In: JENNE, E. A. Chemical Modeling in Aqueous System. England: American Chemical Society, 1979. Cap. 21, p. 499-535.

MUCCI, A.; MORSE, J. W. The solubility of calcite in seawater solutions of various magnesium concentration, $\mathrm{I}=0.697 \mathrm{~m}$ at $25^{\circ} \mathrm{C}$ and atmosphere total pressure. Geochimica et Cosmochimica Acta, v. 48, p. 815-822, 1984.

OERTER, E. J.; BRIMHALL-JR, G. H.; REDMOND, J.; WALDER, B. A method for quantitative pyrite abundance in mine rock piles by powder $\mathrm{X}$-ray diffraction and Rietveld refinement. Applied Geochemistry, v. 22, p. 2907-2925, 2007.

OSAWARU, A.; ORUMWENSE, E.; FORSSBERG, E. Surface and structural changes in wet ground minerals. Powder Technology, v. 68, p. 23-29, 1991.

PAIVA-SANTOS, C. O. Aplicação do método de Rietveld e potencialidades do método de Scarlett-Madsen. Araraquara: UNESP, 2009. 38 p. Apostila didática.

PAIVA, P. R. P.; MONTE, M. B. M.; SIMÃO, R. A.; GASPAR, J. C. In situ AFM study of potassium oleate adsorption and calcium precipitate formation on apatite surface. Minerals Engineering, v. 24, p. 387-395, 2011.

PAPANGKORN, K.; YAN, G.; HESLOP, D. D.; MORIBE, K.; BAIG, A. A.; OTSUKA, M.; HIGUCHI, W. I. Influence of crystallite microstrain on surface complexes governing the metastable equilibrium solubility behavior of carbonated apatites. Journal of Colloid and Interface Science, v. 320, p. 96-109, 2008. 
PAPINI, R. M.; GUIMARÃES, R. C.; PERES, A. E. C. The challenge of floating phosphate ore with silicate-carbonate gangue. In: ZHANG, P.; EL-SHALL, H.; SOMASUNDARAN, P.; STANA, R. Beneficiation of Phosphates: Fundamentals and Technology. Littleton: The Society of Mining, Metallurgy, and Exploration Inc., 2002. p. 213-220.

PENG, F. F.; GU, Z. Processing Florida dolomitic phosphate pebble in a double reverse fine flotation process. Minerals and Metallurgical Processing, v. 22, p. 23-30, 2005.

PLUMMER, L. N. The dissolution of calcite in $\mathrm{CO}_{2}$-saturated solutions at $25^{\circ} \mathrm{C}$ and 1 atmosphere total pressure. Geochimica et Cosmochimica Acta, v. 40, p. 191-202, 1976.

PLUMMER, L. N.; MACKENZIE, R. T. Predicting mineral solubility from rate data: Application to the dissolution of magnesian calcites. American Journal of Science, v. 274, p. 61-83, 1974.

PLUMMER, L. N.; PARKHURST, D. L.; WIGLEY, T. M. L. Critical review of the kinetics of calcite dissolution and precipitation. In: JENNE, E. A. Chemical Modeling in Aqueous System. England: American Chemical Society, 1979. cap. 25, p. 537573.

PLUMMER, L. N.; WIGLEY, T. M. L.; PARKHURST, D. L. The kinetics of calcite dissolution in $\mathrm{CO}_{2}$-water systems at $5^{\circ} \mathrm{C}$ to $60^{\circ} \mathrm{C}$ and 0 to 1 atm $\mathrm{CO}_{2}$. American Journal of Science, v. 278, p. 179-216, 1978.

POKROVSKY, O. S.; SCHOTT, J. Surface chemistry and dissolution kinetics of divalent metal carbonates. Environmental Science \& Technology, v. 36, p. 426-432, 2002.

POKROVSKY, O. S.; SCHOTT, J.; THOMAS, F. Dolomite surface speciation and reactivity in aquatic systems. Geochimica et Cosmochimica Acta, v. 63, p. 3133-3143, 1999.

PRASAD, M.; MAJUMDER, A. K.; RAO, T. C. Reverse flotation of sedimentary calcareous dolomitic rock phosphate ore - an overview. Minerals and Metallurgical Processing, v. 17, p. 49-55, 2000. 
PUGH, R.; STENIUS, P. Solution chemistry studies and flotation behavious of apatite, calcite and fluorite minerals with sodium oleate collector. International Journal of Mineral Processing, v. 15, p. 193-218, 1985.

RAJU, G. B.; HOLMGREN, A.; FORSLING, W. Adsorption of dextrin at mineral water interface. Journal of Colloid and Interface Science, v. 193, p. 215-222, 1997.

RAJU, G. B.; HOLMGREN, A.; FORSLING, W. Complexation mechanism of dextrin with metal hydroxides. Journal of Colloid and Interface Science, v. 200, p. 1-6, 1998.

RAO, K. H.; FORSSBERG, K. S. E. Mechanism of fatty acid adsorption in salt-type mineral flotation. Minerals Engineering, v.4, p. 879-890, 1991.

RAO, K. H.; CASES, J. M.; FORSSBERG, K. S. E. Mechanism of oleate interaction on salt-type minerals. Journal of Colloid and Interface Science, v. 145, p. 330-348, 1991.

REEDER, J. R. Crystal chemistry of the rombohedral carbonates. In: REEDER, J. R. Carbonates: Mineralogy and Chemistry. Chelsea: Mineralogical Society of America, 1983. p. 227-264.

RIETVELD, H. M. A Method for Including Line Profiles of Neutron Powder Diffraction Peaks in Determination of Crystal Structures. Acta Crystallographica, v. $21 \mathrm{~A}, \mathrm{p}$. 228-242, 1966.

RIETVELD, H. M.A Profile Refinement Method for Nuclear and Magnetic Structures. Journal of Applied Crystallography, v.2, p. 65-71, 1969.

RICKARD, D.; SJÖBERG, E. L. Mixed kinetic control of calcite dissolution. American Journal of Science, v. 283, p. 815-830, 1983.

RODRIGUES, A. J.; BRANDÃO, P. R. G. The influence of crystal chemistry properties on the floatability of apatites with sodium oleate. Minerals Engineering, v. 6, p. 643-653, 1993.

ROOTARE, H. M.; DEITZ, V. R.; CARPENTER, F. G. Solubility product phenomena in hydroxyapatite water systems. Journal of Colloid Science, v. 17, p. 179-206, 1962. 
ROSS, S. D. Phosphates and other ory-anions of group V. In: FARMER, V. C. The infrared spectra of minerals London: Mineralogical Society, 1974. Monograph 4, p. 383-419.

SANTOS, R. V.; CLAYTON, R. N. The carbonate content in high-temperature apatite: $\mathrm{Na}$ analytical method applied to apatite from Jacupiranga alcaline complex. American Mineralogist, v. 80, p. 336-344, 1995.

SILVA, J. M.; COELHO, E. M. Caracterização das rochas fosfáticas brasileiras; estágio atual e perspectivas futuras. In: CONFERENCIA LATINOAMERICANA DE ROCHA FOSFÓRICA, 1, 1984, Cochabamba. Anais... Cochabamba: S.n.t., 1984. p. 159-172.

SILVA, J. M.; LEAL FILHO, L. S.; COELHO, E. M.; ASSIS S. M. Continuação de apatitas brasileiras e hidrofobicidade na presença de oleato de sódio. In: ENCONTRO NACIONAL DE TRATAMENTO DE MINÉRIO E MINERALOGIA EXTRATIVA, 11, Natal, 1985. Anais... Natal: URRGN, 1985. p. 87-101.

SIS, H.; CHANDER, S. Reagents used in the flotation of phosphate ores: A critical review. Minerals Engineering, v. 16, p. 577-585, 2003a.

SIS, H.; CHANDER, S. Improving froth characteristics and flotation recovery of phosphate ores with nonionic surfactants. Minerals Engineering, v. 16, p. 587-595, 2003b.

SJÖBERG, E. L. A fundamental equation for calcite dissolution kinetics, Geochimica et Cosmochimica Acta, v. 40, p. 441-447, 1976.

SJÖBERG, E. L. Kinetics and mechanism of calcite dissolution in aqueous solutions at low temperatures. Stockholm Contributions in Geology, v. 32, p. 1-96, 1978.

SJÖBERG, E. L.; RICKARD, D. The influence of experimental design on the rate of calcite dissolution. Geochimica et Cosmochimica Acta, v. 47, p. 2281-2285, 1983.

SJÖBERG, E. L.; RICKARD, D. Calcite dissolution kinetics: Surface specitation and the origin of the variable $\mathrm{pH}$ dependence. Chemical Geology, v. 42, p. 119-136, 1984.

SKÁLA, R.; JAKES, P. Shock-induced effects in natural calcite-rich targets as revealed by X-ray powder diffraction. Geologial Society of America, v. 339, p. 205214, 1999. 
SLANSKY, M. Mineralogy of sedimentary phosphates, In: SLANSKY, M. Geology of sedimentary phosphates. Anchor Brendon: North Oxford Academic, 1980. cap.2, p. 19-33.

SMITH, A. N.; POSNER, A. M.; QUIRK, J. P. Incongruent dissolution and surface complexes of hydroxyapatite. Journal of Colloid and Interface Science, v. 48, p. 442-449, 1974.

SMITH, A. N.; POSNER, A. M.; QUIRK, J. P. A model describing the kinetics of dissolution of hydroxyapatite. Journal of Colloid and Interface Science, v. 62, p. 475-493, 1977.

SMITH, L.; GRIFFITHS, N. Potash and Phosphate: Back from the brink. Mining Journal <http://www.mining-journal.com/reports/potash-and-phosphate-back-fromthe-brink>. Acesso em 10 de janeiro de 2013.

SNOW, R.; ZHANG, P. Challenging the Crago "double float" process IV: Selectivity enhancement in all-anionic flotation of florida phosphates. In: ZHANG, P.; MILLER, J.; EL-SHALL, H. Benefitiation of Phosphates: Technology and Sustainability. Florida: The Society of Mining, Metallurgy, and Exploration Inc., 2006. p. 113-122.

SOMASUNDARAN, P. Adsorption of starch and oleate and interaction between them on calcite in aqueous solution. Journal of Colloid and Interface Science, v. 31, p. 557-568, 1969.

SOMASUNDARAN, P.; ZHANG, L. Role of surface chemistry of phosphate in its beneficiation. In: ZHANG, P.; EL-SHALL, H.; WIEGEL, R. Beneficiation of

Phosphates: Advances in Research and Practice. Littleton: The Society of Mining, Metallurgy, and Exploration Inc., 1999. p. 141-154.

SVENSSON, U.; DREYBRODT, W. Dissolution kinetics of natural calcite minerals in $\mathrm{CO}_{2}$-water systems approaching calcite equilibrium. Chemical Geology, v. 100, p. $129-145,1992$.

TOLEDO, M. C. M.; PEREIRA, V. P. A variabilidade de composição da apatita associada a carbonatitos. Revista do Instituto Geológico, v. 22, p. 27.64, 2001.

TOLEDO, M. C. M.; LENHARO, L. R.; FERRARI, V. C.; FONTAN, F.; PARSEVAL, P.; LEROY, G. The compositional evolution of apatite in the weathering profile of the Catalão I alkaline-carbonatitic complex, Goias, Brazil. The Canadian Mineralogist, v. 42, p. 1139-1158, 2004. 
TROMMER, R. T.; SANTOS, L. A.; BERGMANN, C. P. Alternative technique for hydroxyapatite coatings. Surface \& Coatings Technology, v. 201, p. 9587-9593, 2007.

VALSAMI-JONES, E.; RAGNARSDOTTIR, K. V.; PUTNIS, A.; BOSBACH, D.; KEMP, A. J.; CRESSEY, G. The dissolution of apatite in de presence of aqueous metal cations at pH 2-7. Chemical Geology, v. 151, p. 215-233, 1998.

YAO, F.; LEGEROS, J. P.; LEGEROS, R. Z. Simultaneous incorporation of carbonate and fluoride in synthetic apatites: Effect on crystallographic and phisico-chemical properties. Acta Biomaterialia, v. 5, p. 2169-2177, 2009.

YEHIA, A.; MILLER, J. D.; ATEYA, B. T. Analysis of the adsorption behavior of oleate on some synthetic apatites. Minerals Engineering, v. 6, p. 79-86, 1993.

YOUNG, R. A. The Rietvled Method. $1^{\text {st }}$ ed. New York: Oxford, 1993. 312 p.

YOUNG, C. A.; MILLER, J. D. Effect of temperature on oleate adsorption at a calcite surface: an FT-NIR/IRS study and review. International Journal of Mineral Processing, v. 58, p. 331-350, 2000.

WU, L.; FORSLING, W.; SCHINDLER P. W. Surface complexation of calcium minerals in aqueous solution. Journal of Colloid and Interface Science, v. 147, p. 178-185, 1991.

ZHENG, S.; CAO, X.; GE, Z.; SONG, W. Beneficiation studies on sedimentary siliceous and calcareous phosphate ores in China. In: ZHANG, P.; MILLER, J.; ELSHALL, H.; STANA, R. Beneficiation of Phosphates IV: Technology and Sustainability. Florida: The Society of Mining, Metallurgy, and Exploration Inc., 2006. p. 217-221.

ZHENG, X.; SMITH, R. W. Dolomite depressants in the flotation of apatite and cellophane from dolomite. Minerals Engineering, v. 10, p. 537-545, 1997.

ZHENGXING, G.; ZHIZHONG, G.; SHIBO, Z. Beneficiation of Florida dolomitic phosphate pebble with a fine-particle flotation process. In: ZHANG, P., EL-SHALL, H., WIEGEL, R. Beneficiation of Phosphates: Advances in Research and Practice. Littleton: The Society of Mining, Metallurgy, and Exploration Inc., 1999. p. 155-162. 


\section{APÊNDICES}

\section{APÊNDICE A - Análises WDS/EDS}

Apêndice A.1 Espectros das análises por WDS/EDS

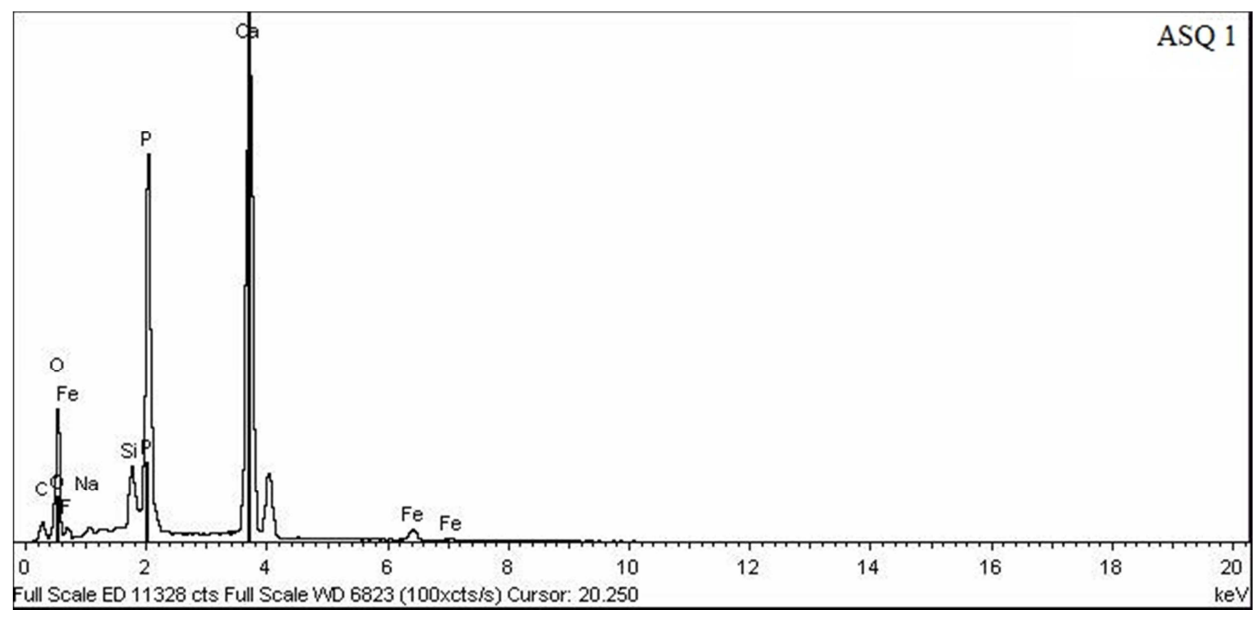

Figura A.1 - Exemplo de um dos espectros das análises por WDS/EDS da apatita ASQ.

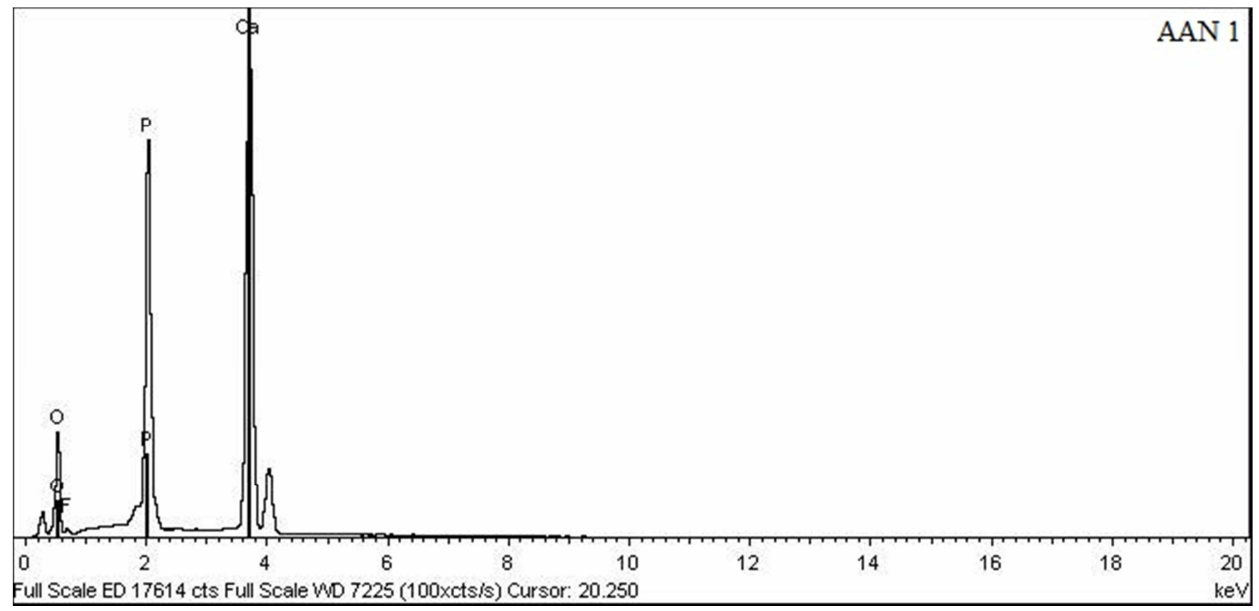

Figura A.2 - Exemplo de um dos espectros das análises por WDS/EDS da apatita AAN. 


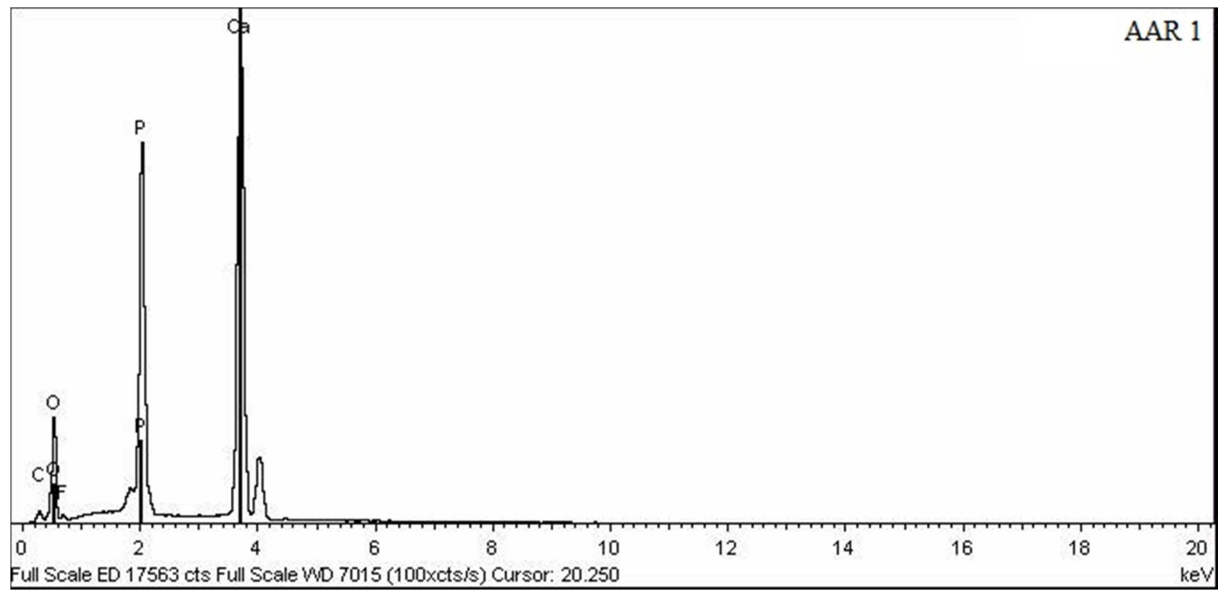

Figura A.3 - Exemplo de um dos espectros das análises por WDS/EDS da apatita AAR.

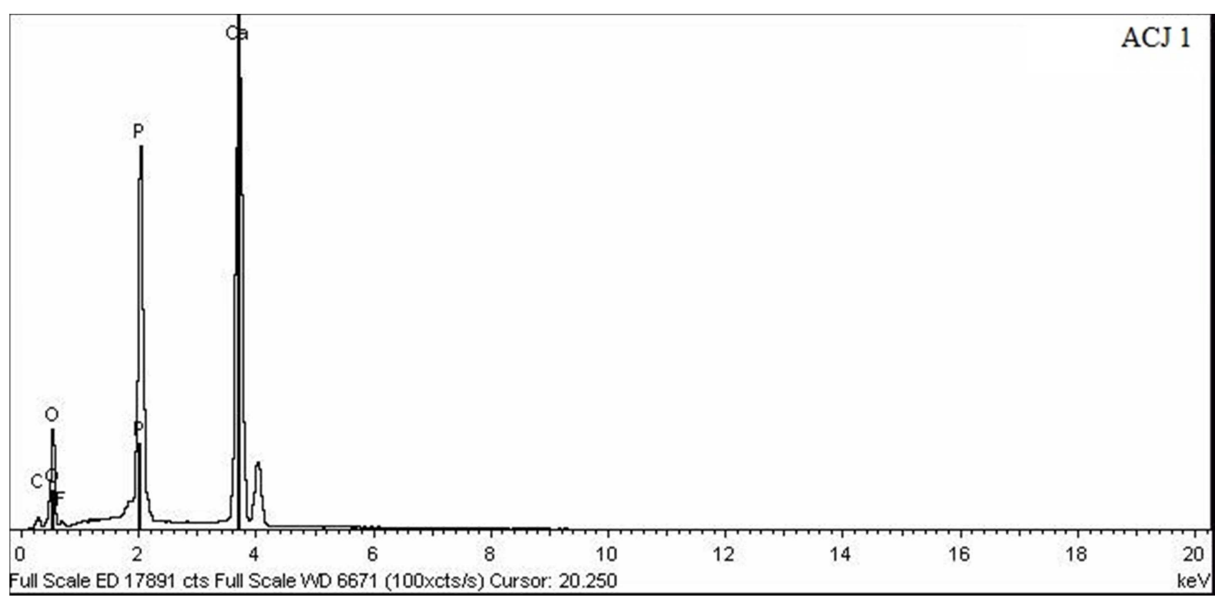

Figura A.4 - Exemplo de um dos espectros das análises por WDS/EDS da apatita ACJ.

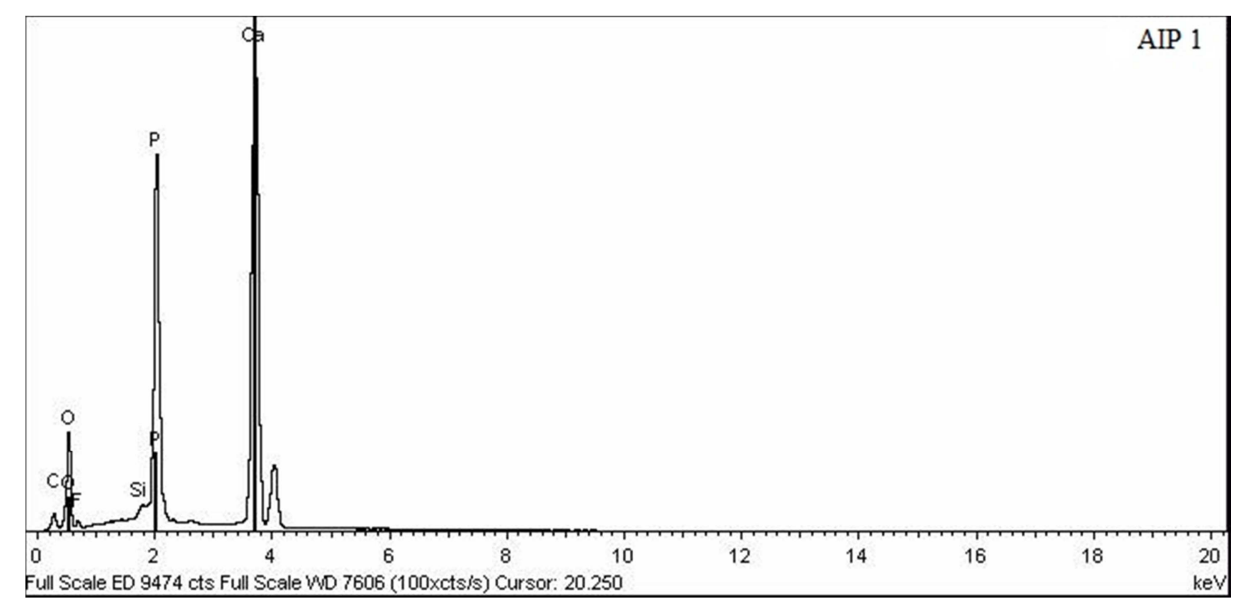

Figura A.5 -Exemplo de um dos espectros das análises por WDS/EDS da apatita AIP. 


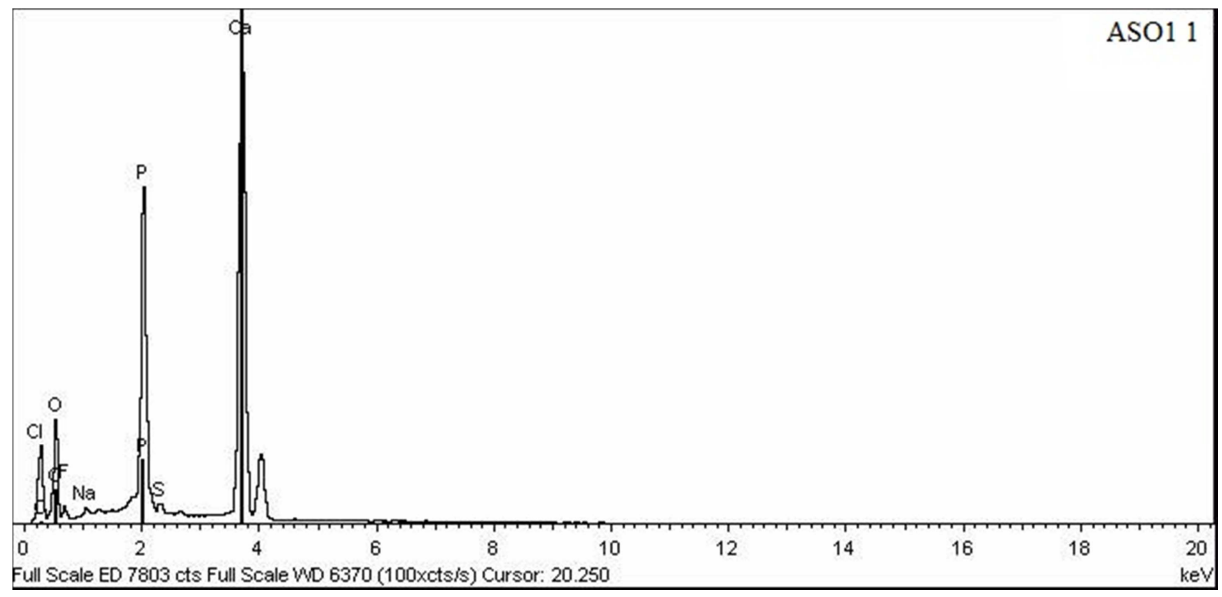

Figura A.6 - Exemplo de um dos espectros das análises por WDS/EDS da apatita ASO-1.

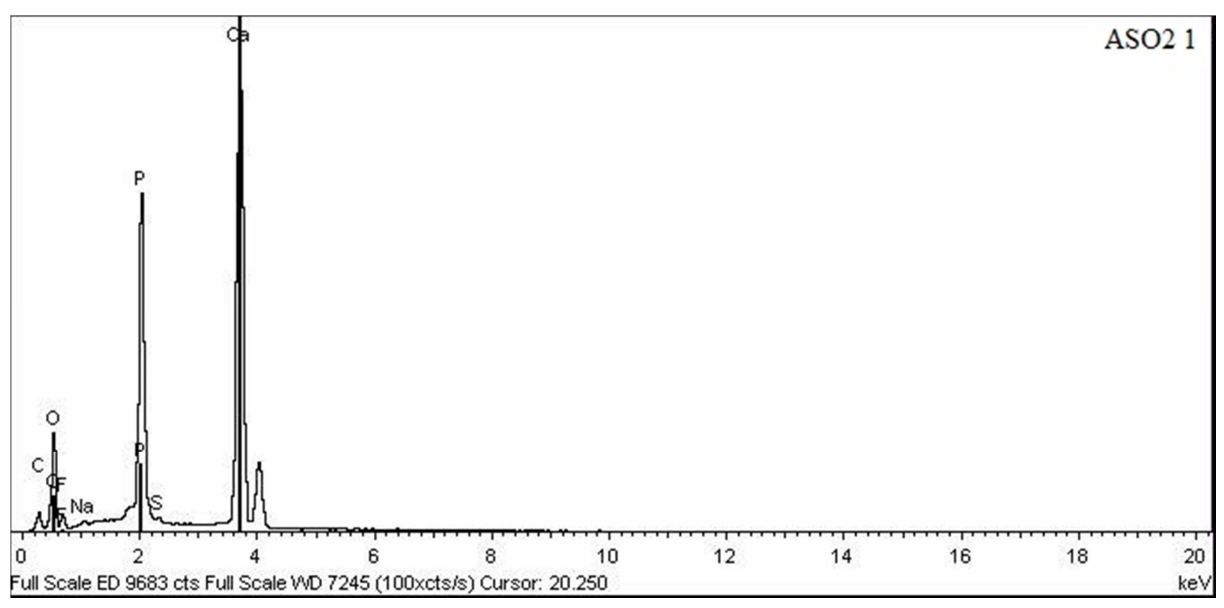

Figura A.7 - Exemplo de um dos espectros das análises por WDS/EDS da apatita ASO-2.

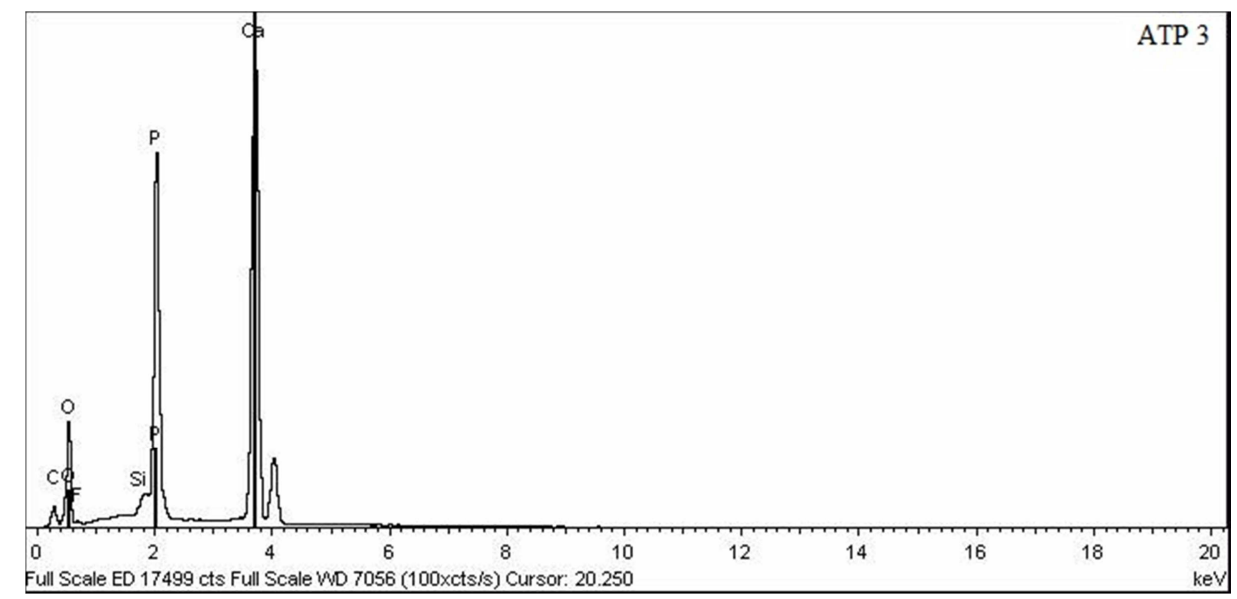

Figura A.8- Exemplo de um dos espectros das análises por WDS/EDS da apatita ATP. 


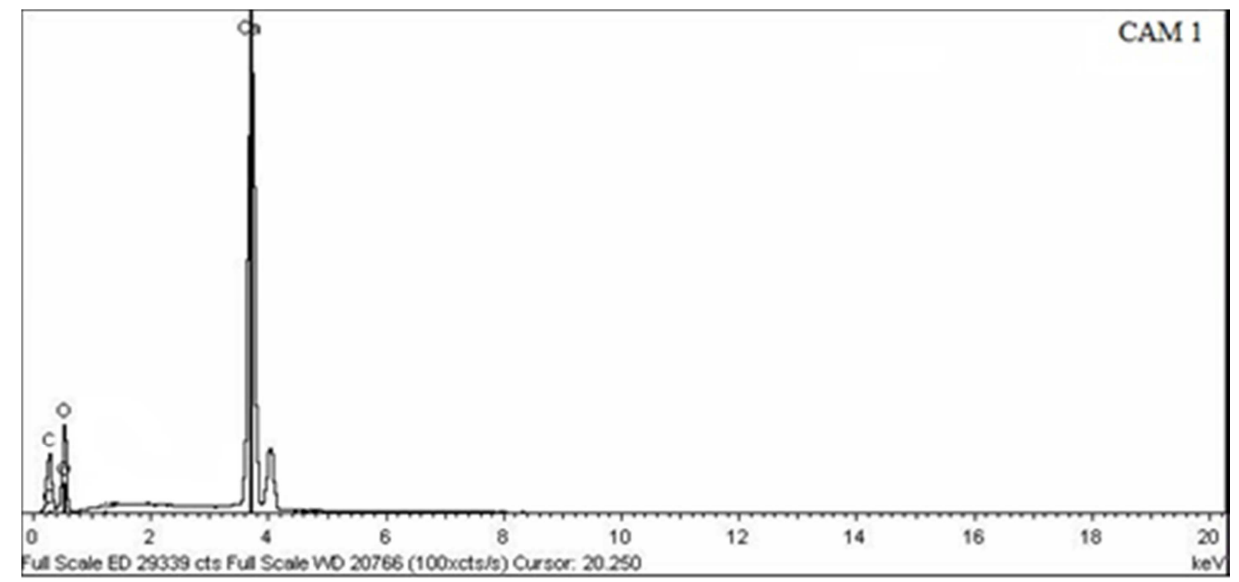

Figura A.9 - Exemplo de um dos espectros das análises por WDS/EDS da calcita CAM.

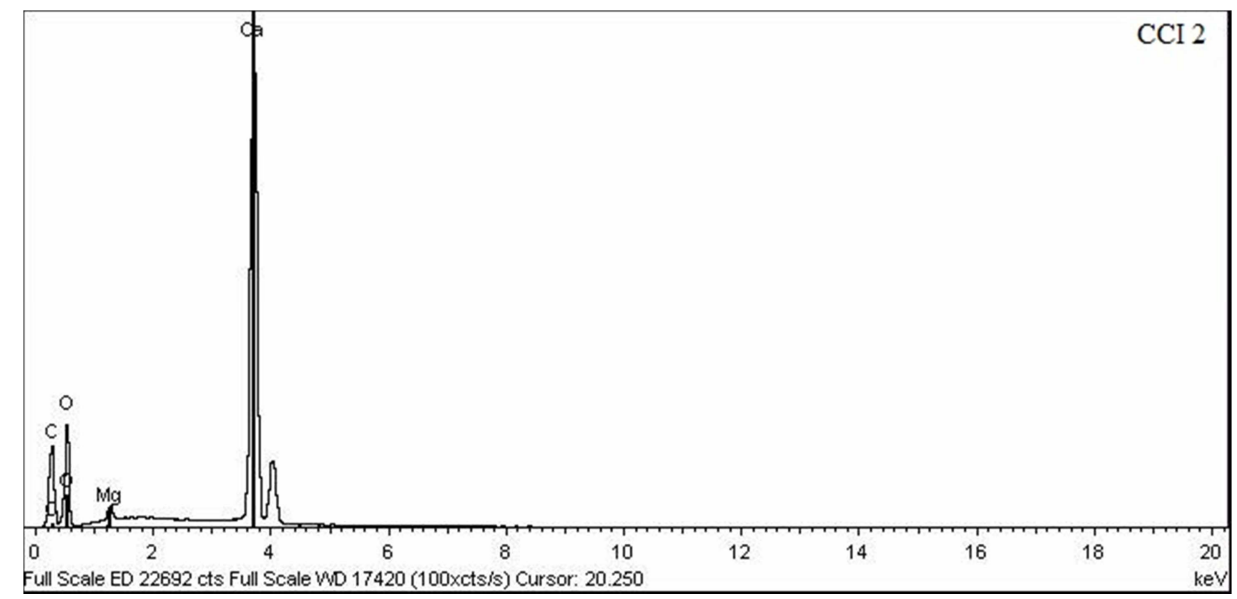

Figura A.10 - Exemplo de um dos espectros das análises por WDS/EDS da calcita CCl.

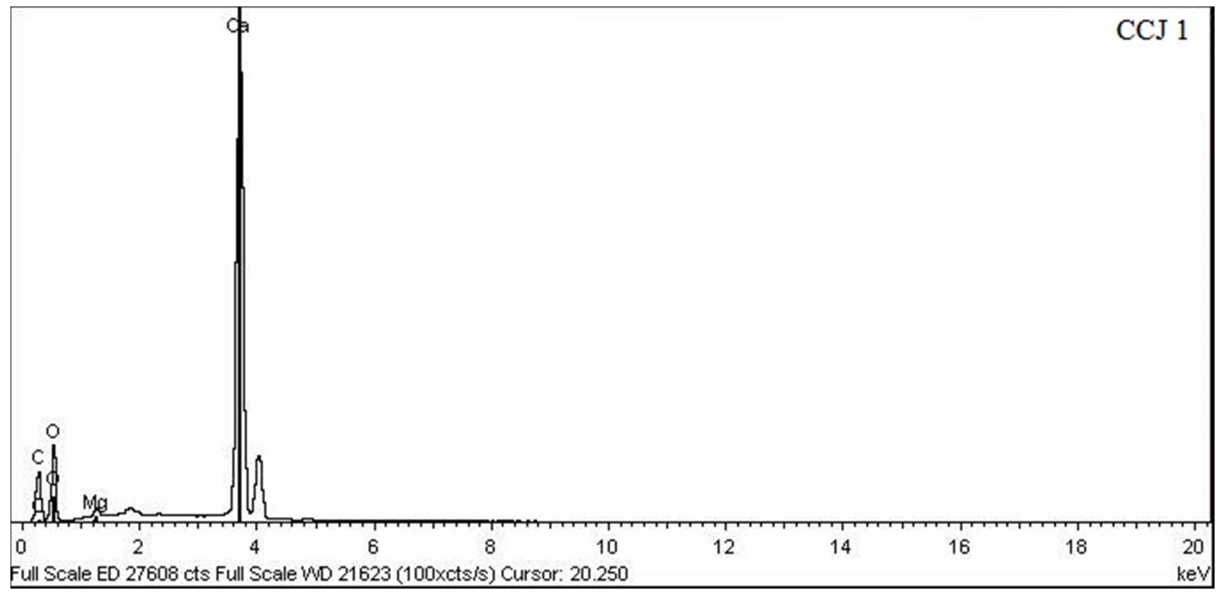

Figura A.11- Exemplo de um dos espectros das análises por WDS/EDS da calcita CCJ. 


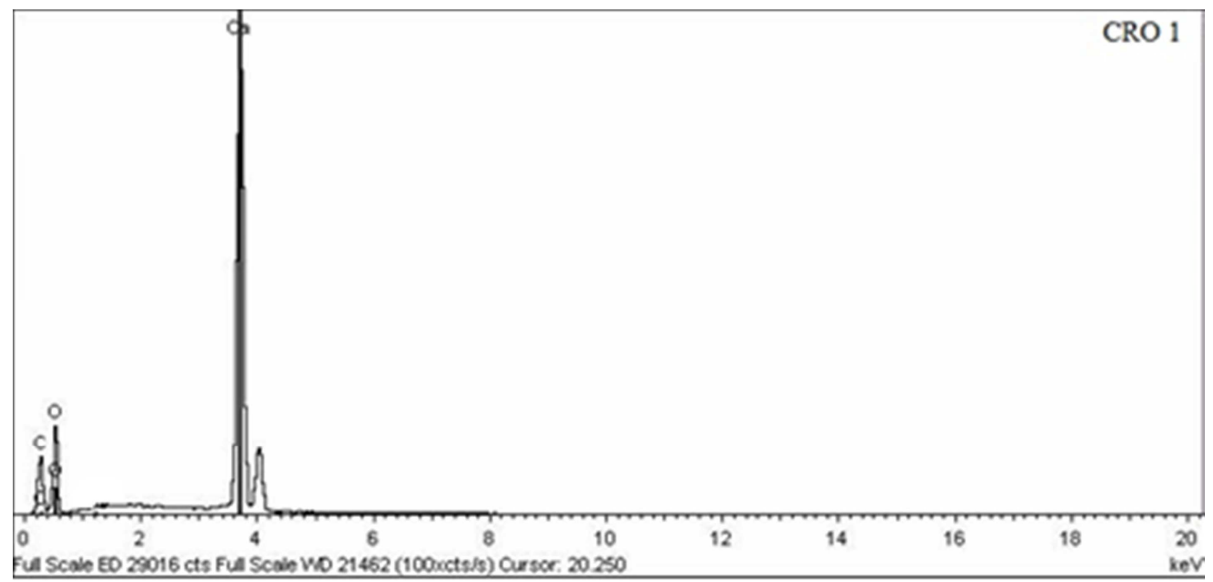

Figura A.12 - Exemplo de um dos espectros das análises por WDS/EDS da calcita CRO.

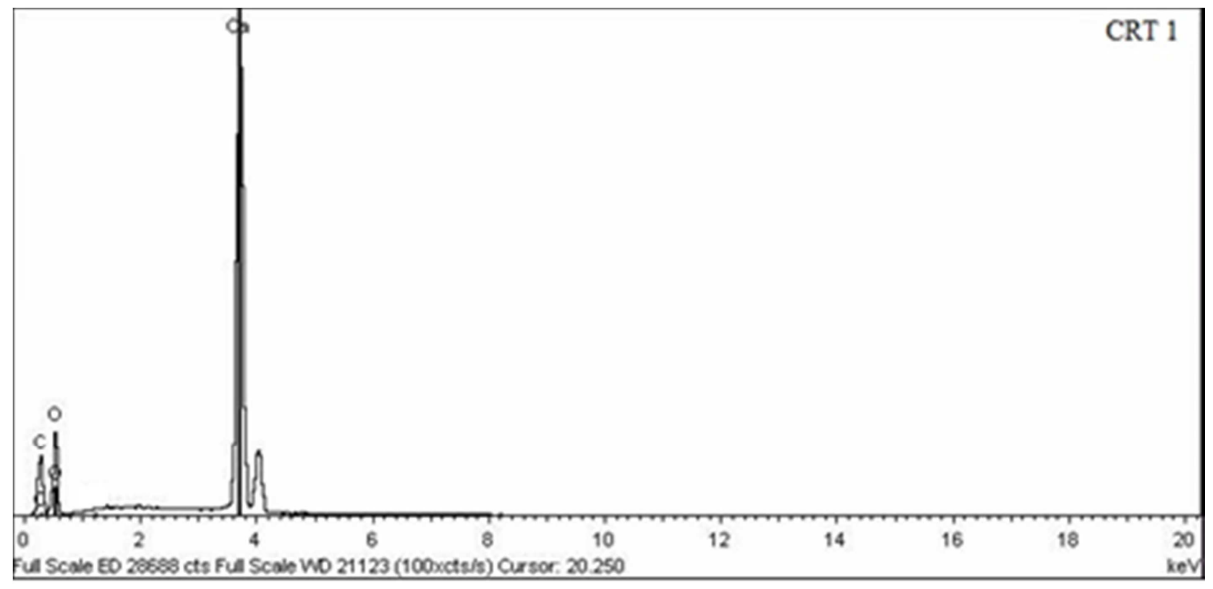

Figura A.13 - Exemplo de um dos espectros das análises por WDS/EDS da calcita CRT.

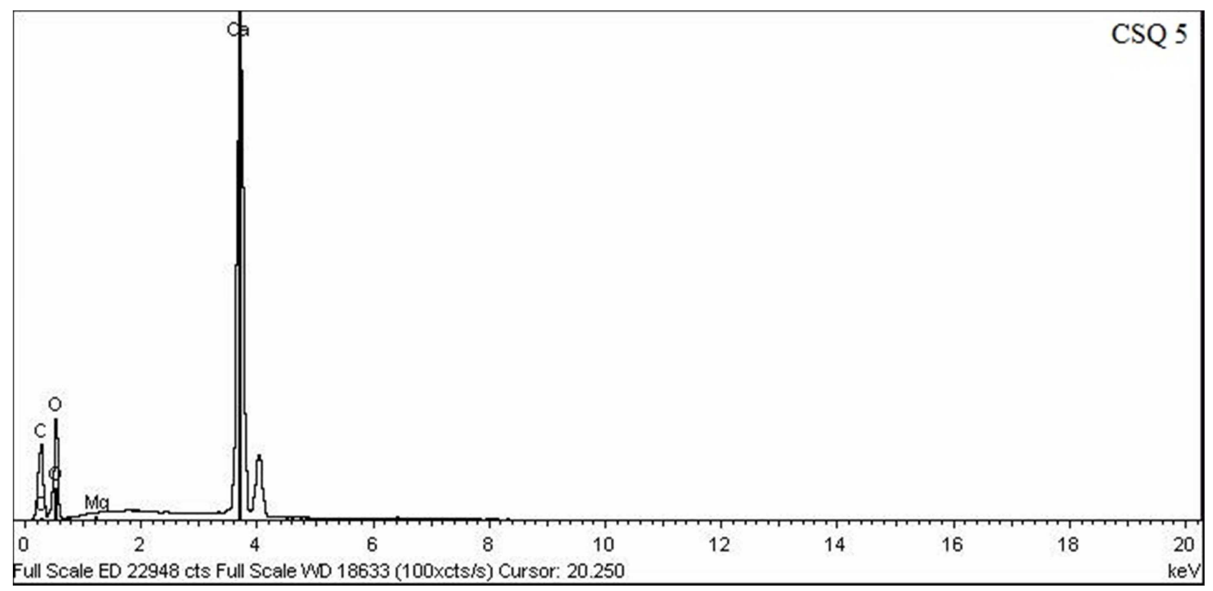

Figura A.14 - Exemplo de um dos espectros das análises por WDS/EDS da calcita CSQ. 
Apêndice A.2 Imagens de MEV das partículas analisadas

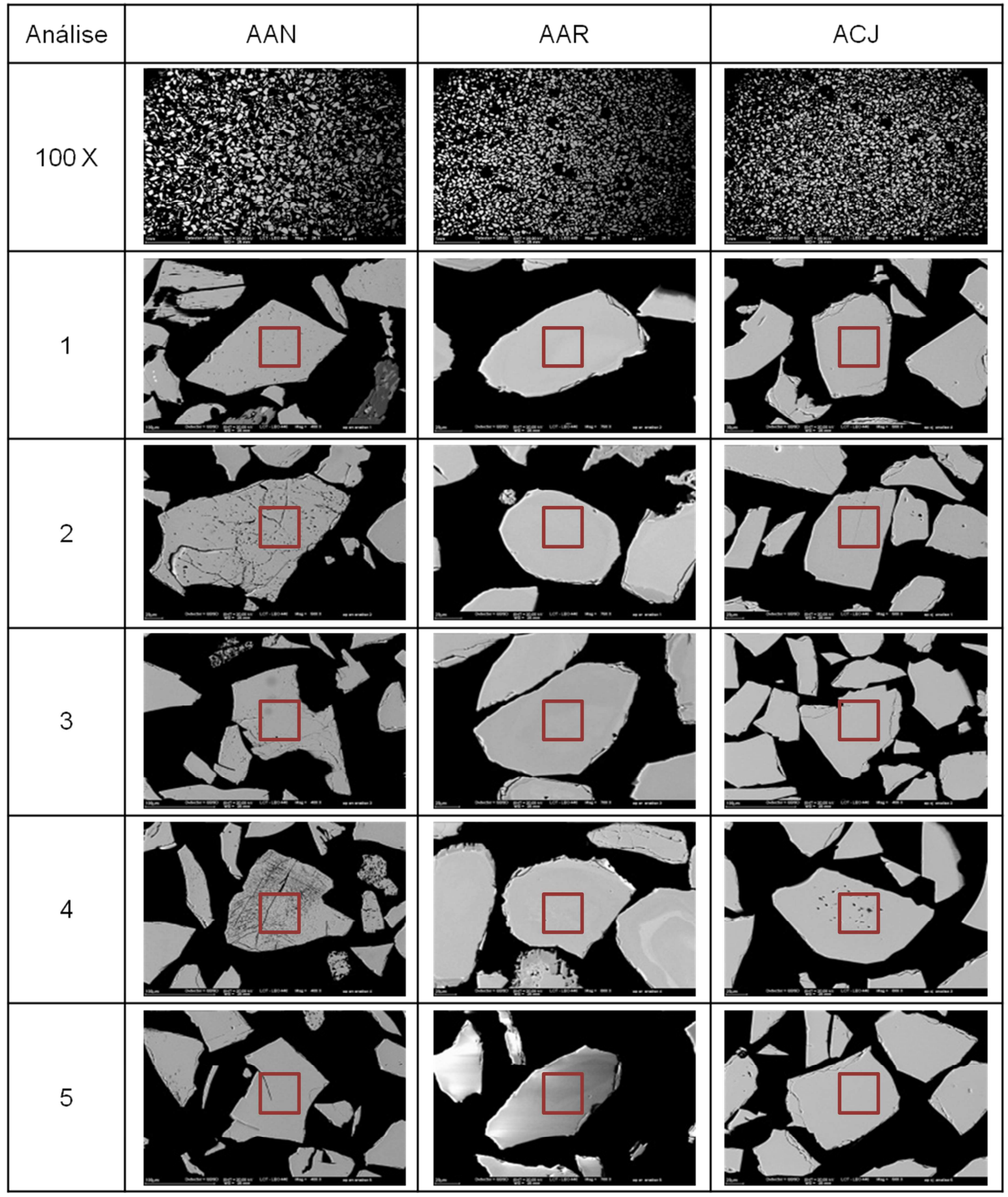

Figura A.15 - Imagens de MEV das partículas de apatita (AAN, AAR e ACJ). 


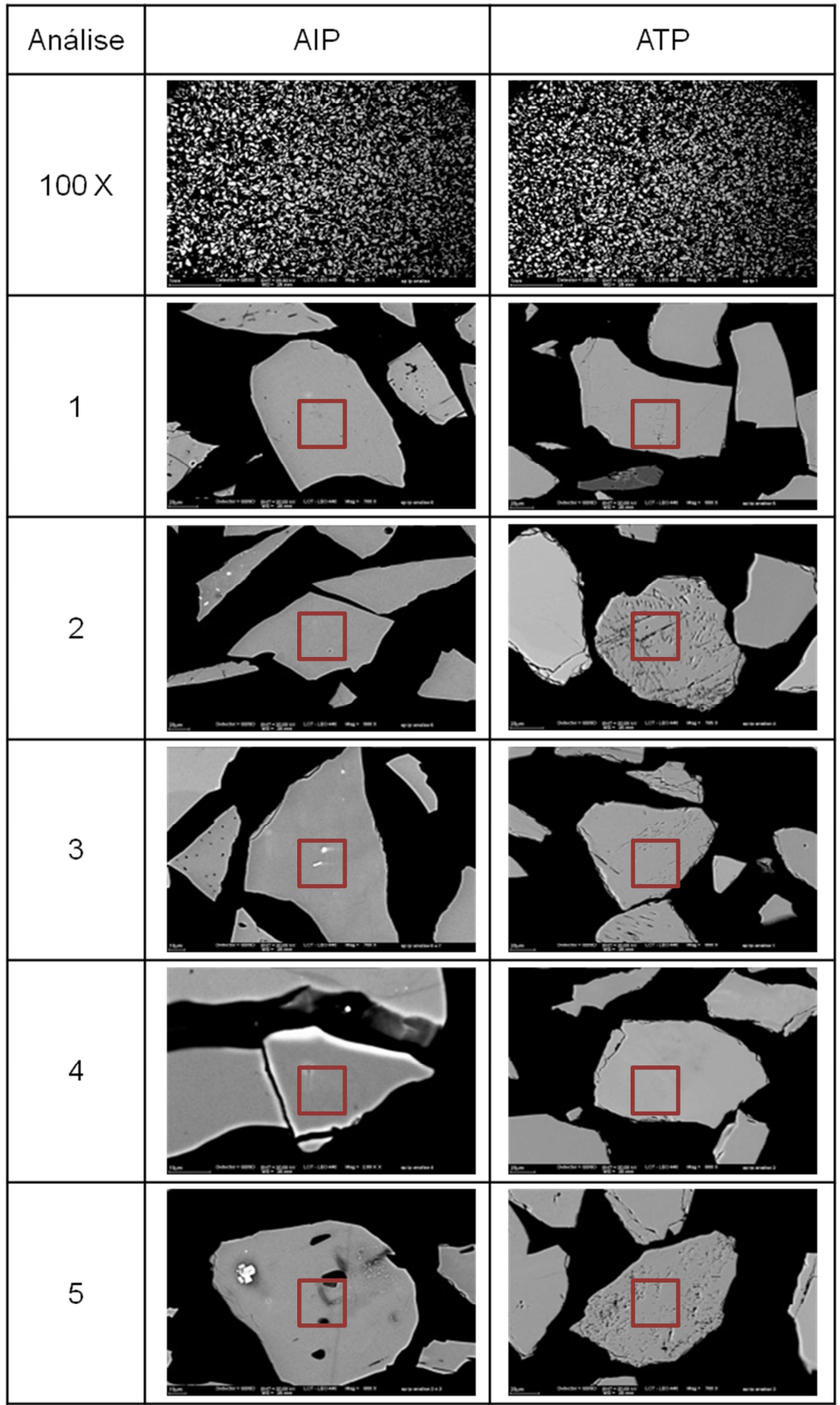

Figura A.16 - Imagens de MEV das partículas de apatita (AIP e ATP). 


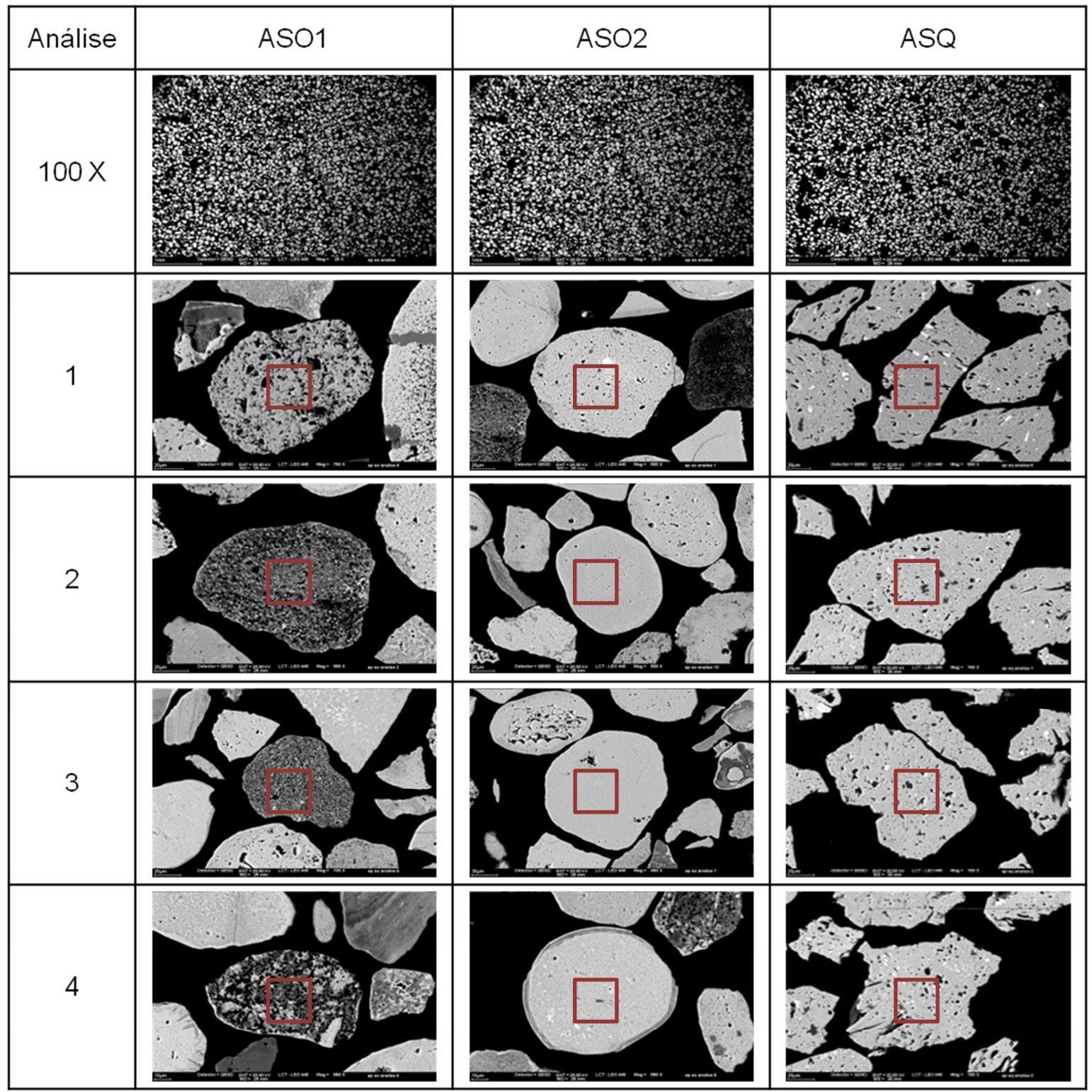

Figura A.17 - Imagens de MEV das partículas de apatita (ASO1, ASO2 e ASQ). 


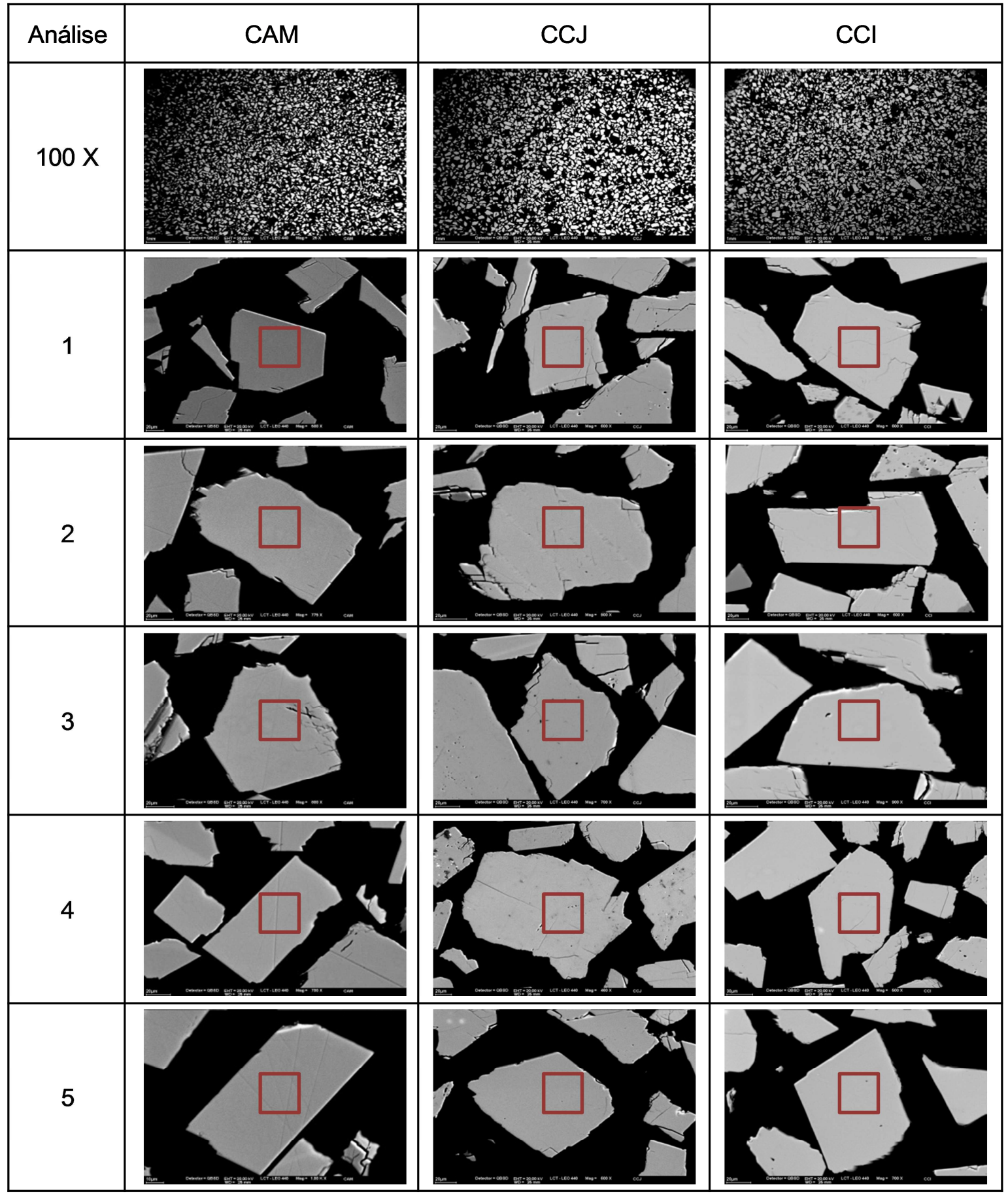

Figura A.18 - Imagens de MEV das partículas de calcita (CAM, CCJ e CCI). 


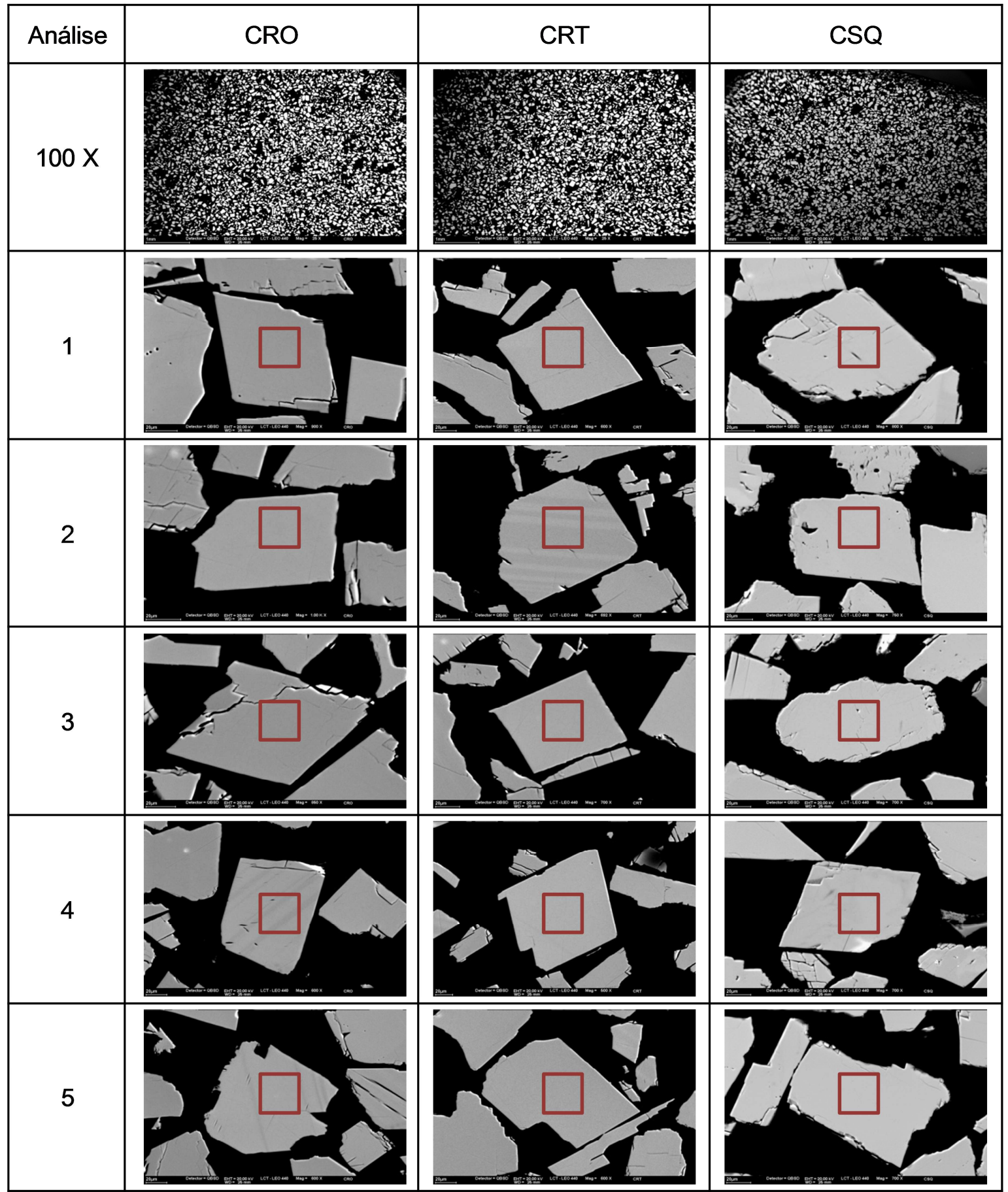

Figura A.19 - Imagens de MEV das partículas de calcita (CRO, CRT e CSQ). 
Apêndice A.3 Resultados das análises

Tabela A.3 - Análise por WDS/EDS das apatitas de Anitápolis (AAN, AAR, ACJ e AIP).

\begin{tabular}{|c|c|c|c|c|c|c|c|c|c|c|c|c|}
\hline \multirow{2}{*}{$\begin{array}{c}\text { Espécie } \\
\text { analisada }\end{array}$} & \multicolumn{3}{|c|}{$\mathbf{A A N}$} & \multicolumn{3}{|c|}{ AAR } & \multicolumn{3}{|c|}{$\mathbf{A C J}$} & \multicolumn{3}{|c|}{ AIP } \\
\hline & Média & Mínimo & Máximo & Média & Média & Média & Média & Mínimo & Máximo & Média & Mínimo & Máximo \\
\hline $\mathrm{F}$ & 2,09 & 1,82 & 2,30 & 3,03 & 3,03 & 3,03 & 1,62 & 1,17 & 2,04 & 3,03 & 2,7 & 3,42 \\
\hline $\mathrm{Cl}$ & 0,01 & 0,00 & 0,03 & 0,29 & 0,29 & 0,29 & 0,01 & 0,00 & 0,03 & 0,29 & 0,15 & 0,68 \\
\hline $\mathrm{Na}_{2} \mathrm{O}$ & 0,18 & 0,14 & 0,22 & 0,10 & 0,07 & 0,12 & 0,16 & 0,06 & 0,24 & 0,07 & 0,00 & 0,14 \\
\hline $\mathrm{MgO}$ & 0,02 & 0,00 & 0,06 & 0,04 & 0,00 & 0,07 & 0,03 & 0,00 & 0,10 & 0,03 & 0,00 & 0,09 \\
\hline $\mathrm{Al}_{2} \mathrm{O}_{3}$ & 0,06 & 0,03 & 0,09 & 0,01 & 0,00 & 0,03 & 0,07 & 0,03 & 0,12 & 0,07 & 0,00 & 0,12 \\
\hline $\mathrm{SiO}_{2}$ & 0,52 & 0,43 & 0,59 & 0,54 & 0,47 & 0,60 & 0,51 & 0,48 & 0,58 & 0,82 & 0,53 & 1,05 \\
\hline $\mathrm{P}_{2} \mathrm{O}_{5}$ & 42,14 & 41,55 & 42,68 & 42,37 & 41,72 & 42,77 & 42,83 & 41,87 & 43,71 & 40,20 & 39,18 & 41,07 \\
\hline $\mathrm{SO}_{3}$ & 0,01 & 0,00 & 0,03 & 0,06 & 0,03 & 0,08 & 0,05 & 0,00 & 0,14 & 0,44 & 0,12 & 0,70 \\
\hline $\mathrm{K}_{2} \mathrm{O}$ & 0,01 & 0,00 & 0,02 & $<0,01$ & - & - & 0,02 & 0,00 & 0,05 & 0,01 & 0,00 & 0,04 \\
\hline $\mathrm{CaO}$ & 54,45 & 53,97 & 55,03 & 53,25 & 52,43 & 53,93 & 54,26 & 53,02 & 55,39 & 55,00 & 54,89 & 55,13 \\
\hline $\mathrm{TiO}_{2}$ & 0,01 & 0,00 & 0,05 & $<0,01$ & & & $<0,01$ & - & - & 0,01 & 0,00 & 0,05 \\
\hline $\mathrm{MnO}$ & $<0,01$ & - & - & 0,00 & - & - & 0,00 & - & - & 0,01 & 0,00 & 0,04 \\
\hline $\mathrm{Fe}_{2} \mathrm{O}_{3}$ & 0,06 & 0,00 & 0,11 & 0,07 & 0,00 & 0,13 & 0,03 & 0,00 & 0,09 & 0,04 & 0,00 & 0,13 \\
\hline $\mathrm{SrO}$ & 0,46 & 0,41 & 0,57 & 1,04 & 0,91 & 1,19 & 0,40 & 0,26 & 0,55 & 0,01 & 0,00 & 0,03 \\
\hline $\mathrm{CaO} / \mathrm{P}_{2} \mathrm{O}_{5}$ & 1,29 & - & - & 1,26 & - & - & 1,27 & - & - & 1,34 & - & - \\
\hline $\mathrm{F} / \mathrm{P}_{2} \mathrm{O}_{5}$ & 0,05 & - & - & 0,06 & - & - & 0,04 & - & - & 0,08 & - & - \\
\hline
\end{tabular}


Tabela A.2 - Análise por WDS/EDS das apatitas (ASO1, ASO2, ASQ e ATP).

\begin{tabular}{|c|c|c|c|c|c|c|c|c|c|c|c|c|}
\hline \multirow{2}{*}{$\begin{array}{c}\text { Espécie } \\
\text { analisada }\end{array}$} & \multicolumn{3}{|c|}{ ASO1 } & \multicolumn{3}{|c|}{ ASO2 } & \multicolumn{3}{|c|}{ ASQ } & \multicolumn{3}{|c|}{ ATP } \\
\hline & Média & Média & Média & Média & Mínimo & Máximo & Média & Mínimo & Máximo & Média & Mínimo & Máximo \\
\hline $\mathrm{F}$ & 5,76 & 5,13 & 6,12 & 5,65 & 5,22 & 5,93 & 3,44 & 3,15 & 3,94 & 1,98 & 1,66 & 2,50 \\
\hline $\mathrm{Cl}$ & 0,14 & 0,06 & 0,20 & 0,03 & 0,01 & 0,05 & 0,02 & 0,01 & 0,02 & 0,01 & 0,00 & 0,02 \\
\hline $\mathrm{Na}_{2} \mathrm{O}$ & 0,55 & 0,43 & 0,75 & 0,46 & 0,26 & 0,61 & 0,49 & 0,31 & 0,68 & 0,09 & 0,00 & 0,22 \\
\hline $\mathrm{MgO}$ & 0,17 & 0,43 & 0,75 & 0,27 & 0,19 & 0,30 & 0,04 & 0,00 & 0,10 & 0,05 & 0,00 & 0,07 \\
\hline $\mathrm{Al}_{2} \mathrm{O}_{3}$ & 0,15 & 0,03 & 0,32 & 0,25 & 0,02 & 0,47 & 0,26 & 0,10 & 0,55 & 0,04 & 0,00 & 0,13 \\
\hline $\mathrm{SiO}_{2}$ & 0,60 & 0,34 & 0,88 & 1,09 & 0,64 & 1,58 & 2,11 & 0,52 & 4,33 & 1,00 & 0,79 & 1,50 \\
\hline $\mathrm{P}_{2} \mathrm{O}_{5}$ & 35,84 & 34,94 & 36,39 & 35,91 & 35,45 & 36,48 & 39,17 & 38,33 & 40,73 & 43,35 & 40,60 & 41,72 \\
\hline $\mathrm{SO}_{3}$ & 1,03 & 0,75 & 1,30 & 0,87 & 0,61 & 1,27 & 0,23 & 0,03 & 0,45 & 0,06 & 0,00 & 0,19 \\
\hline $\mathrm{K}_{2} \mathrm{O}$ & 0,02 & 0,00 & 0,05 & 0,03 & 0,00 & 0,07 & 0,02 & 0,00 & 0,05 & 0,02 & 0,00 & 0,05 \\
\hline $\mathrm{CaO}$ & 55,03 & 53,33 & 56,83 & 54,53 & 53,18 & 55,63 & 51,79 & 50,09 & 54,07 & 54,50 & 53,75 & 55,21 \\
\hline $\mathrm{TiO}_{2}$ & 0,04 & 0,00 & 0,10 & 0,05 & 0,00 & 0,10 & 0,06 & 0,00 & 0,11 & 0,01 & 0,00 & 0,06 \\
\hline $\mathrm{MnO}$ & 0,00 & - & - & 0,03 & 0,00 & 0,05 & 0,01 & 0,00 & 0,03 & $<0,01$ & - & - \\
\hline $\mathrm{Fe}_{2} \mathrm{O}_{3}$ & 0,51 & 0,05 & 1,78 & 0,53 & 0,13 & 1,04 & 2,10 & 0,62 & 3,10 & 0,01 & 0,00 & 0,06 \\
\hline $\mathrm{SrO}$ & 0,13 & 0,09 & 0,17 & 0,25 & 0,11 & 0,36 & 0,28 & 0,24 & 0,31 & 0,85 & 0,64 & 1,09 \\
\hline $\mathrm{CaO} / \mathrm{P}_{2} \mathrm{O}_{5}$ & 1,54 & - & - & 1,52 & - & - & 1,32 & - & - & 1,32 & - & - \\
\hline $\mathrm{F} / \mathrm{P}_{2} \mathrm{O}_{5}$ & 0,16 & - & - & 0,16 & - & - & 0,09 & - & - & 0,05 & - & - \\
\hline
\end{tabular}


Tabela A.3 - Análise WDS/EDS das calcitas (CAM, CCI e CCJ).

CAM CCI

CCJ

\begin{tabular}{|c|c|c|c|c|c|c|c|c|c|}
\hline & Média & Mínimo & Máximo & Média & Mínimo & Máximo & Média & Mínimo & Máximo \\
\hline $\mathrm{Na}_{2} \mathrm{O}$ & $<0,01$ & - & - & $<0,01$ & - & - & $<0,01$ & $<0,01$ & $<0,01$ \\
\hline $\mathrm{MgO}$ & $<0,01$ & - & - & 0,79 & 0,18 & 1,47 & 0,34 & 0,25 & 0,46 \\
\hline $\mathrm{Al}_{2} \mathrm{O}_{3}$ & 0,05 & 0,02 & 0,07 & 0,01 & 0,00 & 0,04 & 0,04 & 0,00 & 0,07 \\
\hline $\mathrm{SiO}_{2}$ & 0,03 & 0,00 & 0,06 & 0,03 & 0,00 & 0,06 & 0,10 & 0,00 & 0,2 \\
\hline $\mathrm{P}_{2} \mathrm{O}_{5}$ & $<0,01$ & - & - & $<0,01$ & - & - & $<0,01$ & $<0,01$ & $<0,01$ \\
\hline $\mathrm{SO}_{3}$ & 0,04 & 0,02 & 0,07 & 0,03 & 0,00 & 0,08 & 0,02 & 0,00 & 0,08 \\
\hline $\mathrm{K}_{2} \mathrm{O}$ & 0,01 & 0,00 & 0,01 & 0,01 & 0,00 & 0,01 & 0,01 & 0,00 & 0,01 \\
\hline $\mathrm{CaO}$ & 56,65 & 54,22 & 59,13 & 49,91 & 47,65 & 51,89 & 56,85 & 55,03 & 59,33 \\
\hline $\mathrm{TiO}_{2}$ & 0,02 & 0 & 0,06 & 0,01 & 0,00 & 0,02 & 0,09 & 0,04 & 0,17 \\
\hline $\mathrm{MnO}$ & $<0,01$ & - & - & 0,01 & 0,00 & 0,05 & $<0,01$ & $<0,01$ & $<0,01$ \\
\hline $\mathrm{Fe}_{2} \mathrm{O}_{3}$ & 0,02 & 0 & 0,07 & 0,03 & 0,05 & 0,12 & 0,05 & 0,00 & 0,14 \\
\hline $\mathrm{SrO}$ & $<0,01$ & - & - & $<0,01$ & - & - & 0,71 & 0,64 & 0,80 \\
\hline
\end{tabular}


Tabela A.4 - Análise WDS/EDS das calcitas (CRO, CRT e CSQ).

\begin{tabular}{|c|c|c|c|c|c|c|c|c|c|}
\hline \multirow{2}{*}{$\begin{array}{c}\text { Espécie } \\
\text { analisada }\end{array}$} & \multicolumn{3}{|c|}{ CRO } & \multicolumn{3}{|c|}{ CRT } & \multicolumn{3}{|c|}{ CSQ } \\
\hline & Média & Mínimo & Máximo & Média & Mínimo & Máximo & Média & Mínimo & Máximo \\
\hline $\mathrm{Na}_{2} \mathrm{O}$ & $<0,01$ & - & - & $<0,01$ & - & - & $<0,01$ & - & - \\
\hline $\mathrm{MgO}$ & $<0,01$ & - & - & $<0,01$ & - & - & $<0,01$ & - & - \\
\hline $\mathrm{Al}_{2} \mathrm{O}_{3}$ & $<0,01$ & - & - & 0,04 & 0,00 & 0,08 & 0,02 & 0,00 & 0,05 \\
\hline $\mathrm{SiO}_{2}$ & 0,07 & 0,04 & 0,10 & 0,08 & 0,03 & 0,14 & 0,03 & 0,00 & 0,05 \\
\hline $\mathrm{P}_{2} \mathrm{O}_{5}$ & $<0,01$ & - & - & $<0,01$ & - & - & $<0,01$ & - & - \\
\hline $\mathrm{SO}_{3}$ & 0,03 & 0,00 & 0,07 & 0,03 & 0,00 & 0,09 & 0,01 & 0,00 & 0,04 \\
\hline $\mathrm{K}_{2} \mathrm{O}$ & $<0,01$ & - & - & $<0,01$ & - & - & $<0,01$ & - & - \\
\hline $\mathrm{CaO}$ & 57,35 & 56,90 & 57,8 & 56,79 & 56,29 & 57,84 & 50,29 & 48,36 & 53,25 \\
\hline $\mathrm{TiO}_{2}$ & 0,03 & 0,00 & 0,05 & 0,03 & 0,00 & 0,09 & $<0,01$ & - & - \\
\hline $\mathrm{MnO}$ & $<0,01$ & - & - & $<0,01$ & - & - & $<0,01$ & - & - \\
\hline $\mathrm{Fe}_{2} \mathrm{O}_{3}$ & 0,07 & 0,06 & 0,08 & $<0,01$ & - & - & 0,10 & 0,06 & 0,15 \\
\hline $\mathrm{SrO}$ & $<0,01$ & - & - & $<0,01$ & - & - & 0,18 & 0,10 & 0,26 \\
\hline
\end{tabular}


APÊNDICE B - Gráficos de Rietveld

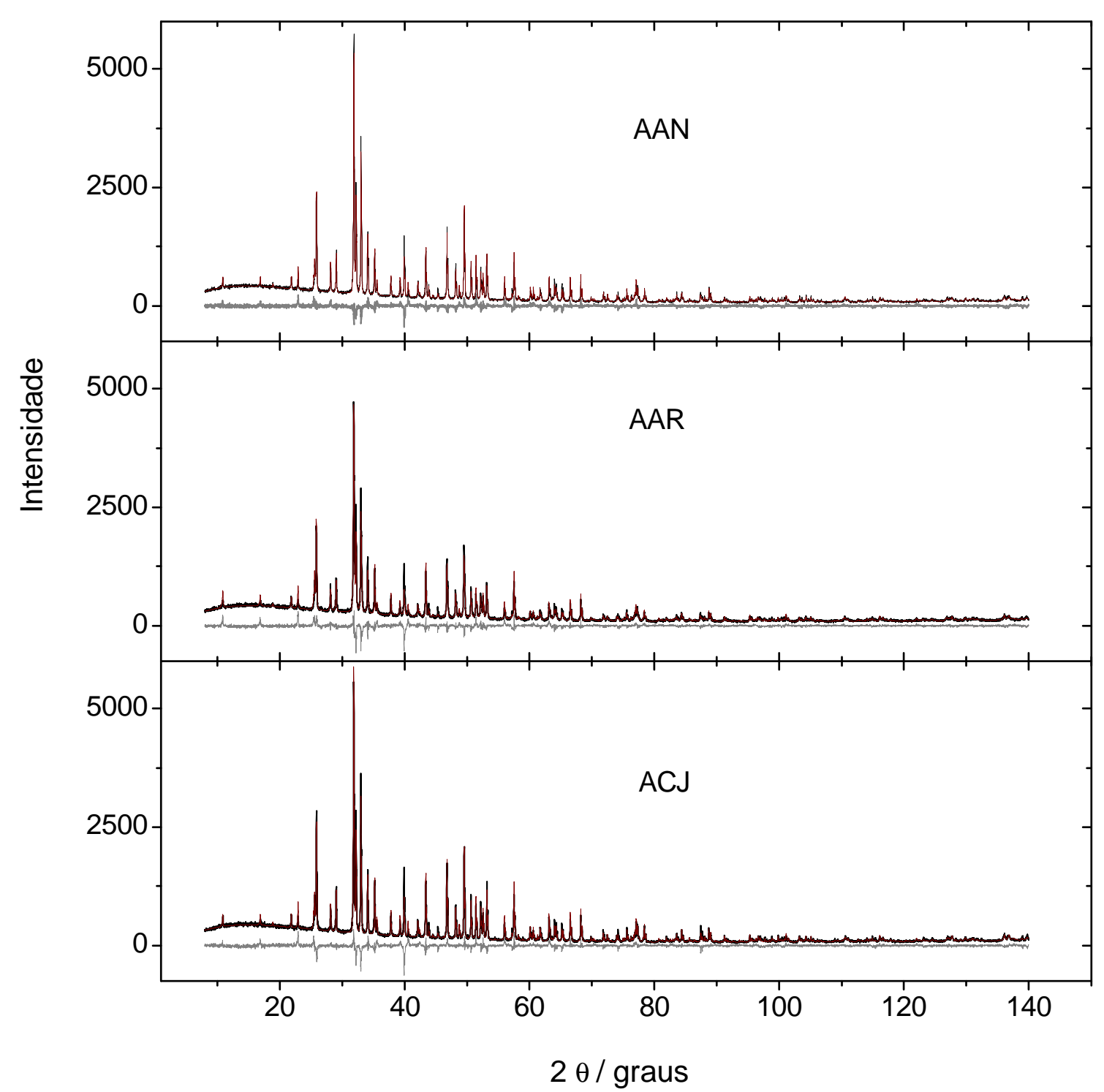

Figura B.1 - Gráficos do refinamento do método de Rietveld das apatitas AAN, AAR e ACJ. Perfis de difração: - observado; - calculado e - resíduo. 


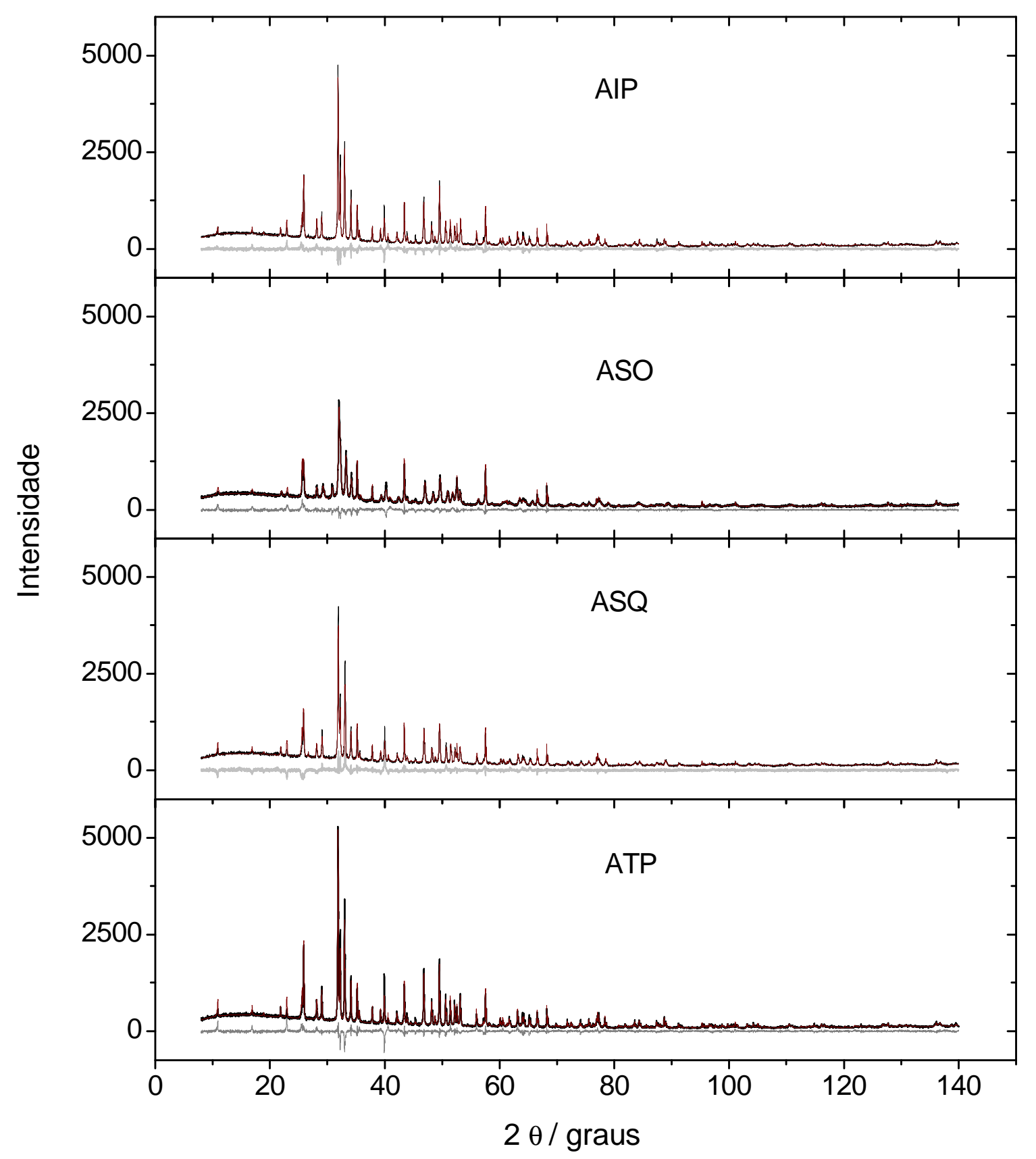

Figura B.2 - Gráficos do refinamento do método de Rietveld das apatitas AIP, ASO, ASQ e ATP. Perfis de difração: - observado; - calculado e - resíduo. 


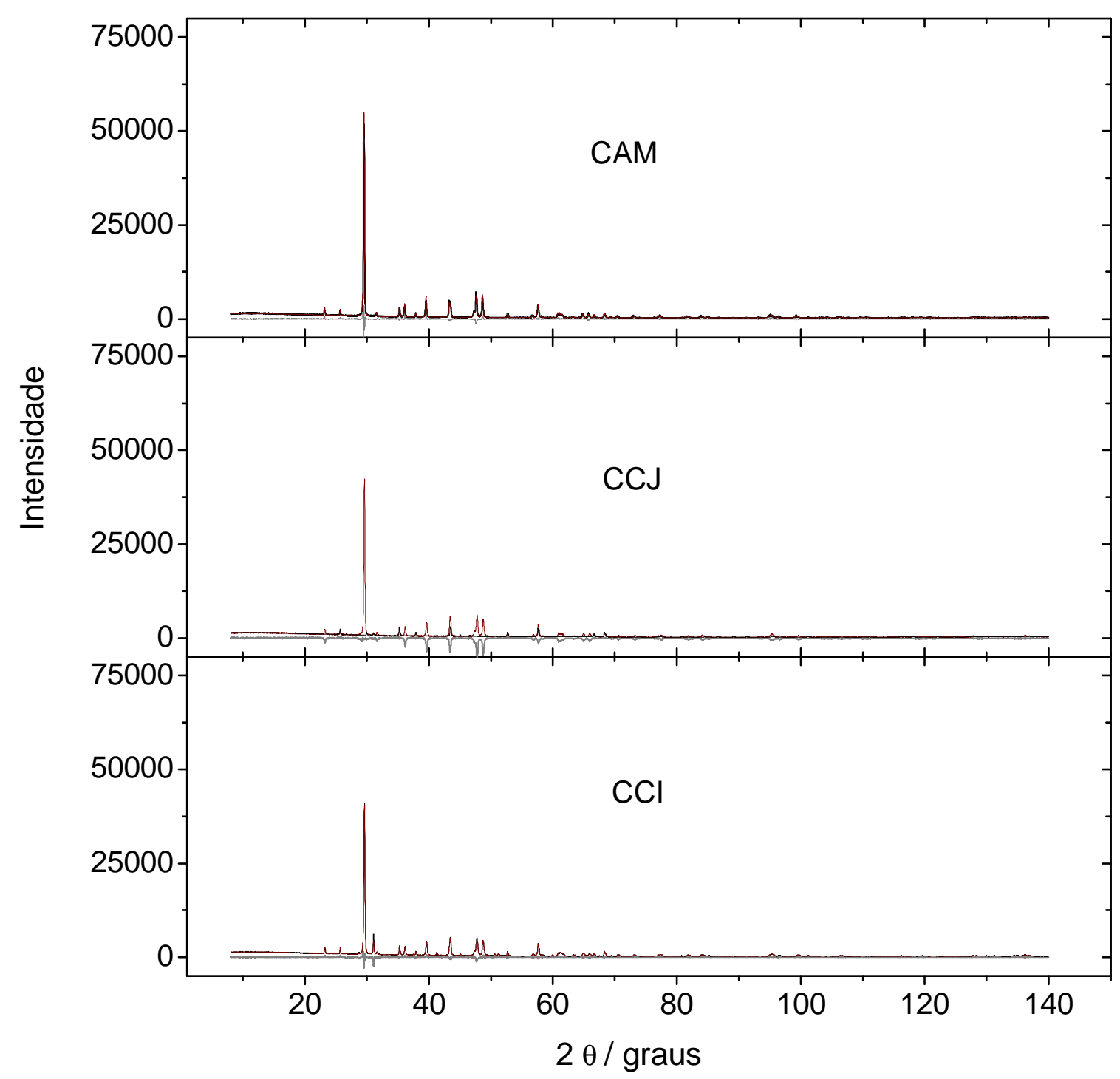

Figura B.3 - Gráficos do refinamento do método de Rietveld das calcitas CAM, CCJ e CCl. Perfis de difração: - observado; - calculado e - resíduo. 


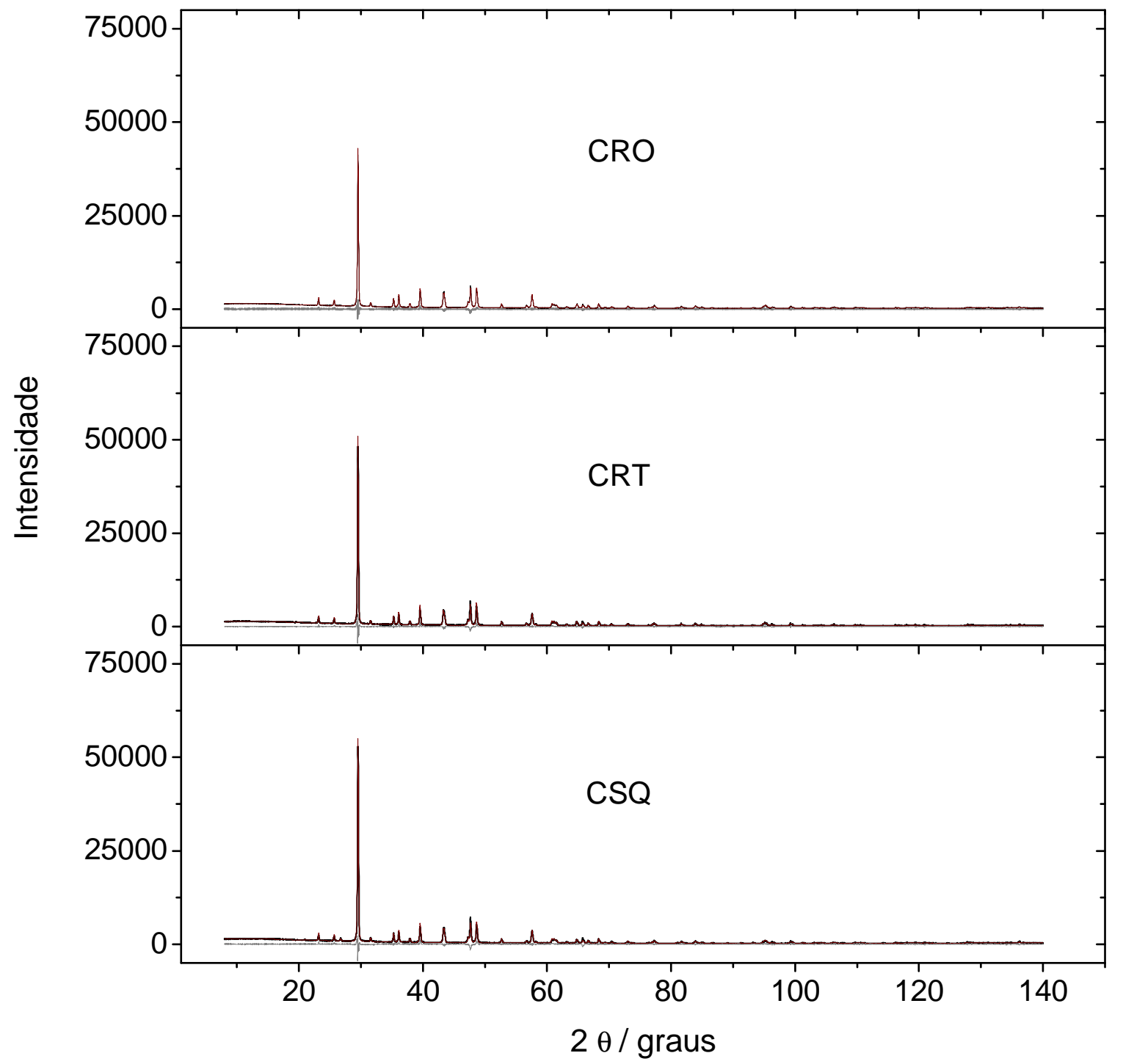

Figura B.4 - Gráficos do refinamento do método de Rietveld das calcitas CRO, CRT e CSQ. Perfis de difração: - observado; - calculado e - resíduo. 